\title{
WestVirginiaUniversity
}

THE RESEARCH REPOSITORY @ WVU

Graduate Theses, Dissertations, and Problem Reports

2004

\section{Evaluation of the ductility of composite steel I-girders in positive bending}

Nicholas R. Roberts

West Virginia University

Follow this and additional works at: https://researchrepository.wvu.edu/etd

\section{Recommended Citation}

Roberts, Nicholas R., "Evaluation of the ductility of composite steel I-girders in positive bending" (2004). Graduate Theses, Dissertations, and Problem Reports. 1556.

https://researchrepository.wvu.edu/etd/1556

This Thesis is protected by copyright and/or related rights. It has been brought to you by the The Research Repository @ WVU with permission from the rights-holder(s). You are free to use this Thesis in any way that is permitted by the copyright and related rights legislation that applies to your use. For other uses you must obtain permission from the rights-holder(s) directly, unless additional rights are indicated by a Creative Commons license in the record and/ or on the work itself. This Thesis has been accepted for inclusion in WVU Graduate Theses, Dissertations, and Problem Reports collection by an authorized administrator of The Research Repository @ WVU. For more information, please contact researchrepository@mail.wvu.edu. 


\title{
EVALUATION OF THE DUCTILITY OF COMPOSITE STEEL I-GIRDERS IN POSITIVE BENDING
}

\author{
Nicholas R. Roberts
}

Thesis submitted to the

College of Engineering and Mineral Resources

at

West Virginia University

in partial fulfillment of the requirements

for the degree of

Master of Science

in

Civil and Environmental Engineering

Karl E. Barth, Ph.D., Chair

Julio F. Davalos, Ph.D.

Indrajit N. Ray, Ph.D.

Department of Civil and Environmental Engineering

Morgantown, WV

2004

Keywords: ductility, composite beams, positive bending, ultimate strength 


\section{ABSTRACT \\ Evaluation of the Ductility of Composite Steel I-Girders in Positive Bending}

\section{Nicholas R. Roberts}

Current AASHTO bridge specifications limit the allowable maximum strength of simple spans and positive bending regions with adjacent compact pier sections to a value between the full plastic moment and the hypothetical yield moment of the cross section. The equation used for this strength prediction is given as a linear function, related to the depth of web in compression. However, this method of strength prediction is based on a series of parametric studies from which the data did not suggest the values close to the yield moment that may be computed using the associated strength equations.

Recent experimental tests by others coupled with finite element analysis and a mechanistic evaluation of the cross-section flexural capacity conducted in this research suggest that significantly larger capacities may be achieved than those determined with AASHTO's prediction equations. Further, AASHTO places restrictions on the bending capacity for sections with non-compact adjacent pier sections (ie., $M_{n}=1.3 R_{h} M_{y}$ ) that for some girder geometries may be too liberal.

This study evaluates the behavior of composite positive bending specimens through performing focused experimental testing coupled with refined analysis. Results of this effort are focused on producing less conservative strength prediction equations for compact composite steel positive bending sections. 


\section{ACKNOWLEDGEMENTS}

First and foremost, I would first like to recognize our Lord and Savior Jesus Christ. For without the strength he gives us, nothing would be possible.

I would also like to thank Dr. Karl Barth, my advisor and friend. His guidance and encouragement have been very valuable and I sincerely believe he has provided me with a strong educational base from which I can build a successful career.

Also, I would like to thank Dr. Julio Davalos and Dr. Indrajit Ray for serving on my academic advisory committee. Their assistance and support throughout my graduate studies and research projects are greatly appreciated.

The large-scale laboratory work required for this research could not have been completed without the help of Bill Comstock. Bill's great work ethic and his compassion towards others cannot be surpassed. I would also like to thank Bill for his wonderful friendship; a friendship that I hope will last a lifetime.

For their friendship and their words of encouragement along the way, many thanks go to my fellow classmates Wesley Hevener and Jennifer Righman.

Special thanks go to my family. My mother and father have supported me not only financially, but have provided a nurturing love and a wonderful home that only the best of parents could offer. Also, thanks go to my beloved sister for her unconditional love and support during my collegiate years.

Funding for this research was provided by the West Virginia Department of Transportation Division of Highways. 


\section{TABLE OF CONTENTS}

Abstract........................................................................ ii

Acknowledgements......................................................... iii

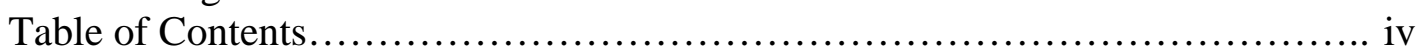

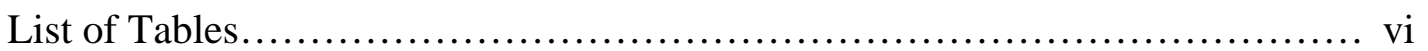

List of Figures.......................................................... vii

Nomenclature..............................................................

Chapter 1 Introduction......................................................1

1.1 Problem Statement and Significance............................... 1

1.2 Objectives and Scope of Work................................... 3

1.2.1 Objectives........................................... 3

1.2.2 Scope of Work....................................... 3

1.3 Thesis Organization......................................... 6

Chapter 2 Literature Review..................................................9 9

$2.1 \quad$ Background................................................9

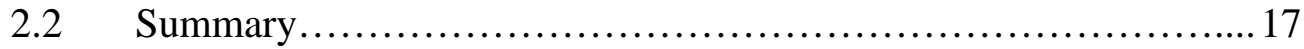

Chapter 3 Experimental Testing..............................................23

3.1 Introduction............................................... 23

3.2 Girder Fabrication...........................................23

3.3 Girder Configuration, Testing Method and Instrumentation......... 24

3.3.1 Girder Configuration.....................................24

3.3.2 Testing Method........................................... 25

3.3.3 Instrumentation........................................ 26

3.4 Material Testing...........................................27

3.4.1 Steel Material Properties.................................27

3.4.2 Concrete Material Properties................................ 28

3.5 Girder Specimen Geometries....................................28

3.5.1 Reinforced Concrete Deck Details..........................28

3.5.2 Specimen R1....................................... 29

3.5.3 Specimen PL1...................................... 29

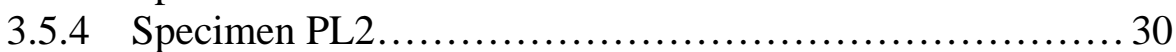

3.6 Test Results.............................................. 30

3.6.1 Specimen R1........................................ 30

3.6.2 Specimen PL1........................................ 31

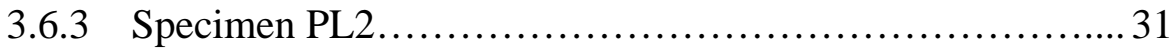

Chapter 4 Compatibility Analyses............................................58

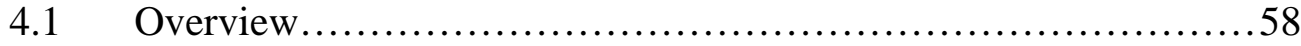

$4.2 \quad$ Methodology ................................................ 58

4.2.1 Iterative Procedure..................................... 59 
4.2.2 Verification................................................. 60

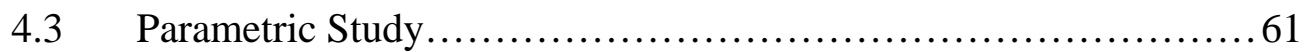

4.4 Strain Compatibility Results.....................................63

Chapter 5 Finite Element Modeling........................................75

$5.1 \quad$ Introduction.................................................... 75

5.2 Nonlinear Finite Element Analysis Technique..................... 75

5.2.1 Description of Elements/Mesh...............................75

5.2.2 Material Models.............................................. 76

5.2.2.1 Modified CEB Model.............................. 76

5.2.2.2 Steel Material Models............................... 77

5.2.3 Modified RIKS Algorithm..................................78

$5.3 \quad$ Verification Study ............................................ 79

5.4 Finite Element Modeling of Experimental Girders................... 80

5.5 Finite Element Analysis Parametric Studies.........................8 80

5.5.1 Naming Convention........................................ 81

5.6 Parametric Study Finite Element Analysis Results.................. 82

Chapter 6 Evaluation of Results.............................................121

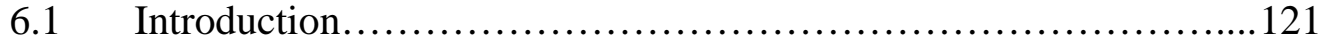

$6.2 \quad$ Comparison of Results........................................ 121

6.3 Development of Prediction Equations........................... 122

$6.4 \quad$ Recommendations.............................................

Chapter 7 Concluding Remarks and Recommendations.......................133

7.1 Summary of Work...............................................

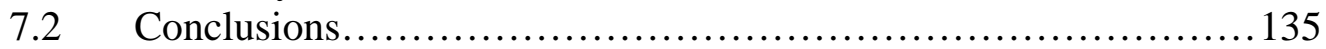

7.3 Recommendations for Future Work................................136

Appendix A Stress-Strain Configurations Used for the Strain

Compatibility Analyses....................................... 137

Appendix B Example - Strain Compatibility Method of Analysis................144

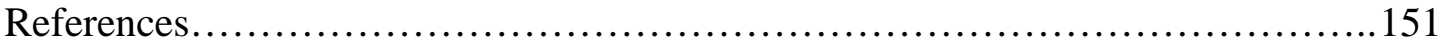




\section{LIST OF TABLES}

Table 2.1 Ultimate moment results for Nebraska POS1

and POS2 (Mans. 2001).....................................19

Table 3.1 Average steel yield strengths.................................. 33

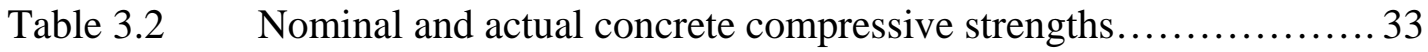

Table 3.3 Nominal and actual dimensions of specimen R1.................. 33

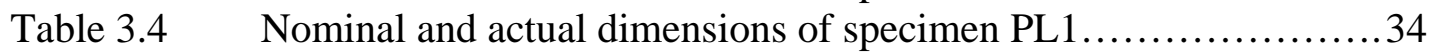

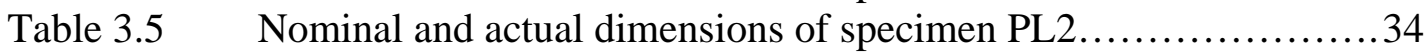

Table $3.6 \quad$ Specimen loading summary..................................... 34

Table 4.1 Experimental peak loads and strain compatibility results for the University of Nebraska test girders............................64

Table 4.2 Parameters used for strain compatibility evaluation..................64

Table 5.1 Experimental peak loads and FEA results for the University of Nebraska test girders....................................... 83

Table 5.2 Girder geometries used in FEA parametric study...................84 


\section{LIST OF FIGURES}

Figure 1.1 Typical steel-concrete composite bridge cross-section..............8

Figure 2.1 Normalized maximum moment versus ductility

parameter (Wittry, 1993)...................................... 20

Figure 2.2 Curve fit of 20 USS short span bridges (Wittry, 1993)............. 20

Figure 2.3 Comparison of $M_{u}$ and analytical results of Wittry's 406

hypothetical girders (Wittry, 1993)..............................21

Figure 2.4 Comparison of $M_{u}$ and analytical results of Witry's 20 USS

short-span bridges (Wittry, 1993)............................21

Figure 2.5 University of Nebraska composite girder specimens (a) POS1

and (b) POS2 (Mans, 2001)................................. 22

Figure 3.1 Typical overhang brace.................................... 35

Figure 3.2 Typical view of finished formwork with reinforcement in place..... 36

Figure 3.3 Typical tow-behind trailer pump used for concrete placement....... 37

Figure $3.4 \quad$ Placement of typical deck....................................... 38

Figure $3.5 \quad$ Girder covered with burlap and plastic............................ 39

Figure 3.6 Typical lateral bracing at (a) ends and (b) intermediate locations ...40

Figure $3.7 \quad$ Typical roller assembly.....................................4 41

Figure 3.8 Typical details for (a) pinned supports and

(b) roller-type supports..................................... 42

Figure 3.9 Experimental test set-up (lateral bracing system not shown)........ 43

Figure 3.10 Typical spreader beam with elastomeric pads.................... 43

Figure 3.11 MTS (Model 634.12E-24) extensometer used for material testing... 44

Figure 3.12 Average stress-strain curves for specimen R1.................... 45

Figure 3.13 Average stress-strain curves for specimen PL1.................... 46

Figure 3.14 Average stress-strain curves for specimen PL2 .................... 47

Figure 3.15 (a) Reinforced concrete deck details for specimen R1............. 48

(b) Reinforced concrete deck details for specimens PL1 and PL2...49

Figure 3.16 Geometry of specimen R1................................. 50

Figure 3.17 Geometry of specimen PL1.................................... 51

Figure 3.18 Geometry of specimen PL2 ..................................... 52

Figure 3.19 Midspan load-deflection plot for specimen R1.....................53

Figure 3.20 Failure of specimen R1.................................... 53

Figure 3.21 Midspan load-deflection plot for specimen PL1....................54

Figure $3.22 \quad$ Failure of specimen PL1..................................... 54

Figure 3.23 Exposed reinforcement of specimen PL1......................... 55

Figure 3.24 Midsapn load-deflection plot for specimen PL2 .................. 56

Figure 3.25 Unexpected bearing rotation of specimen PL2.................... 57

Figure 4.1 Effect of $D_{p} / D^{\prime}$ on moment capacity with respect

to AASHTO (2001)........................................65

Figure 4.2 Effect of $D_{p} / D_{t}$ on moment capacity with respect

to AASHTO (2003).......................................66

Figure 4.3 Effect of $D_{p} / D^{\prime}$ on moment capacity for homogeneous - $50 \mathrm{ksi}$ strength configuration with respect to AASHTO (2001)..............67 
Figure 4.4 Effect of $D_{p} / D^{\prime}$ on moment capacity for homogeneous - HPS 70W strength configuration with respect to AASHTO (2001)............. 68

Figure 4.5 Effect of $D_{p} / D^{\prime}$ on moment capacity for hybrid - 50 ksi top flange, 50 ksi web and HPS 70W bottom flange strength configuration with respect to AASHTO (2001)....................................69

Figure 4.6 Effect of $D_{p} / D^{\prime}$ ' on moment capacity for hybrid - HPS 70W top flange, $50 \mathrm{ksi}$ web and HPS 70W bottom flange strength configuration with respect to AASHTO (2001)..........................70

Figure 4.7 Effect of $D_{p} / D_{t}$ on moment capacity for homogeneous $-50 \mathrm{ksi}$ strength configuration with respect to AASHTO (2003)..............71

Figure 4.8 Effect of $D_{p} / D_{t}$ on moment capacity for homogeneous -HPS 70W strength configuration with respect to AASHTO (2003)...............72

Figure 4.9 Effect of $D_{p} / D_{t}$ on moment capacity for hybrid - 50 ksi top flange, 50 ksi web and HPS 70W bottom flange strength configuration with respect to AASHTO (2003)..................................... 73

Figure 4.10 Effect of $D_{p} / D_{t}$ on moment capacity for hybrid - HPS 70W top flange, $50 \mathrm{ksi}$ web and HPS 70W bottom flange strength configuration with respect to AASHTO (2003)......................74

Figure 5.1 Typical FEA (a) mesh for composite steel girder and

(b) deformed shape........................................... 85

Figure 5.2 Concrete CEB compressive stress-strain model.................... 86

Figure $5.3 \quad$ Modified CEB model......................................... 87

Figure 5.4 Idealized multi-line stress-strain curve for $50 \mathrm{ksi}$ steel.............. 88

Figure 5.5 Idealized multi-line stress-strain curve for $70 \mathrm{ksi}$ steel.............. 89

Figure 5.6 Modified RIKS algorithm (ABAQUS, 2002)..................... 90

Figure 5.7 Load-deflection results for Nebraska girder, POS1..................91

Figure 5.8 Load-deflection results for Nebraska girder, POS2 ..................92

Figure 5.9 Load-deflection results for specimen R1........................ 93

Figure 5.10 Load-deflection results for specimen PL1........................ 94

Figure 5.11 Load-deflection results for specimen PL2......................... 95

Figure 5.12 Naming convention............................................. 96

Figure 5.13 Midspan load-deflection plot - EFA50L........................ 97

Figure 5.14 Midspan normal strain - EFA50L............................. 97

Figure 5.15 Midspan load-deflection plot - EFA50I.......................... 98

Figure 5.16 Midspan normal strain - EFA50I............................ 98

Figure 5.17 Midspan load-deflection plot - EFA50H.........................99

Figure 5.18 Midspan normal strain - EFA50H................................99

Figure 5.19 Midspan load-deflection plot - EFA70L............................ 100

Figure 5.20 Midspan normal strain - EFA70L............................... 100

Figure 5.21 Midspan load-deflection plot - EFA70I........................... 101

Figure 5.22 Midspan normal strain - EFA70I............................... 101

Figure 5.23 Midspan load-deflection plot - EFA70H.........................102

Figure 5.24 Midspan normal strain - EFA70H.............................102

Figure 5.25 Midspan load-deflection plot - EFH50-70L ........................103

Figure 5.26 Midspan normal strain - EFH50-70L.............................. 103

Figure 5.27 Midspan load-deflection plot - EFH50-70I........................... 104 
Figure 5.28 Midspan normal strain - EFH50-70I......................... 104

Figure 5.29 Midspan load-deflection plot - EFH50-70H....................... 105

Figure 5.30 Midspan normal strain - EFH50-70H..............................105

Figure 5.31 Midspan load-deflection plot - EFH70-70L.........................106

Figure 5.32 Midspan normal strain - EFH70-70L.......................... 106

Figure 5.33 Midspan load-deflection plot - EFH70-70I........................ 107

Figure 5.34 Midspan normal strain - EFH70-70I.............................. 107

Figure 5.35 Midspan load-deflection plot - EFH70-70H........................ 108

Figure 5.36 Midspan normal strain - EFH70-70H..............................108

Figure 5.37 Midspan load-deflection - UFA50L.............................. 109

Figure 5.38 Midspan normal strain - UFA50L.............................. 109

Figure 5.39 Midspan load-deflection - UFA50I.............................. 110

Figure 5.40 Midspan normal strain - UFA50I............................. 110

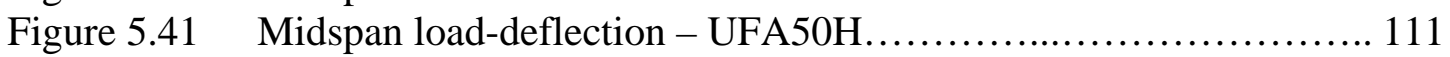

Figure 5.42 Midspan normal strain - UFA50H........................... 111

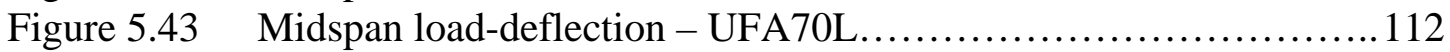

Figure 5.44 Midspan normal strain - UFA70L............................. 112

Figure 5.45 Midspan load-deflection - UFA70I............................. 113

Figure 5.46 Midspan normal strain - UFA70I........................... 113

Figure 5.47 Midspan load-deflection - UFA70H.......................... 114

Figure 5.48 Midspan normal strain - UFA70H............................. 114

Figure 5.49 Midspan load-deflection - UFH50-70L........................... 115

Figure 5.50 Midspan normal strain - UFH50-70L.......................... 115

Figure 5.51 Midspan load-deflection - UFH50-70I........................ 116

Figure 5.52 Midspan normal strain - UFH50-70I.......................... 116

Figure 5.53 Midspan load-deflection - UFH50-70H.......................... 117

Figure 5.54 Midspan normal strain - UFH50-70H........................... 117

Figure 5.55 Midspan load-deflection - UFH70-70L.......................... 118

Figure 5.56 Midspan normal strain - UFH70-70L.......................... 118

Figure 5.57 Midspan load-deflection - UFH70-70I.......................... 119

Figure 5.58 Midspan normal strain - UFH70-70I........................... 119

Figure 5.59 Midspan load-deflection - UFH70-70H........................ 120

Figure 5.60 Midspan normal strain - UFH70-70H......................... 120

Figure 6.1 Histogram of comparing the ultimate strain compatibility

moment to the ultimate moment predicted by AASHTO (2001)..... 125

Figure 6.2 Histogram of comparing the ultimate strain compatibility

moment to the ultimate moment predicted by AASHTO (2003).... 126

Figure 6.3 Comparisons of strain compatibility results to AASHTO (2001).... 127

Figure 6.4 Comparisons of strain compatibility results to AASHTO (2003).... 128

Figure 6.5 Comparison of proposed prediction equation (Eqn. 6.1) to strain compatibility results and AASHTO (2001)...................... 129

Figure 6.6 Comparison of proposed prediction equation (Eqn. 6.2) to strain compatibility results and AASHTO (2003)..................... 130

Figure 6.7 Histogram comparing the ultimate strain compatibility moment to the ultimate moment predicted by Eqn. 6.1. 
Figure 6.8 Histogram comparing the ultimate strain compatibility moment to the ultimate moment predicted by Eqn. 6.2.............132

Figure A.1 Girder Yield Configuration 1.................................... 140

Figure A.2 Girder Yield Configuration 2................................... 140

Figure A.3 Girder Yield Configuration 3.................................. 141

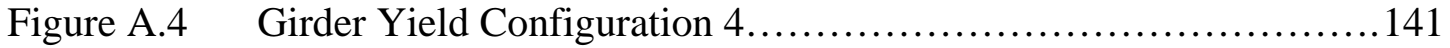

Figure A.5 Girder Yield Configuration 5.................................. 142

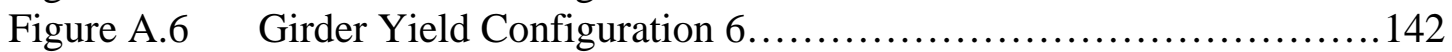

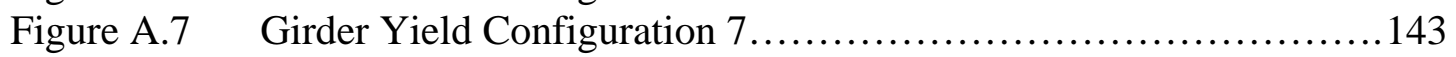




\section{NOMENCLATURE}

$a=6193.6\left(0.85 f_{c}{ }^{\prime}+1.015\right)^{-0.953}$

$A_{s}=$ cross-sectional area of steel beam (in. ${ }^{2}$ )

$b=8074.1\left(0.85 f_{c}{ }^{\prime}+1.450\right)^{-1.085}-850$

$b_{\text {eff }}=$ effective slab width (in.)

$b_{f}=$ width of the flange of steel section (in.)

$b_{f c}=$ width of the compression flange of steel section (in.)

$b_{f t}=$ width of tension flange of steel section (in.)

$b_{\text {slab }}=$ concrete slab width (in.)

$B_{c}=$ concrete slab width (in.)

$B_{s}=$ width of bottom flange of steel section (in.)

$c=$ depth to neutral axis from top of deck (in.)

$c_{F E A}=$ depth to neutral axis at failure determined from FEA anlysis (in.)

$c_{S C}=$ depth to neutral axis at failure determined from strain compatibility (in.)

$C_{1}, C_{2}=$ steel compressive component forces used in strain compatibility analyses (kip)

$C_{\text {slab }}=$ concrete compressive component force used in strain compatibility analyses (kip)

$D=$ depth of the web of steel section (in.)

$D^{\prime}=$ depth at which a composite section reaches its theoretical plastic moment capacity when the maximum strain in the concrete slab is at its theoretical crushing strain

$D_{c}=$ slab thickness (in.)

$D_{s}=$ total depth of steel section (in.)

$D_{t}=$ total depth of composite section (in.)

$D_{p}=$ depth of plastic neutral axis (in.)

$D_{w}=$ depth of the web of steel section (in.)

$E=$ modulus of elasticity of steel (ksi)

$E_{s h}=$ strain hardening modulus of steel (ksi)

$E_{s t}=$ strain hardening modulus of steel (ksi)

$\mathrm{EI}=$ elastic rigidity of the girder of the composite girder

$(E I)_{t}=$ tangent stiffness of the composite girder 


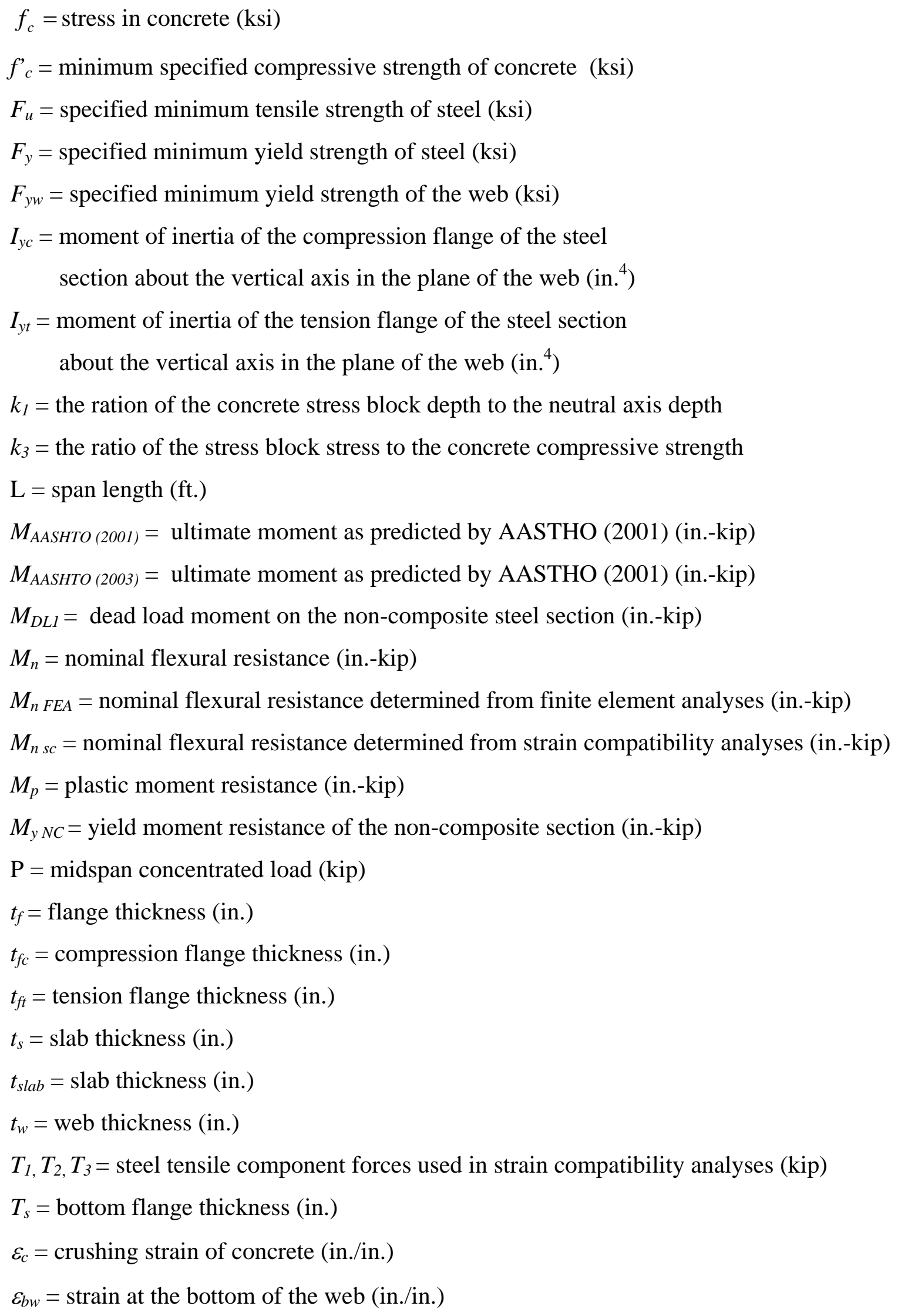


$\varepsilon_{f c}=$ strain at the extreme fiber of the compression flange (in./in.)

$\varepsilon_{f t}=$ strain at the extreme fiber of the tension flange (in./in.)

$\varepsilon_{s h}=$ strain at first sign of strain hardening (in./in.)

$\varepsilon_{s t}=$ strain hardening strain (in./in.)

$\varepsilon_{t w}=$ strain at the top of the web (in./in.)

$\varepsilon_{u}=$ ultimate steel strain (in./in.)

$\varepsilon_{y}=$ yield strain (in./in.)

$\phi_{s h}=$ curvature at development of strain hardening

$\phi_{u}=$ curvature at unloading 


\section{Chapter 1}

\section{INTRODUCTION}

\subsection{Problem Statement and Significance}

One of the most common forms of highway bridges is the steel-concrete composite member configuration, where a cast in place reinforced concrete deck is used in conjunction with an I-shaped steel girder. Figure 1.1 shows a cross section for a typical 5-girder arrangement.

Primary design limit states for these structures consist of evaluating capacity related to live-load deflections, fatigue, permanent deflections, and ultimate strength. In the ultimate strength evaluation, positive bending sections are typically classified as compact as a result of the low amount of web depth in compression and due to the fact that the deck provides continuous lateral support to the compression flange.

The ultimate capacity of simple spans and positive bending regions of continuous spans with adjacent compact pier sections is related to the depth of web in compression. This is given as a linear relationship between the plastic moment capacity and the yield moment of the section. Further, this is a function of an assumed depth of web in compression at which it is felt that the section may simultaneously develop crushing of the concrete and yielding of the steel. Using 
this equation for the worst case scenario applicable to the current specifications (AASHTO, 2003) can result in capacities as low as $0.75 M_{p}$.

Research that was conducted leading to the development of current AASHTO requirements (AASHTO, 2001; Wittry, 1993) did not produce results with the low strength values that may be obtained using the strength prediction equations described above. Analyses by Wittry resulted in no capacities less than $0.96 M_{p}$. Further research conducted by investigators at West Virginia University and independent experimental testing conducted by others (Mans, 2001) has demonstrated that these equations may be overly conservative for some girder configurations.

Conversely, when a compact positive bending section has adjacent pier sections which are classified as non-compact (determined as a function of the flange slenderness, web slenderness, and lateral brace spacing) current AASHTO specifications allow the engineer to limit the strength of the positive bending section to $1.3 R_{h} M_{y}$ (where $M_{y}$ is the actual yield moment of the composite girder accounting for the actual application of load). Research by Barth (2000) has demonstrated that for some girder geometries this may actually cause too much load to be redistributed to the adjacent non-compact pier section and may thereby rapidly exhaust the ultimate capacity of this section. 


\subsection{Objectives and Scope of Work}

\subsubsection{Objectives}

This research is focused on developing a more complete understanding of the ductility of composite positive bending sections over a wide range of practical member geometries that may be used in typical bridge designs. Specifically, a small series of full-scale composite girders will be tested to failure and a parametric investigation will be conducted using refined 3-D finite element modeling coupled with an analytical investigation using a strain compatibility approach. Results of the testing and analysis will be used to identify those parameters which most significantly influence the ultimate flexural capacity of the positive bending sections. These parameters will be used to develop a less conservative ultimate strength equation for compact composite positive bending sections.

\subsubsection{Scope of Work}

The research plan consists of five tasks:

- A comprehensive literature review will be conducted investigating both domestic and foreign archival publications as well as dissertations and university reports.

- Large scale experimental testing will be conducted on 3 full-scale composite girders to physically verify major trends that affect the ultimate bending capacity.

- Refined FEA tools will be developed to accurately capture the response of composite girders subjected to positive bending. These tools will be used to perform a parametric study of hypothetical 
girders, from which the data will be correlated with experimental results and results from the mechanistic strain compatibility analyses.

- A mechanistic strain compatibility approach will be used to perform a comprehensive parametric study of hypothetical girders. The results will be correlated with the experimental and FEA results.

- Results from the large scale experimental tests, FEA analyses and the mechanistic parametric study will be used to develop accurate strength prediction equations.

\section{Literature Review}

In order to study and recognize the development of technologies leading to the current specifications which pertain to the ultimate positive bending strength of composite girders, a comprehensive literature review will be conducted. Domestic and foreign archival publications as well as dissertations and university reports will be investigated.

\section{Experimental Testing}

Focused physical testing will be conducted on 3 full-scale composite girders. One of the girders will be comprised of a rolled steel section and the remaining two girders will be plate girder sections. Of these three tests, 2 of the girders will be designed using all Grade 50 steel $\left(\mathrm{F}_{\mathrm{y}}=50 \mathrm{ksi}\right)$ and one of the girders will be designed with a hybrid girder configuration. The hybrid girder will have a HPS $70 \mathrm{~W}\left(\mathrm{~F}_{\mathrm{y}}=70 \mathrm{ksi}\right)$ bottom flange and the web and top flange will consist of Grade 50 steel. Including a hybrid girder in this research is important because recent research (Clingenpeel, 2001; Horton et. al., 2000; Barker, 2000) has suggested that hybrid girders produce the most economical 
designs. To date, there has not been any flexural tests of hybrid composite positive bending specimens and it is anticipated that design engineers will use these hybrid configurations.

\section{Finite Element Modeling}

Refined three-dimensional finite element modeling will be employed by using the commercially available package, ABAQUS. General shell elements with reduced integration (S4R) will be used for all components of the composite girders. To simulate shear connectors, rigid MPC Beam elements will be used to connect the top flange of the steel girder to the deck elements. The finite element analysis will then be used to correlate with the results of the experimental tests and the results of the mechanistic strain compatibility analysis.

\section{Mechanistic Strain Compatibility Analysis}

Iteratively determining the depth of the neutral axis of a given composite cross section, the ultimate moment can be determined by implementing a strain compatibility approach. Using this approach, a parametric study, which will determine the ultimate flexural strength, will be performed on a comprehensive set of girder cross-sections with a wide range of web depths in compression. Results of this parametric study will be correlated with the experimental tests and the finite element analyses and will be further used to develop refined ultimate strength prediction equations.

\section{Development of Recommended Strength Prediction Equations}

The results of the full scale experimental testing, refined FEA and strain compatibility analyses will be used to develop less conservative ultimate strength equations for positive bending sections. The goal of developing the new ultimate 
strength equation is to develop a less conservative, easier to use prediction equation for the ultimate flexural capacity of steel-concrete composite I-girders in positive bending.

\subsection{Thesis Organization}

This thesis is organized into seven chapters. Chapter 2 provides a comprehensive literature review concerning previous studies of the behavior of composite members in positive bending with respect to ductility limits and ultimate flexural strength.

The experimental testing for this research is discussed in Chapter 3. The chapter focuses on 3 full-scale tests, the test objectives, test set-ups and the test results. In addition to the positive bending tests, a discussion of the material testing required for this research is also provided in this chapter.

Chapter 4 provides an overview of a strain compatibility based ultimate strength prediction. This chapter also discusses an extensive parametric study based on this procedure conducted to obtain the primary data set used for subsequent development of a simplified strength prediction equation.

Chapter 5 focuses on finite element modeling used to assess the ultimate capacity of composite positive bending sections. This chapter first presents the objectives of the modeling, then provides a description of the FEA modeling techniques used in this study. Also presented in this chapter is a parametric study of 24 hypothetical girders comprised of both homogeneous and hybrid composite sections. The finite element methods employed are verified through comparisons with physical tests conducted by others and the physical test results obtained in this study.

Chapter 6 presents the findings of this research by providing a discussion of the influence of the parameters and an overview of the results. The results of this research 
will be compared to the current AASHTO Specifications. Chapter 6 also presents a less conservative ultimate moment prediction equation based on the results of the strain compatibility parametric study.

Lastly, Chapter 7 presents final conclusions and recommendations from this work as well as providing a summary of proposed future work. 


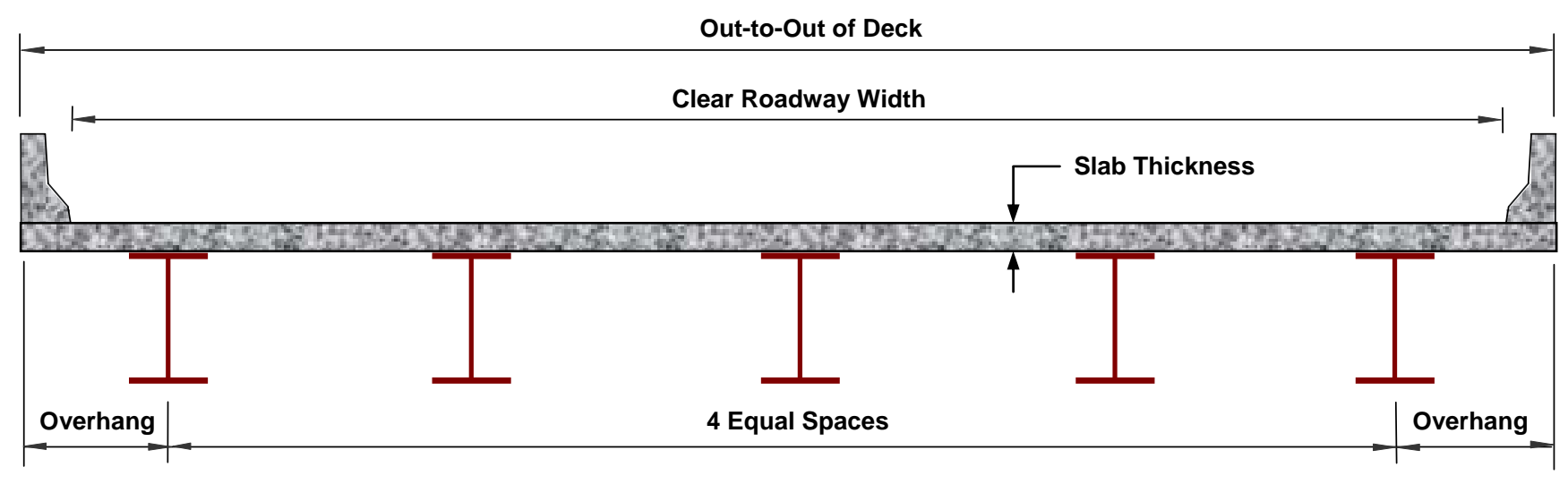

Figure 1.1 Typical steel-concrete composite bridge cross-section 


\section{Chapter 2}

\section{LITERATURE REVIEW}

\subsection{Background}

Many previous works have been conducted concerning the ultimate moment capacity and ductility of composite steel girders. This chapter presents an overview of the primary work that has been conducted which has lead to the development of current AASTHO Specifications for composite steel girders in positive bending. Also, a summary of recent testing conducted at the University of Nebraska in presented. Ansourian (1982)

Ansourian (1982) conducted an experimental investigation of four full-scale composite girders in the range of ductility parameter $(\chi)$, shown in Eqn. 2.1, from 0.65 to 3.0 to investigate the rotation capacity of sections subjected to positive bending. This ductility parameter is an index of the degree of strain-hardening developed in the steel beam at collapse.

$$
\chi=\frac{0.72 f_{c}^{\prime} B_{c} \varepsilon_{c}\left(D_{s}+D_{c}\right)}{A_{s} F_{y}\left(\varepsilon_{u}+\varepsilon_{s h}\right)}
$$

In his studies, Ansourian identified two potential failure modes, ductile and brittle behavior. Ductile failure is characterized by crushing failure of the slab when strain hardening in the tension flange occurs before the collapse moment is reached. Brittle failure is characterized by crushing of the concrete before strain hardening occurs. Ansourian suggested that ductile behavior is desirable for 3 key reasons: 
1. Ultimate strength always exceeds the full plastic moment, $M_{p}$, by an amount that can be easily calculated.

2. Failure is preceded by the appearance of large deflections.

3. The well-defined curvature plateau followed by a short strain-hardening segment allows redistribution of moments when the sagging hinge is the last to form.

Based on the results of the full-scale tests and a computer investigation of the rotation capacity of 60 beams, lower bound expressions for the ratio of ultimate to elastic deflection, $\delta_{u r}$, and the ratio of ultimate to elastic rotation, $\theta_{p r}$, where recommended.

Also based on the full-scale tests and computer investigation, Ansourian proposed a minimum value of the ductility parameter for which sufficient plastic redistribution was available for any combination of spans and loading. Girders with a ductility parameter equal to 1.0 were found to just begin strain hardening at collapse. This was said to relate to a girder with a strain profile in which the neutral axis at collapse is at a level where the strain hardening strain of the steel, $\varepsilon_{s h}$, and the crushing strain of the concrete, $\varepsilon_{c}$, are developed simultaneously. The ductility ratio was defined as the ratio of the limiting neutral axis depth to the actual depth at collapse. The limiting neutral axis depth is:

$$
\left(k D_{c}\right)_{\lim }=\frac{\varepsilon_{c}}{\varepsilon_{c}+\varepsilon_{s h}}\left(D_{s}+D_{c}\right)
$$

The actual depth of the neutral axis at collapse was approximated by the conventional neutral axis depth at the full plastic moment, when $\chi \geq 1.0$. Neglecting longitudinal reinforcement, the approximate neutral axis depth was:

$$
k D_{c}=\frac{A_{s} F_{y}}{k_{1} k_{3} B_{c} f_{c}^{\prime}}
$$


This lead to the following expression for the ductility parameter:

$$
\chi=\frac{0.72 f_{c}{ }^{\prime} B_{c} \varepsilon_{c}\left(D_{s}+D_{c}\right)}{A_{s} F_{y}\left(\varepsilon_{c}+\varepsilon_{s h}\right)}
$$

Assuming that strain hardening would occur in the bottom flange, the slope of the strain hardening portion of the moment curvature graph was expressed as:

$$
(E I)_{t}=E_{s h} B_{s} T_{f}\left(D_{s}+D_{c}\right)^{2}
$$

Therefore, the ultimate moment could me predicted as:

$$
M_{n}=M_{p}+(E I)_{t}\left(\phi_{u}-\phi_{s h}\right)
$$

As follows, the midspan deflection of a symmetrically loaded simply supported beam was found by integrating the function of the curvature distribution (where $x=$ distance from support):

$$
\delta_{c}=\int_{0}^{L / 2} \phi x d x
$$

For the case of a concentrated midspan load, the plastic rotation was obtained by subtracting the elastic rotation component as follows:

$$
\theta_{p}=2\left(\int_{0}^{L / 2} \phi d x-\frac{P L}{16 E I}\right)
$$

For the range of $\chi=1.0$ to 3.5, it was recommended that the following lower bound expressions be used for the ratio of ultimate to elastic deflection and the ratio of ultimate to elastic rotation, respectively:

$$
\begin{aligned}
& \delta_{u r}=3.0 \chi-1.5 \\
& \theta_{p r}=2.3 \chi-1.85
\end{aligned}
$$


Based on the full-scale tests and the computer analysis, Ansourian concluded that with a minimum value of $\chi=1.4$, sufficient rotation should be available to develop the plastic collapse load for any combination of spans and loading. Vasseghi (1989)

An experimental evaluation of composite plate girders to assess the shear and bending moment capacity of these sections was conducted by Vasseghi (1989). Three of Vasseghi's tests consisted of composite girders in positive bending. The results of these tests were used in the development of initial limits established to reduce the potential for concrete crushing in composite positive bending sections, which is the basis of the ductility requirement in the AASHTO LFD Specifications (1989). Assuming a concrete crushing strain of 0.003 , a steel strain at strain hardening of 0.012 and a linear strain distribution, Vasseghi derived the ductility factor, $D^{*}$, as shown in Eqn. 2.10. As an added factor of safety, $D^{*}$ was divided by 1.5 to ensure that the composite section can attain $M_{p}$ without crushing the concrete.

$$
D^{*}=\frac{D_{t}}{1.5 \times 5}=\frac{D_{t}}{7.5}
$$

Given this, if the depth of the plastic neutral axis, $D_{p}$, is less than or equal to $D^{*}$, then the section is considered ductile and the design moment capacity, $M_{n}$, is equal to the simple plastic moment, $M_{p}$. The three experimental girders tested by Vasseghi had $D^{*} / D_{p}$ ratios of 1.39, 1.44, and 1.86. And all the girders had a moment capacity greater than $M_{p}$. 
Wittry (1993)

Using a moment curvature analysis, a parametric study was performed by Wittry (1993) on 406 hypothetical composite girders with a wide range of ductility ratios. Because Wittry’s study had a broad range of plate and slab sizes it also covered a broad range of depths of web in compression. Most of the $D_{p} / D^{*}$ ratios fall between 0.2 and 1.6, with very few falling between 1.6 and 5. The results of Wittry's study are shown in Fig. 2.1. To use the ductility factor to distinguish between ductile and non-ductile sections and to determine the moment capacity, the ductility factor should be normalized based on Fig. 2.1 so that when the ductility ratio equals one, the moment capacity is $M_{p}$. Wittry determined that sections using $36 \mathrm{ksi}$ steel reached $M_{p}$ at a ratio of $D_{p} / D^{*}$ equal to approximately 0.9 , and sections utilizing $50 \mathrm{ksi}$ steel reached $M_{p}$ at a ratio of $D_{p} / D^{*}$ equal to approximately 0.7 . The values of 0.9 and 0.7 are specified as the values to use as the $\beta$ factor, which is multiplied by $D^{*}$ to develop $D^{\prime}$. Utilization of the $\beta$ factors ensures that when the ductility ratio is equal to one, the moment capacity is equal to $M_{p}$. The $\beta$ factors allow the use of $D$ ' to distinguish between ductile and non-ductile sections and to determine the moment capacity of the section. As a result, the ductility ratio $D^{*}$ is replaced with a new ductility ratio, $D^{\prime}$, shown in Eqns. 2.11a and 2.11b:

$$
\begin{aligned}
& D^{\prime}=0.7 \frac{D_{t}}{7.5} \quad \text { for } 50 \text { ksi sections } \\
& D^{\prime}=0.9 \frac{D_{t}}{7.5} \quad \text { for A36 sections }
\end{aligned}
$$

The larger the number on the x-axis of Fig. 2.1, the larger the ductility ratio becomes. The ductility ratio is the ratio of the depth of web in compression to the depth of web in compression that is hypothetically assumed to produce the plastic moment 
capacity at the instant crushing of the concrete deck and strain hardening of the section occur simultaneously. In other words, as the $D_{p} / D^{\prime}$ ratio increases, the ductility of the section decreases. Also shown in Fig. 2.1, the lower bound value for the most nonductile specimen was found to be approximately 96 percent of $M_{p}$.

In addition to Wittry’s parametric study, he also performed a moment curvature analysis on 20 USS short-span bridge sections. Figure 2.2 shows the results of this study. A curve fit of the data presented in Fig. 2.2 shows that at a $D_{p} / D^{\prime}$ ratio equal to 5 the moment capacity is equal to the yield moment based on an extrapolation from the linear regression of the non-ductile sections $\left(D_{p} / D^{\prime}>1\right)$, and that at a $D_{p} / D^{\prime}$ ratio equal to 1 , the moment capacity is equal to the simple plastic moment. At $D_{p} / D^{\prime}$ equal to 5 , it was found that a section will fail in a brittle manner. This results in the use of a $\phi$ factor of 0.85 being used at this limit (at $D_{p} / D^{\prime}=5, M_{u}=\phi M_{p}$ ). Considering these two limits, the moment capacity for non-ductile sections can be predicted by using Eqn. 2.12:

$$
M_{n}=\frac{5 M_{p}-\phi M_{y}}{4}+\frac{\phi M_{y}-M_{p}}{4}\left(\frac{D_{p}}{D^{\prime}}\right)
$$

where, $\phi=0.85$

$$
1 \leq\left(D_{p} / D^{\prime}\right) \leq 5
$$

Ductile sections (sections with $D_{p} / D^{\prime} \leq 1$ ), have a moment capacity, $M_{n}$, equal to $M_{p}$. Using Eqn. 2.12, the predicted ultimate moment capacity was compared with the analytical results of the hypothetical sections and the USS short-span bridge sections. The results of these comparisons are shown in Figs. 2.3 and 2.4, respectively. In Fig. 2.3, the data labeled "50 ksi Steel” and "36 ksi Steel” are the results of the analytical momentcurvature analysis and the data labeled "50 ksi $\mathrm{M}_{\mathrm{u}} / \mathrm{M}_{\mathrm{p}}$ ” and "36 ksi $\mathrm{M}_{\mathrm{u}} / \mathrm{M}_{\mathrm{p}}$ ” are the 
moment capacities as calculated by Eqn. 2.12. The comparisons show that at lower ductility ratios $M_{n}$ is relatively close to the moment capacity calculated using Eqn. 2.12. As the ductility ratio increases, the difference between $M_{n}$ and the calculated moment capacity increases.

Although Wittry's study lead to the current design limits in the AASTHO LRFD Specifications (2001), some of the sections in this study violate the proportional limits in AASHTO LRFD (2001) and the Preferred Practices for Steel Bridge Design (TxDOT, 2000), which contain extreme proportions such as unusually thick webs, very slender webs, almost no top flanges, and unusually wide top flanges. And only 20 USS shortspan bridge sections, with ductility ratios ranging from 0.6 to 2, were used to develop the moment capacity equations shown in Eqn. 2.12. Therefore, it is reasonable to evaluate the conservatism found in the AASHTO LRFD Specifications.

Also, the lack of experimental data presents limitations that restrict the optimum use of high yield strength steels in bridges. One limitation, related to higher yield strength steel, such as HPS 70W, is that it lowers the ductility of composite sections and may cause premature crushing of the concrete slab prior to development of the design ultimate capacity. The AASHTO LRFD Specifications (2000 Interim) have extended the positive bending prediction equations to include HPS 70W and to use a ductility factor ( $\beta$ ) of 0.7 for $70 \mathrm{ksi}$ steel, the same value as $50 \mathrm{ksi}$ steel, as shown in Eqn. 2.11a.

Implementing the philosophy introduced by Wittry, that an additional margin of safety should be applied to the theoretical nominal flexural resistance when $D_{p}$ exceeds a certain value, AASHTO (2003) has developed new equations, as shown in Eqns. 2.13 and 2.14. This additional margin of safety, which increases approximately as a linear 
function of $D_{p} / D_{t}$, is intended to protect the concrete deck from premature crushing, ensuring adequate ductility of the composite section. These equations are presented in the newly adopted revisions to the current bridge specifications and give approximately the same results as Eqn. 2.12 but are presented in a simpler form that depends only on the plastic moment capacity, $M_{p}$, and the parameter $D_{p} / D_{t}$ where,

$$
M_{u}=M_{p}
$$

where, $D_{p} \leq 0.1 D_{t}$

$$
M_{u}=M_{p}\left(1.07-0.7 \frac{D_{p}}{D_{t}}\right)
$$

where, $D_{p}>0.1 D_{t}$

Equation 2.14 is more restrictive than Eqn. 2.12 for sections with small values of $M_{p} / M_{y}$, such as sections with hybrid configurations, a relatively small deck area and a highstrength tension flange. For larger values of $M_{p} / M_{y}$, it is less restrictive.

The limit of $D_{p} \leq 0.1 D_{t}$ for use in Eqn. 2.13 is obtained by use of a single implicit $\beta$ value of 0.75 in the similar equations provided by Wittry. AASHTO (2001) specifies $\beta=0.7$ for $\mathrm{Fy}=50 \mathrm{ksi}$ and $70 \mathrm{ksi}$ and $\beta=0.9$ for $\mathrm{Fy}=36 \mathrm{ksi}$. The value of $\beta=$ 0.75 is justifiable for all cases based on the scatter in strain-hardening data. The derived $\beta$ values are sensitive to the assumed strain-hardening characteristics. The limit of $D_{p} / D^{\prime} \leq 5$ in AASHTO (2001) corresponds to $D_{p} / D_{t} \leq 0.5$ for $\beta=0.75$. The $D_{p} / D_{t}$ ratio is lowered to 0.42 to ensure significant yielding of the bottom flange when the crushing strain is reached at the top of the concrete deck for all potential cases. 


\section{Mans (2001)}

Two recent experiments on composite plate girders were conducted at the University of Nebraska (Mans, 2001). These experiments showed that for girders with large $D_{p} / D^{\prime}$ values, the AASHTO equations may be conservative for section geometries with high ductility ratios. Figure 2.5 shows the cross sections for the University of Nebraska test girders. Both girders had a span length of $40 \mathrm{ft}$. between bearings and were tested in 3-point bending with appropriate transverse stiffeners and lateral bracing.

A comparison between the experimental results obtained by Mans and the AASHTO prediction equations is provided in Table 2.1. This table shows that the AASHTO prediction equations for non-ductile $\left(D_{p} / D^{\prime}>1\right)$ composite sections may be somewhat conservative.

\subsection{Summary}

Over many years, researchers have sought to reliably predict the ultimate strength of composite steel girders. The previous research on this topic has consisted of extensive parametric studies and limited experimental tests. The results of these efforts where used to investigate the parameters that most influence the ductility of composite girders and further to develop the current ultimate strength prediction equations for composite girders in positive bending presented in the AASHTO Bridge Specifications. However, recent research has shown that the prediction equations in use today may be conservative for some girder geometries.

Through full-scale experimental tests, a parametric study conducted with refined non-linear finite element analysis and a mechanistic analysis of over 20,000 girder cross- 
sections, this research will study the behavior of composite steel girders with respect to ultimate flexural capacity. Additionally, with the data colleted from these studies, refined and less conservative strength prediction equations will be developed and provided. 
Table 2.1 Ultimate moment results for Nebraska POS1 and POS2 (Mans, 2001)

\begin{tabular}{|c|c|c|c|}
\cline { 2 - 4 } \multicolumn{1}{c|}{} & $\boldsymbol{D}_{\boldsymbol{p}} / \boldsymbol{D}^{\prime}$ & $\begin{array}{c}\text { Experimental } \\
\text { Results (in-kips) }\end{array}$ & $\begin{array}{c}\text { AASHTO Prediction } \\
\text { Equations (in-kips) }\end{array}$ \\
\hline POS1 & 2.0694 & 46,947 & 43,883 \\
\hline POS2 & 0.8806 & 38,666 & 37,814 \\
\hline
\end{tabular}




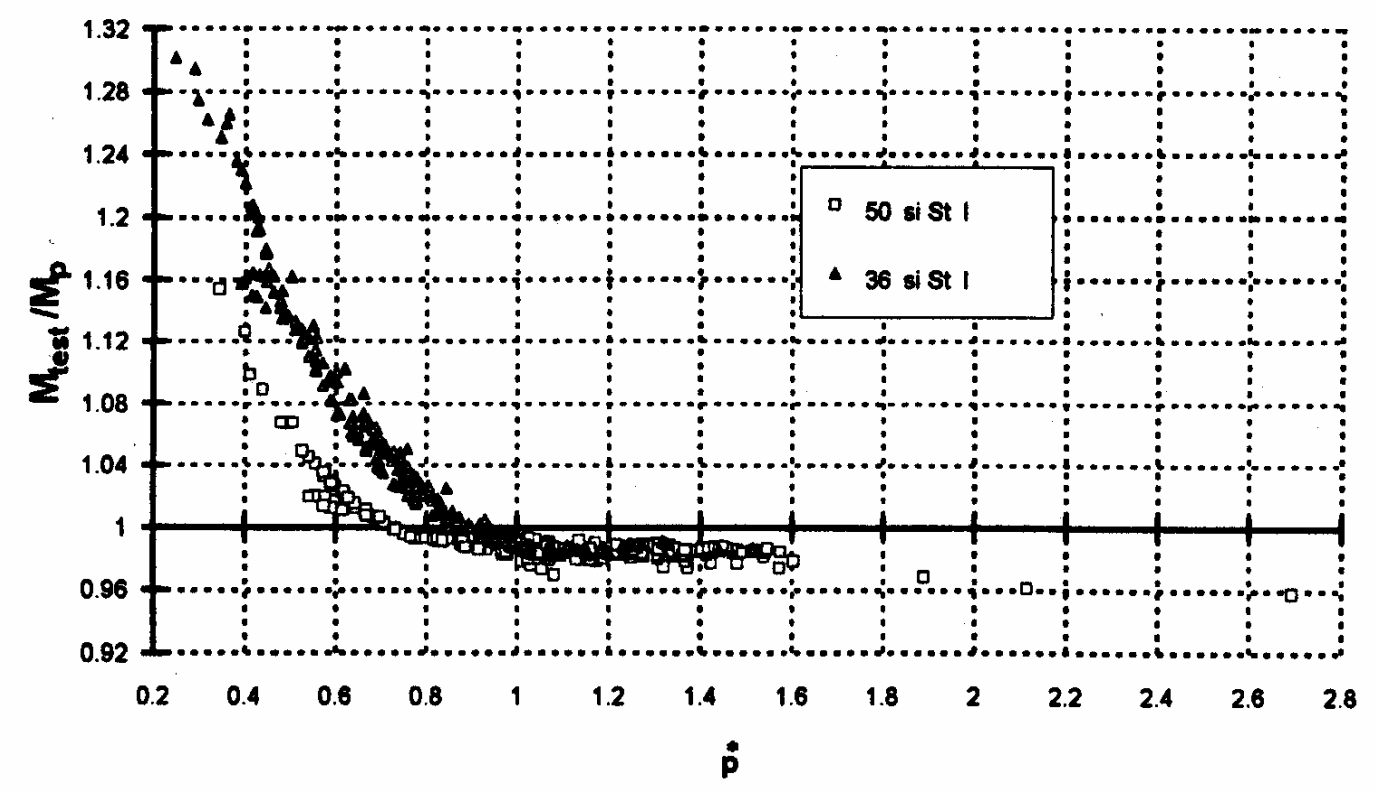

Figure 2.1 Normalized maximum moment versus ductility parameter (Wittry, 1993)

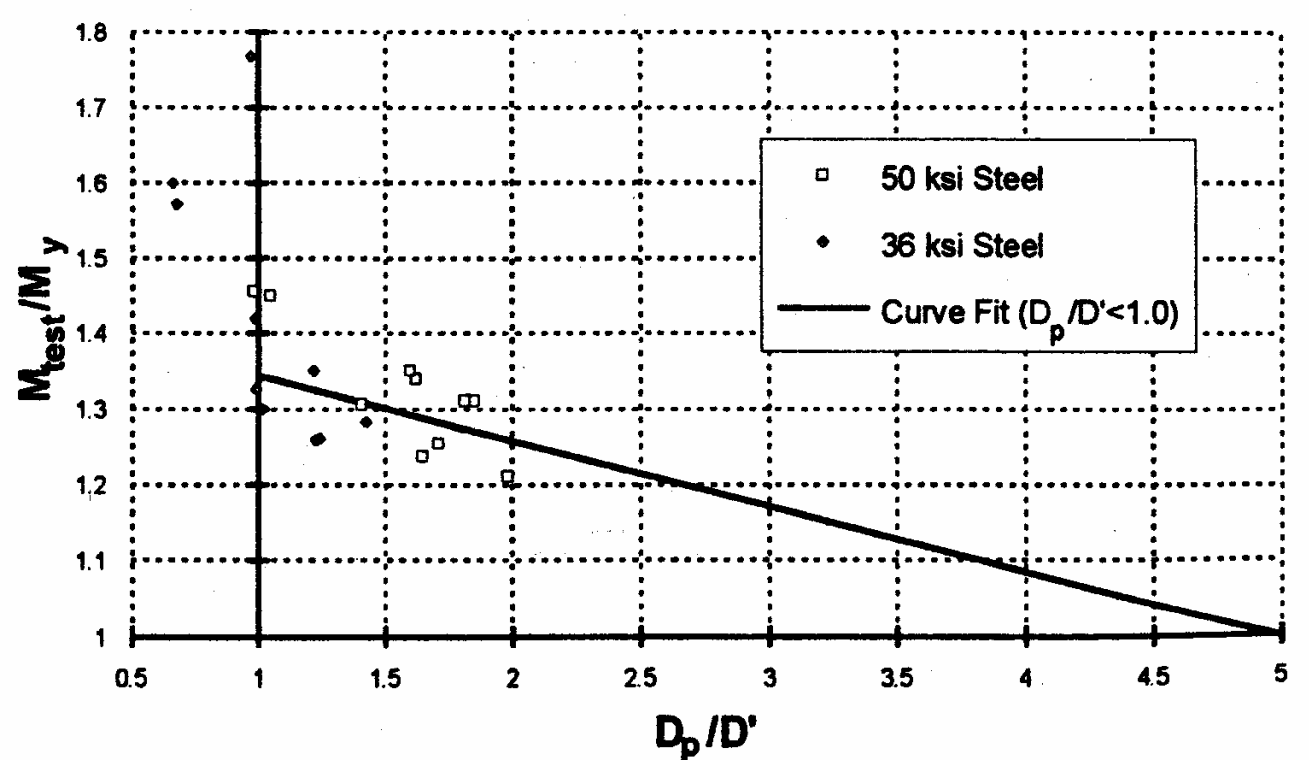

Figure 2.2 Curve fit of 20 USS short span bridges (Wittry, 1993) 


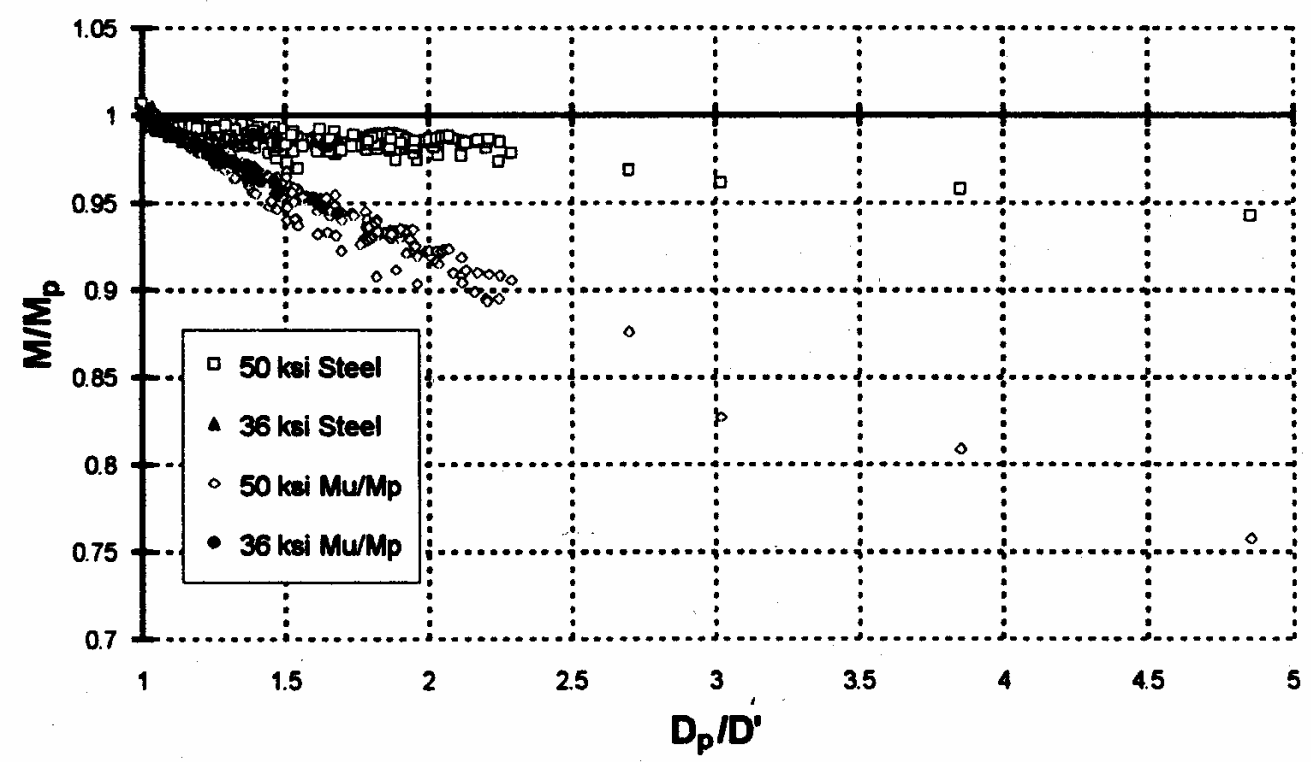

Figure 2.3 Comparison of $\mathrm{M}_{\mathrm{u}}$ and analytical results of Wittry's 406 hypothetical girders (Wittry, 1993)

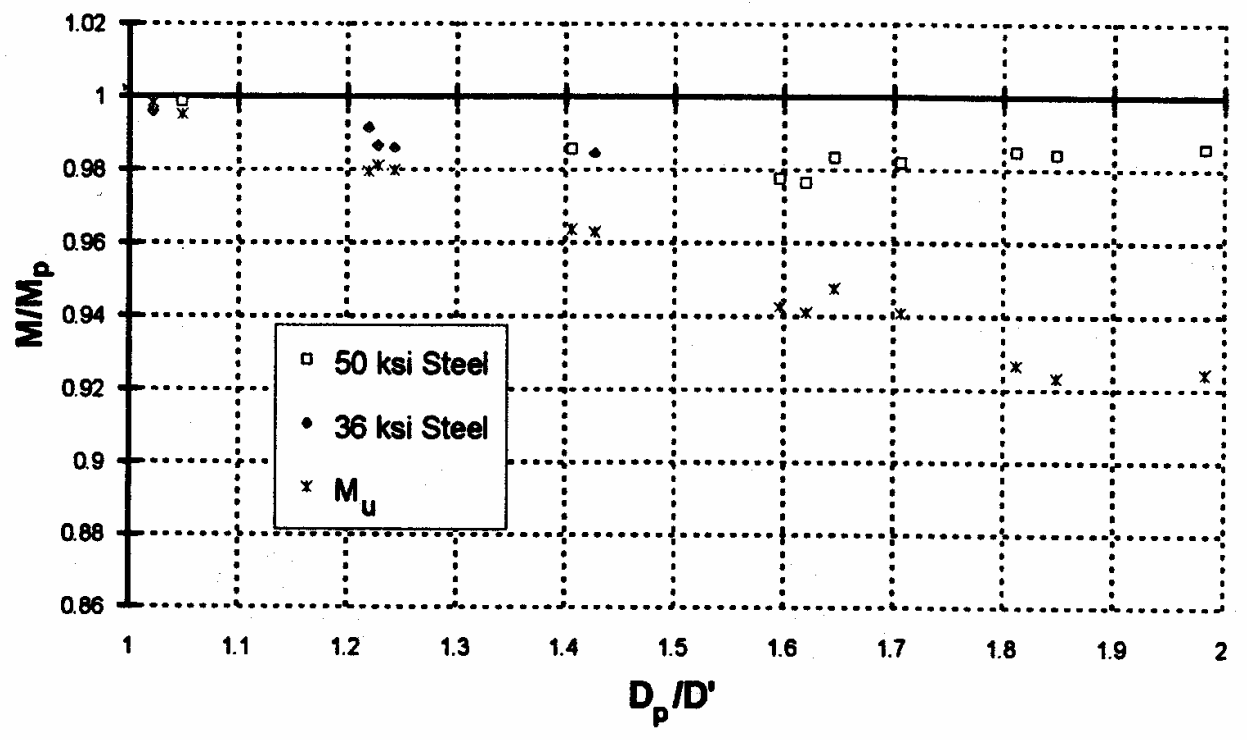

Figure 2.4 Comparison of $\mathrm{M}_{\mathrm{u}}$ and analytical results of Wittry's 20 USS short-span bridges (Wittry, 1993) 


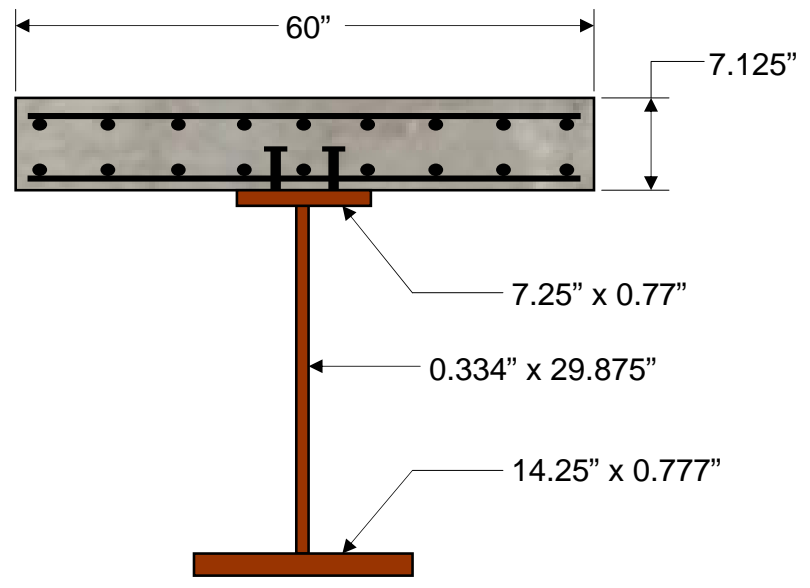

(a) Specimen POS1

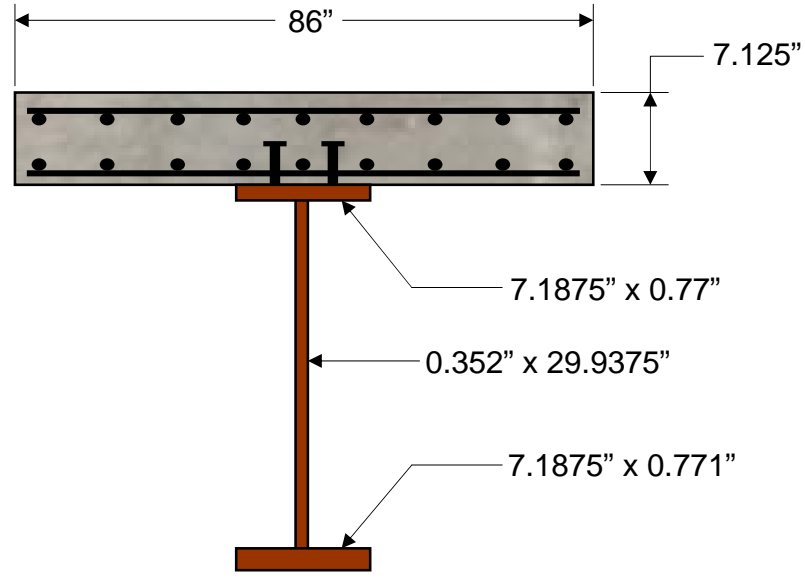

(b) Specimen POS2

Figure 2.5 University of Nebraska composite girder specimens (a) POS1 and (b) POS2 (Mans, 2001) 


\section{Chapter 3}

\section{EXPERIMENTAL TESTING}

\subsection{Introduction}

The experimental testing component of this research consisted of testing three full-scale composite steel girder specimens (named R1, PL1, and PL2) under three-point bending. Each specimen consisted of a steel beam fitted with a composite reinforced concrete deck. Deck designs consisted of Grade 60 standard deformed bars spaced longitudinally and transversely to meet the recommended standards for the West Virginia Division of Highways [WVDOH] empirical deck (WVDOH, 1999). The goal of these tests is to physically verify the influence of key parameters on the ultimate strength of composite positive bending sections. This data will serve to verify analytical modeling conducted in this effort and to assess current design specifications.

\subsection{Girder Fabrication}

The composite girders described in this report consisted of one rolled section and two plate girders. The plate girders were fabricated by High Steel Structures, Inc. and all testing was conducted in the WVU major units lab. Coupons were taken from appropriate locations on the steel sections to obtain actual material properties.

Once the steel girders were fitted in the testing frame, a system of overhang deck

forms were built by university personnel. Figure 3.1 shows a typical view of these forms, 
which were intended to support the weight of the uncured concrete deck, reinforcement and construction loads on the girder overhang.

The steel reinforcement for each deck (see section 3.5.1 for specific reinforcement patterns) was also placed by university personnel. A typical view of the finished formwork (including reinforcement) is shown in Fig. 3.2.

The concrete was pumped into place using a tow-behind trailer pump (see Fig. 3.3) and a 2 in. diameter hose. Concrete placement is illustrated in Fig. 3.4. Once the concrete began to cure, approximately 5 hours after placement, the deck was covered with burlap that was saturated with water. The burlap was then kept wet for 14 consecutive days after the pour. For the entire 14 days, the burlap was covered with plastic (see Fig. 3.5). These precautions were taken to prevent the concrete from curing too fast, which would cause surface cracking. Once the burlap and plastic were removed from the deck, the formwork was removed approximately one week later.

\subsection{Girder Configuration, Testing Method and Instrumentation}

\subsubsection{Girder Configuration}

The primary concern of this experimental testing was to investigate flexural behavior. Therefore, it was necessary to minimize secondary force effects. This was accomplished by providing each girder with appropriate transverse stiffeners, bearing stiffeners and lateral bracing. Lateral bracing for these experiments was provided by a system of cross frames and rollers, shown in Figs. 3.6 and 3.7. The lateral bracing system allowed the composite girders to displace vertically while remaining laterally constrained. 
Simply supported boundary conditions were created by the use of a pinned support at one end of each girder and a roller-type support at the other end. The pinned supports were comprised of a steel plate with a steel rod welded parallel to the top face of the plate and a threaded rod welded perpendicular to the bottom face of the plate (see Fig. 3.8a). While similarly built, the steel rod of the roller-type support was not welded to the top face of the steel plate. Instead, the rod was allowed to move freely in the longitudinal direction inside of a groove milled into the top face of the plate (see Fig. 3.8b). Each of the support assemblies were then threaded into the center of a 200 kip load cell. The assemblies were then placed at each end of the girders to obtain reaction forces.

\subsubsection{Testing Method}

The test load was applied at midspan using a MTS 330 kip servo-hydraulic actuator which was mounted to a large structural reaction frame as shown in Fig. 3.9. In addition to the load cells placed at each end of the girders, the MTS actuator was equipped with an internal load cell, used to acquire the load at midspan. To minimize bearing effects, the load was applied through a steel spreader beam placed on top of an elastomeric bearing pad (see Fig. 3.10).

For safety and accurate data collection, girders were loaded in the stroke control. Each load step consisted of the application of a small increment of displacement (typically between 0.10 and $0.15 \mathrm{in}$.) over a time interval of one minute. Allowing for stabilization of the applied load, the following load step was applied after a time period of approximately 5 minutes had elapsed. 


\subsubsection{Instrumentation}

The midspan deflection of each girder was determined by means of a linear variable displacement transducer (LVDT) with a total range of 10 inches. The reactions at each support location were obtained by employing 200 kips load cells. Also, the hydraulic actuator was equipped with an internal load cell that was used to obtain the load at midspan.

The data was acquired using StrainSmart software, in conjunction with a MicroMeasurements Model 5100 Scanner. This data acquisition system was also used to obtain the deflection data from the midspan LVDT and the reactions from the load cells at the support locations. The actual load at midspan for each load step was acquired from the internal actuator load cell by using MTS Test Star software. 


\subsection{Material Testing}

Both the steel and concrete from each girder were also tested to obtain actual properties for use in subsequent finite element modeling and strain compatibility assessments of these members.

\section{$\underline{\text { 3.4.1 Steel Material Properties }}$}

To obtain the steel properties, coupons were taken from the top flange, web, and bottom flange of each girder and were tested in accordance with ASTM A 370. Elongation data from these tension tests was collected using an MTS (Model 634.12E24) extensometer, shown in Fig. 3.11, and loading data was collected from direct output of the universal testing machine. The resulting data was reduced to obtain average stressstrain curves for the top flange, web, and bottom flange coupons from each girder. Figures 3.12-3.14 illustrate the average stress-strain curves for Specimen R1, Specimen PL1 and Specimen PL2, respectively.

The material testing of the coupons taken from Specimen R1 (A572 Grade 50) resulted in average yield strengths, as shown in Table 3.1, of $51.43 \mathrm{ksi}$ for the top flange, $53.19 \mathrm{ksi}$ for the web and $51.43 \mathrm{ksi}$ for the bottom flange.

Also shown in Table 3.1, tension testing of the coupons from Specimen PL1 resulted in average yield strengths of $55.29 \mathrm{ksi}, 57.44 \mathrm{ksi}$ and $56.35 \mathrm{ksi}$ for the top flange, web and bottom flange, respectively.

Testing of the coupons taken from Specimen PL2 resulted in average yield strengths of $55.29 \mathrm{ksi}$ in the top flange, $57.44 \mathrm{ksi}$ in the web and $81.06 \mathrm{ksi}$ in the bottom flange, as shown in Table 3.1. 


\subsubsection{Concrete Material Properties}

For each test, six concrete cylinders were cast during deck placement. For each test, three of the cylinders were tested for compressive strength at 7 days after deck placement. To obtain the actual compressive strength at the time of each test, the remaining three cylinders were tested for compressive strength on the same day the corresponding flexural tests were conducted, which was at least 28 days after the deck placement. These compressive strengths were then averaged to obtain the compressive strength used in the analytical and mechanistic models.

Table 3.2 shows the nominal and actual compressive strengths of the concrete used for each specimen in this work. As shown in Table 3.2, the concrete used in Specimens R1 and PL2 had a nominal compressive strength of $4 \mathrm{ksi}$, while the concrete used in Specimen PL1 had a nominal compressive strength of 6 ksi. However, the actual compressive strengths for R1, PL1 and PL2 were 5.32 ksi, $5.67 \mathrm{ksi}$ and $4.32 \mathrm{ksi}$, respectively.

\subsection{Girder Specimen Geometries}

\subsubsection{Reinforced Concrete Deck Details}

Each of the girder specimens were fabricated with a 42 in. wide by 7 in. thick concrete deck with two layers of longitudinal and transverse reinforcement. The bottom layer had a nominal cover of 1 in. and consisted of \#5 bars spaced at 8 in. center-to-center transversely and \#5 bars spaced at 12 in. center-to-center longitudinally. The top layer of reinforcement had a nominal cover of 2 in. and consisted of \#4 bars spaced at 12 in. 
center-to-center transversely and longitudinally. Figures 3.15 illustrates the reinforcement pattern used in each girder.

\subsubsection{Specimen R1}

Specimen R1, with a span length of $18 \mathrm{ft}$. from centerline of bearing to centerline of bearing, was comprised of a W24x55 A572 Grade 50 beam. Full composite action was developed by using 25 pairs of 7/8 in. diameter, 5 in. tall headed shear studs spaced on 9 in. centers along the length of the girder. Also, to minimize secondary effects, bearing and intermediate stiffeners were placed at the ends and at the midspan of the girder. The stiffeners were fabricated of 1-1/4 in. thick steel and were 5 in. wide. Lateral bracing was also provided at all stiffener locations (see Fig. 3.16 for lateral bracing locations). Figure 3.16 shows an elevation and cross-sectional view of Specimen R1. The actual and nominal dimensions of Specimen R1 are presented in Table 3.3.

\subsubsection{Specimen PL1}

Specimen PL1, Fabricated by High Steel Structures, Inc., was a plate girder comprised entirely of Grade 50 steel with a span length of $30 \mathrm{ft}$. from centerline bearing to centerline bearing. Specimen PL1 was fitted with 41 pairs of 7/8 in. diameter, 5 in. tall headed shear connectors placed at 9 in. intervals. Specimen PL1 also consisted of bearing and intermediate stiffeners at each end of the girder, at midspan and at quarter span locations. Lateral bracing was also provided at all stiffener locations (see Fig 3.17 for lateral bracing locations). Dimensioned elevation and cross-sectional views of Specimen PL1, including stiffeners and shear connectors is shown in Fig. 3.17. Table 3.4 presents the nominal and actual dimensions of Specimen PL1. 


\subsubsection{Specimen PL2}

Specimen PL2 had the same nominal span length, girder cross-sectional geometry and deck cross-section as PL1. The top flange and web were fabricated from Grade 50 steel and the bottom flange was fabricated from HPS70W. The size and location of shear connectors, bearing stiffeners, intermediate stiffeners and lateral bracing found on Specimen PL2 were also identical to Specimen PL1. The geometry of Specimen PL2 is shown in Fig. 3.18 and the actual and nominal dimensions are presented in Table 3.5.

\subsection{Test Results}

\section{$\underline{3.6 .1 \text { Specimen R1 }}$}

Figure 3.19 shows the midspan load-deflection plot for R1. As can be seen from the plot, the load deflection curve is linear up to a load of approximately 168 kips, which coincides well with the predicted load of 175 kips at the yield moment, $M_{y}$. After initial yielding of the specimen, inelastic deformation continued and the slope of the load deflection plot began to decrease up to an ultimate load of 274 kips at a midspan deflection of 2.43 inches. Three additional load steps were recorded after reaching this ultimate load before failure occurred as shown in Fig. 3.20.

The moment at the ultimate load was 14,796 in-kips, which is greater than the theoretical plastic moment of 13,900 in-kips. In addition, the ultimate load was greater than the load predicted by Eqns. 2.6 and 2.8, which predict the moment at the ultimate load to be 13,106 in-kips and 13,473 in-kips, respectively.

The development of cracks was observed during the load test. Specimen R1 began to exhibit hairline cracks on the underside on the deck near the centerline of the 
girder on both sides at approximately 205 kips with considerably more developed cracks appearing around 225 kips.

\subsubsection{Specimen PL1}

The midspan load-deflection plot for Specimen PL1 is illustrated in Fig. 3.21 which is linear up to about 154 kips, which again coincides well with the predicted load at first yield of 148 kips. The slope then begins to decrease and the plot reaches an ultimate load of 216 kips with a midspan deflection of 3.79 inches. Once the ultimate load was reached, 5 additional increments of deflection were applied and the corresponding loads recorded. Failure of Specimen PL1 occurred as shown in Fig. 3.22. The concrete was crushed to the point it could be flaked off, exposing the steel reinforcement as shown in Fig. 3.23.

At the ultimate load, the moment in Specimen PL1 was 19,489 in-kips, which is slightly larger than the plastic moment, $M_{p}$, of 18,913 in-kips. Also, the ultimate load was significantly greater than the predicted ultimate capacities of Eqns. 2.6 and 2.8, 17,565 in-kips and 18,120 in-kips, respectively.

Hairline cracks began to appear on the underside of both sides of the deck at approximately 204 kips with considerably more developed cracks by 209 kips. Full failure of the deck occurred only on one side of the girder at 216 kips.

\subsubsection{Specimen PL2}

Midspan load-deflection results for Specimen PL2 are shown in Fig. 3.24, where the plot is linear up to a load of approximately 200 kips, again closely agreeing with the predicted yield load of 182 kips. After the first yielding of the specimen, the slope begins to sharply decrease and the plot reaches a maximum load of 234 kips at a midspan 
deflection of 3.803 inches. Because of unexpected rotations in the bearing supports, shown in Fig. 3.25, test PL2 was terminated prior to development of the peak load. However, the plot does provide results well enough to compare with the other methods of analysis presented in the later chapters.

While the ultimate load was not reached, the moment corresponding to the maximum experimental load, 21,446 in-kips, was slightly greater than $M_{p}, 20,910$ inkips, and significantly greater than those predicted by Eqns. 2.6 and 2.8, 17,504 in-kips and 17,720 in-kips, respectively. 
Table 3.1 Average steel yield strengths

\begin{tabular}{|c|c|c|c|}
\cline { 2 - 4 } \multicolumn{1}{c|}{} & $\begin{array}{c}\text { R1 } \\
\text { (ksi) }\end{array}$ & $\begin{array}{c}\text { PL1 } \\
\text { (ksi) }\end{array}$ & $\begin{array}{c}\text { PL2* } \\
\text { (ksi) }\end{array}$ \\
\hline Top Flange & 51.43 & 55.29 & 55.29 \\
\hline Web & 53.19 & 57.44 & 57.44 \\
\hline Bottom Flange & 51.43 & 56.35 & 81.06 \\
\hline
\end{tabular}

*Values obtained from 3 coupons from random locations

Table 3.2 Nominal and actual concrete compressive strengths

\begin{tabular}{|c|c|c|}
\hline Specimen & $\begin{array}{c}\text { Nominal } \\
\text { (ksi) }\end{array}$ & $\begin{array}{c}\text { Actual } \\
\text { (ksi) }\end{array}$ \\
\hline R1 & 4.00 & 5.32 \\
\hline PL1 & 6.00 & 5.67 \\
\hline PL2 & 4.00 & 4.32 \\
\hline
\end{tabular}

Table 3.3 Nominal and actual dimensions of specimen R1

\begin{tabular}{|c|c|c|}
\hline Dimension & $\begin{array}{c}\text { Nominal } \\
\text { (in.) }\end{array}$ & $\begin{array}{c}\text { Actual } \\
\text { (in.) }\end{array}$ \\
\hline Top Flange Width & 7.01 & 7.00 \\
\hline Top Flange Thickness & 0.5050 & 0.5064 \\
\hline Total Depth & 23.600 & 23.625 \\
\hline Web Thickness & 0.3950 & 0.395 \\
\hline Bottom Flange Width & 7.01 & 7.00 \\
\hline Bottom Flange Thickness & 0.5050 & 0.5059 \\
\hline
\end{tabular}


Table 3.4 Nominal and actual dimensions of specimen Pl1

\begin{tabular}{|c|c|c|}
\hline Dimension & $\begin{array}{c}\text { Nominal } \\
\text { (in.) }\end{array}$ & $\begin{array}{c}\text { Actual } \\
\text { (in.) }\end{array}$ \\
\hline Top Flange Width & 6.00 & 6.00 \\
\hline Top Flange Thickness & 0.5000 & 0.5071 \\
\hline Web Depth & 24.000 & 24.125 \\
\hline Web Thickness & 0.4375 & 0.4507 \\
\hline Bottom Flange Width & 6.00 & 6.00 \\
\hline Bottom Flange Thickness & 0.7500 & 0.7564 \\
\hline \multicolumn{2}{|l}{}
\end{tabular}

Table 3.5 Nominal and actual dimensions of specimen PL2

\begin{tabular}{|c|c|c|}
\hline Dimension & $\begin{array}{c}\text { Nominal } \\
\text { (in.) }\end{array}$ & $\begin{array}{c}\text { Actual } \\
\text { (in.) }\end{array}$ \\
\hline Top Flange Width & 6.00 & 6.00 \\
\hline Top Flange Thickness & 0.5000 & 0.5071 \\
\hline Web Depth & 24.000 & 24.125 \\
\hline Web Thickness & 0.4375 & 0.4507 \\
\hline Bottom Flange Width & 6.00 & 6.00 \\
\hline Bottom Flange Thickness & 0.7500 & 0.7599 \\
\hline
\end{tabular}

Table 3.6 Specimen loading summary

\begin{tabular}{|c|c|c|c|c|c|c|c|}
\hline Specimen & $\boldsymbol{D}_{p} / \mathbf{D}^{\prime}$ & $\boldsymbol{D}_{\boldsymbol{p}} / \boldsymbol{D}_{\boldsymbol{t}}$ & $\begin{array}{c}\boldsymbol{M}_{\boldsymbol{p}} \\
\text { (in.- } \\
\text { kips) }\end{array}$ & $\begin{array}{c}\boldsymbol{M}_{\boldsymbol{y}} \\
\text { (in.- } \\
\text { kips) }\end{array}$ & $\begin{array}{c}\boldsymbol{M}_{\text {exp }} \\
\text { (in.- } \\
\text { kips) }\end{array}$ & $\begin{array}{c}\boldsymbol{M}_{\text {AASHTO (2001) }} \\
\begin{array}{c}\text { Eq. } \mathbf{2 . 6} \\
\text { (in.-kips) }\end{array}\end{array}$ & $\begin{array}{c}\boldsymbol{M}_{\text {AASHTO (2003) }} \\
\begin{array}{c}\text { Eq. 2.8 } \\
\text { (in.-kips) }\end{array}\end{array}$ \\
\hline R1 & 1.541 & 0.144 & 13,900 & 9,452 & 14,796 & 13,106 & 13,473 \\
\hline PL1 & 1.714 & 0.160 & 18,913 & 13,362 & 19,489 & 17,565 & 18,120 \\
\hline PL2 & 2.357 & 0.220 & 20,910 & 16,398 & $21,446^{*}$ & 17,504 & 17,720 \\
\hline
\end{tabular}

*Specimen PL2 did not reach ultimate load, load reported is the maximum load before the test was prematurely ended. 


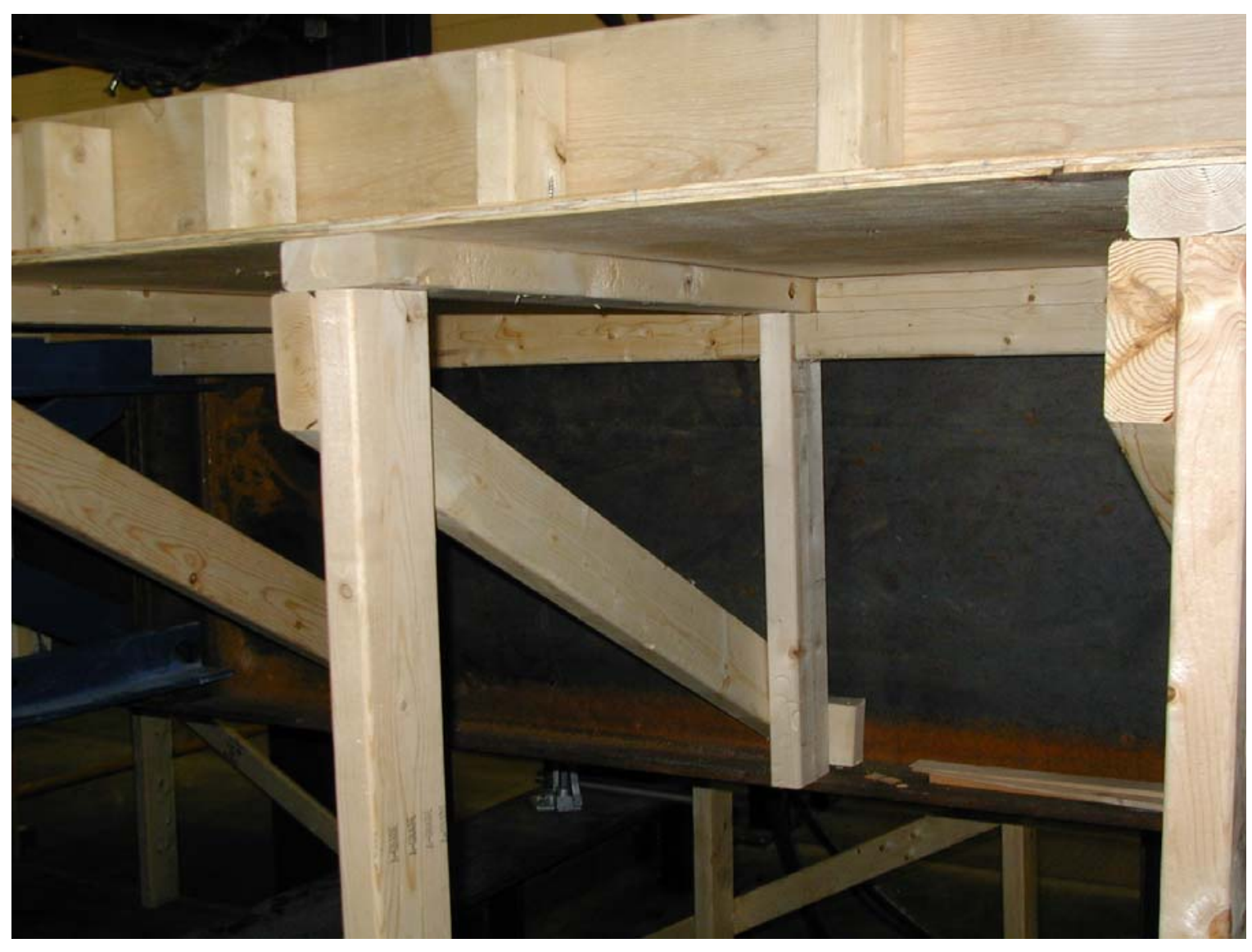

Figure 3.1 Typical overhang brace 


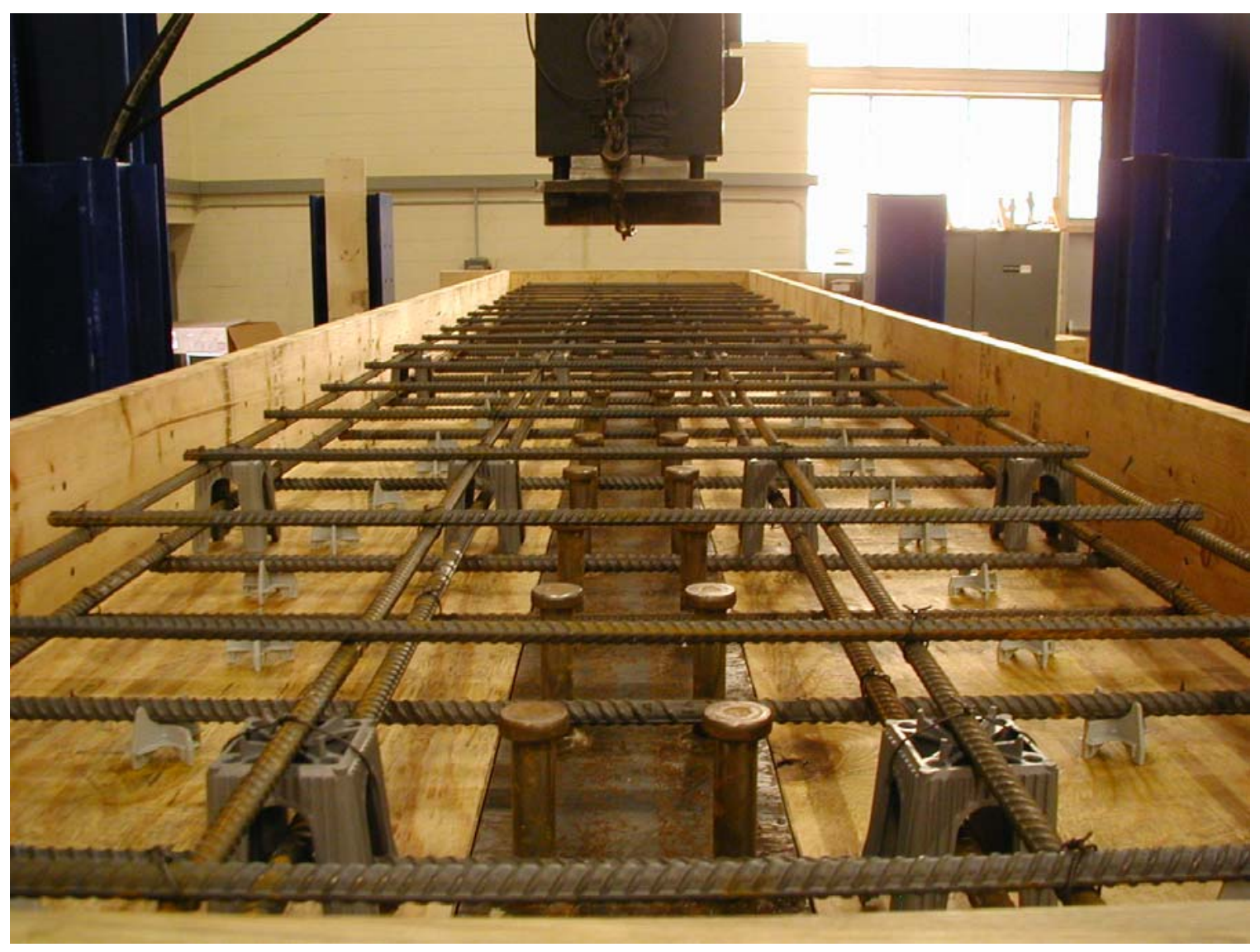

Figure 3.2 Typical view of finished formwork with reinforcement in place 


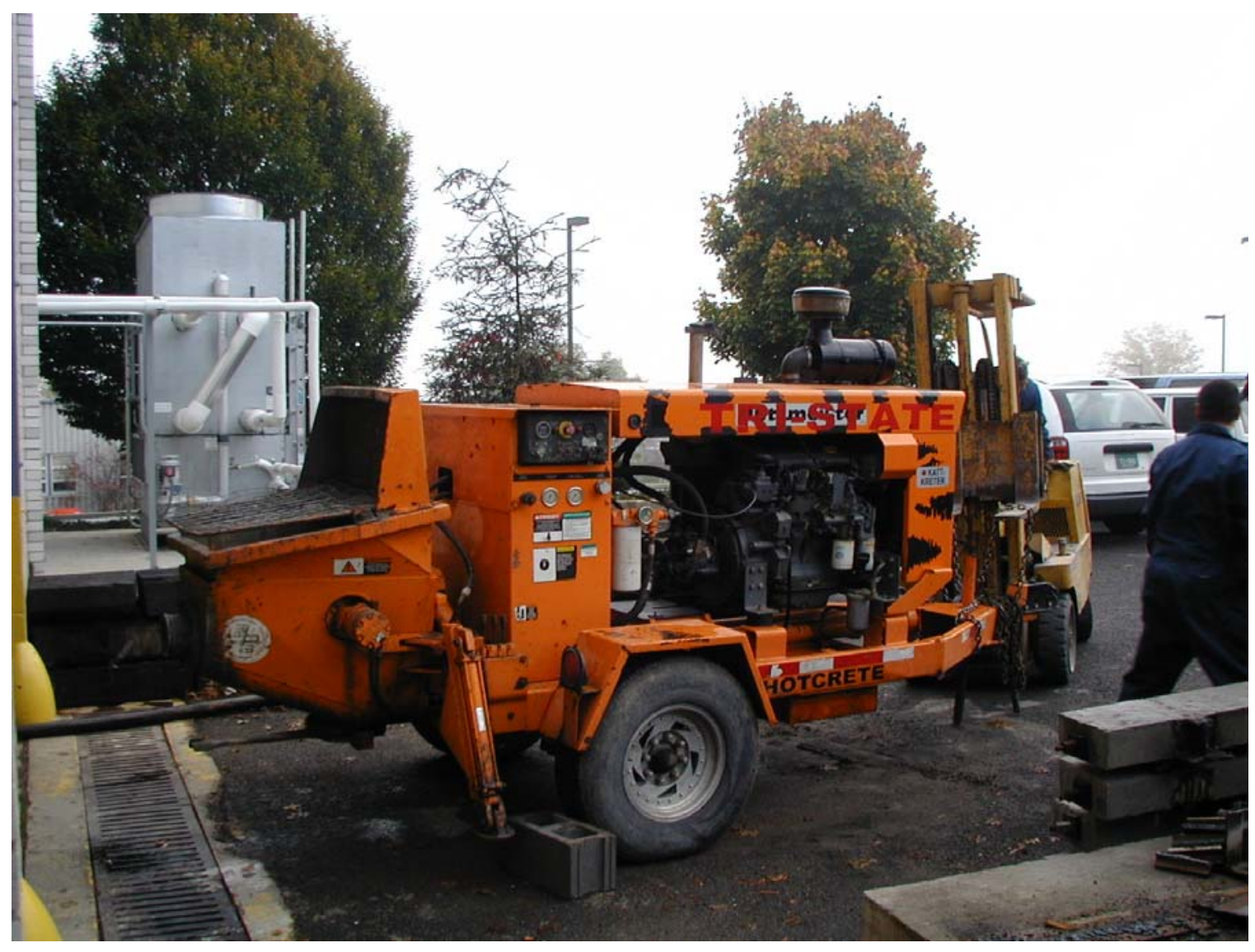

Figure 3.3 Typical tow-behind trailer pump used for concrete placement 


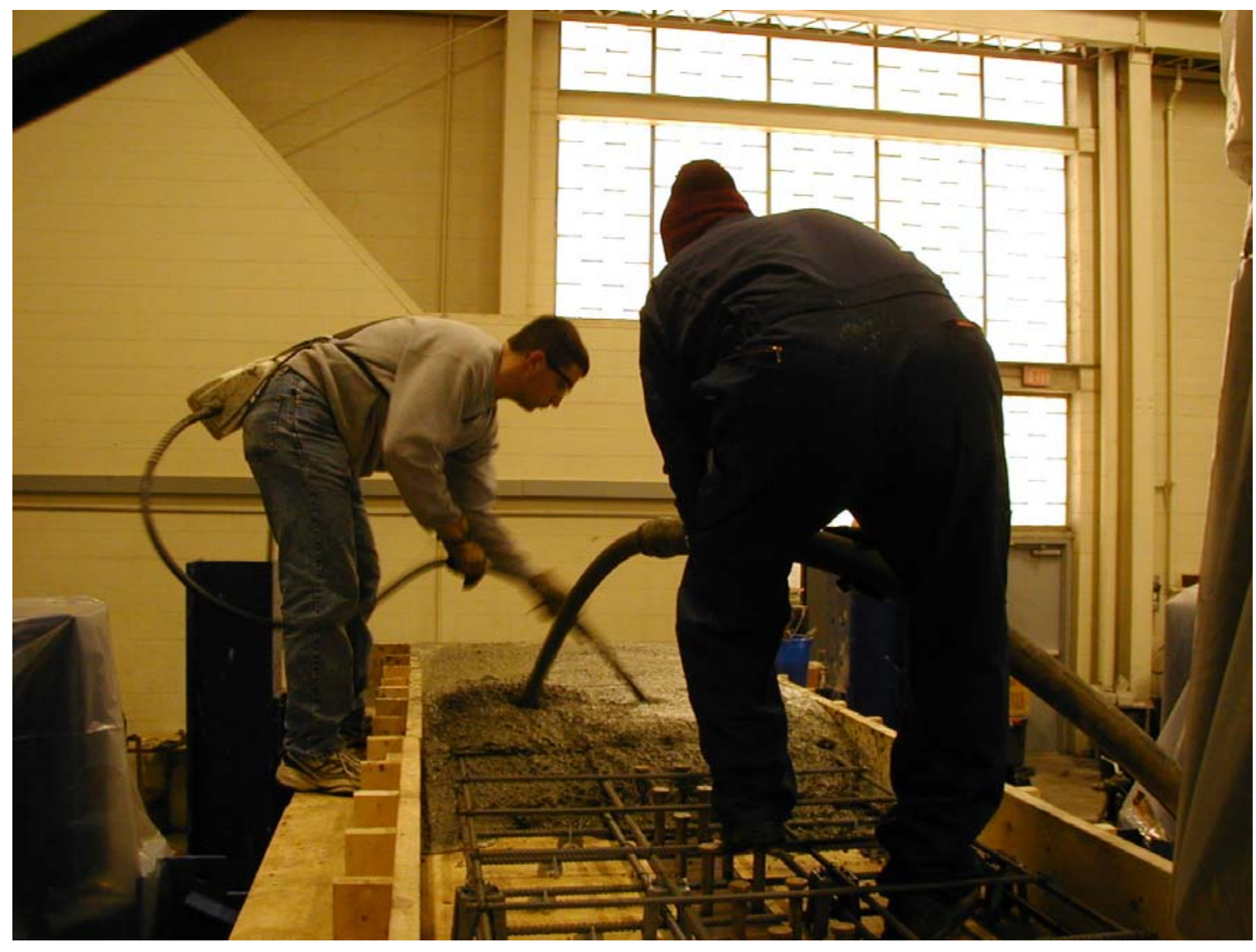

Figure 3.4 Placement of typical deck 


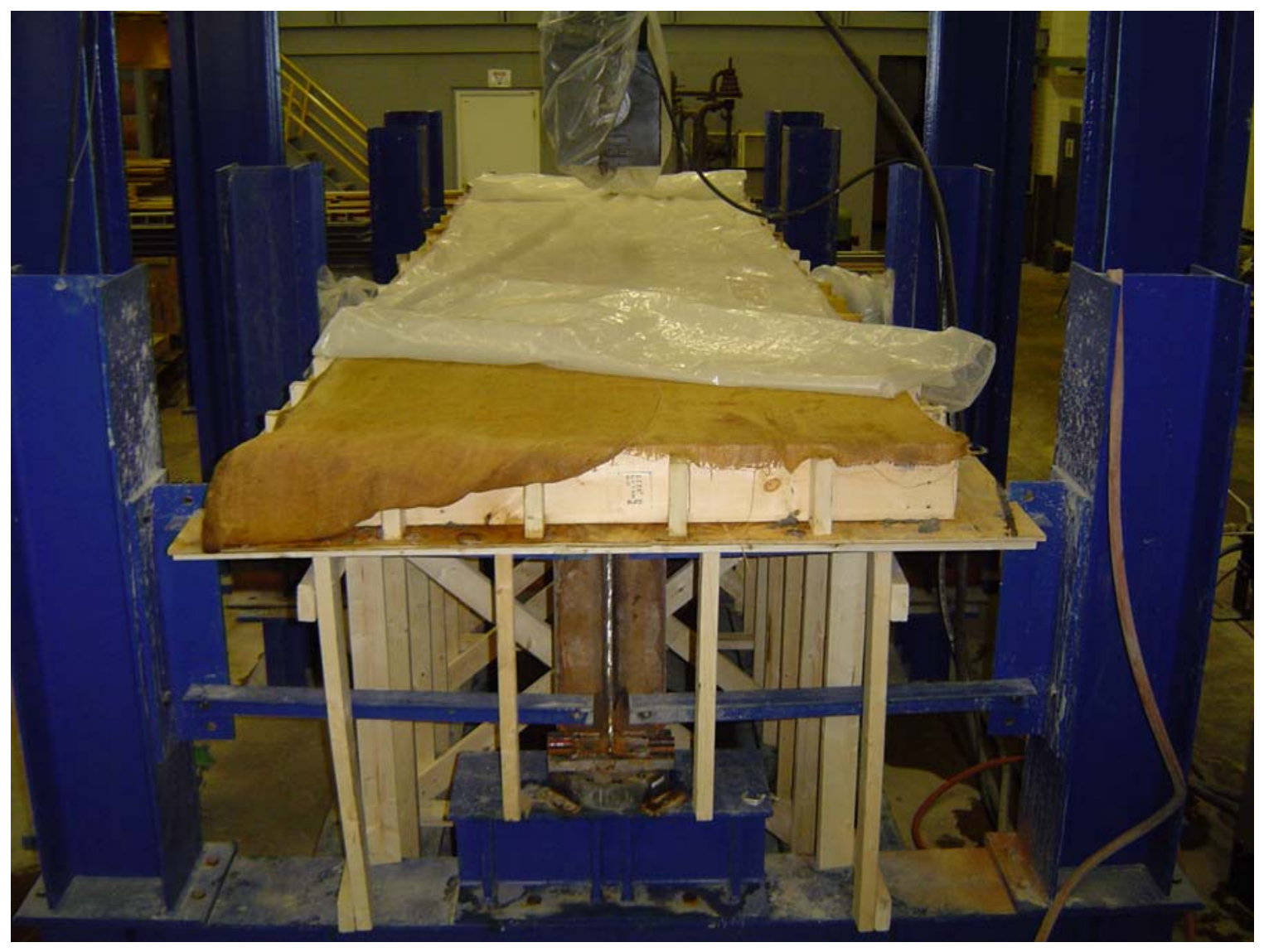

Figure 3.5 Girder covered with burlap and plastic 


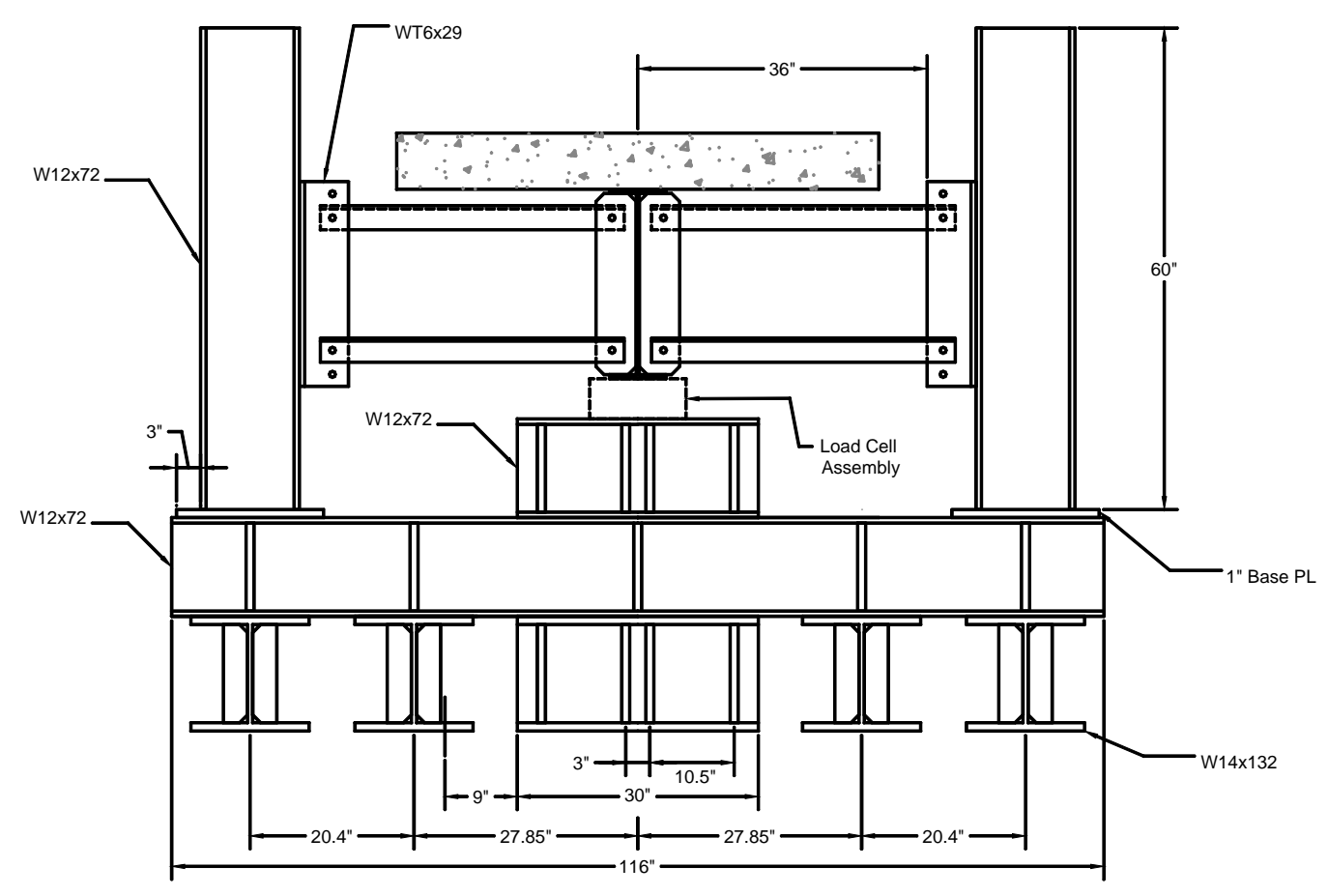

(a) Lateral bracing at ends

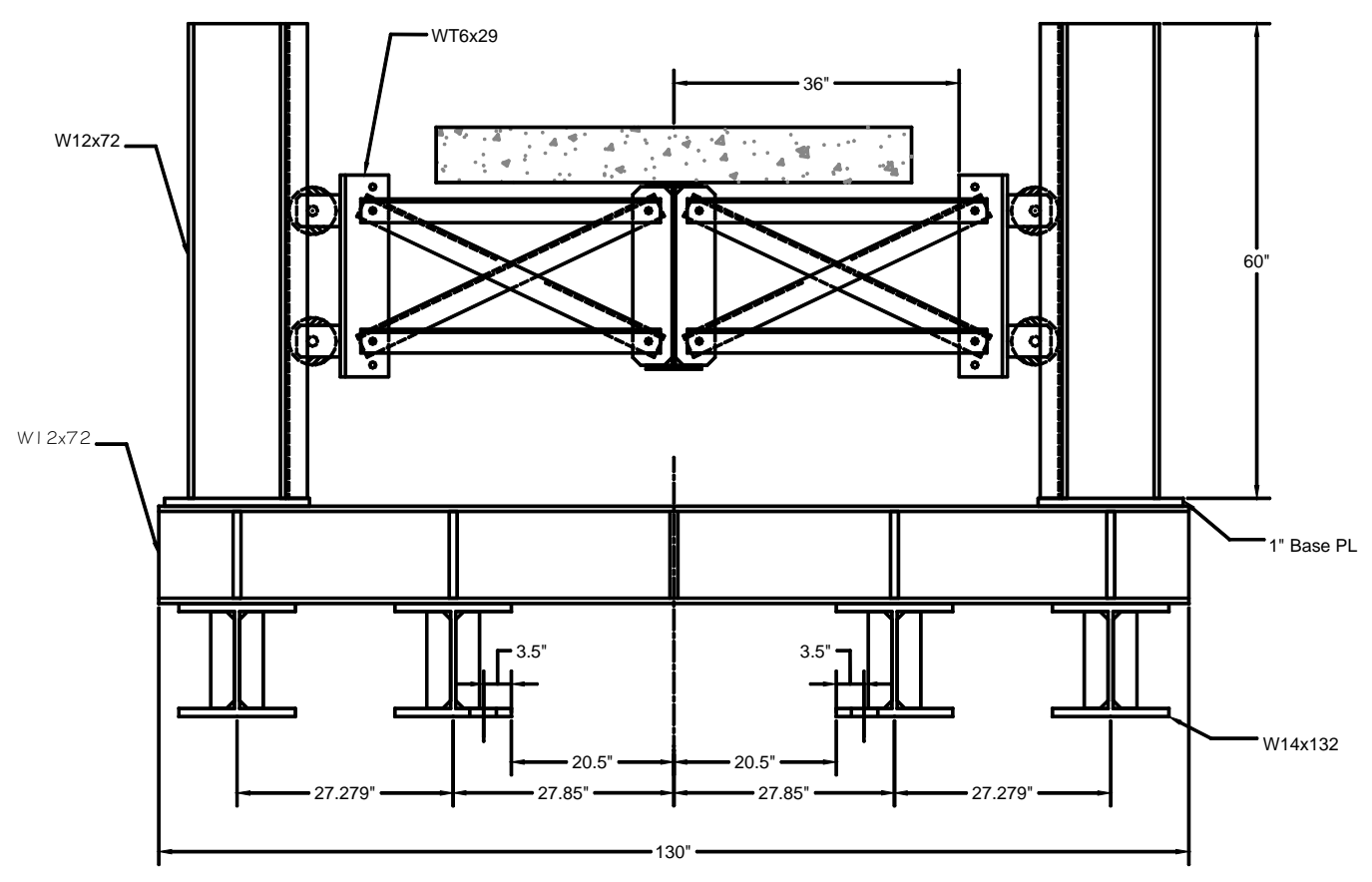

(b) Lateral bracing at intermediate locations

Figure 3.6 Typical lateral bracing at (a) ends and (b) intermediate locations 


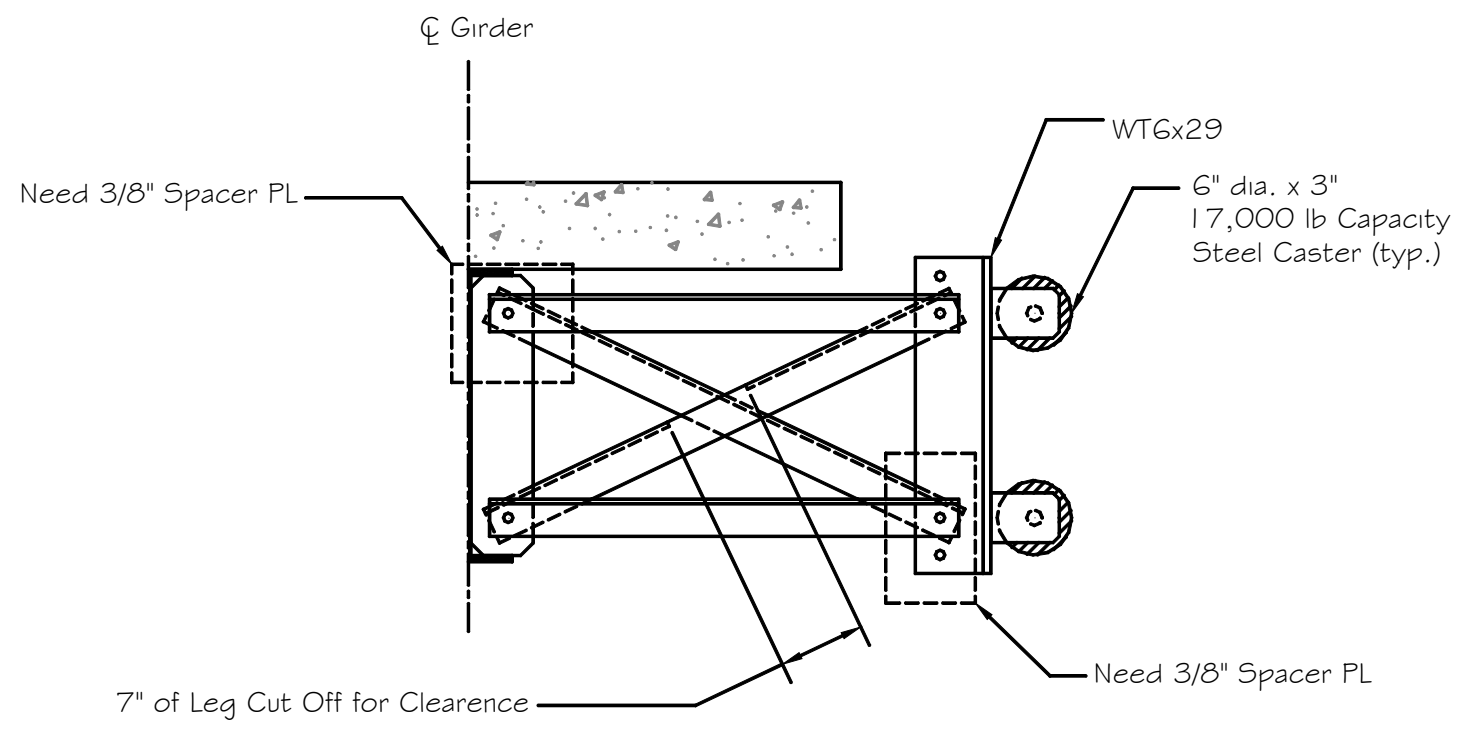

Figure 3.7 Typical roller assembly 


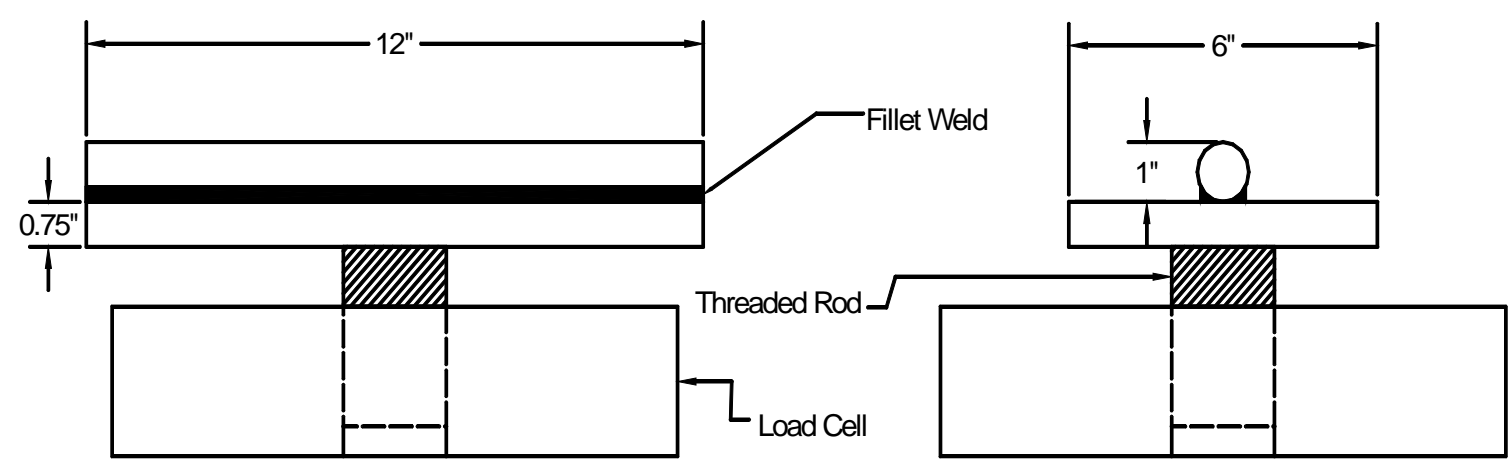

Front View

Side View

(a) pinned support

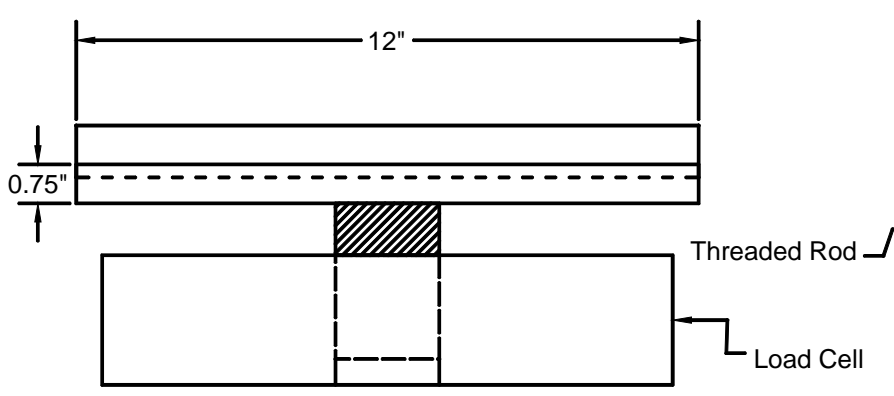

Front View

Side View

(b) roller support

Figure 3.8 Typical details for (a) pinned supports and (b) roller-type supports 


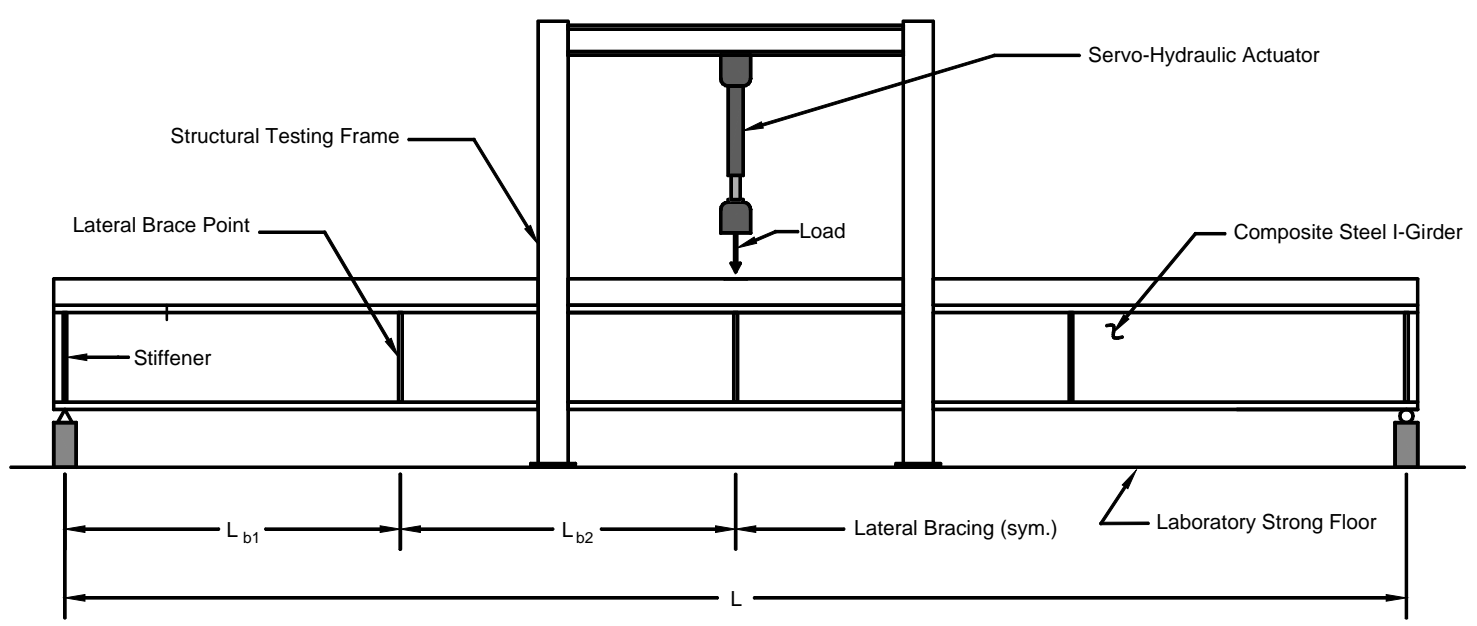

Figure 3.9 Experimental test set-up (lateral bracing system not shown)

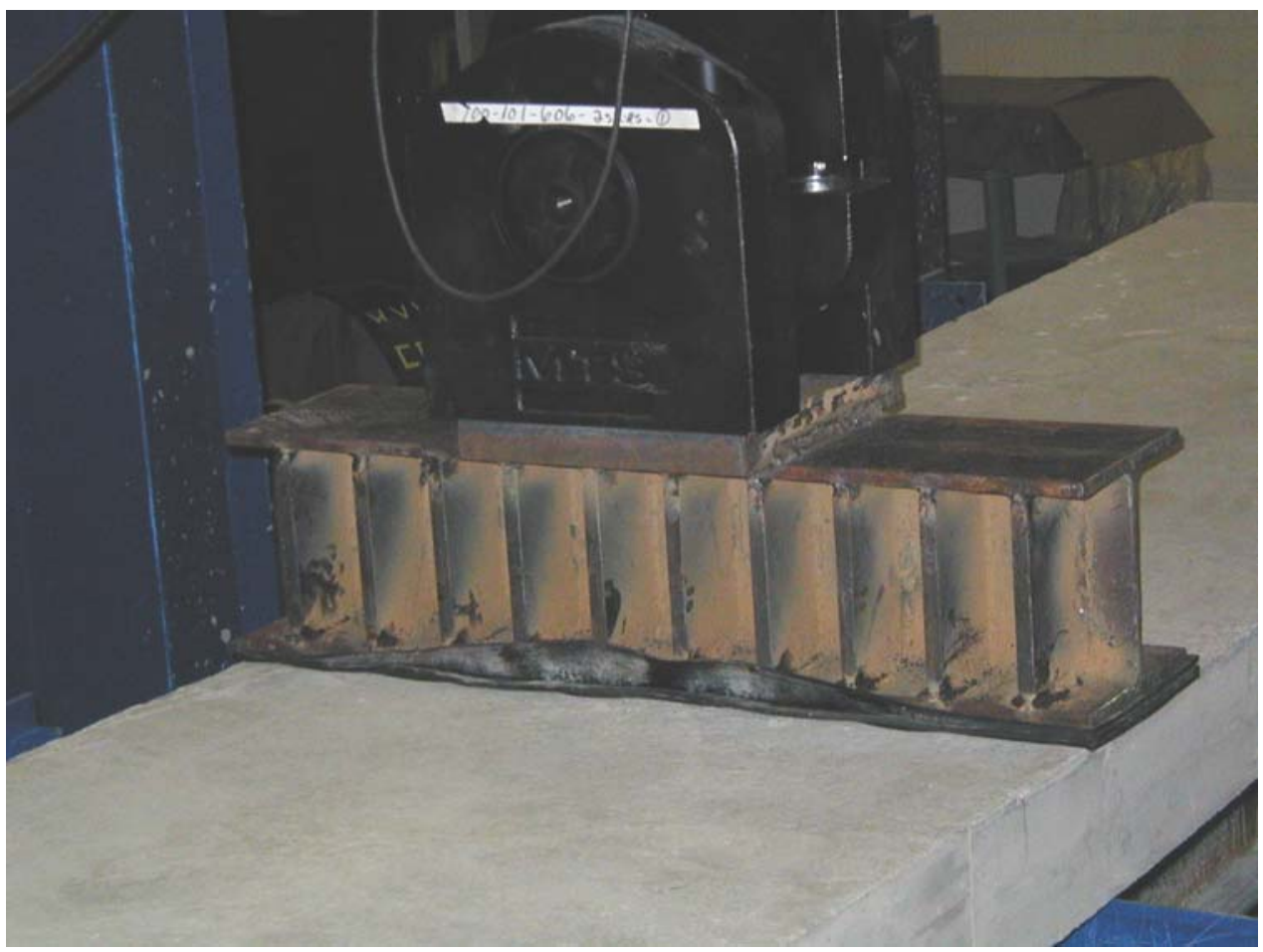

Figure 3.10 Typical spreader beam with elastomeric pads 


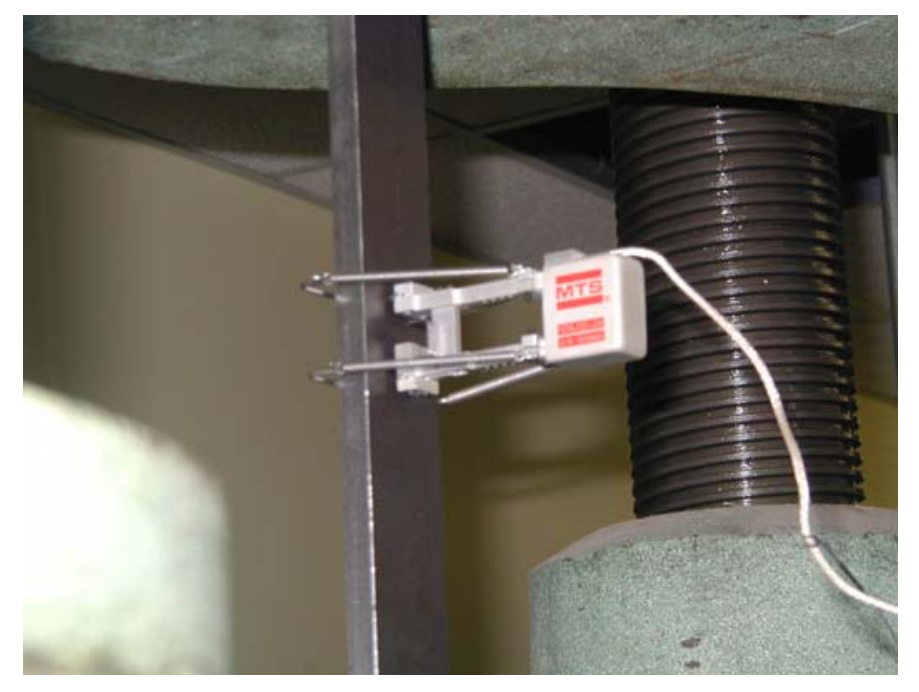

Figure 3.11 MTS (Model 634.12E-24) extensometer used for material testing 


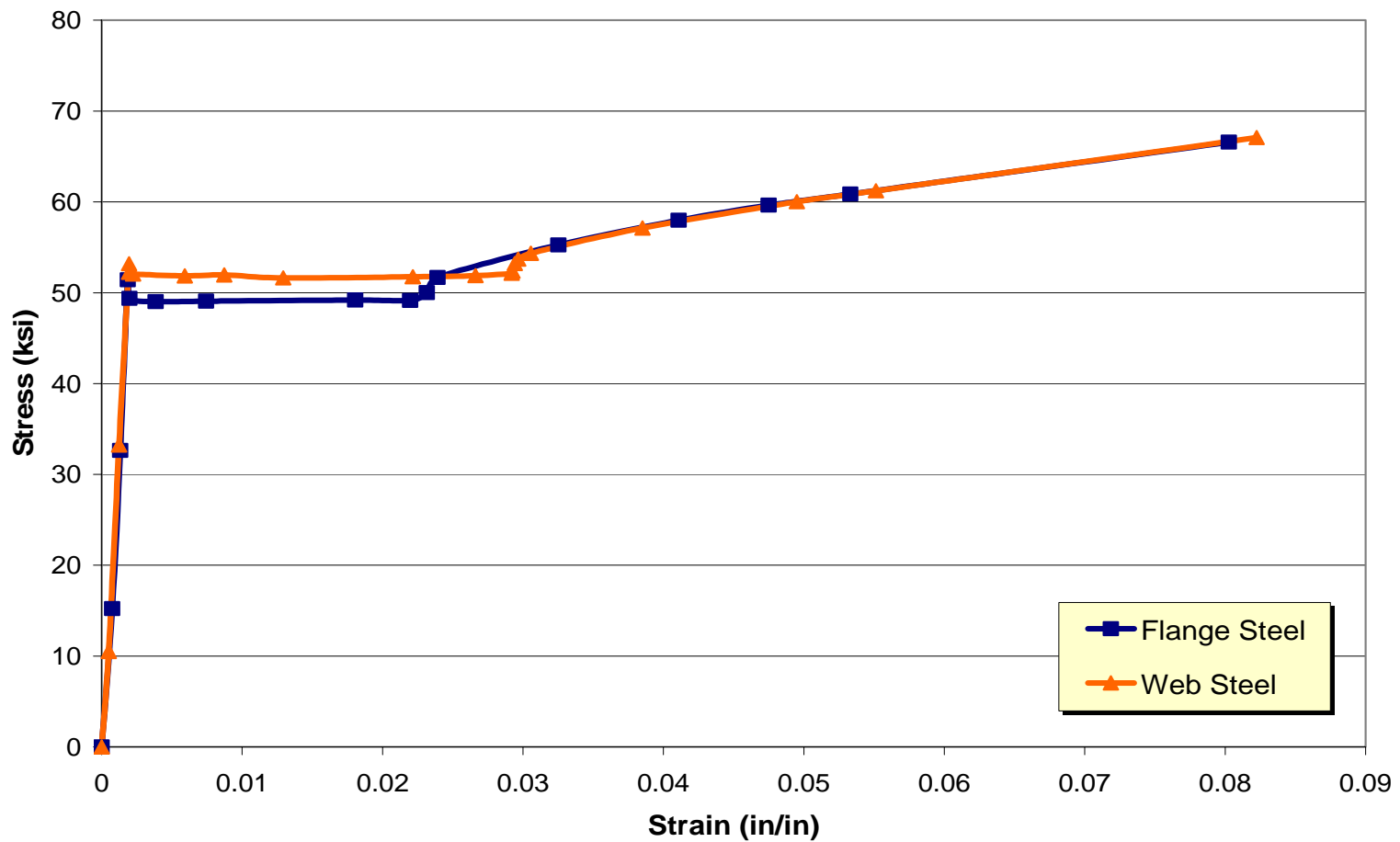

Figure 3.12 Average stress-strain curves for specimen R1 


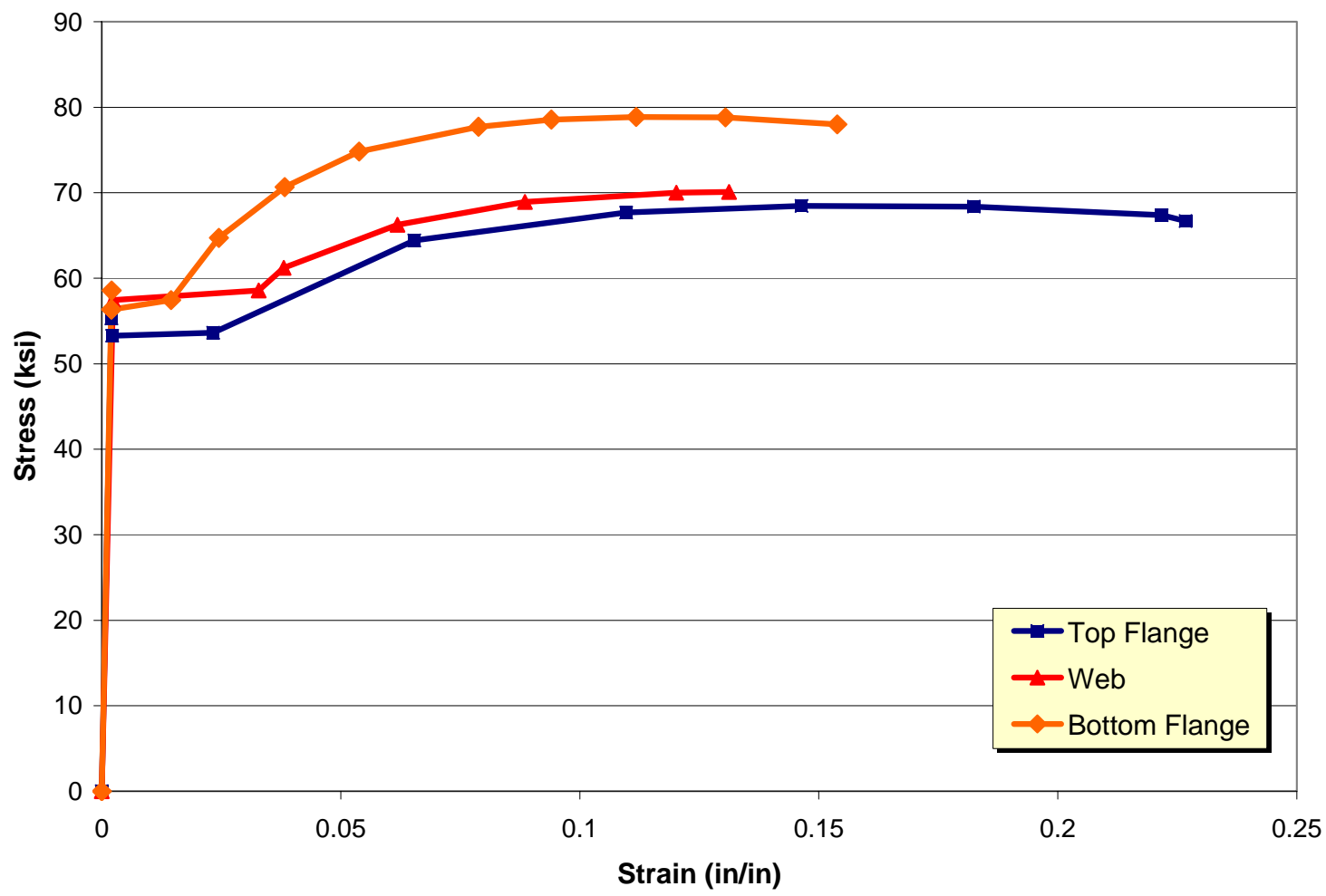

Figure 3.13 Averages stress-strain curves for specimen PL1 


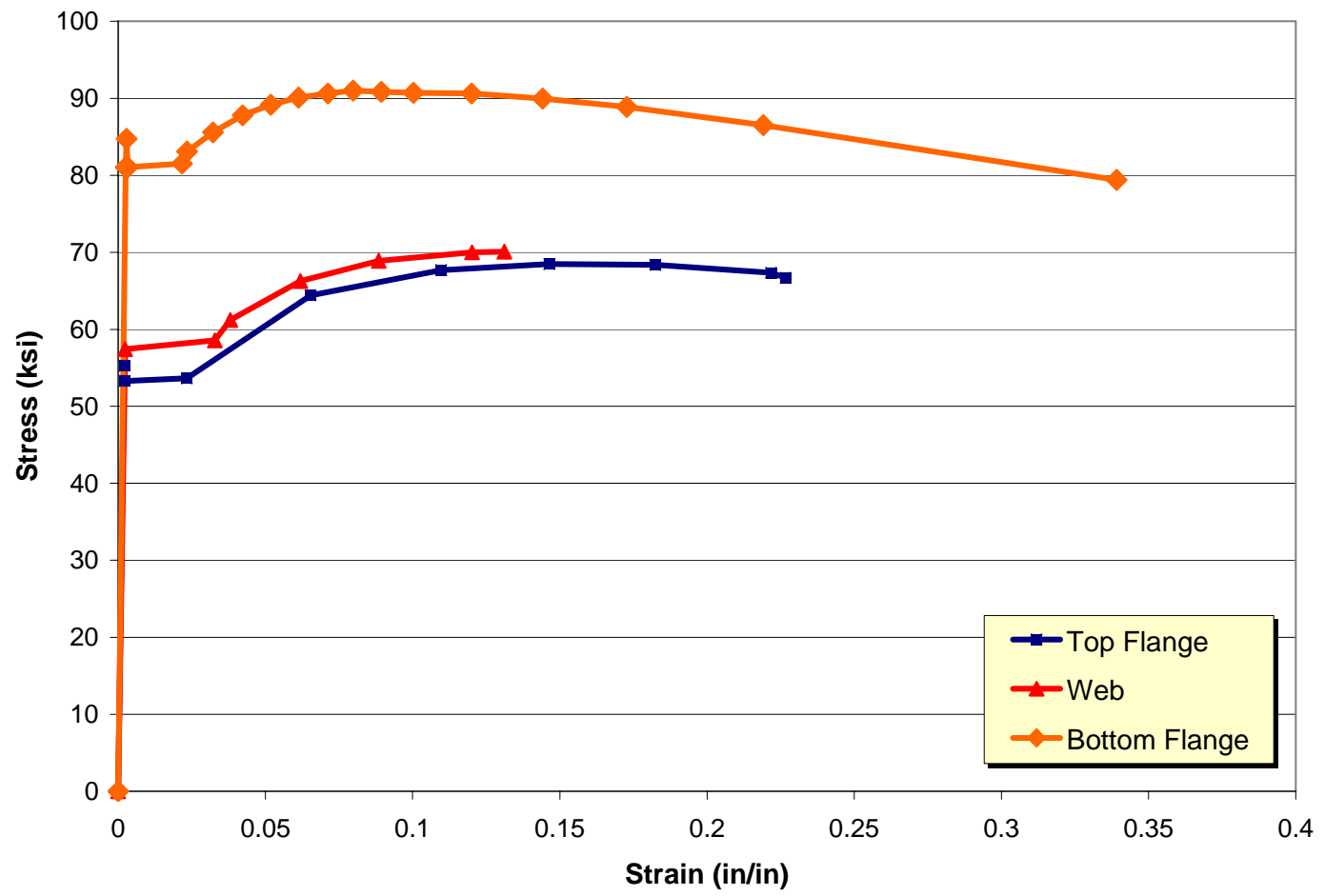

Figure 3.14 Average stress-strain curves for specimen PL2 


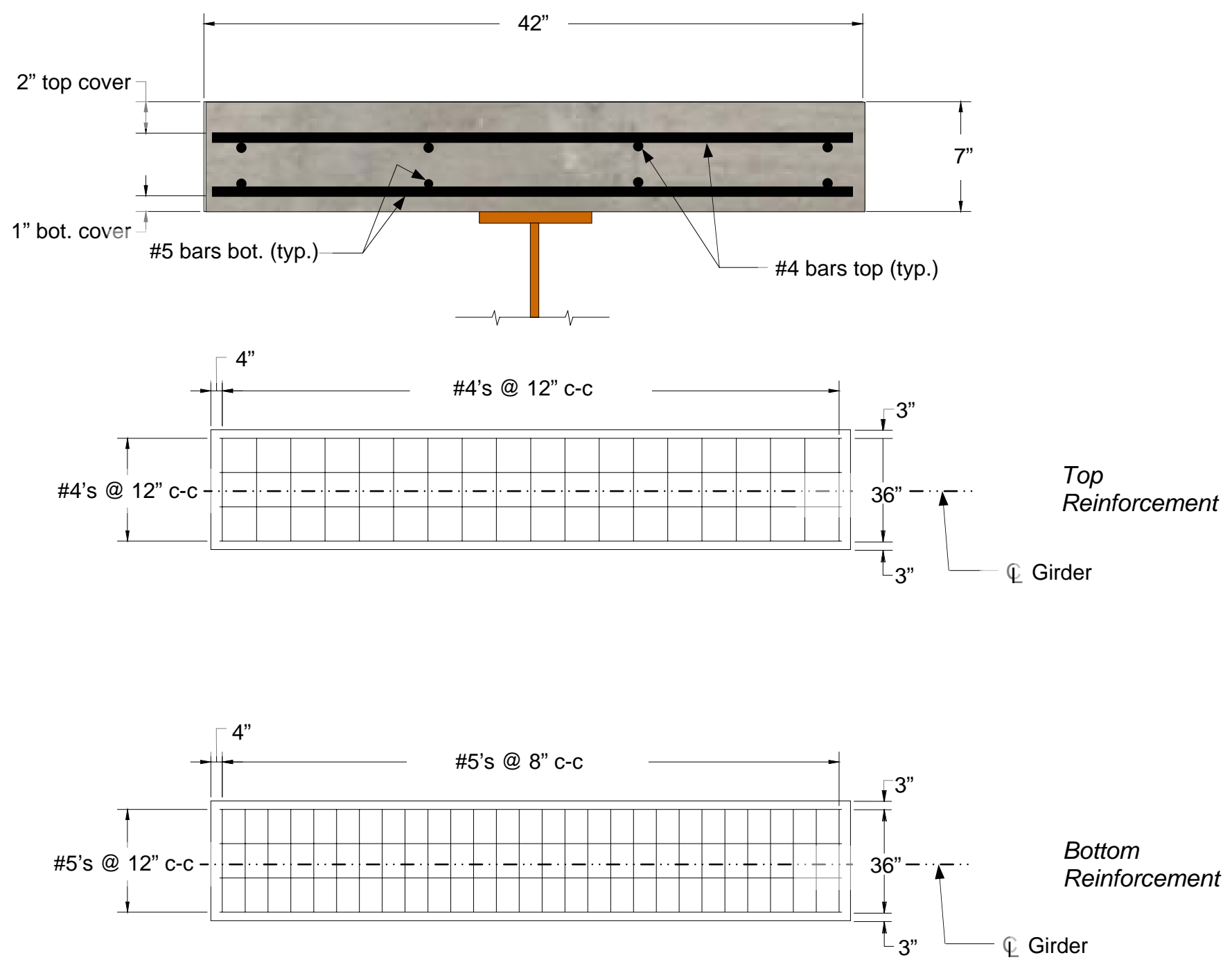

Figure 3.15(a) Reinforced concrete deck details for specimen R1 


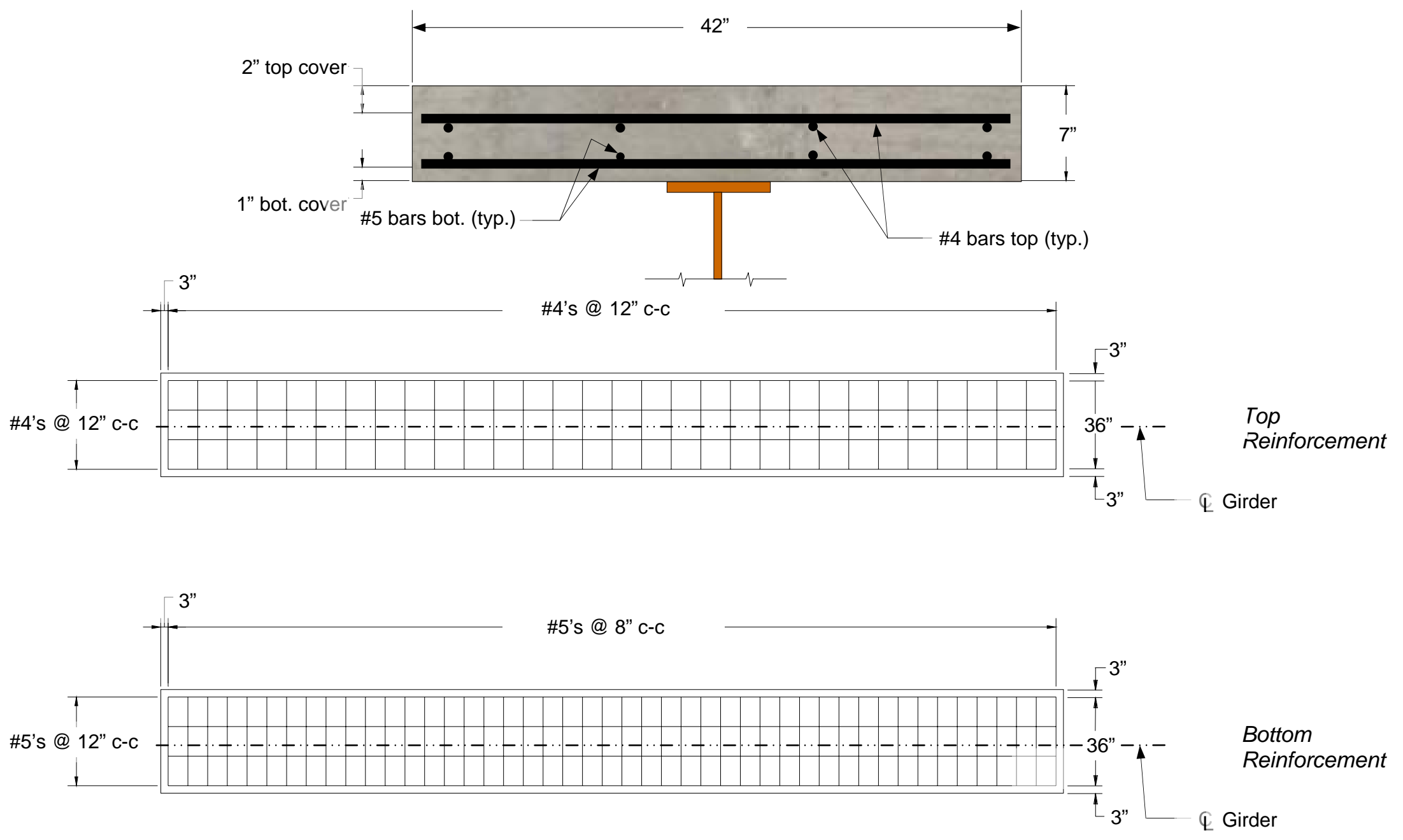

Figure 3.15(b) Reinforced concrete deck details for specimens PL1 and PL2 

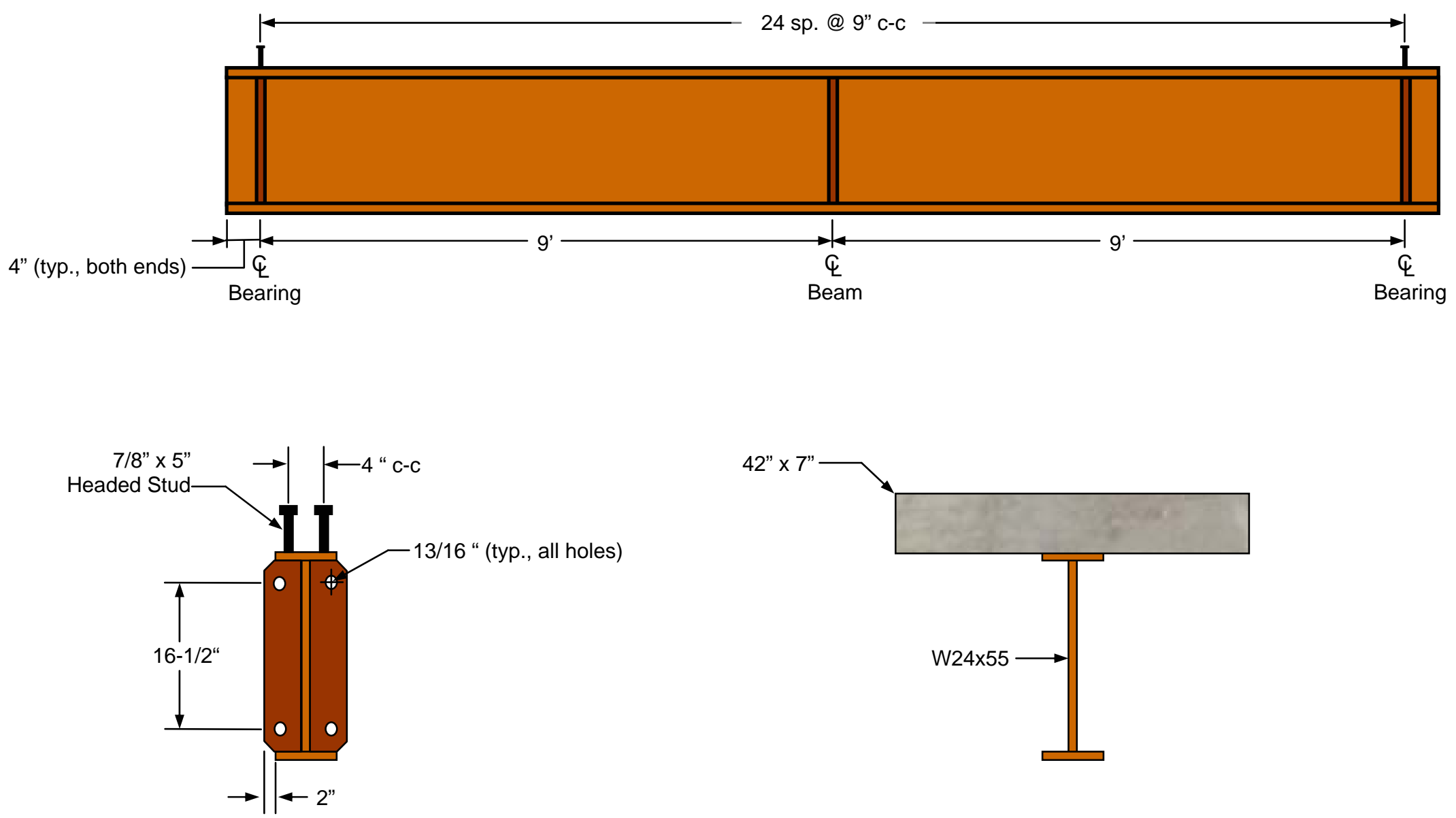

Figure 3.16 Geometry of specimen R1 

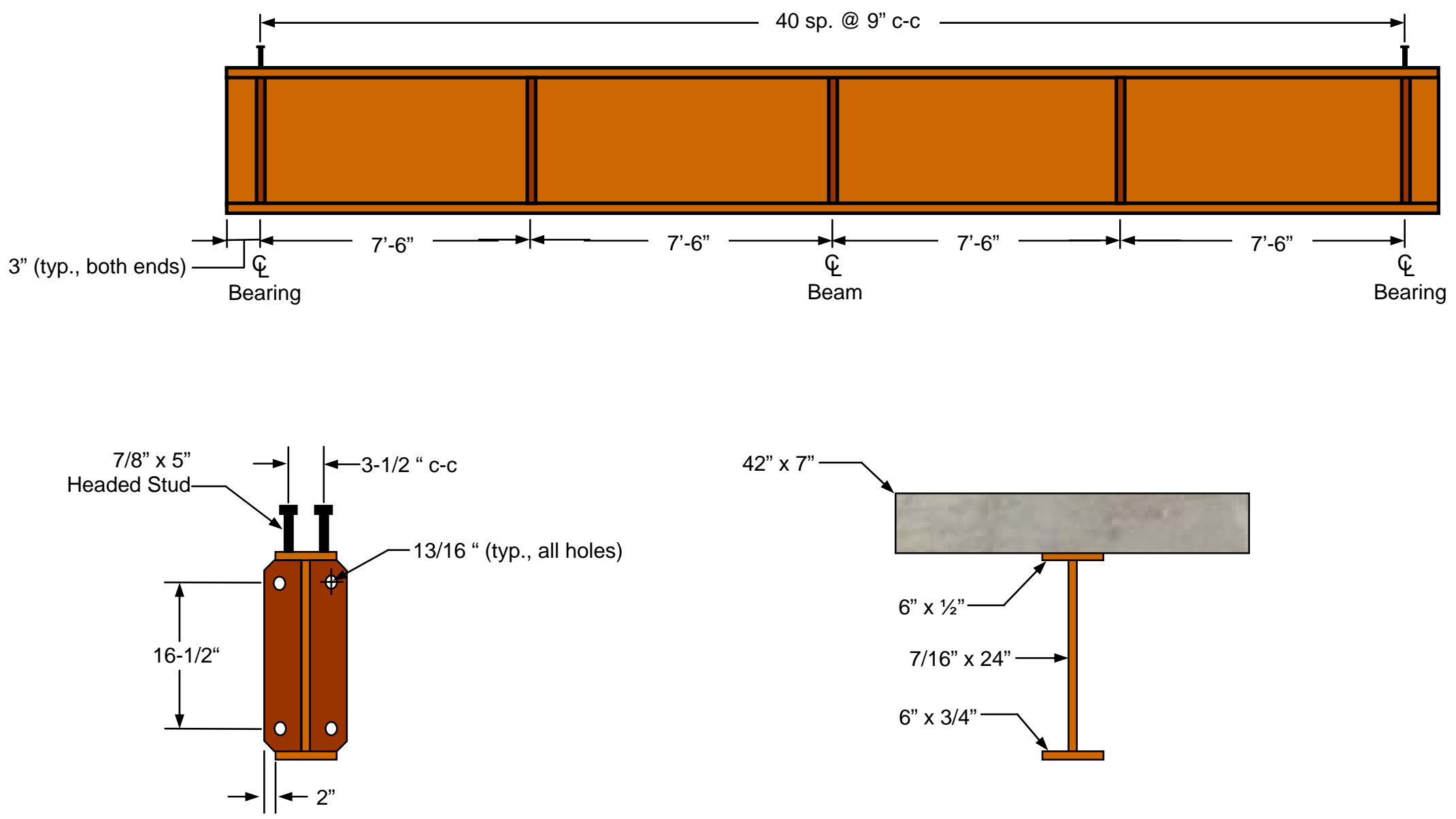

Figure 3.17 Geometry of specimen PL1 

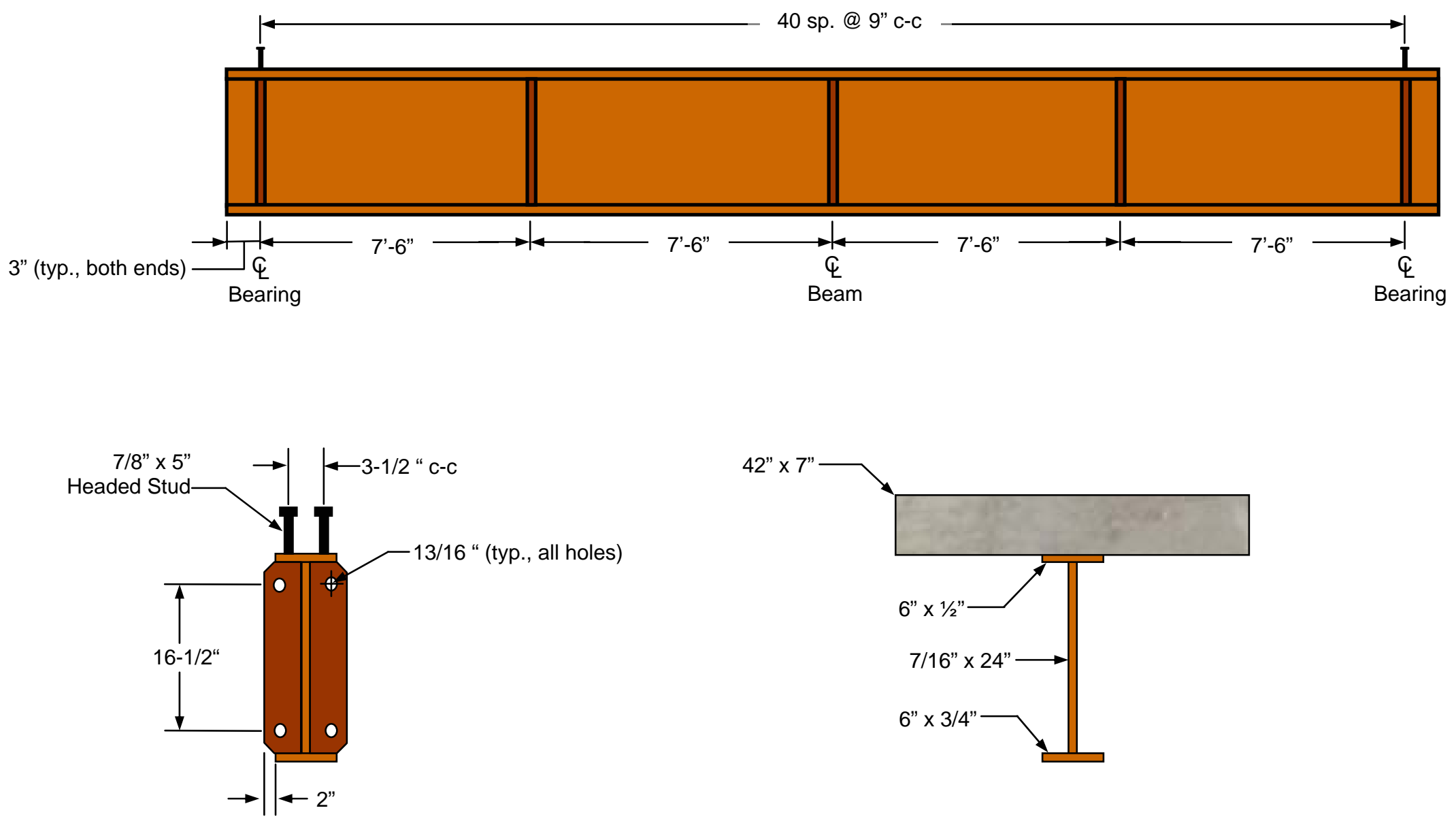

Figure 3.18 Geometry of specimen PL2 


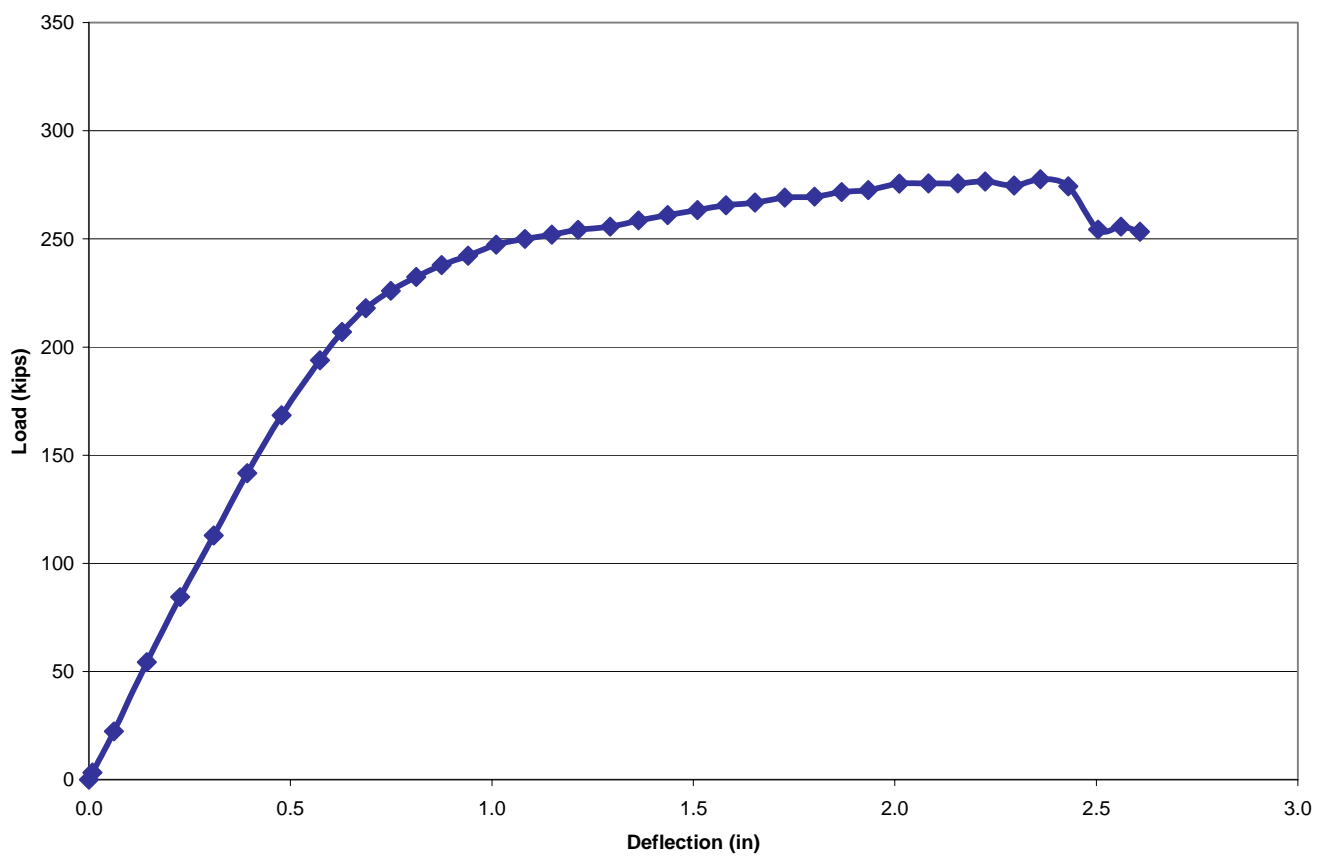

Figure 3.19 Midspan load-deflection plot for specimen R1

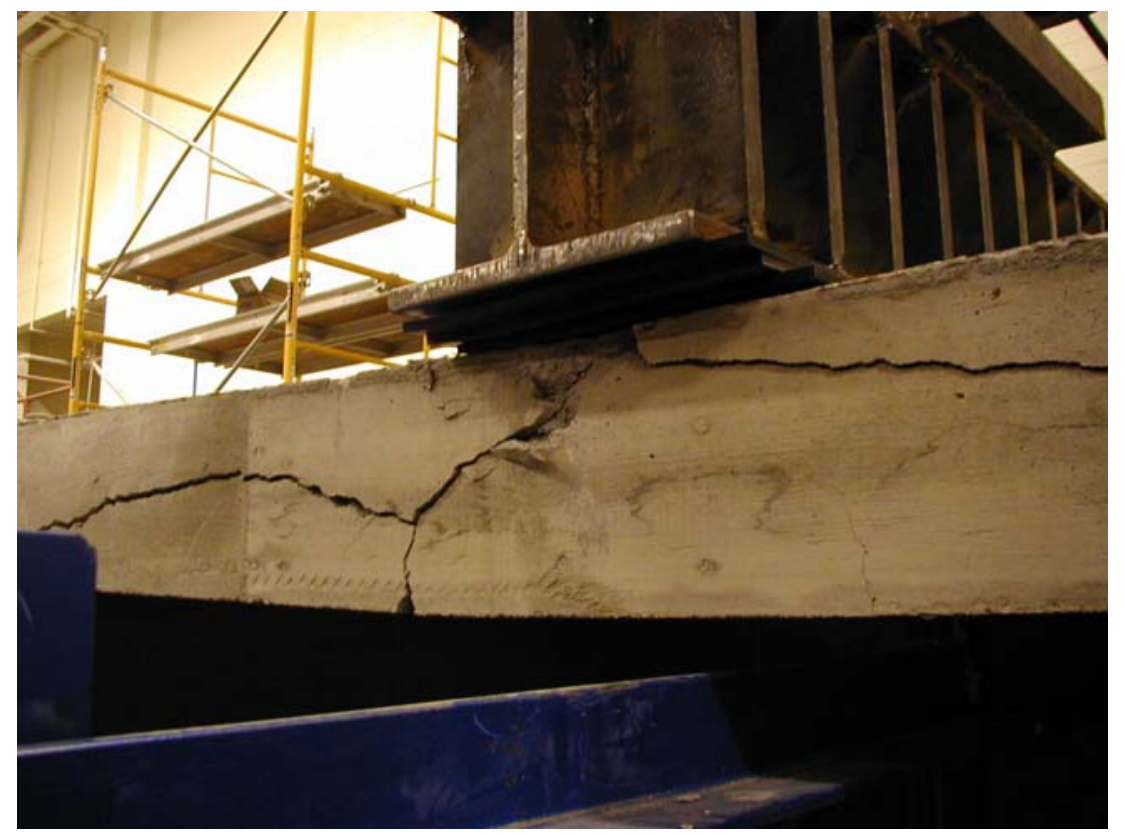

Figure 3.20 Failure of specimen R1 


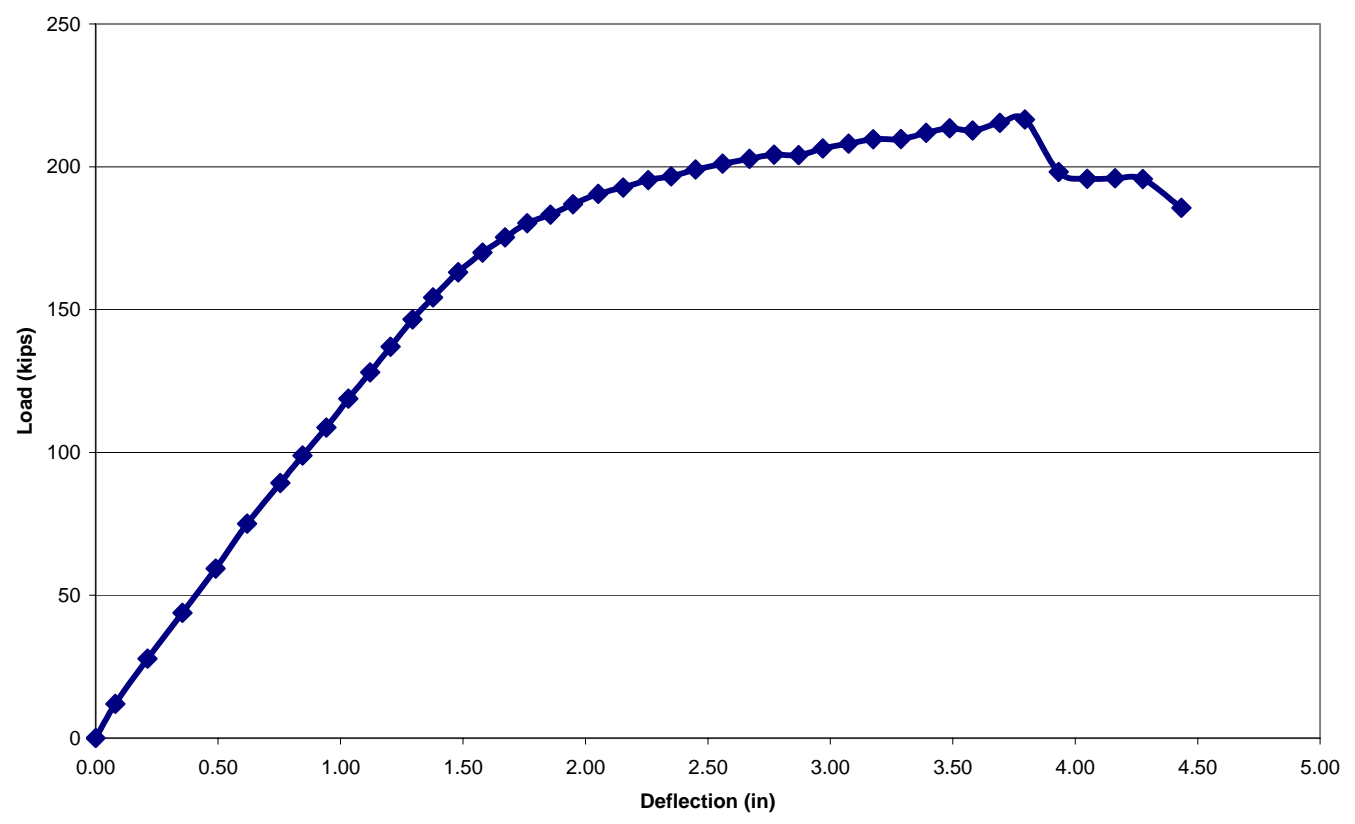

Figure 3.21 Midspan load-deflection plot for specimen PL1

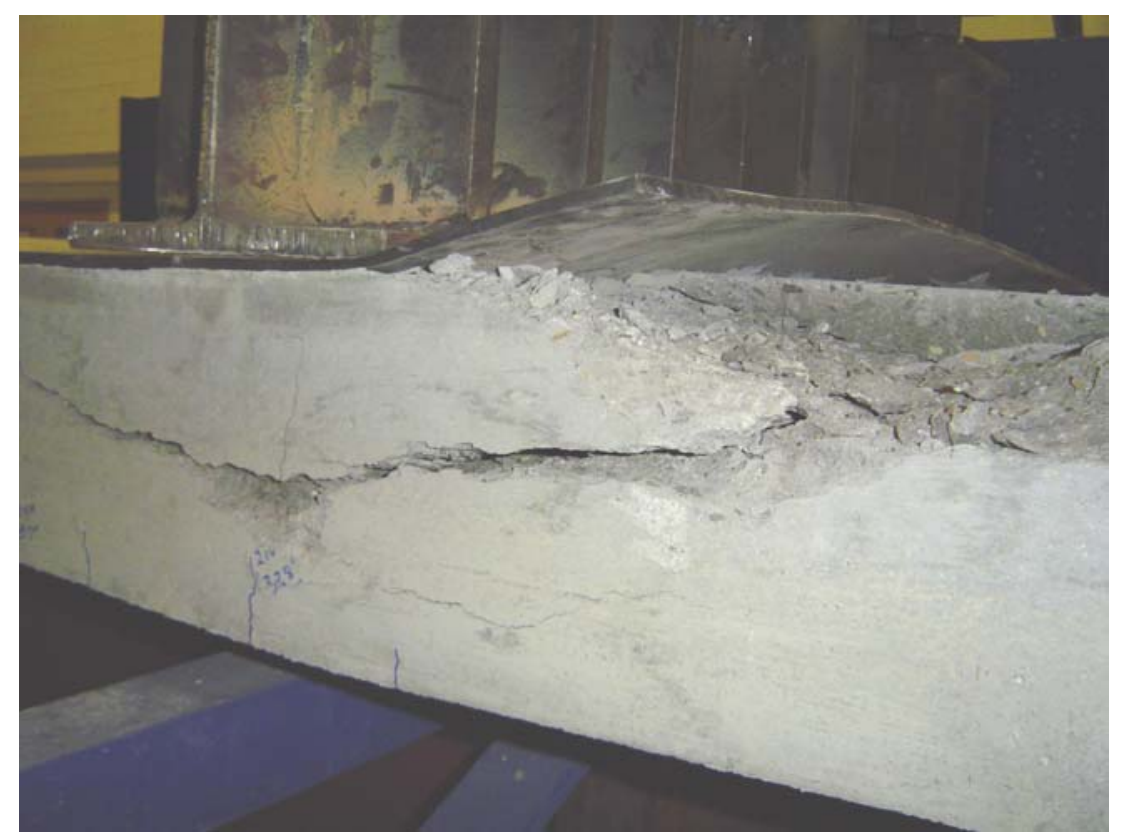

Figure 3.22 Failure of specimen PL1 


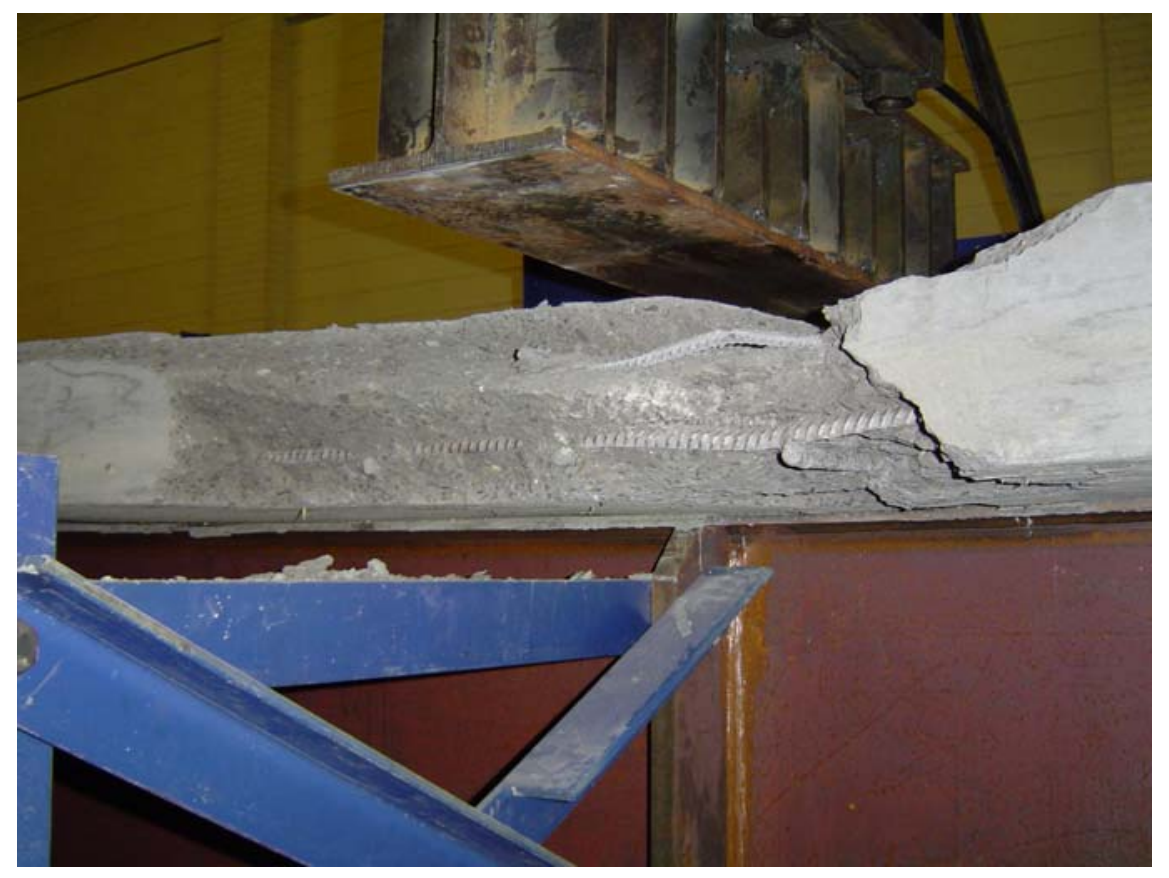

Figure 3.23 Exposed reinforcement of specimen PL1 


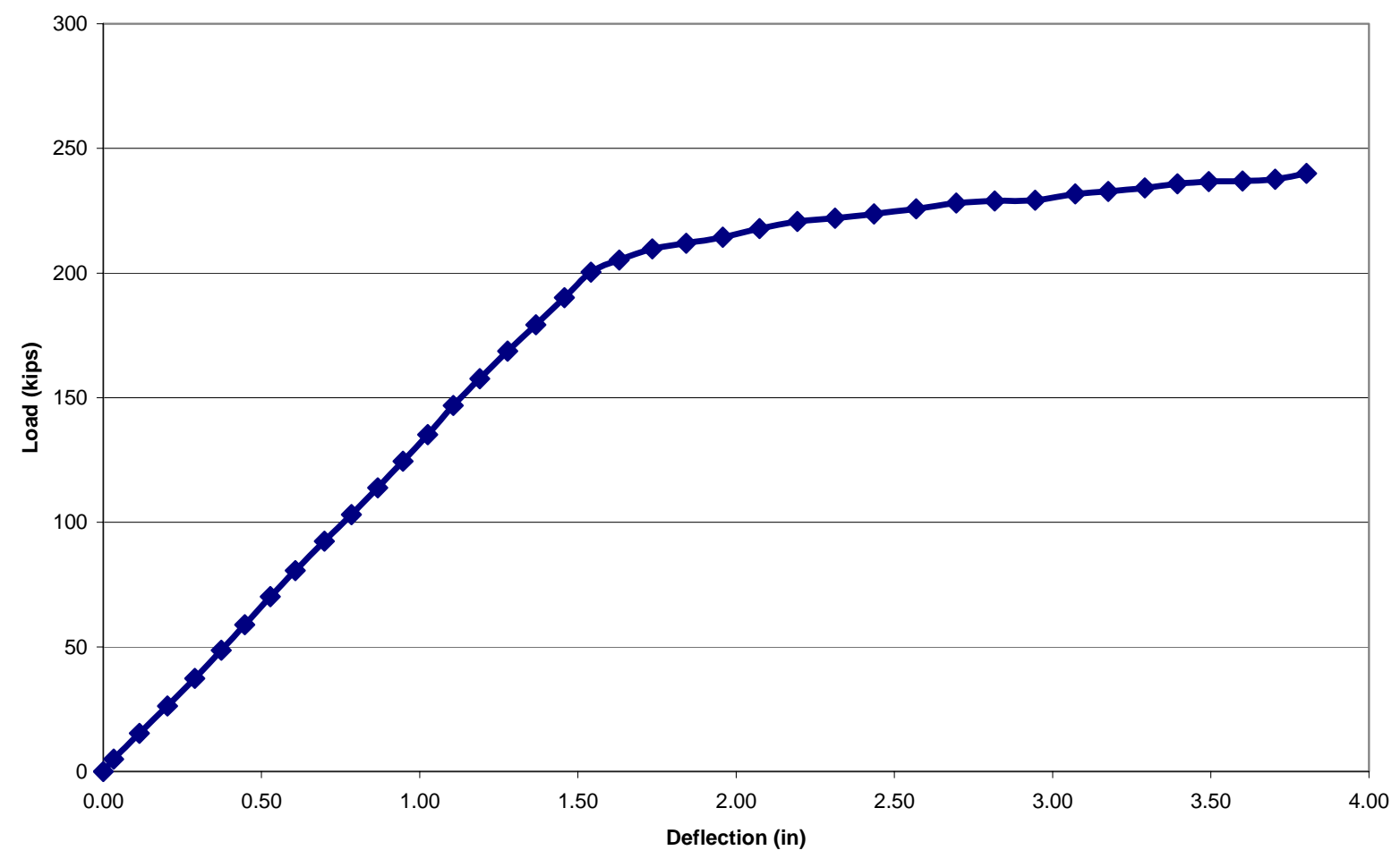

Figure 3.24 Midspan load-deflection plot for specimen PL2 


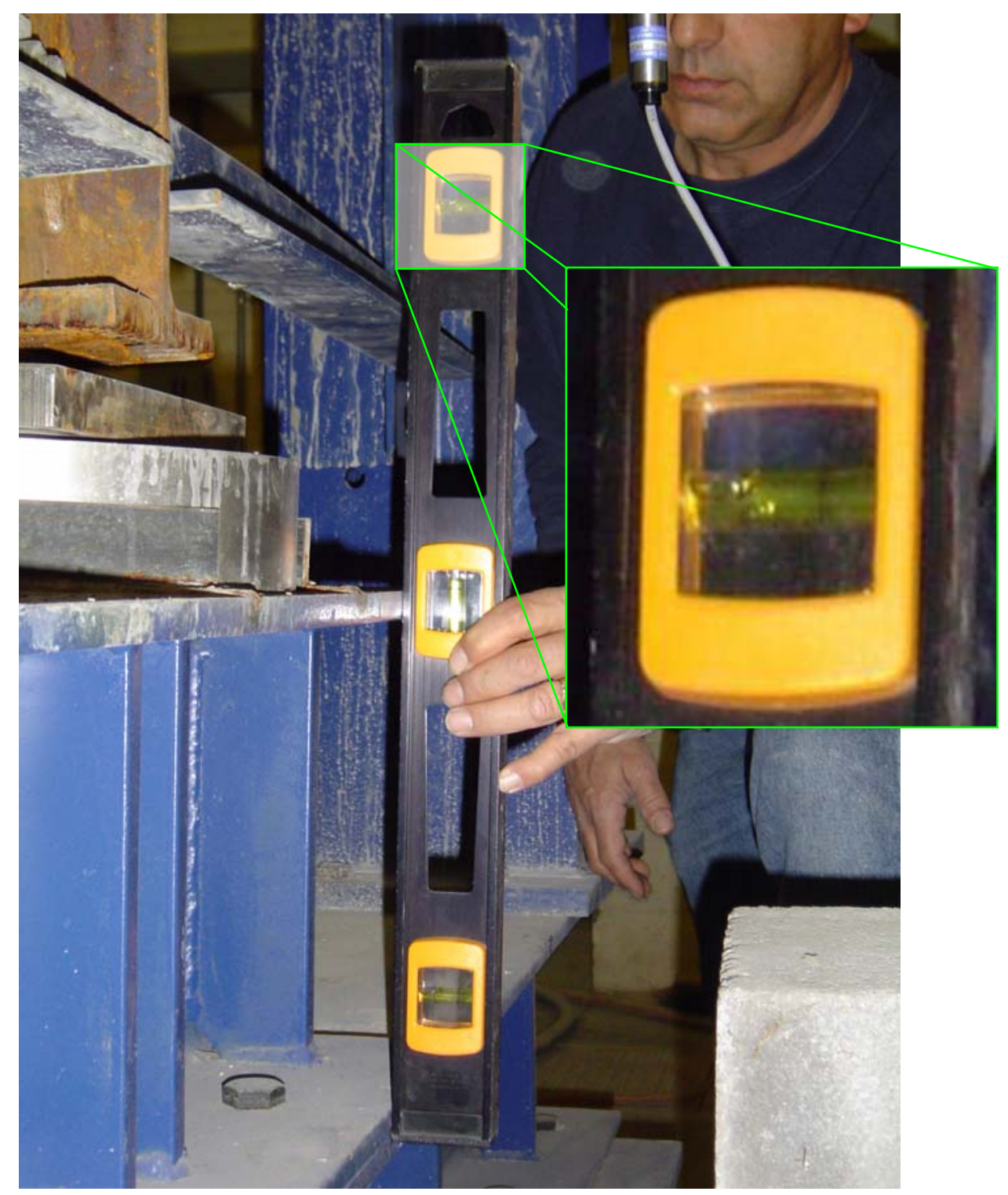

Figure 3.25 Unexpected bearing rotation of specimen PL2 


\section{Chapter 4}

\section{COMPATIBILITY ANALYSES}

\subsection{Overview}

To assess the ultimate flexural capacity of composite steel girders, a parametric study was performed using a strain compatibility based analysis procedure. The results of this parametric study are used to determine the parameters that most influence the behavior of composite steel girders in positive bending with respect to ultimate flexural capacity. Subsequent verification of this procedure through refined FEA modeling is discussed in Chapter 5.

\subsection{Methodology}

Using the mechanistic strain compatibility procedure, it was possible to determine the ultimate flexural capacity of a given cross-section defined by geometric and material properties. By assuming the ratio $M_{D L 1} / M_{y N C}=0.50$, the dead load moment acting on the non-composite steel girder could be determined as 50\% of the non-composite yield moment. Assuming this ratio allowed for the dead load effects to be accounted for in the compatibility analyses, an iterative procedure was developed to perform this analysis technique. 


\subsubsection{Iterative Procedure}

Assuming a concrete strain of 0.003 at crushing and a linear strain distribution, the ultimate capacity of a typical composite steel girder in positive flexure can be predicted using the following iterative procedure:

1.) Compute the yield moment of the non-composite steel section, $M_{y N C}$

2.) Use an assumed ratio of the non-composite dead load to the yield moment of the non-composite section, $M_{D L 1} / M_{y N C}$, to compute a dead load moment (note that all analyses in this effort assumed $M_{D L 1} / M_{y N C}=0.50$ )

3.) Assume a concrete crushing strain at the top of the deck, $\varepsilon_{c}$, equal to 0.003 and a subsequent linear strain distribution

4.) Choose an assumed value to the depth of the neutral axis, $c$, from the top of the deck

5.) Using the linear strain distribution and superimposing the strains induced by dead load effects on the non-composite steel girder, solve for the strains at the extreme top fibers of the steel, $\varepsilon_{f c}$; top of the web, $\varepsilon_{t w}$; bottom of the web, $\varepsilon_{b w}$; and extreme bottom fibers of the steel, $\varepsilon_{f t}$

6.) Determine which of the seven (7) girder yield configurations (see Appendix A) the calculated strains will produce in the web. The possible yield configurations used in this work are defined in Appendix A and illustrated in Figs. A.1-A.7

7.) For the yield configuration, integrate the stress profile to determine the component forces: $C_{s l a b}, F_{t f}, C_{1}, C_{2}, T_{1}, T_{2}, T_{3}, F_{b f}$ 
8.) Compute the force summation, $P=C_{\text {slab }}+F_{t f}+C_{1}+C_{2}+T_{1}+T_{2}+T_{3}+F_{b f}$. If the calculated value of $P$ is not equal to zero, adjust the value of $c$ and repeat steps 5-8 until $P=0$.

9.) Given the component forces, the ultimate moment, $M_{n s c}$, may be obtained by summing the moments produced by the respective forces about a suitable point. In this effort, moments were summed about the middle of the top flange. Summing the moments about this point eliminated the concern raised by the neutral axis occurring in the top flange.

Appendix B presents a detailed example of the use of this technique for a hypothetical girder.

A MICROSOFT EXCEL spreadsheet was employed to perform these iterative calculations. A macro was developed that used the Goal Seek function to solve for the depth of the neutral axis and perform the subsequent computations outlined above.

\section{$\underline{4.2 .2 ~ V e r i f i c a t i o n ~}$}

This technique has been relatively successful in identifying peak loads for the experiments conducted by Mans (2001) at the University of Nebraska (see Section 2.1 for a description of the University of Nebraska testing). Table 4.1 shows a comparison of the experimental peak loads from the University of Nebraska testing and the peak loads predicted by the strain compatibility analysis. 


\subsection{Parametric Study}

To evaluate the positive bending behavior of composite girders it is necessary to derive a set of parameters that cover a wide range of $D_{p} / D^{\prime}$ and $D_{p} / D_{t}$ values. The variables found in the left hand column of Table 4.2 adequately define a composite section and Table 4.2 lists the maximum and minimum value for each parameter along with the increment used for discretization and total number of increments used in the parametric study.

Combinations of key variables result in some impractical sections. The criteria used to discard the impractical sections are derived from the cross-section proportion limits provided by AASHTO (2003) LRFD Specifications. According to these specifications, Eqns. 4.1 through 4.5 must be satisfied:

$$
\begin{aligned}
& \frac{D}{t_{w}} \leq 150 \\
& \frac{b_{f}}{2 t_{f}} \leq 12.0 \\
& b_{f} \geq \frac{D}{6} \\
& t_{f} \geq 1.1 t_{w} \\
& 0.1 \leq \frac{I_{y c}}{I_{y t}} \leq 10
\end{aligned}
$$


In addition to these limitations, Eqn. 4.6, which is provided by AASHTO (2001), is also used to limit the width of the concrete slab.

$$
b_{e f f} \leq 12.0 t_{s}+\frac{b_{f c}}{2.0}
$$

Additionally, it is necessary to evaluate the effects different strength combinations have on the behavior of composite beams in positive bending. To accomplish this, four combinations of strength configurations are introduced into the parameters being analyzed. Keeping the concrete compressive strength constant at $4 \mathrm{ksi}$, the strength configurations studied in the research are as follows:

- Homogeneous - 50 ksi Steel

- Homogeneous - HPS 70W Steel

- Hybrid Configuration - 50 ksi top flange, 50 ksi web and HPS 70W bottom flange

- Hybrid Configuration - HPS 70W top flange, 50 ksi web and HPS 70W bottom flange

Limiting the parameters to the geometric proportion limits in Eqns. 4.1 through 4.6 and introducing the six strength configurations results in a set of 24,483 acceptable girders.

Further limiting the girders to $1.0<D_{p} / D^{\prime} \leq 5.0$, as recommended by AASHTO (2001), the acceptable set of girders is now at 21,712. Evaluation of the AASHTO (2003) Specifications requires that composite positive bending sections be limited to $0.1<D_{p} / D_{t} \leq 0.42$. Imposing this limitation provides a set of 20,066 girders applicable to the AASHTO (2003) Specifications. 


\subsection{Strain Compatibility Results}

The results of the moment capacity analysis using the strain compatibility method described previously are presented in Figs 4.1 and 4.2, which contain the data from the analysis of all strength configurations. The ultimate moment capacity based on the strain compatibility analysis, $M_{n s c}$, is non-dimensionalized by dividing it by the plastic moment, $M_{p}$, of the composite section. Figure 4.1 shows the results for the 21,712 sections that fall within the AAHSTO (2001) criterion summarized by Eqns. 4.1-4.6. Similarly, Fig. 4.2 illustrates the results of the 20,066 sections that fall within the AASHTO (2003) criterion. As can be seen from Figs. 4.1 and 4.2, as the sections become less ductile, the moment capacity slightly decreases with none of the sections falling below a $M_{n s c} / M_{p}$ value of 0.95 .

The ultimate moment capacities for each strength combination studied are presented in Figs. 4.3 through 4.6 with respect to $D_{p} / D^{\prime}$ and Figs. 4.7 through 4.10 with respect to $D_{p} / D_{t}$. Evaluation of these figures suggests that the different strength combinations do not a have a significant effect on the ultimate moment capacity. As a result, the data from the strain compatibility analyses used hereafter in this study will be studied as a whole, including all strength combinations. 
Table 4.1 Experimental peak loads and strain compatibility results for the University of Nebraska test girders

\begin{tabular}{|c|c|c|}
\hline Specimen & $\begin{array}{c}\text { Experiment } \\
\text { (kips) }\end{array}$ & $\begin{array}{c}\text { Strain Compatibility } \\
\text { (kips) }\end{array}$ \\
\hline POS1 & 391 & 386 \\
\hline POS2 & 322 & 316 \\
\hline
\end{tabular}

Table 4.2 Parameters used for strain compatibility evaluation

\begin{tabular}{|c|c|c|c|c|}
\hline Variable & Minimum & Maximum & Increment & Number of Points \\
\hline Slab Width, $\mathbf{b}_{\text {slab }}$ & 60 & 96 & 12 & 4 \\
\hline Slab Thickness, $\mathbf{t}_{\text {slab }}$ & 7 & 10 & 1 & 4 \\
\hline Top Flange Width, $\mathbf{b}_{\mathbf{f c}}$ & 12 & 30 & 6 & 4 \\
\hline Top Flange Thickness, $\mathbf{t}_{\mathbf{f c}}$ & 1.0 & 3.0 & 0.5 & 5 \\
\hline Web Depth, $\mathbf{D}_{\mathbf{w}}$ & 24 & 96 & 24 & 4 \\
\hline Web Thickness, $\mathbf{t}_{\mathbf{w}}$ & 0.50 & 1.00 & 0.25 & 3 \\
\hline Bottom Flange Width, $\mathbf{b}_{\mathbf{f t}}$ & 12 & 30 & 6 & 4 \\
\hline Bottom Flange Thickness, $\mathbf{t}_{\mathbf{f t}}$ & 1.0 & 3.0 & 0.5 & 5 \\
\hline
\end{tabular}

* Note: All dimensions are inches (in.) 


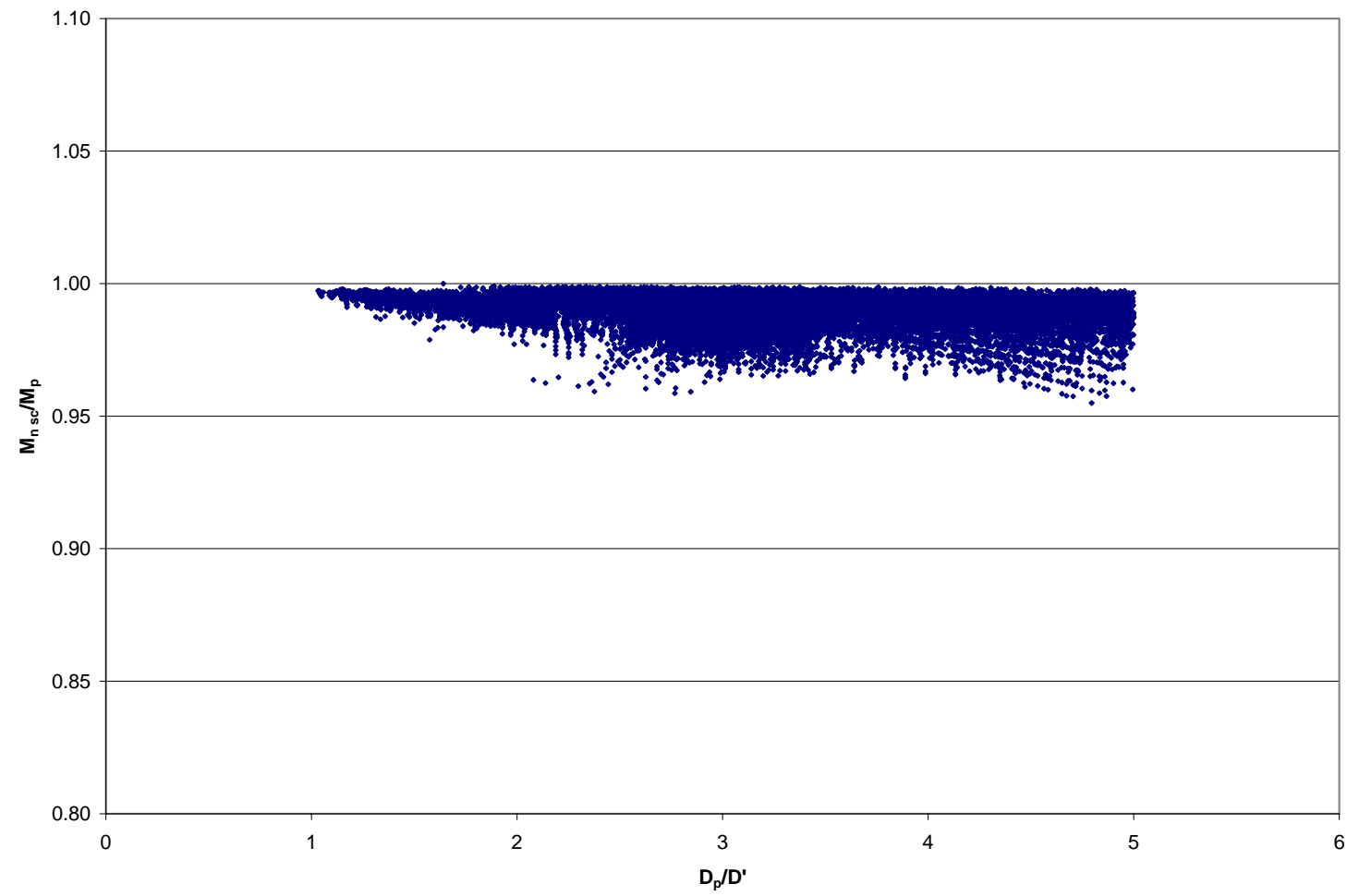

Figure 4.1 Effect of $D_{p} / D^{\prime}$ on moment capacity with respect to AASHTO (2001) 


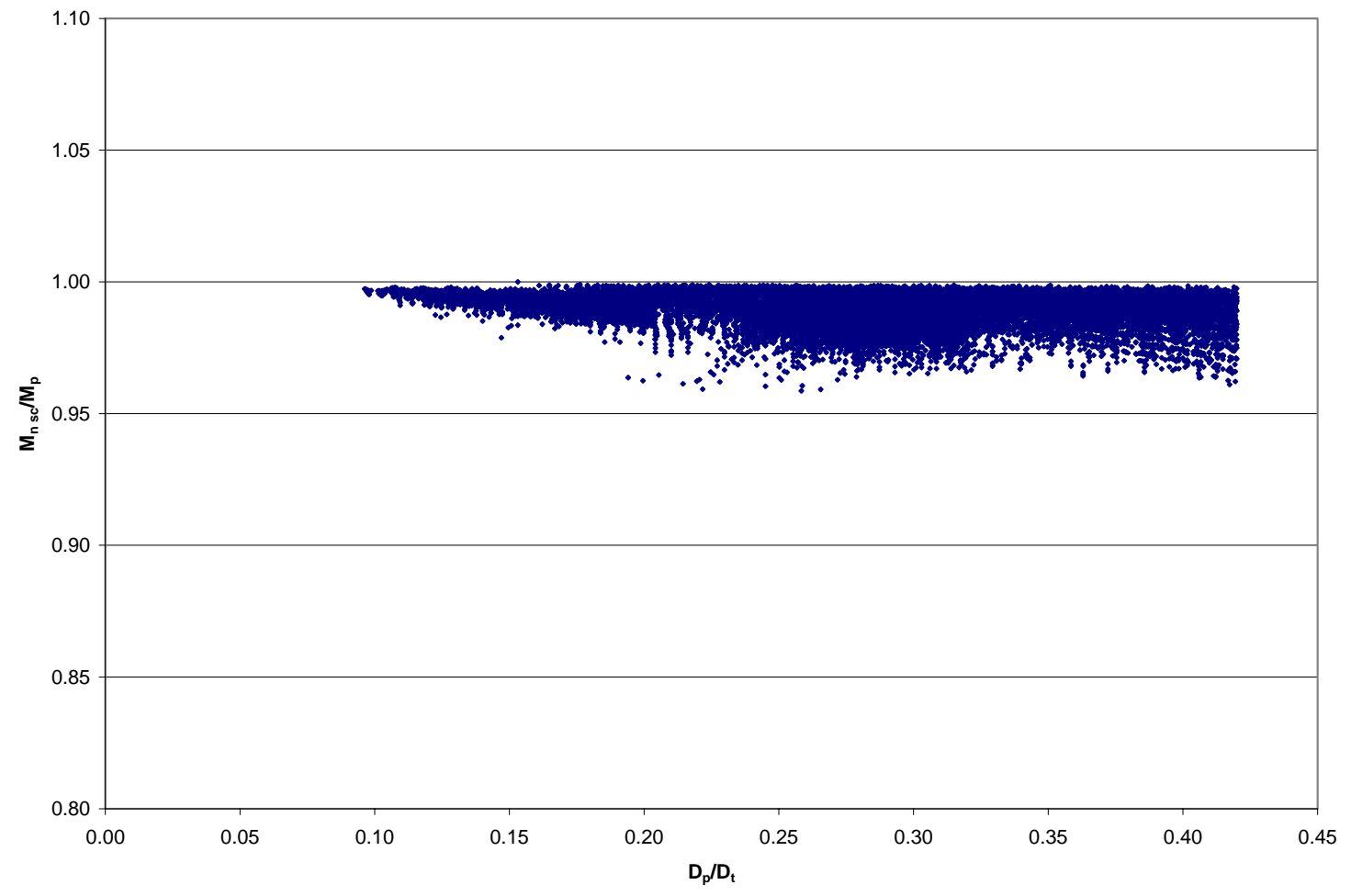

Figure 4.2 Effect of $D_{p} / D_{t}$ on moment capacity with respect to AASHTO (2003) 


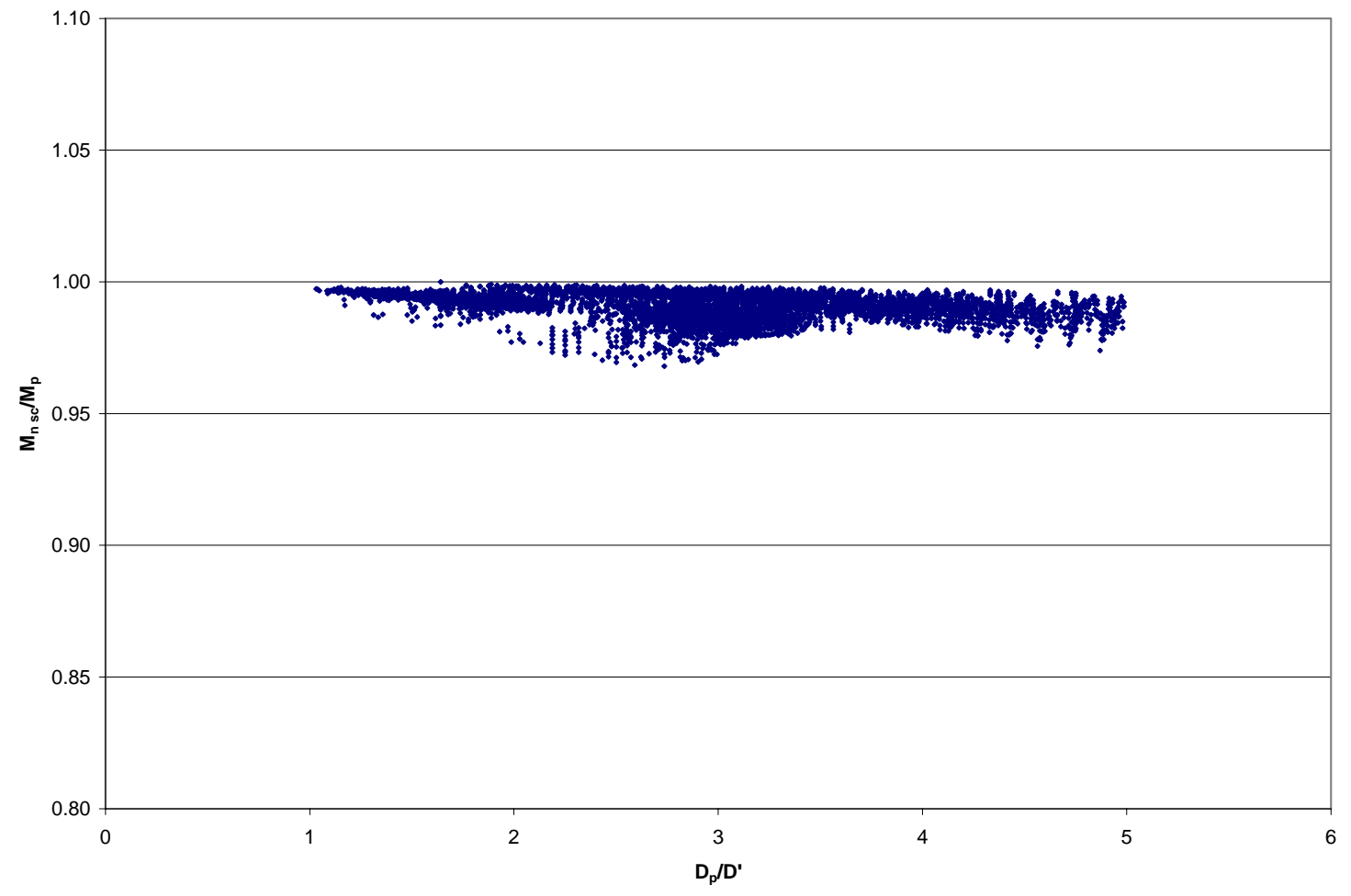

Figure 4.3 Effect of $D_{p} / D^{\prime}$ on moment capacity for homogeneous - $50 \mathrm{ksi}$ strength configuration with respect to AASHTO (2001) 


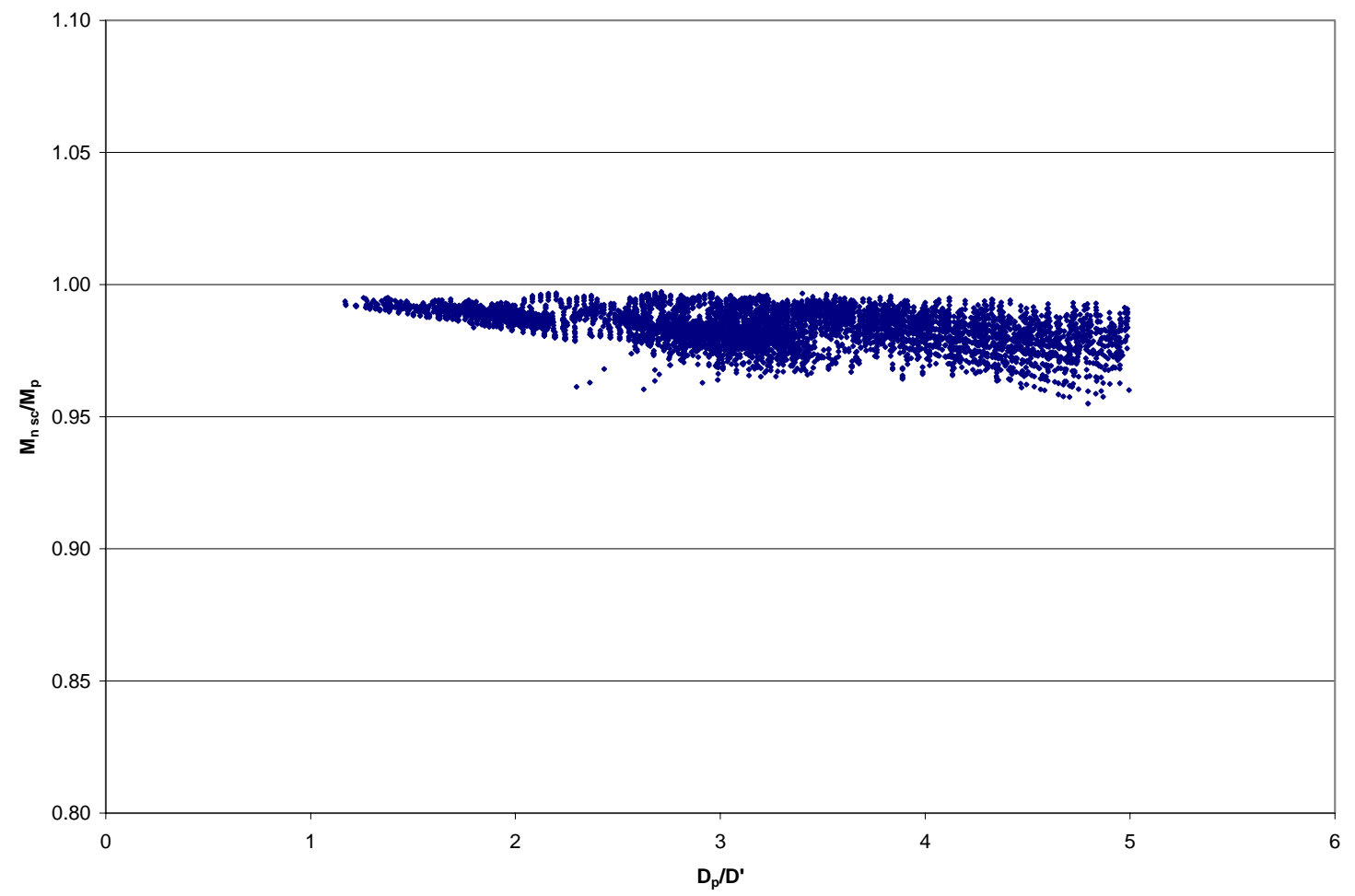

Figure 4.4 Effect of $D_{p} / D^{\prime}$ on moment capacity for homogeneous - HPS 70W strength configuration with respect to AASHTO (2001) 


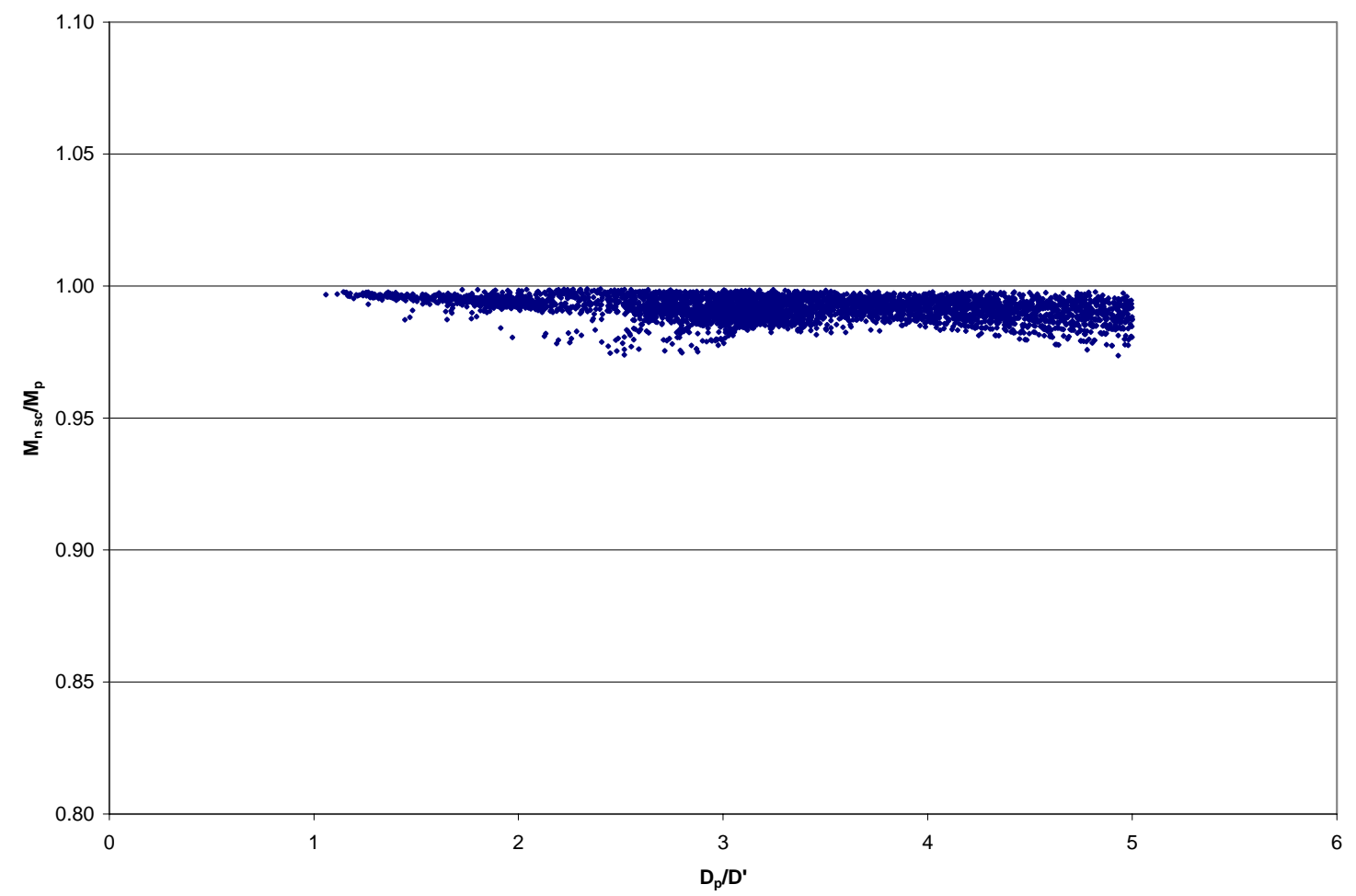

Figure 4.5 Effect of $D_{p} / D^{\prime}$ on moment capacity for hybrid - 50 ksi top flange, 50 ksi web and HPS 70W bottom flange strength configuration with respect to AASHTO (2001) 


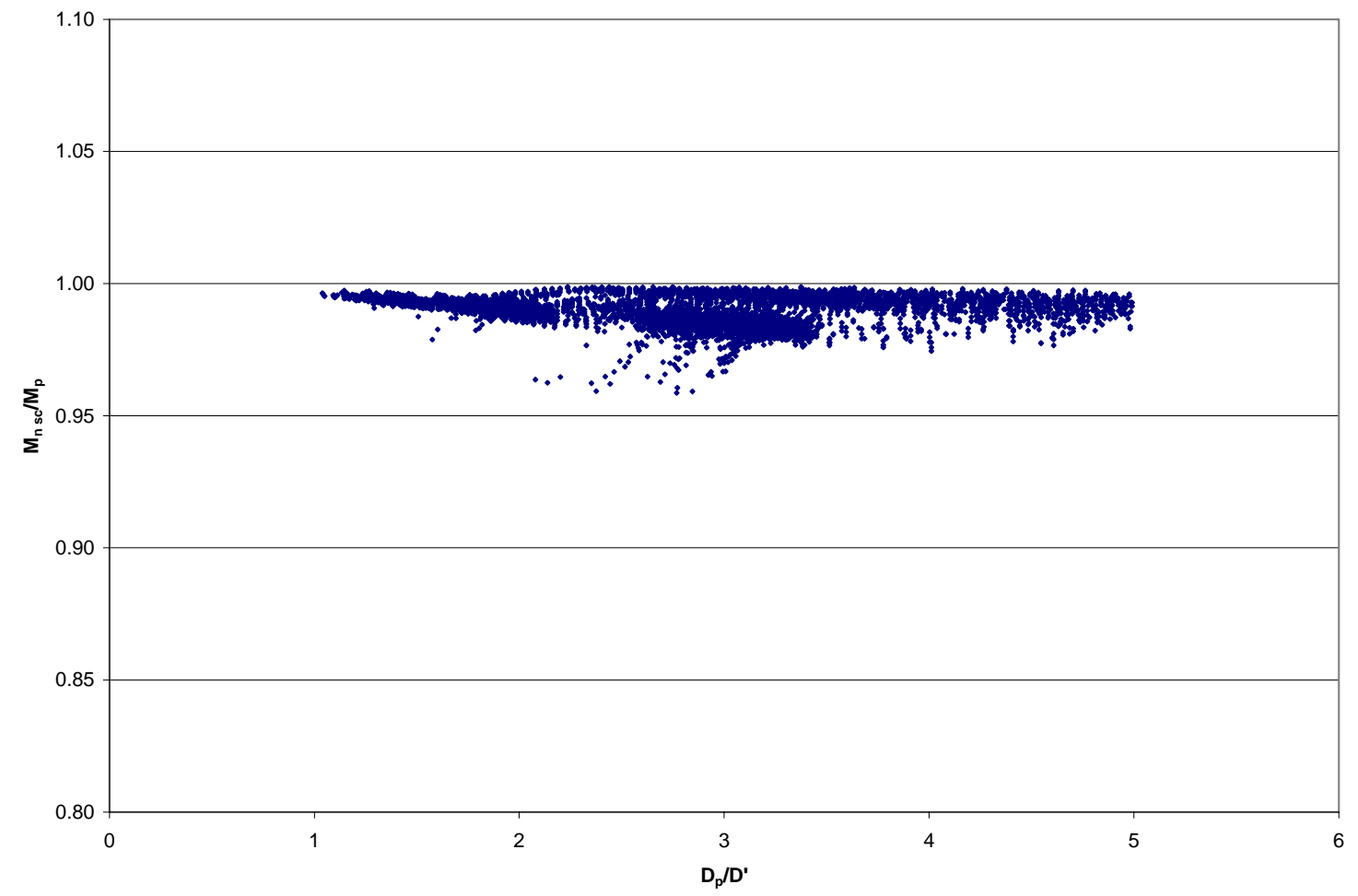

Figure 4.6 Effect of $D_{p} / D^{\prime}$ on moment capacity for hybrid - HPS $70 \mathrm{~W}$ top flange, $50 \mathrm{ksi}$ web and HPS 70W bottom flange strength configuration with respect

to AASHTO (2001) 


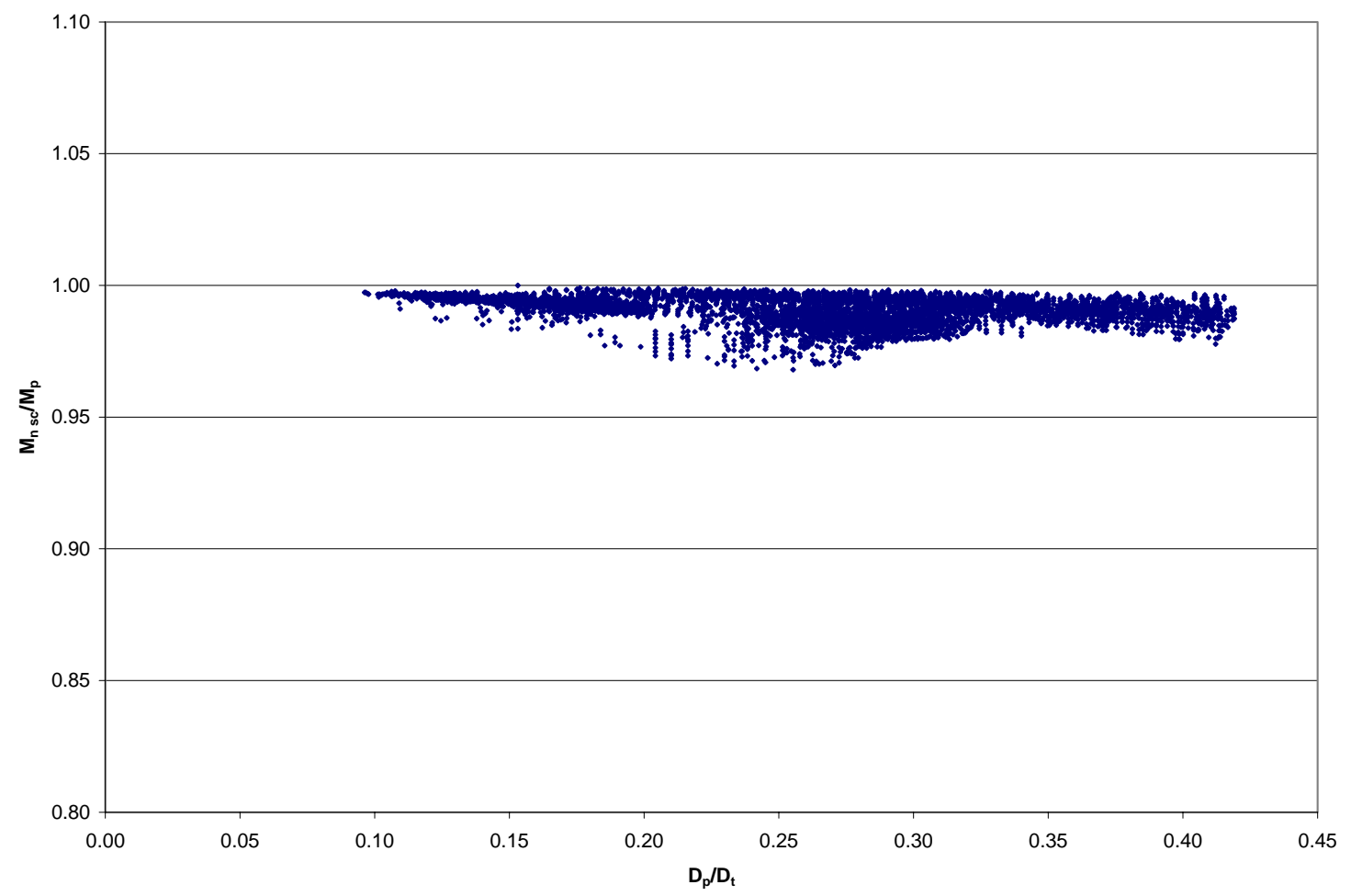

Figure 4.7 Effect of $D_{p} / D_{t}$ on moment capacity for homogeneous -50 ksi strength configuration with respect to AASHTO (2003) 


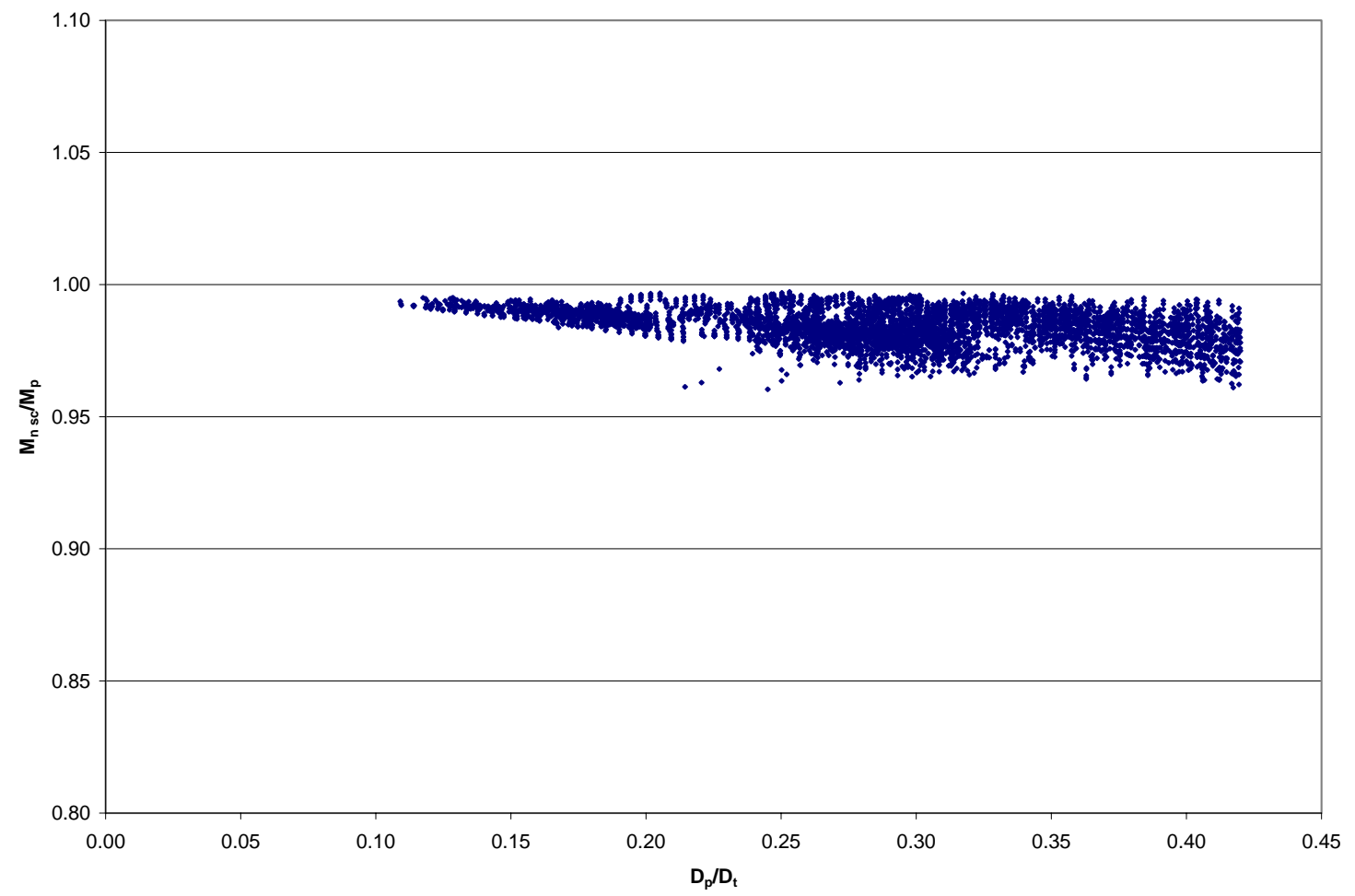

Figure 4.8 Effect of $D_{p} / D_{t}$ on moment capacity for homogeneous -HPS 70W strength configuration with respect to AASHTO (2003) 


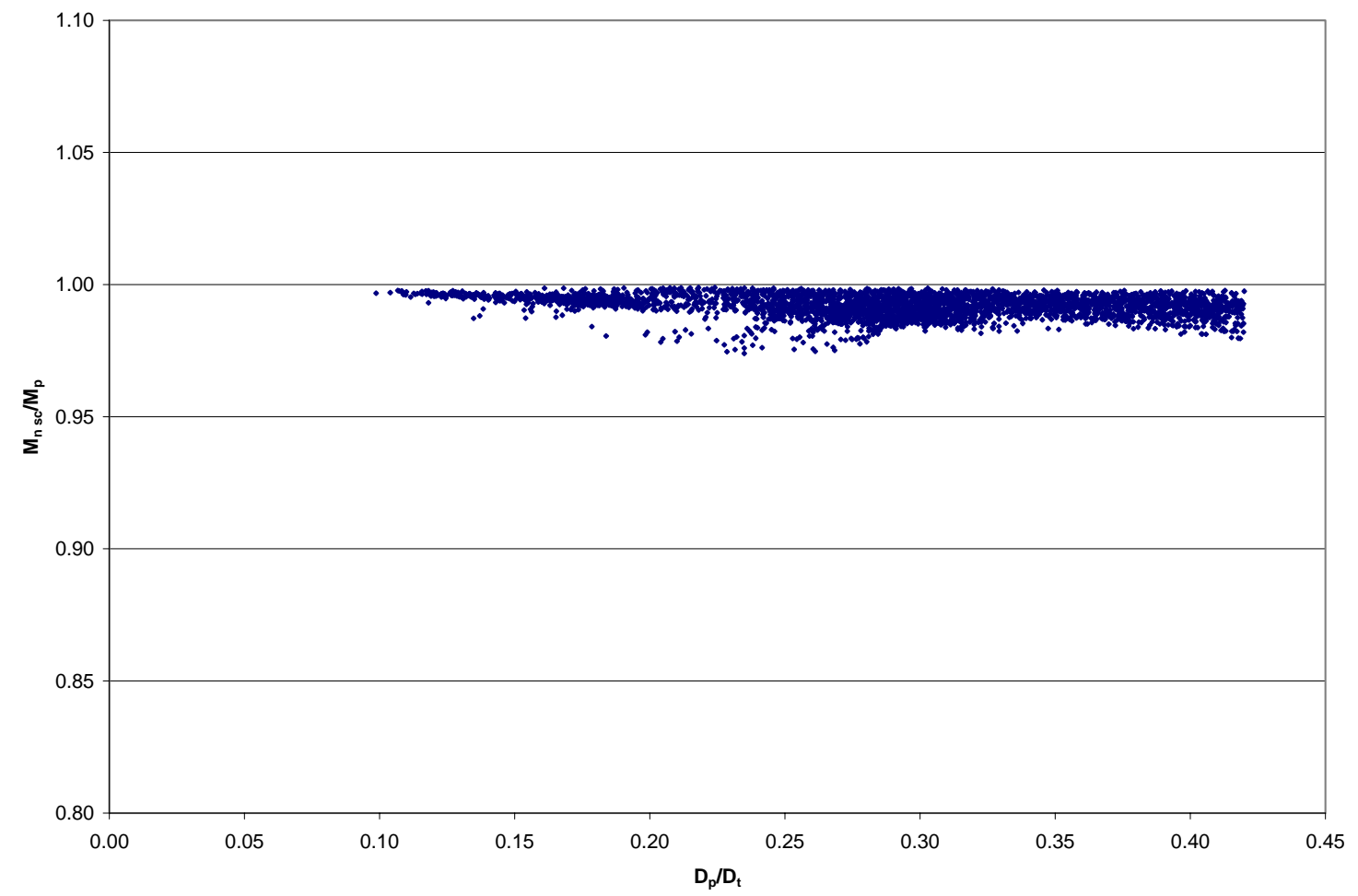

Figure 4.9 Effect of $D_{p} / D_{t}$ on moment capacity for hybrid - 50 ksi top flange, 50 ksi web and HPS 70W bottom flange strength configuration with respect to AASHTO (2003) 


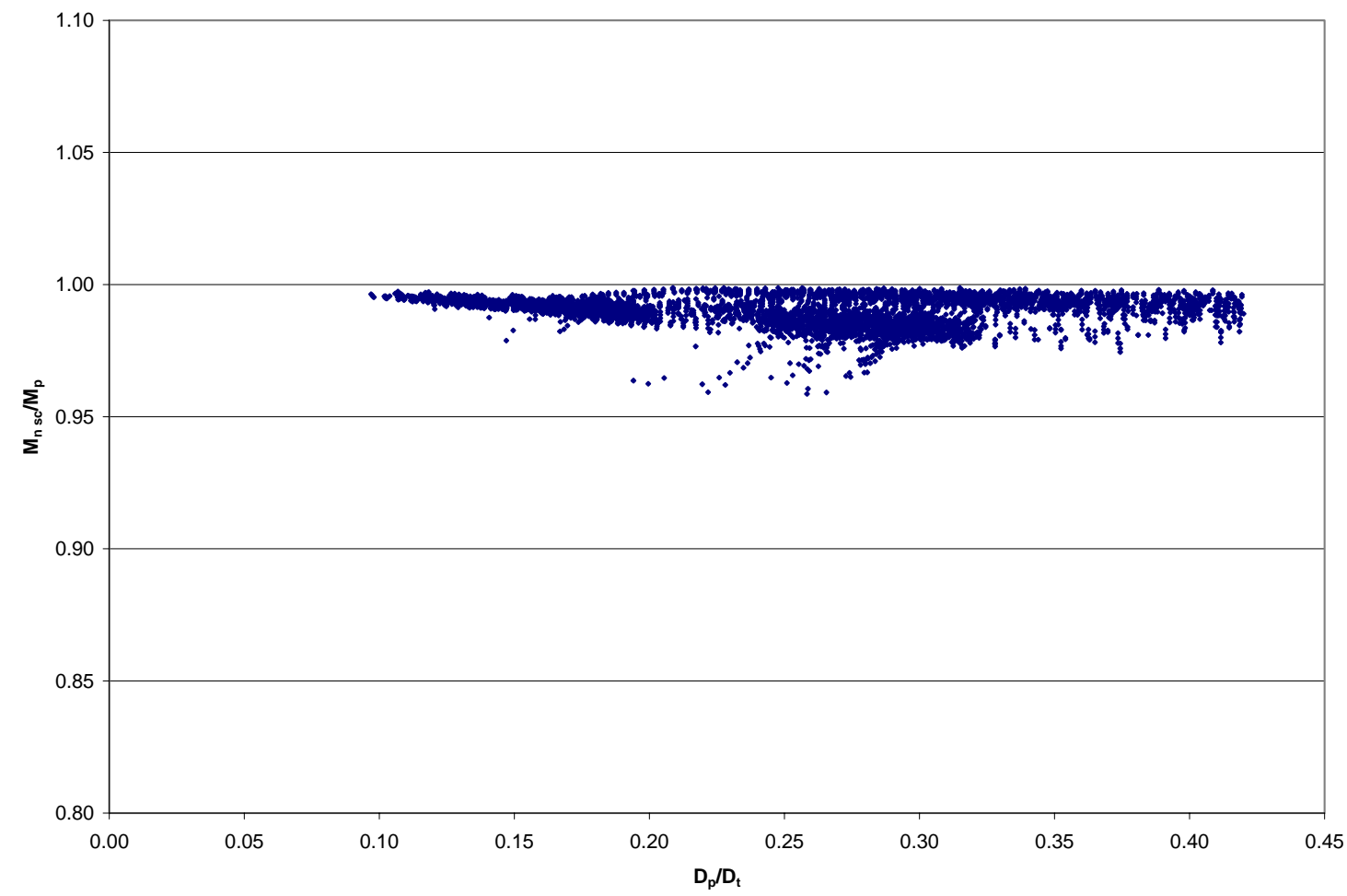

Figure 4.10 Effect of $D_{p} / D_{t}$ on moment capacity for hybrid - HPS 70W top flange, $50 \mathrm{ksi}$ web and HPS 70W bottom flange strength configuration with respect to AASHTO (2003) 


\section{Chapter 5}

\section{FINITE ELEMENT MODELING}

\subsection{Introduction}

This chapter discusses non-linear finite element modeling used in this research. This modeling is calibrated with the University of Nebraska tests (see Section 2.1) and with the experimental tests conducted in this work (see Chapter 3). This modeling is also used to conduct a parametric suite of studies of representative hypothetical composite girders covering the range of parameters assessed in the strain compatibility analyses.

\subsection{Nonlinear Finite Element Analysis Technique}

Refined FEA modeling is conducted using the commercial program ABAQUS (version 6.3; ABAQUS, 2002) in conjunction with the software program FEMAP (version 8.3). FEMAP is used to create the geometry (e.g. nodes and elements) for each girder and then is used to write the basic ABAQUS input files. These files are modified by the user to include material properties, loading and analysis information.

\subsubsection{Description of Elements/Mesh}

General shell elements with reduced integration (S4R) are used for the steel girders, concrete slab and stiffeners. S4R elements provide accurate solutions for thin and thick shells, using the classical (Kirchoff) shell theory when appropriate for relatively thin shells and Mindlin shell theory as the shell thickness increases. These elements 
allow for finite membrane strains and rotations of the shell. Therefore, they are suitable for large strain analysis involving inelastic deformation of material with nonzero effective Poisson's ratio. These elements also allow for change in shell thickness as a function of the membrane strain. Transverse shear deformation is also included.

Full composite action between the reinforced concrete deck and the steel girder is ensured by the use of beam-type multi-point constraint elements (MPC Beam). These elements are placed between the girder top flange and the deck to ensure nodal compatibility at these locations. To create the MPC Beam elements, the mesh for the concrete slab was generated to have nodes vertically above the nodes on the middle of the top flange. A typical FEA mesh and deformed shape are shown in Fig. 5.1(a) and Fig. 5.1(b), respectively. It is important to note that the mesh for the concrete slabs and steel girders was generated to keep an aspect ratio close to one (1) for the analyses conducted in this effort. The modeling efforts in this work also incorporate steel reinforcement within the deck. This is included by using the *REBAR option in the ABAQUS input file and is represented by a smeared layer of reinforcement at the specified location within the deck.

\subsubsection{Material Models}

\subsubsection{Modified CEB Model}

The Comitè Europèen du Bèton (CEB) concrete model was chosen to represent the compressive concrete properties used in the analyses in this work. Previous research, conducted by Wittry (1993) and Mans (2001), has shown that the CEB model (see Eqn. 5.1) successfully captures the compressive behavior of the type of decks studied in this work. Figure 5.2 shows the CEB compressive model for compressive strengths of $4 \mathrm{ksi}$ 
and $6 \mathrm{ksi}$, with a concrete crushing strain of $0.003 \mathrm{in} / \mathrm{in}$. The concrete material properties are included in the ABAQUS input file using the *CONCRETE option, which allows the user to input stress and strain values that represent the non-linear material properties of the concrete. The CEB model is modified to include tension behavior with a bi-linear constitutive model.

$$
f_{c}=\frac{0.85 f_{c}^{\prime}\left(a-206,000 \varepsilon_{c}\right) \varepsilon_{c}}{1+b \varepsilon_{c}}
$$

Figure 5.3 shows the complete concrete model, which includes the tension portion, for both $f^{\prime}{ }_{c}=4 \mathrm{ksi}$ and $f_{c}{ }_{c}=6 \mathrm{ksi}$. Tension stiffening is introduced into the concrete crack model to approximately model the effects associated with the concrete/rebar interface, such as bond slip and dowel action.

\subsubsection{Steel Material Models}

In this effort, the steel is modeled with a tri-linear constitutive model. The following parameters are used to characterize the material stress-strain behavior: the yield strength, $F_{y}$, the yield ratio, $F_{y} / F_{u}$, the ratio of the strain at strain hardening to the yield strain $\varepsilon_{s t} / \varepsilon_{y}$, and the stain hardening modulus, $E_{s t}$.

The idealized multi-line stress-strain models used in this study are shown in Figs. 5.4 and 5.5 for Fy = $50 \mathrm{ksi}$ and Fy $=70 \mathrm{ksi}$, respectively. Finite element modeling of the experimental girders is performed with the actual material properties and nominal properties are used for the analysis of hypothetical girders. 


\subsubsection{Modified RIKS Algorithm}

To capture the load-deflection response of the FEA models, unstable collapse and post-buckling analysis procedures are used to trace the complete nonlinear loaddeflection behavior. Specifically the Modified Riks Algorithm, shown in Fig. 5.6, is used to analyze the girders.

Assuming the loading is proportional (i.e., all load magnitudes vary with a single scalar parameter) and that the response is reasonably smooth (sudden bifurcations do not occur), the modified Riks method uses the load magnitude as an additional unknown and solves simultaneously for loads and displacements. Because the progress of the solution is independent of the load increment, ABAQUS uses the "arc length,” which is the distance along the static equilibrium path in load-displacement space, to control the increment size. The "arc length" value is initially set by the users and is later adjusted by the ABAQUS automatic load increment algorithm based on the convergence rate. The fundamental nature of the method is that the solution is viewed as the discovery of a single equilibrium path in a space defined by the nodal variables and the loading parameter (ABAQUS, 2002).

Development of the solution requires navigation of this path as far as required. The basic algorithm remains the Newton method; therefore, at any time there will be a finite radius of convergence. During each increment, the solution is found by moving a given distance along the tangent line to the current solution point and then searching for equilibrium in the plane that not only passes through the point obtained, but also is orthogonal to the same tangent line. 
The total path length traversed is determined by the load magnitudes supplied by the user in the loading options. The number of increments is determined by the userspecified time increment data, assisted by ABAQUS automatic incrementation scheme, if chosen.

Also important to note is that the number of Gauss integration points through the slab thickness has been changed from 5 points (the ABAQUS default value) to 7 points and a linear search technique by changing the load level during an iteration is used. These changes have been well established to better capture the crushing and cracking of the concrete and speed of convergence (Barth and $\mathrm{Wu}, 2004)$.

\subsection{FEA Verification Study}

The previously described finite element methods have been implemented successfully by WVU to determine the positive bending behavior of two experimental girders (POS1 and POS2) tested by Mans (2001) at the University of Nebraska (see Fig. 2.5). As shown in Figs. 5.7 and 5.8, these finite element analysis methods have been successful in predicting not only the yield loads and the ultimate flexural capacity but are also capable of accurately reproducing the load-deflection response.

The experimental testing of POS1 $\left(D_{p} / D^{\prime}=2.07\right)$ resulted in an ultimate capacity of 391 kips applied at midspan. As can be seen in Table 5.1, the finite element analysis resulted in an ultimate load of 396 kips. Also shown in Table 5.1, the finite element analysis for POS2 $\left(D_{p} / D^{\prime}=0.88\right)$ resulted in an ultimate load at midspan of 328 kips, while the experimental load at midspan was 322 kips. 


\subsection{Finite Element Modeling of Experimental Girders}

Using the methods described above, nonlinear finite element analyses were conducted for each of the three experimental girders (R1, PL1 and PL2) presented in Chapter 3. The actual girder dimensions and actual properties presented in Chapter 3 were used to generate the models. These analyses were performed to further validate the FEA methods used in this research.

Figures 5.9 through 5.11 show the load-deflection plots obtained from the FEA for Specimens R1, PL1 and PL2, respectively. As is illustrated in Figs. 5.9 through 5.11, the finite element analysis of the experimental girders provides results that are extremely close to the actual results in both the linear and nonlinear regions of the load-deflection curves.

\subsection{Finite Element Analysis Parametric Studies}

To further validate the strain compatibility analyses, a subset of these girders was selected for FEA analysis. This was performed by selecting 3 girders from each of the following material configurations for girders having both equal and unequal flange areas from the parametric set of girders used in the strain compatibility analyses:

- Homogeneous - 50 ksi steel

- Homogeneous - HPS 70W steel

- Hybrid Configuration - 50 ksi top flange, 50 ksi web and HPS 70W bottom flange

- Hybrid Configuration - HPS 70W top flange, $50 \mathrm{ksi}$ web and HPS 70W bottom flange 
By selecting one low, one intermediate and one high $D_{p} / D^{\prime}$ value from each material/geometry configuration, the three girders selected represented the range of $1.0 \leq D_{p} / D^{\prime} \leq 5.0$. This resulted in a parametric set containing 24 girders. The girder geometries, $D_{p} / D^{\prime}$ and $D_{p} / D_{t}$ values for each girder are shown in Table 5.2.

\subsubsection{Naming Convention}

Figure 5.12 shows the naming convention used in the FEA parametric study. The parameters are as follows:

- Equal/Unequal Flange Area

$\mathrm{EF}=$ equal flange area

$\mathrm{UF}=$ unequal flange area

- Strength Configuration

A50 = homogeneous, 50 ksi steel

A70 = homogeneous, 70 ksi steel

H50-70 = hybrid, 50 ksi top flange, 50 ksi web, 70 ksi bottom flange

H70-70 = hybrid, 70 ksi top flange, 50 ksi web, 70 ksi bottom flange

- Low/Intermediate/High $D_{p} / D^{\prime}$

$\mathrm{L}=$ low value

$\mathrm{I}=$ intermediate value

$\mathrm{H}=$ high value 


\subsection{Parametric Study Finite Element Analysis Results}

The results of the FEA parametric study are presented in Figs. 5.13 through 5.60. These figures contain load-deflection plots and strain profiles for each girder analyzed. The load-deflection plots show the locations of the moments, $M_{y}, 1.1 M_{y}, 1.3 M_{y}, M_{n s c}$, $M_{\text {AASHTO (2001), }} M_{\text {AASHTO (2003), and }} M_{p}$. Strain data obtained from the FEA output files is presented in the strain level plots, which illustrate the strain profile at each of the respective moments shown on the load-deflection plots.

The load-deflection plots for each analysis indicate that the moment obtained from the strain compatibility analysis coincides extremely well with the moment at failure of the FEA model. Comparing the ultimate FEA moments to the predicted ultimate moments from both the AASHTO (2001) Specifications and the AASHTO (2003) Specifications demonstrates that the current prediction equations are conservative for the girders analyzed in this effort. This conservativeness increases at higher ductility ratios (i.e., $D_{p} / D^{\prime}$ or $D_{p} / D_{t}$ ).

Also, as can be seen from the load-deflection plots, many of the girders were not capable of reaching $1.3 M_{y}$ before failure; this is due to the fact that many the shape factors were less than 1.3. Because the girders could not reach this upper bound limit, this suggests that further investigation of the upper bound strength limit of $1.3 M_{y}$ is warranted. 
Table 5.1 Experimental peak loads and FEA results for the University of Nebraska test girders

\begin{tabular}{|c|c|c|}
\hline Specimen & $\begin{array}{c}\text { Experiment } \\
\text { (kips) }\end{array}$ & $\begin{array}{c}\text { WVU FEA } \\
\text { (kips) }\end{array}$ \\
\hline POS1 & 391 & 396 \\
\hline POS2 & 322 & 328 \\
\hline
\end{tabular}


Table 5.2 Girder geometries used in FEA parametric study

\begin{tabular}{|c|c|c|c|c|c|c|c|c|c|c|c|}
\hline \multicolumn{2}{|c|}{ Girder } & $\begin{array}{l}b_{f c} \\
\text { (in.) }\end{array}$ & $\begin{array}{c}t_{f c} \\
\text { (in.) }\end{array}$ & $\begin{array}{l}D_{w} \\
\text { (in.) }\end{array}$ & $\begin{array}{c}t_{w} \\
\text { (in.) }\end{array}$ & $\begin{array}{l}b_{f t} \\
\text { (in.) }\end{array}$ & $\begin{array}{c}t_{f t} \\
\text { (in.) }\end{array}$ & $\begin{array}{c}b_{s} \\
\text { (in.) }\end{array}$ & $\begin{array}{c}t_{s} \\
\text { (in.) }\end{array}$ & $D_{p} / D^{\prime}$ & $D_{p} / D_{t}$ \\
\hline \multirow{3}{*}{ EFA50 } & $\mathbf{L}$ & 24 & 1 & 72 & 0.5 & 24 & 1 & 96 & 7 & 1.031 & 0.096 \\
\hline & I & 12 & 1 & 24 & 0.75 & 12 & 1 & 72 & 7 & 2.377 & 0.222 \\
\hline & $\mathbf{H}$ & 24 & 1 & 96 & 1 & 24 & 1 & 60 & 7 & 4.257 & 0.397 \\
\hline \multirow{3}{*}{ EFA70 } & $\mathbf{L}$ & 12 & 1 & 72 & 0.5 & 12 & 1 & 96 & 8 & 1.169 & 0.109 \\
\hline & $\mathbf{I}$ & 12 & 3 & 24 & 1 & 12 & 3 & 84 & 7 & 2.841 & 0.265 \\
\hline & $\mathbf{H}$ & 18 & 1 & 96 & 1 & 18 & 1 & 60 & 7 & 4.673 & 0.436 \\
\hline \multirow{3}{*}{ EFH50-70 } & $\mathbf{L}$ & 24 & 1 & 72 & 0.5 & 24 & 1 & 96 & 7 & 1.058 & 0.099 \\
\hline & I & 12 & 3 & 72 & 0.5 & 12 & 3 & 60 & 9 & 3.163 & 0.295 \\
\hline & $\mathbf{H}$ & 18 & 3 & 72 & 1 & 18 & 3 & 72 & 7 & 5.000 & 0.467 \\
\hline \multirow{3}{*}{ EFH70-70 } & $\mathbf{L}$ & 24 & 1 & 72 & 0.5 & 24 & 1 & 96 & 7 & 1.039 & 0.097 \\
\hline & I & 12 & 2.5 & 72 & 1 & 12 & 2.5 & 84 & 9 & 2.715 & 0.253 \\
\hline & $\mathbf{H}$ & 24 & 1 & 96 & 1 & 24 & 1 & 60 & 7 & 4.257 & 0.397 \\
\hline \multirow{3}{*}{ UFA50 } & $\mathbf{L}$ & 24 & 1.5 & 72 & 0.5 & 30 & 1.5 & 96 & 7 & 1.109 & 0.103 \\
\hline & I & 24 & 3 & 24 & 0.5 & 30 & 3 & 60 & 8 & 3.086 & 0.288 \\
\hline & $\mathbf{H}$ & 12 & 2.5 & 48 & 0.75 & 24 & 2.5 & 72 & 8 & 4.986 & 0.465 \\
\hline \multirow{3}{*}{ UFA70 } & $\mathbf{L}$ & 18 & 1 & 72 & 0.5 & 24 & 1 & 96 & 9 & 1.295 & 0.121 \\
\hline & I & 12 & 2 & 72 & 0.75 & 18 & 2 & 96 & 10 & 3.104 & 0.290 \\
\hline & $\mathbf{H}$ & 12 & 1 & 72 & 1 & 24 & 1 & 72 & 7 & 4.995 & 0.466 \\
\hline \multirow{3}{*}{ UFH50-70 } & $\mathbf{L}$ & 12 & 1 & 72 & 0.5 & 18 & 1 & 96 & 8 & 1.159 & 0.108 \\
\hline & $\mathbf{I}$ & 12 & 2 & 24 & 1 & 18 & 2 & 72 & 10 & 3.586 & 0.335 \\
\hline & $\mathbf{H}$ & 18 & 1.5 & 48 & 1 & 24 & 1.5 & 72 & 7 & 5.000 & 0.467 \\
\hline \multirow{3}{*}{ UFH70-70 } & $\mathbf{L}$ & 24 & 2 & 72 & 0.5 & 30 & 2 & 96 & 8 & 1.349 & 0.126 \\
\hline & I & 12 & 2 & 72 & 0.5 & 18 & 2 & 72 & 7 & 3.554 & 0.332 \\
\hline & $\mathbf{H}$ & 18 & 2 & 48 & 1 & 30 & 2 & 84 & 8 & 4.991 & 0.466 \\
\hline
\end{tabular}




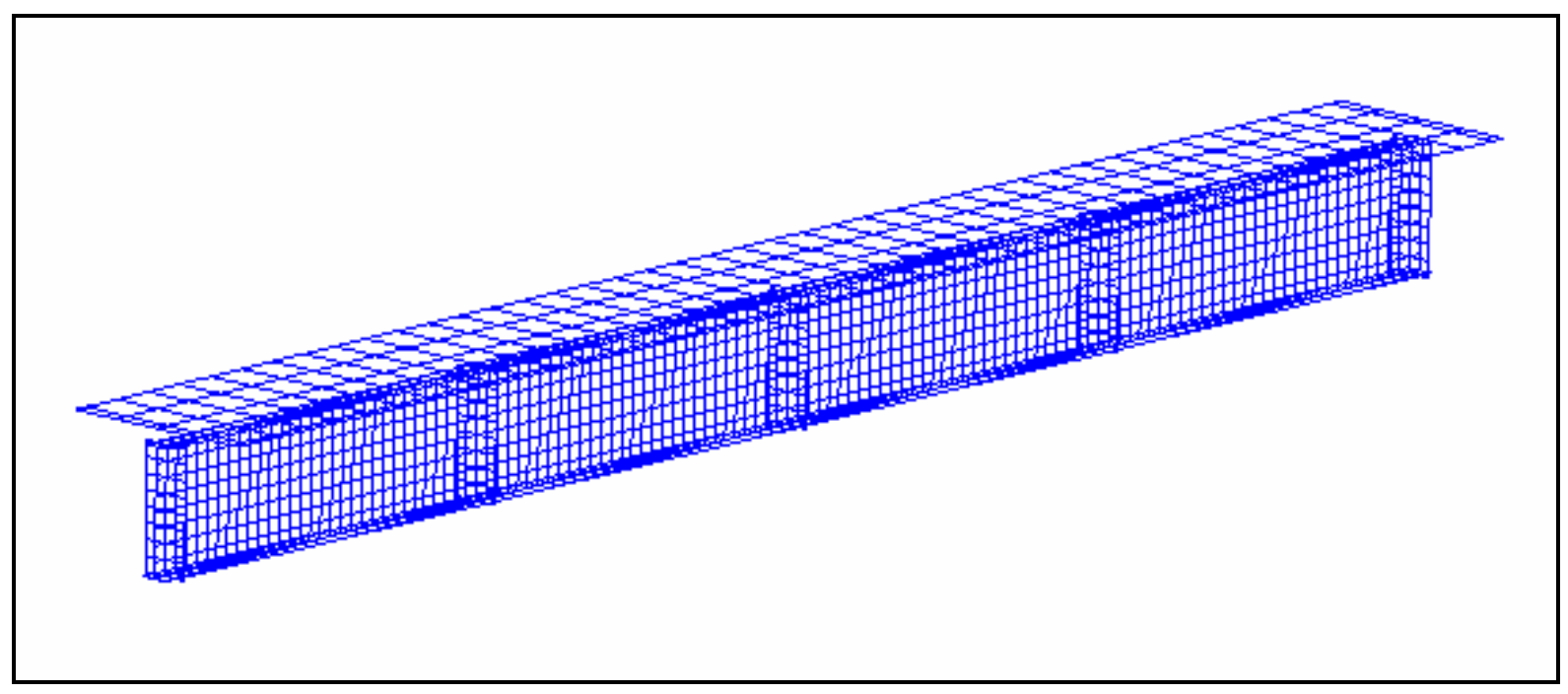

(a) FEA mesh

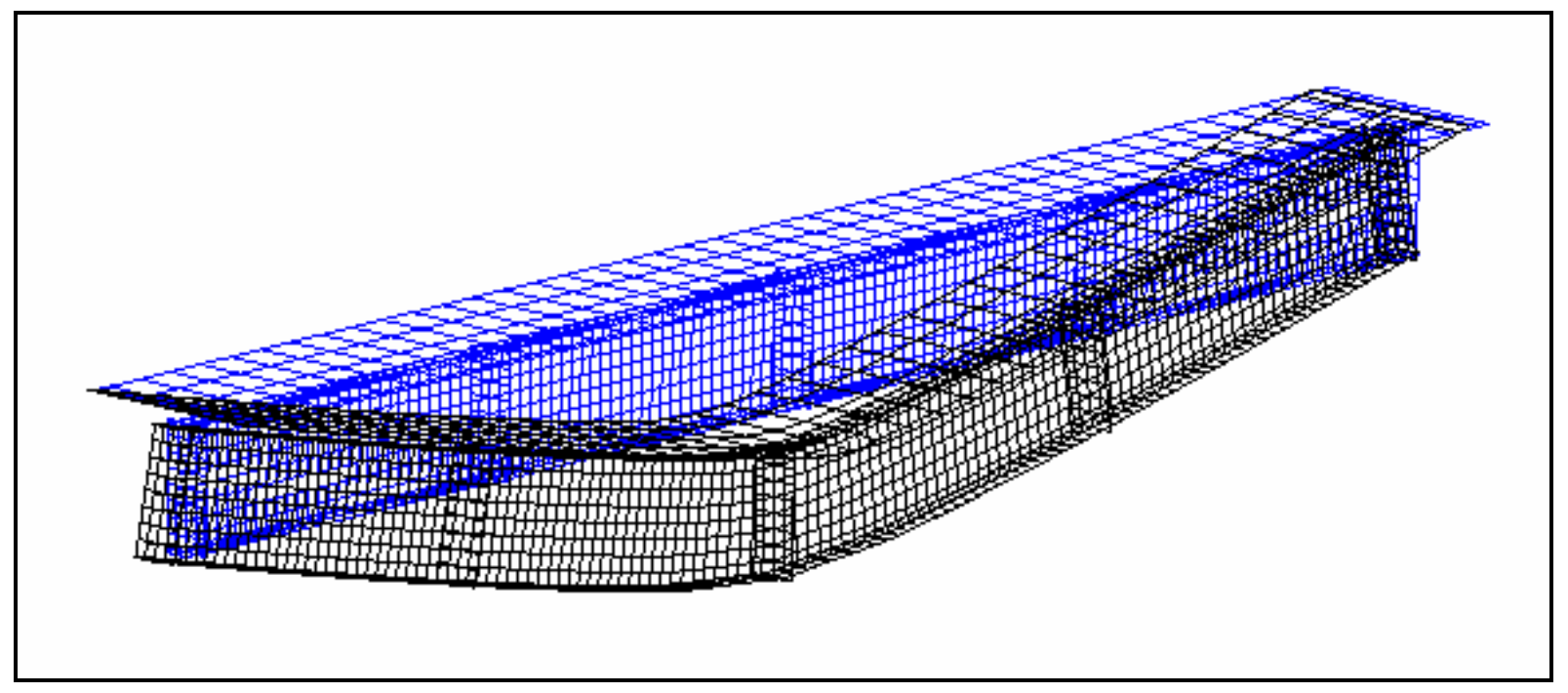

(b) deformed shape

Figure 5.1 Typical FEA (a) mesh for composite steel girder and (b) deformed shape 


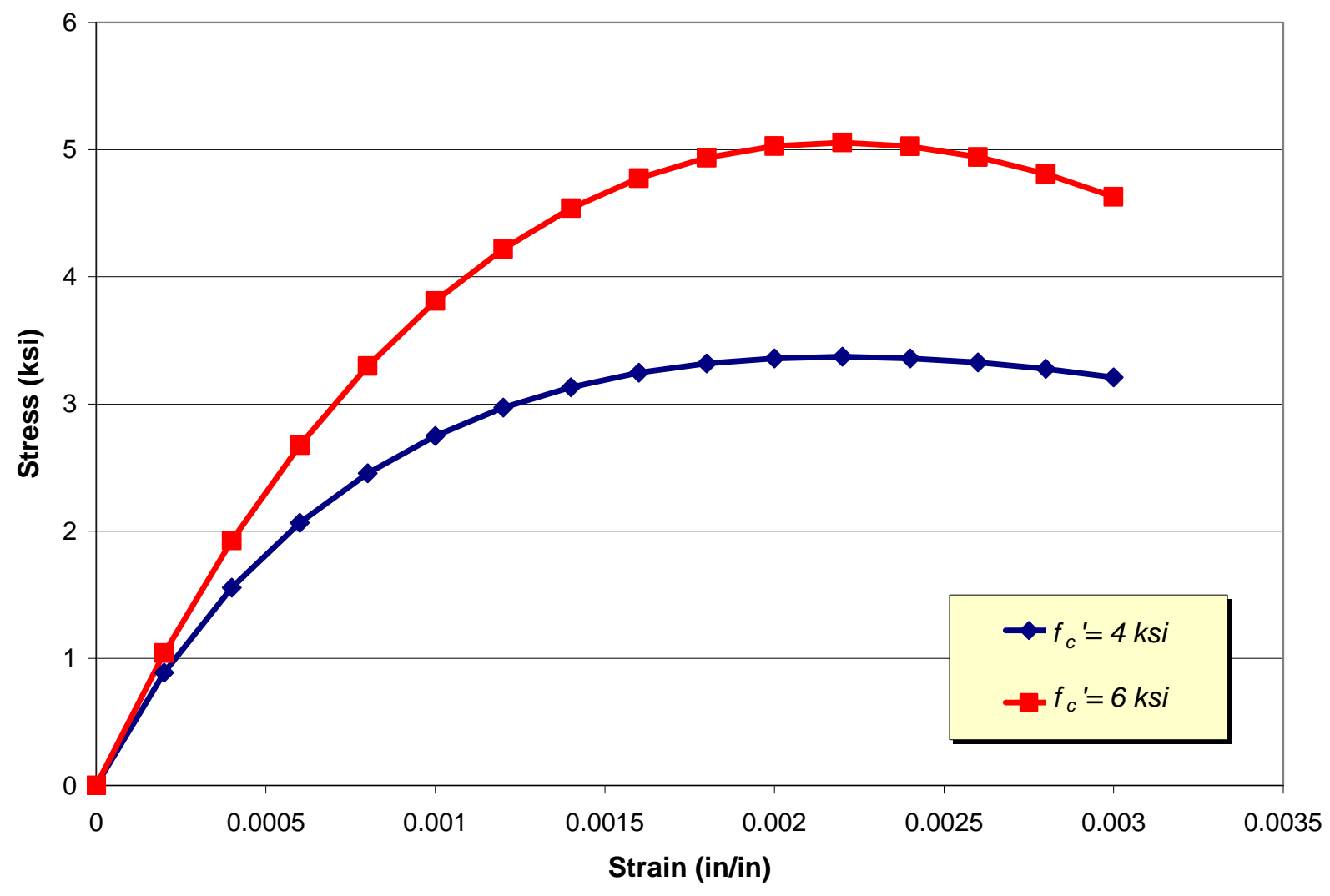

Figure 5.2 Concrete CEB compressive stress-strain model 


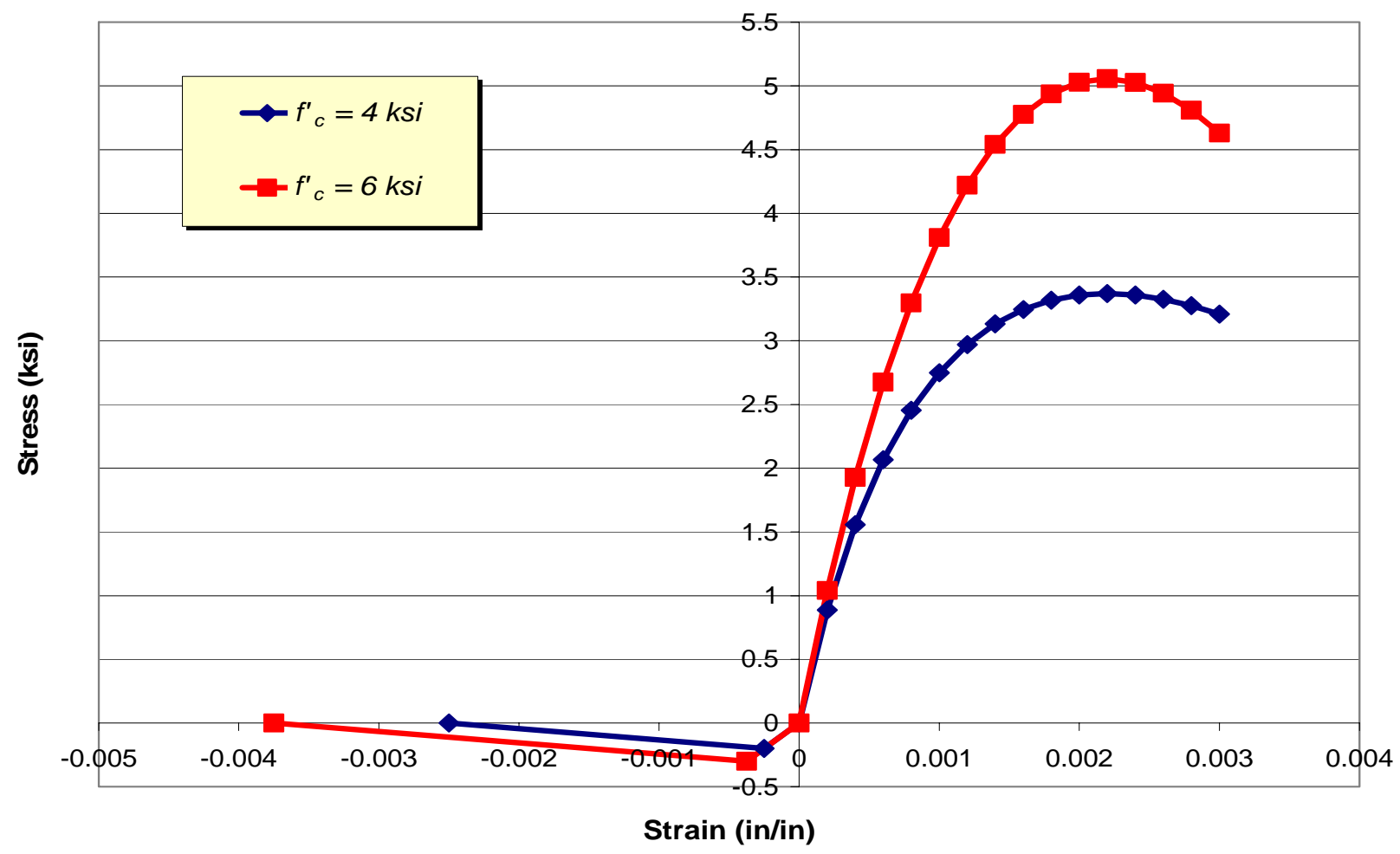

Figure 5.3 Modified CEB model 


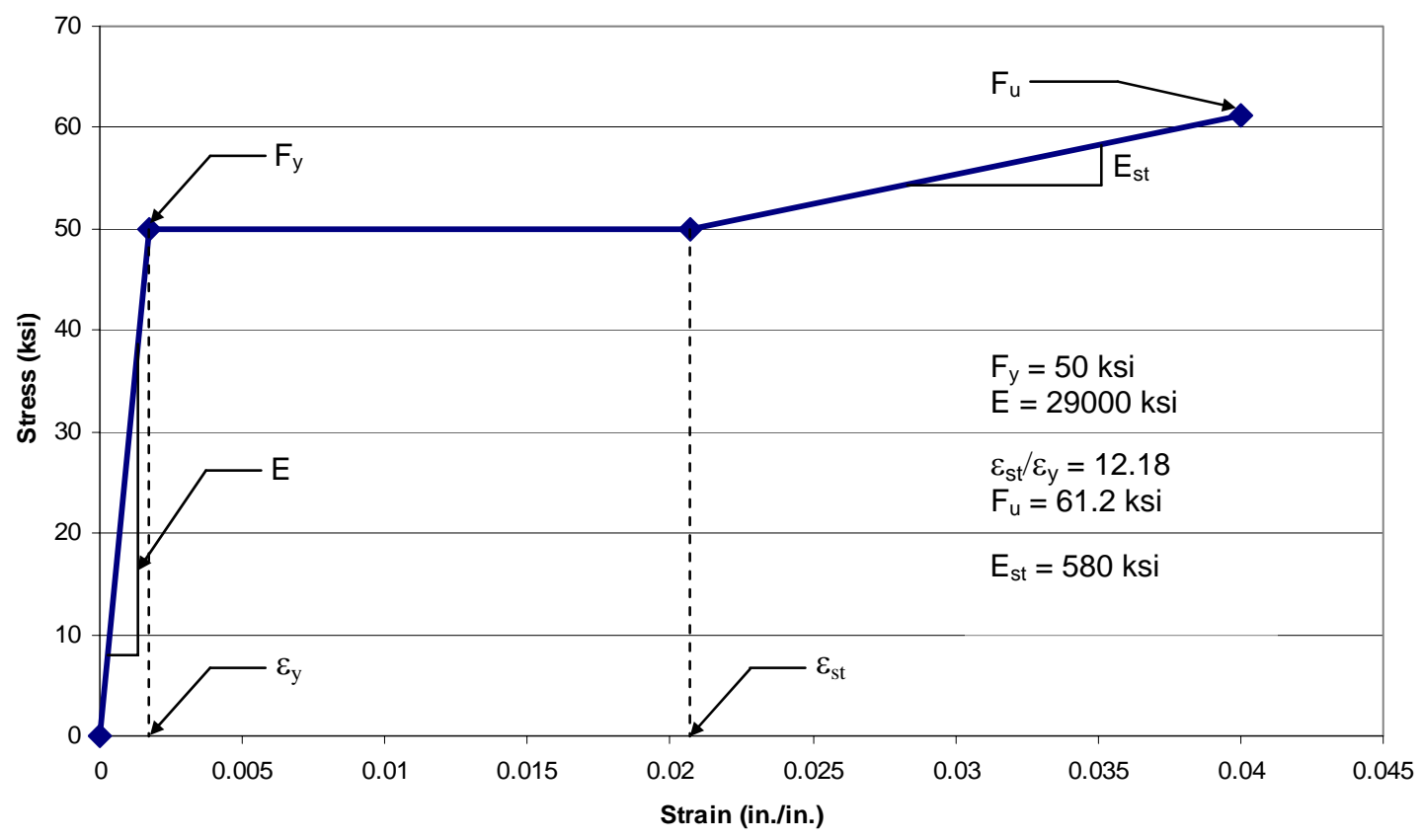

Figure 5.4 Idealized multi-line stress-strain curve for $50 \mathrm{ksi}$ steel 


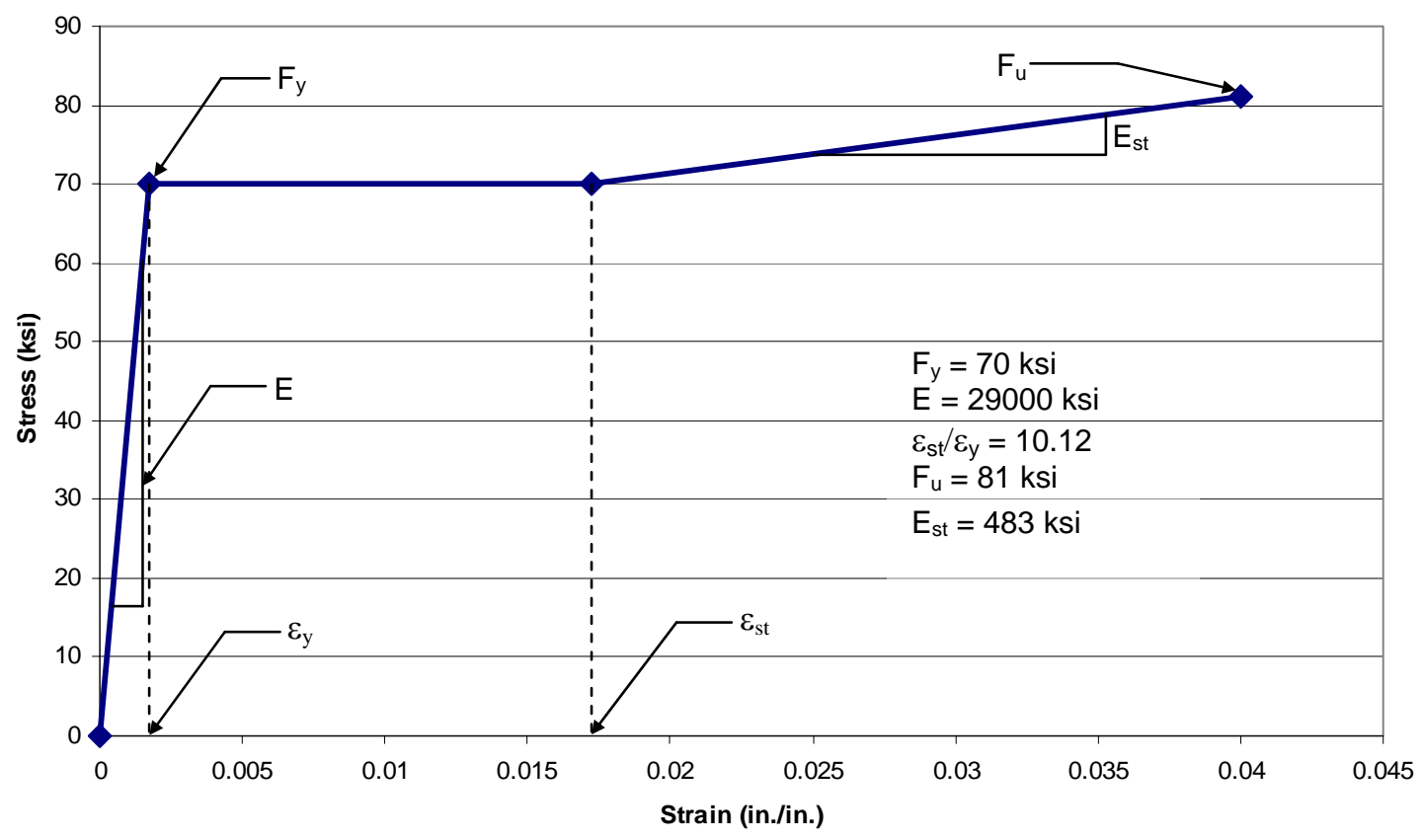

Figure 5.5 Idealized multi-line stress-strain curve for $70 \mathrm{ksi}$ steel 


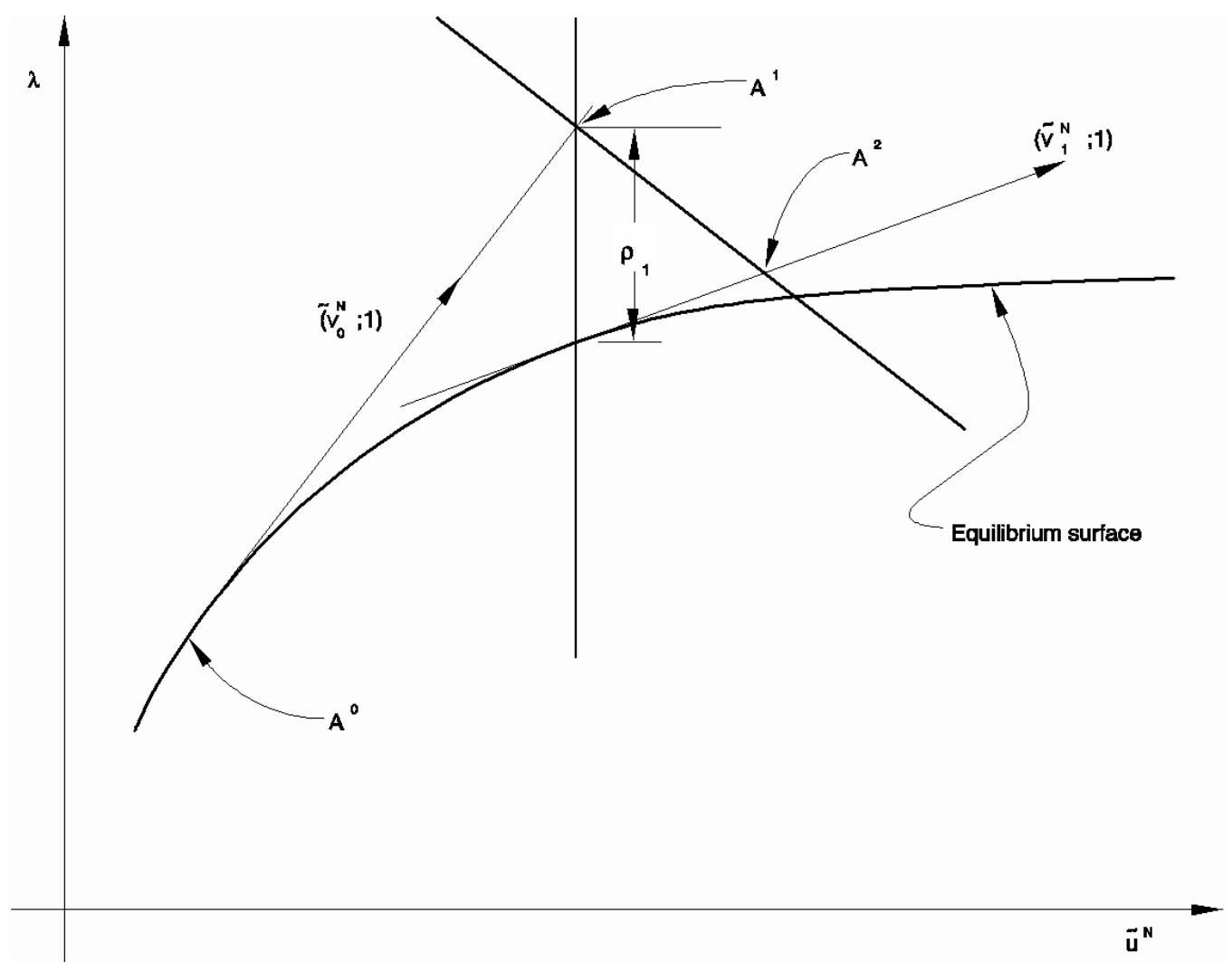

Figure 5.6 Modified Riks algorithm (ABAQUS, 2002) 


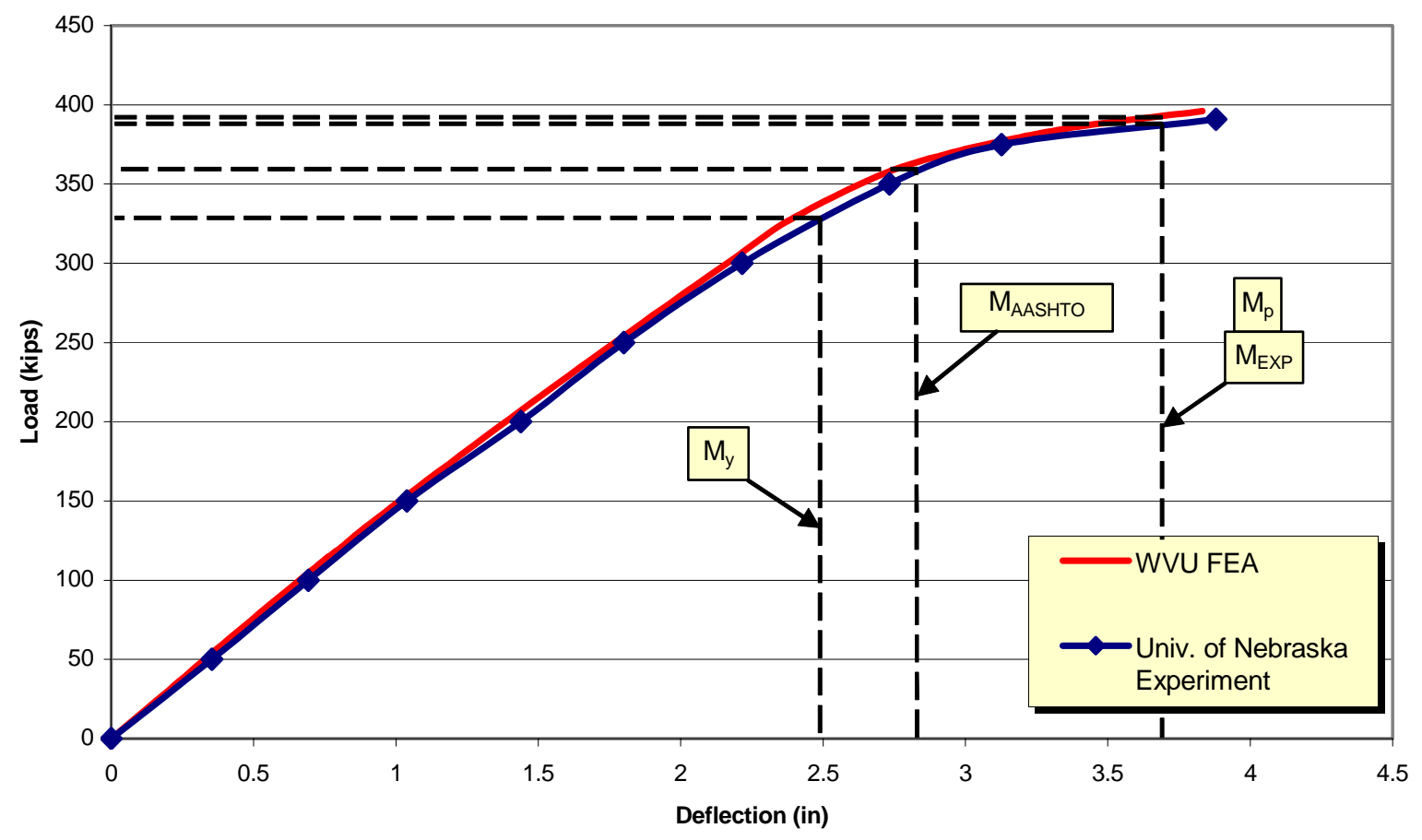

Figure 5.7 Load-deflection results for Nebraska girder, POS1 


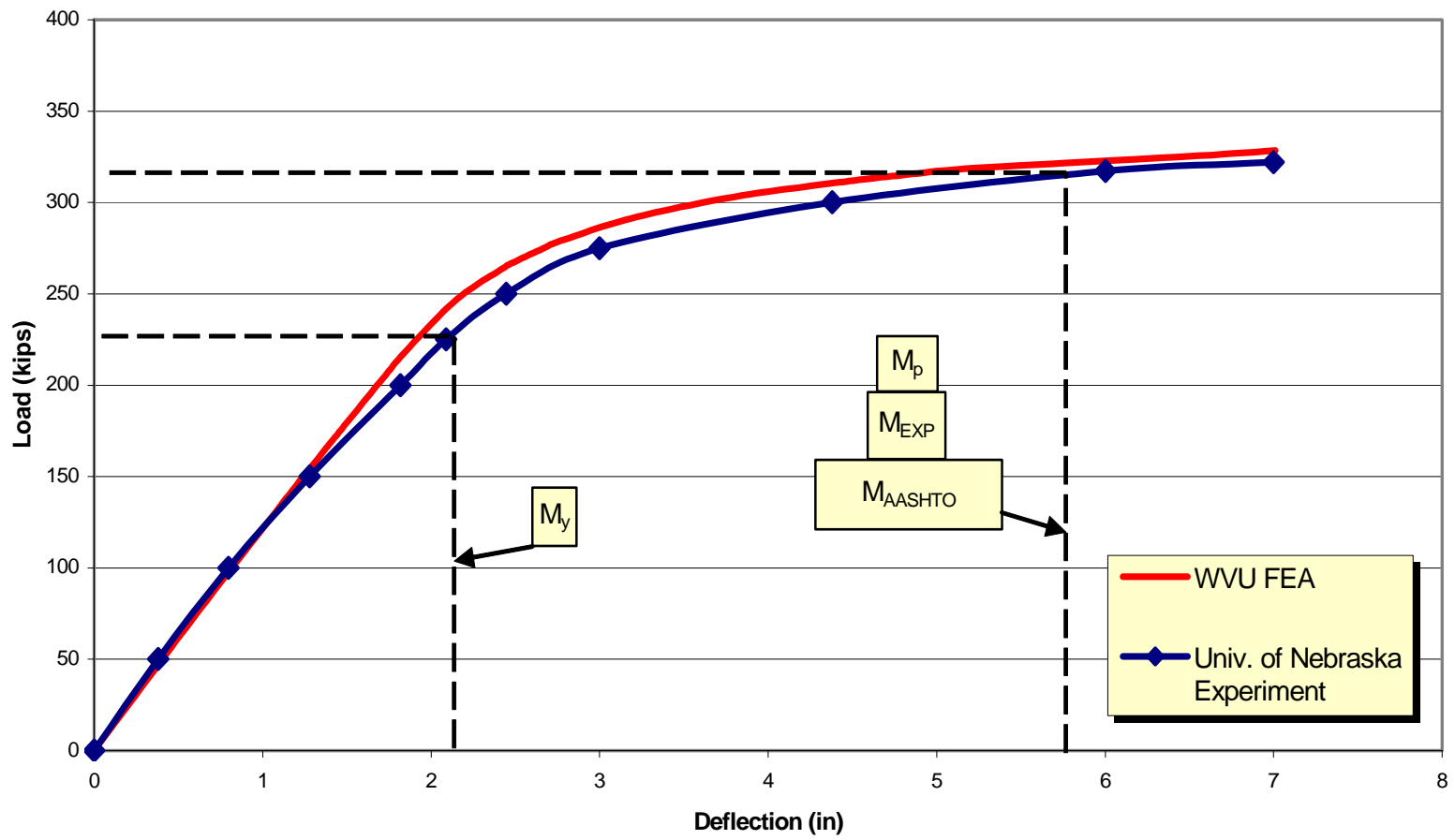

Figure 5.8 Load-deflection results for Nebraska girder, POS2 


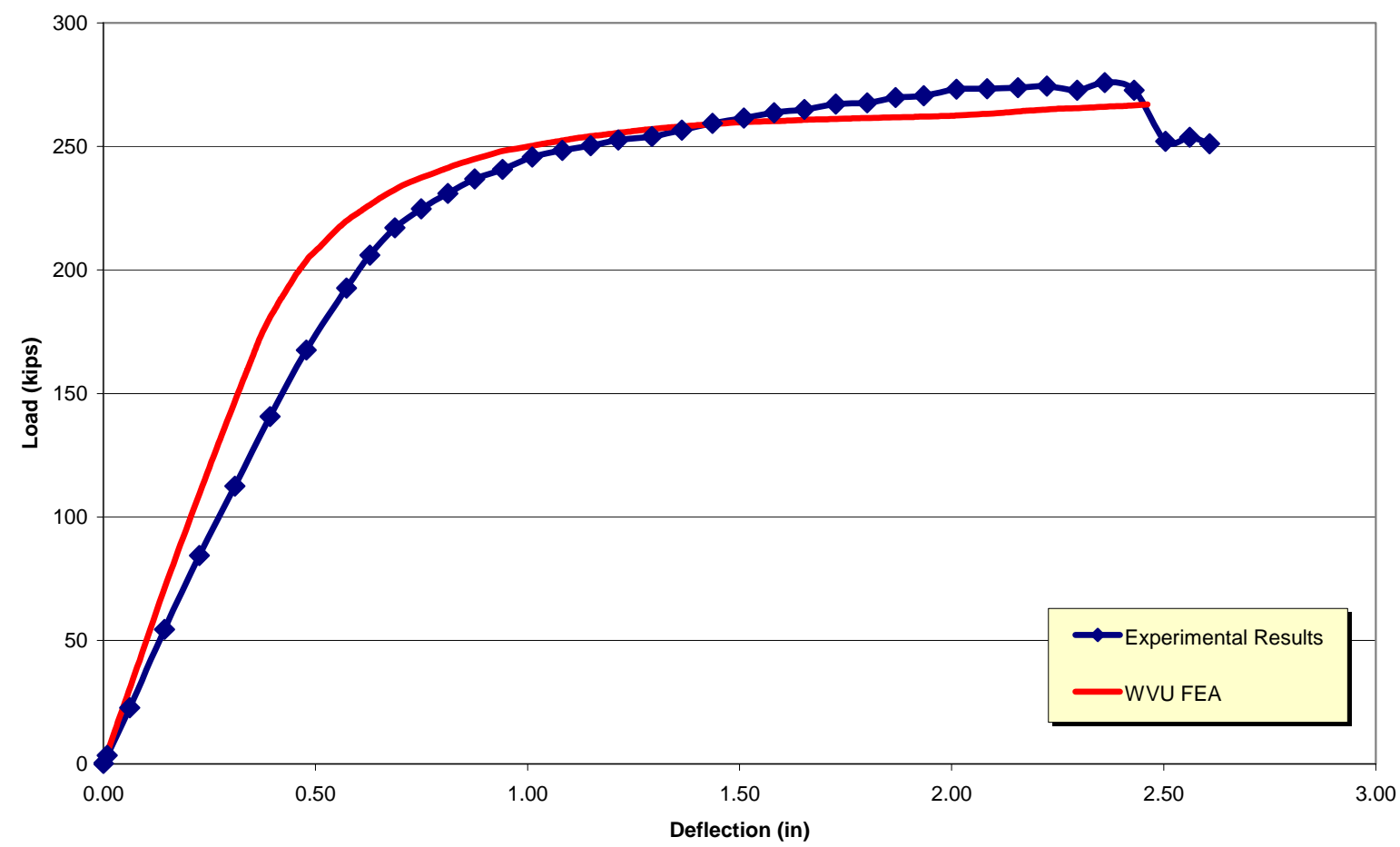

Figure 5.9 Load-deflection results for specimen R1 


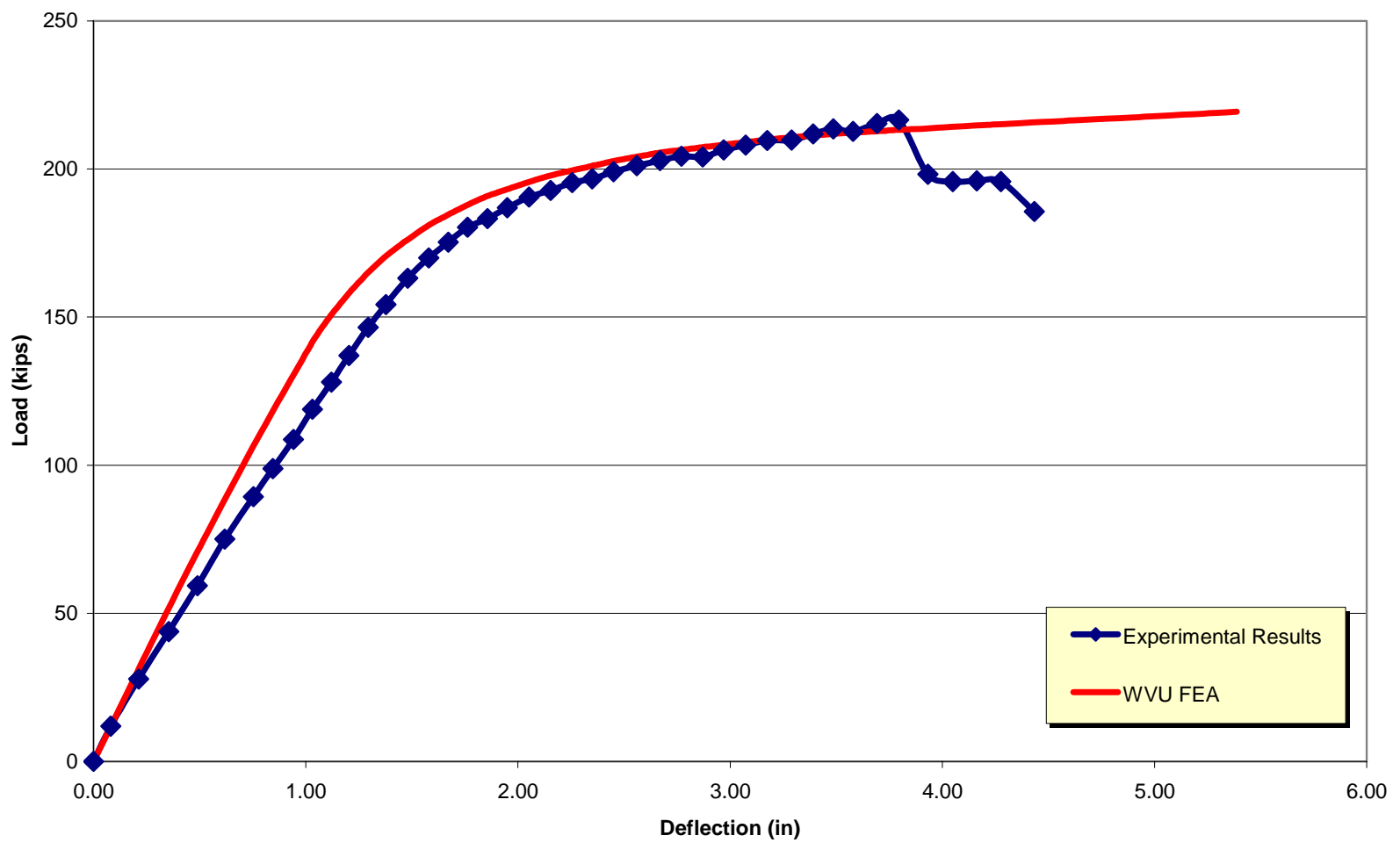

Figure 5.10 Load-deflection results for specimen PL1 


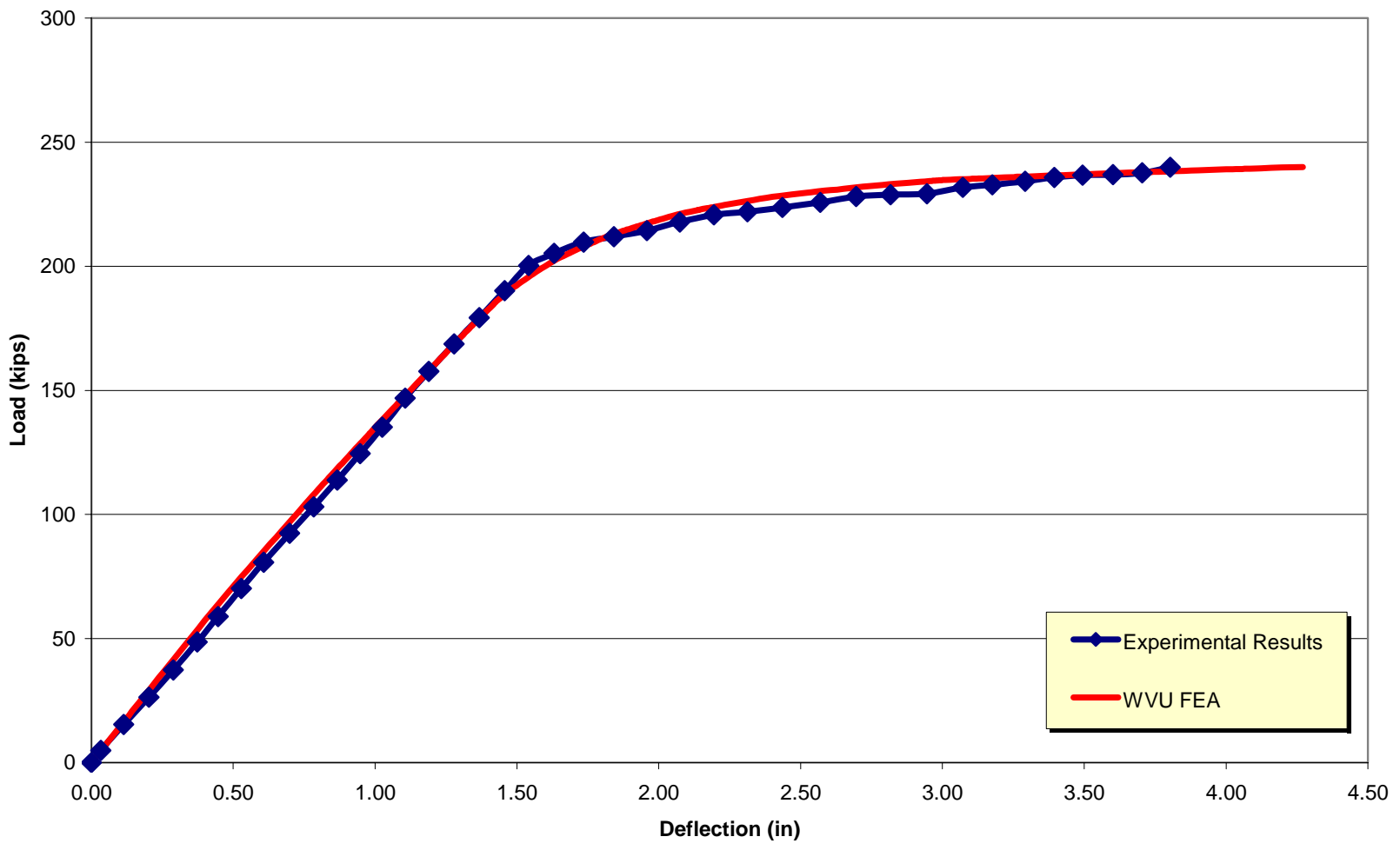

Figure 5.11 Load-deflection results for specimen PL2 


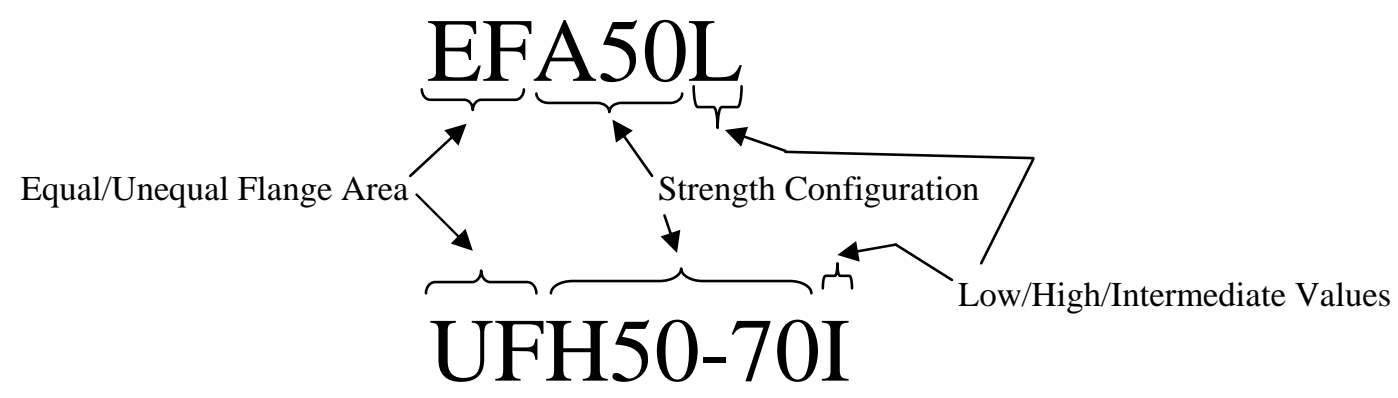

Figure 5.12 Naming convention 


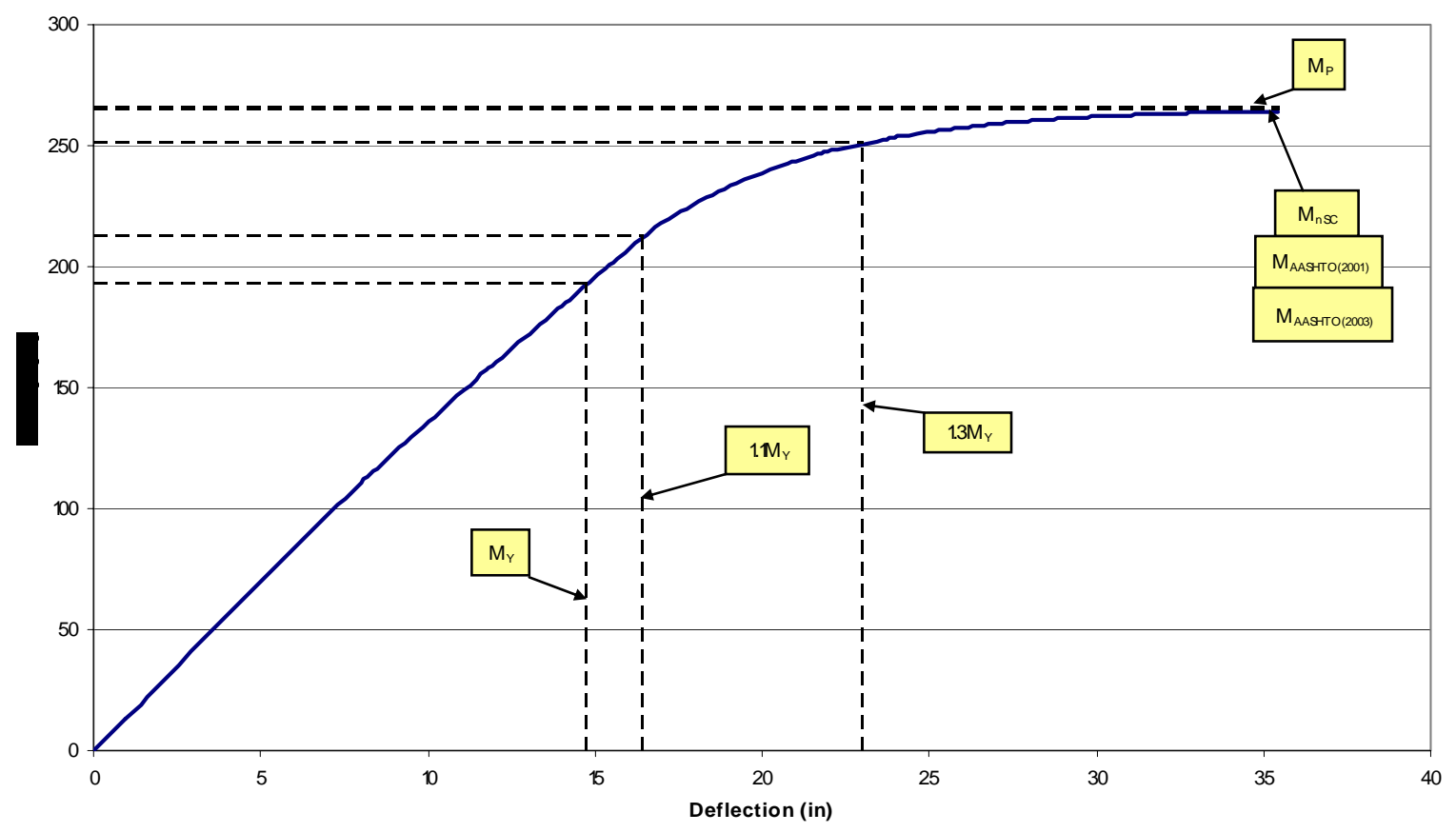

Figure 5.13 Midspan load-deflection plot - EFA50L

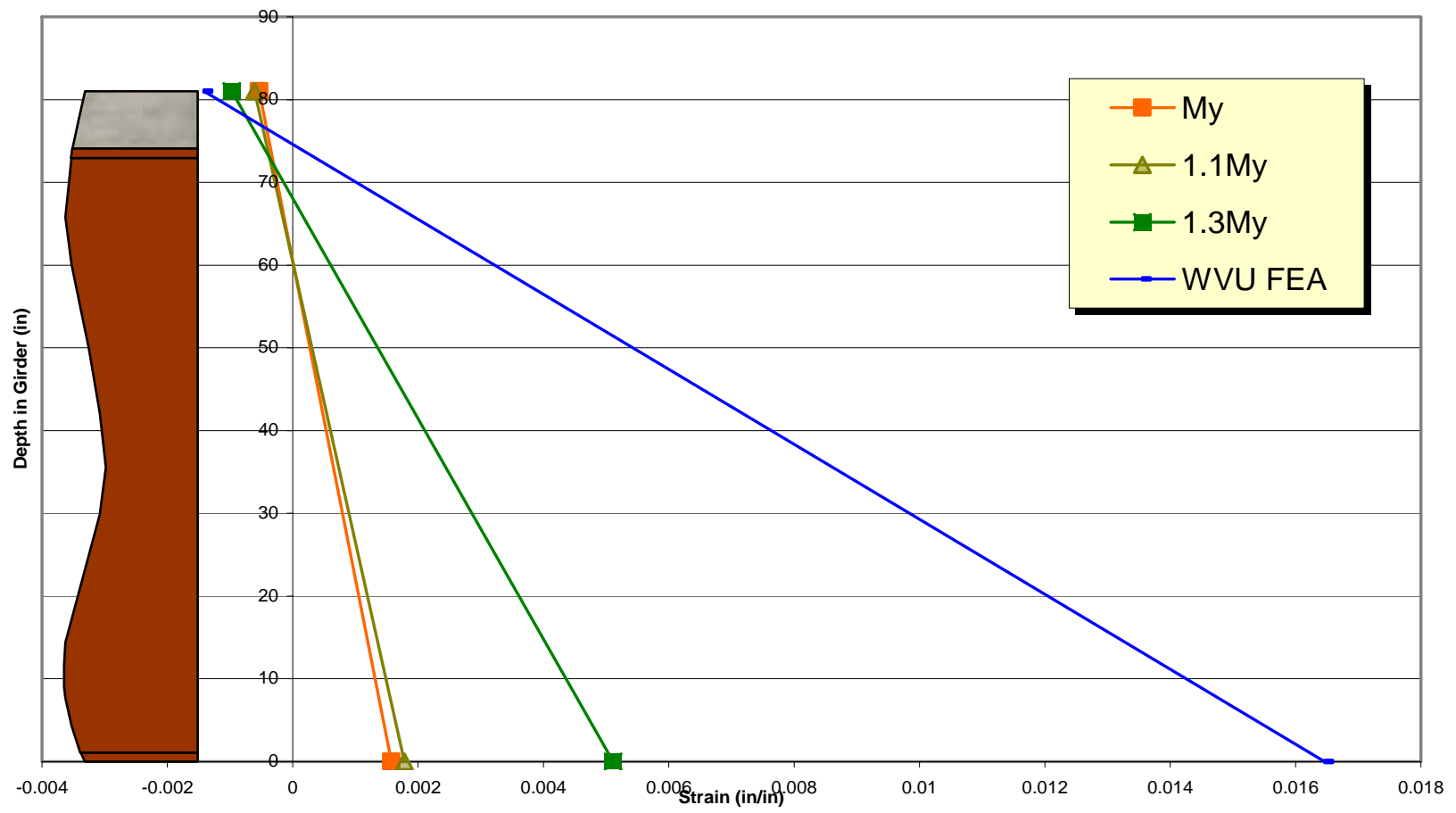

Figure 5.14 Midspan normal strain - EFA50L 


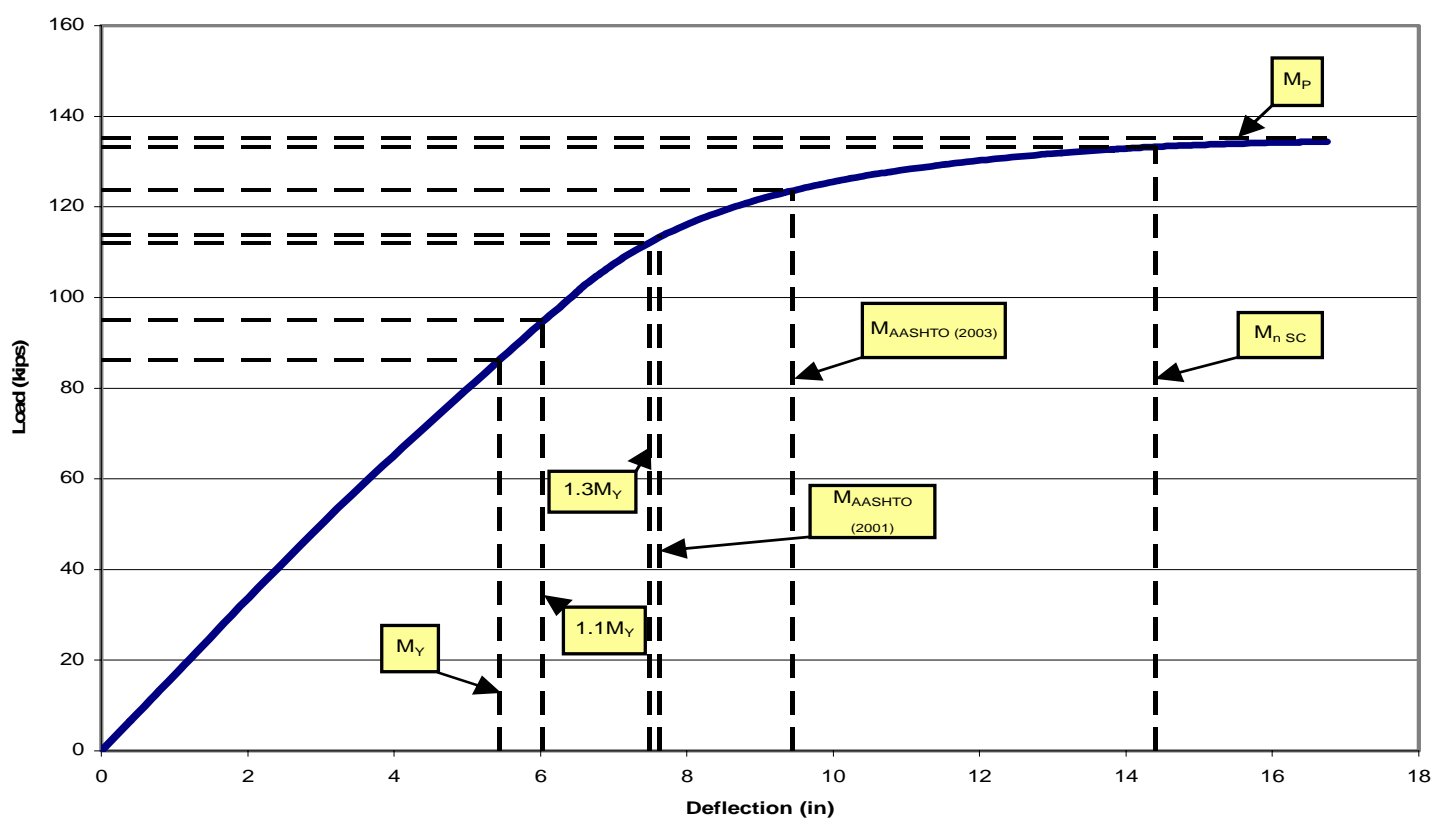

Figure 5.15 Midspan load-deflection plot - EFA50I

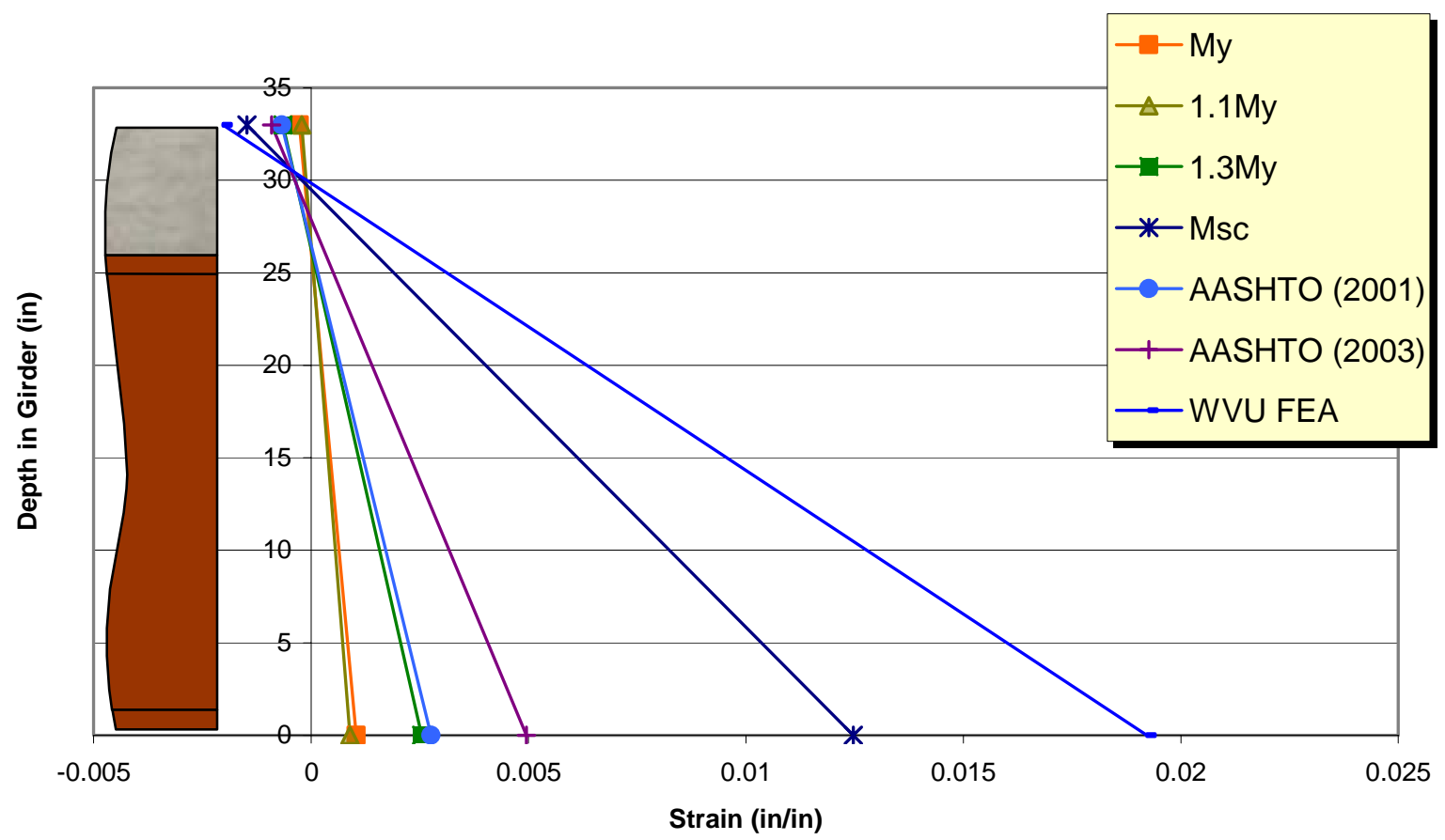

Figure 5.16 Midspan normal strain - EFA50I 


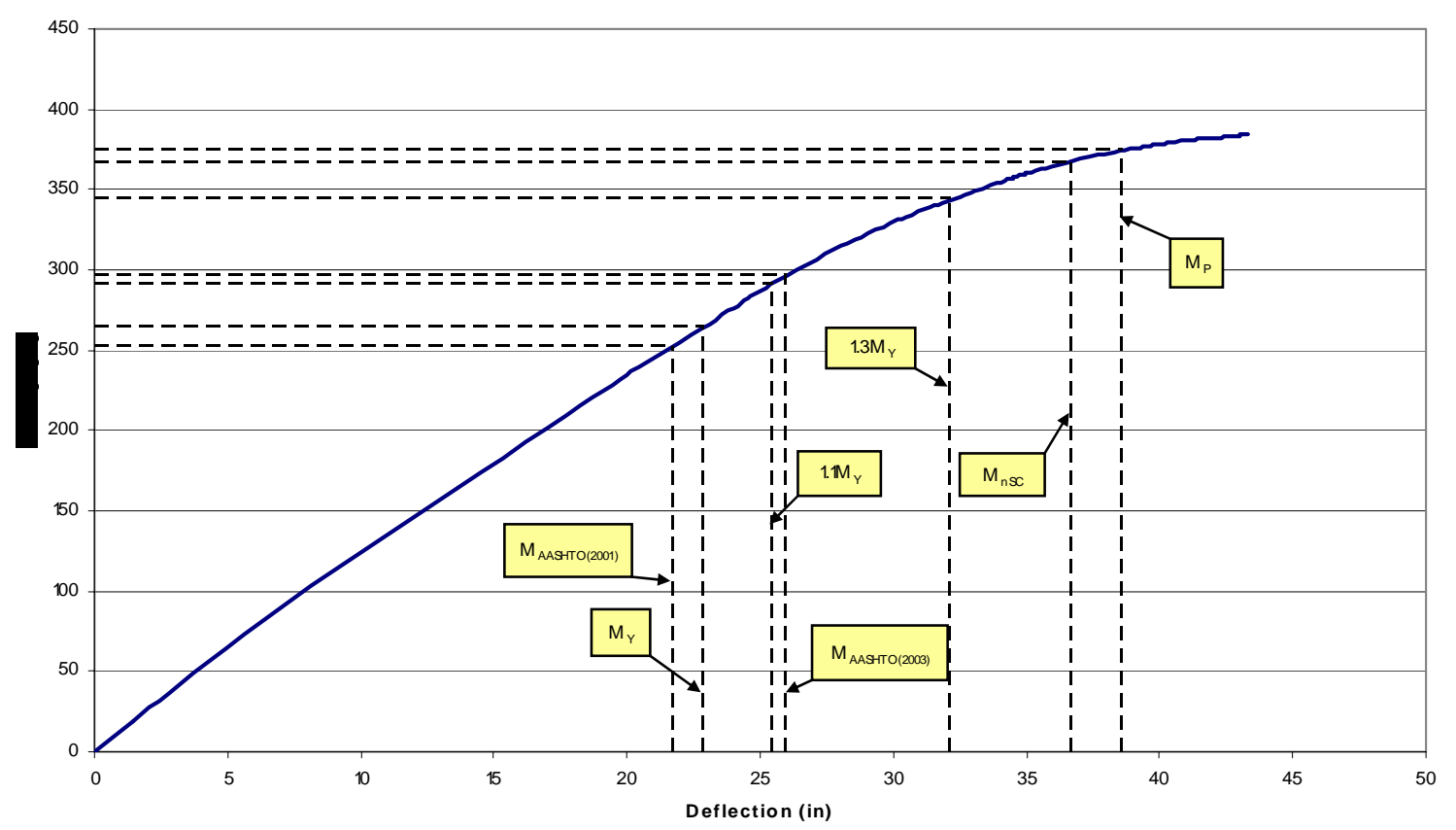

Figure 5.17 Midspan load-deflection plot - EFA50H

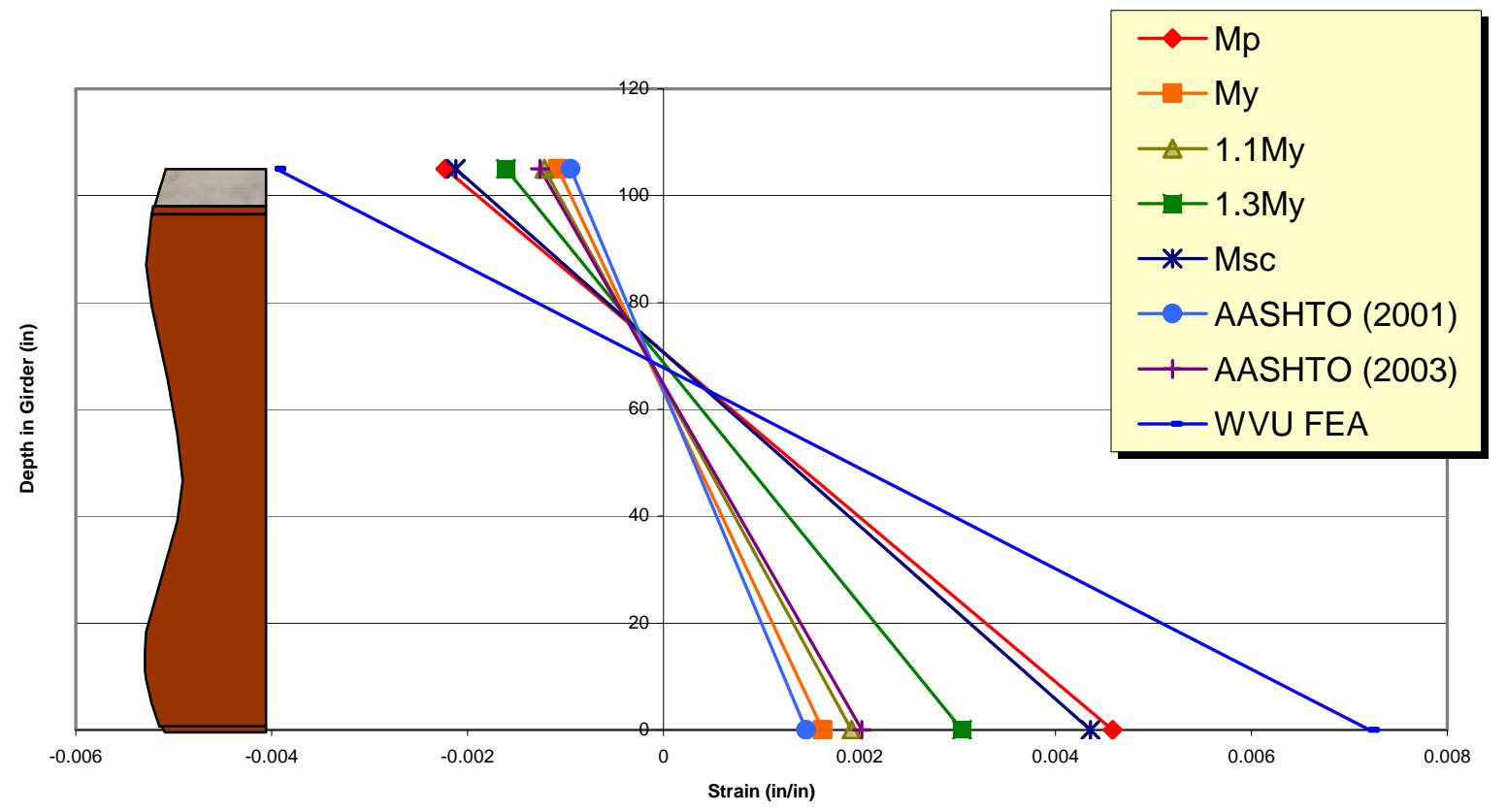

Figure 5.18 Midspan normal strain - EFA50H 


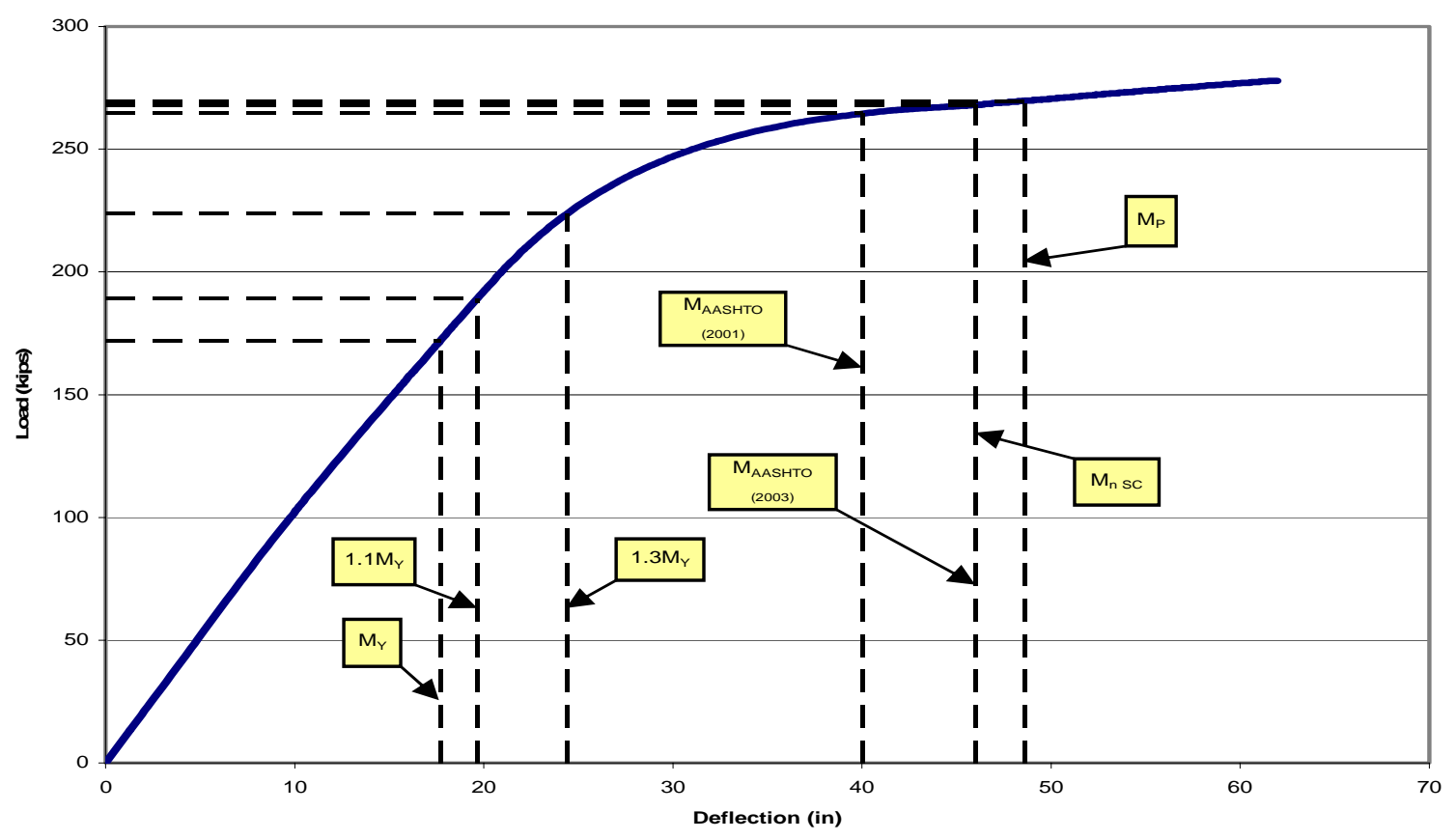

Figure 5.19 Midspan load deflection plot - EFA70L

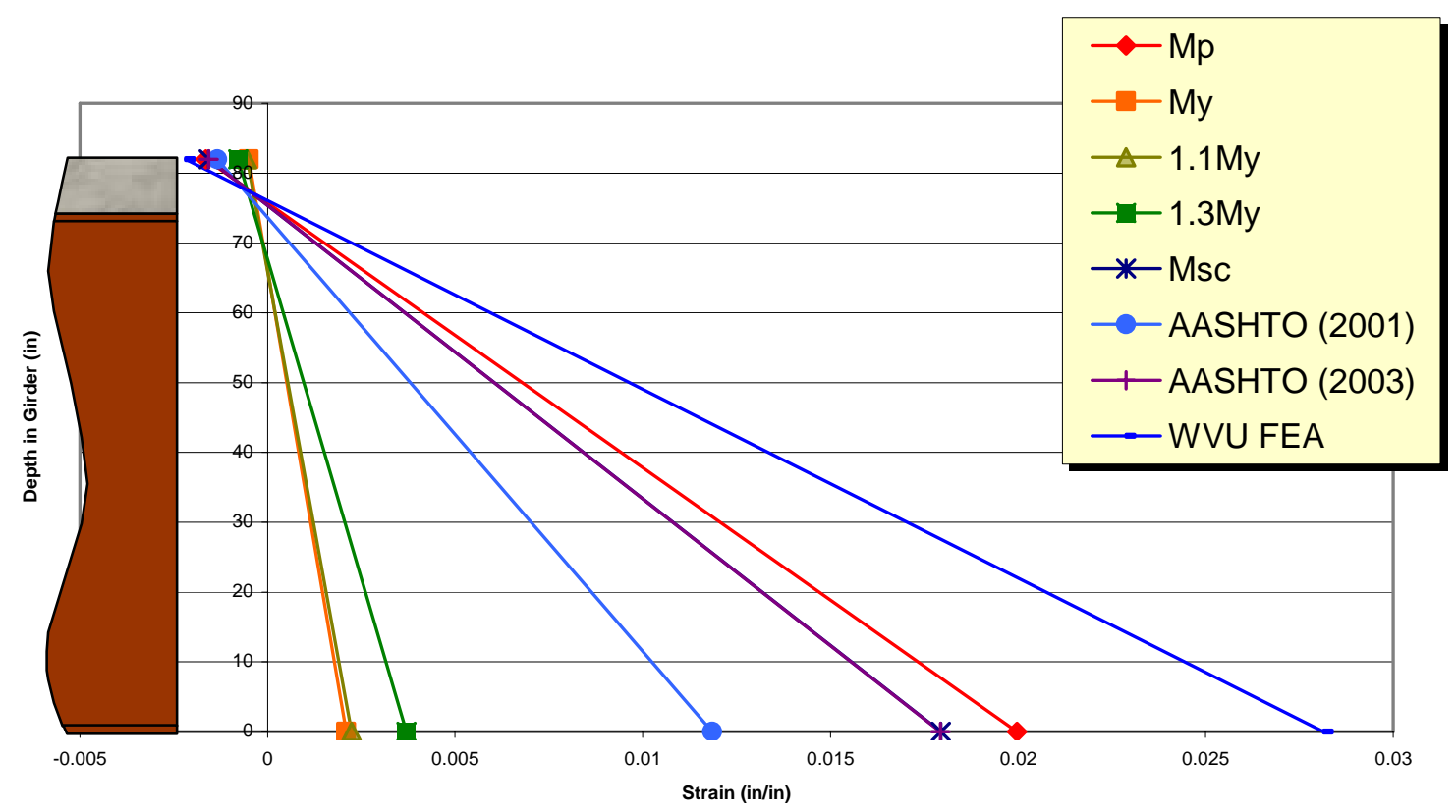

Figure 5.20 Midspan normal strain - EFA70L 


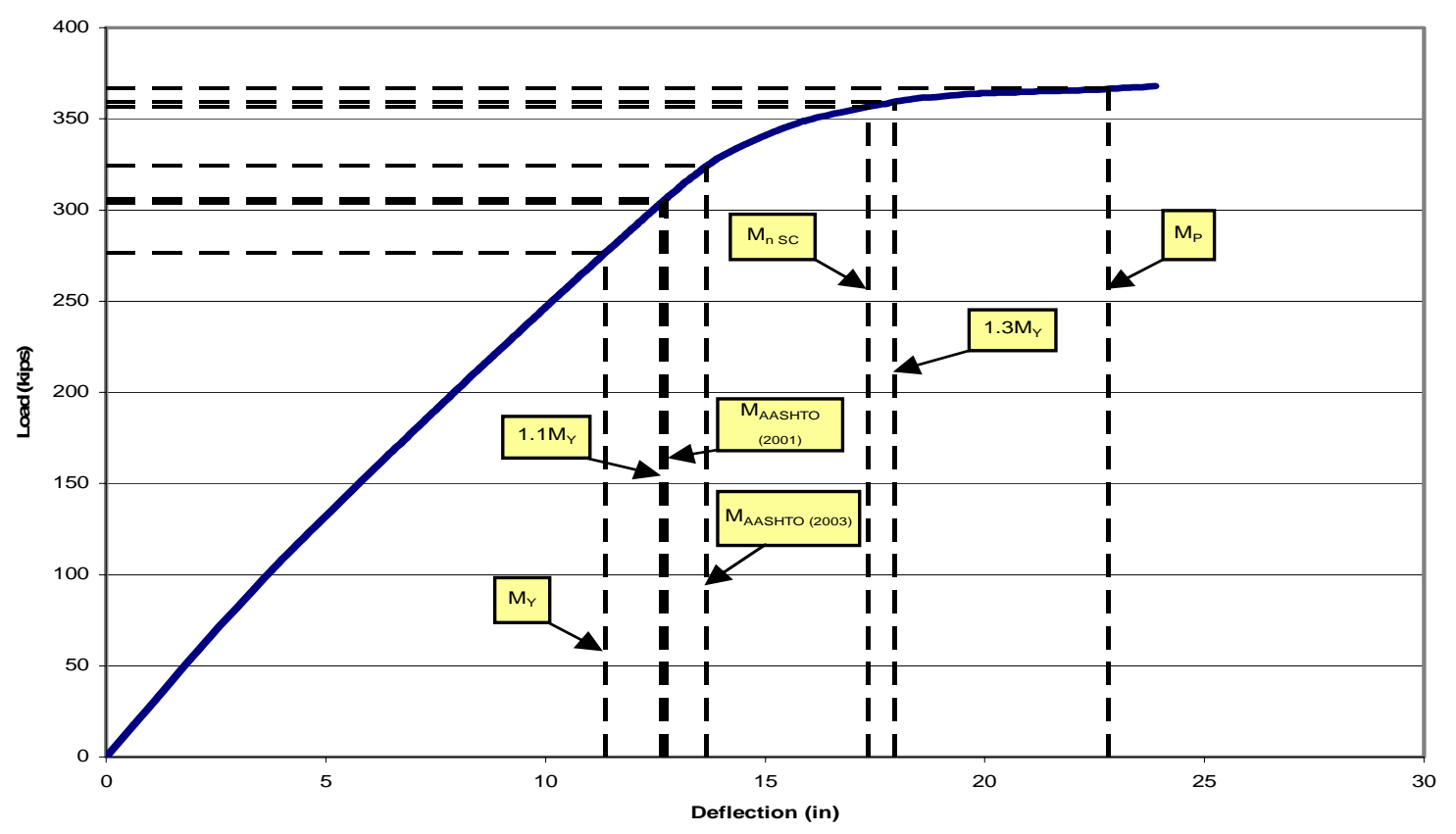

Figure 5.21 Midspan load-deflection plot EFA70I

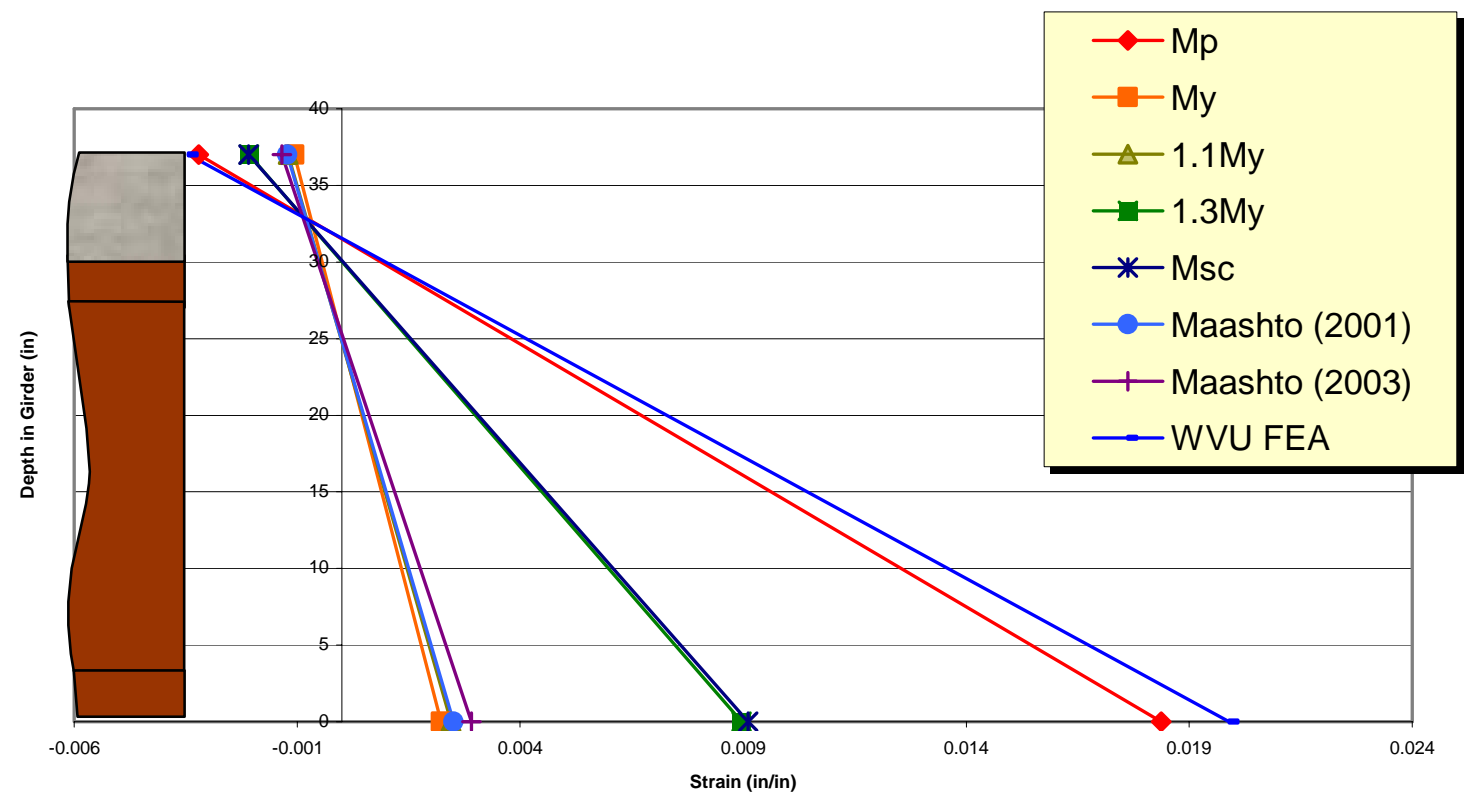

Figure 5.22 Midspan normal strain - EFA70I 


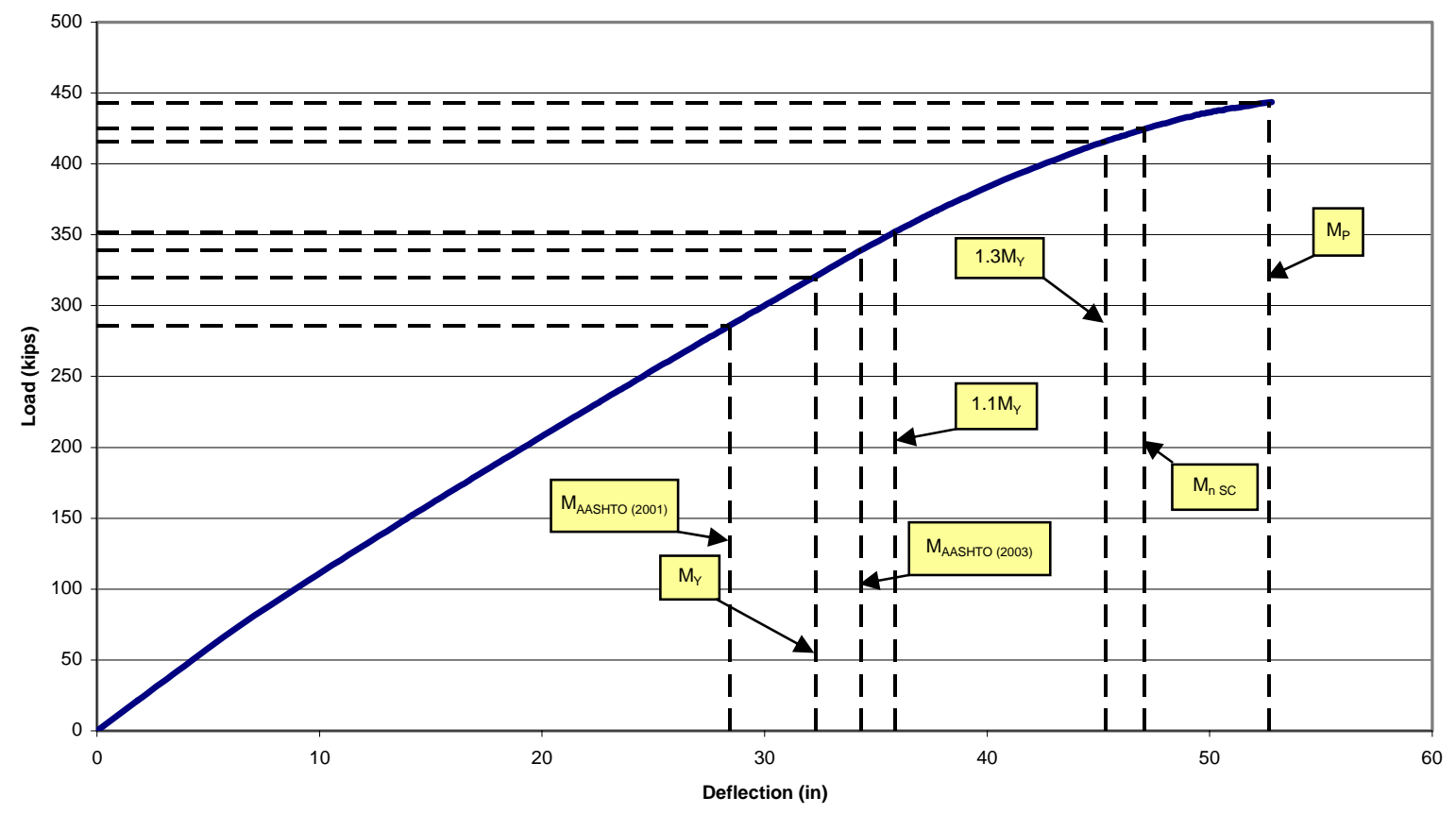

Figure 5.23 Midspan load-deflection plot - EFA70H

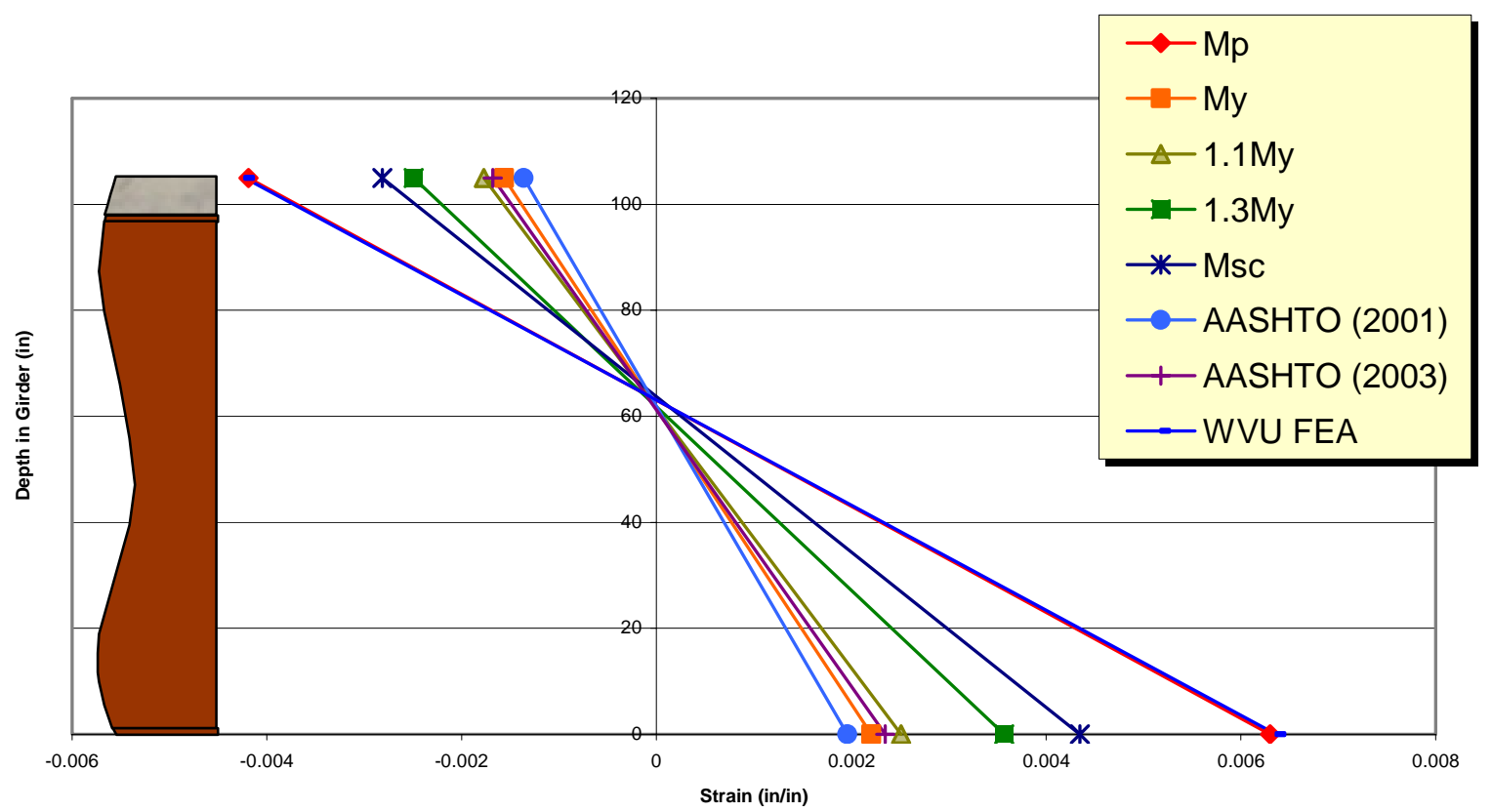

Figure 5.24 Midspan normal strain - EFA70H 


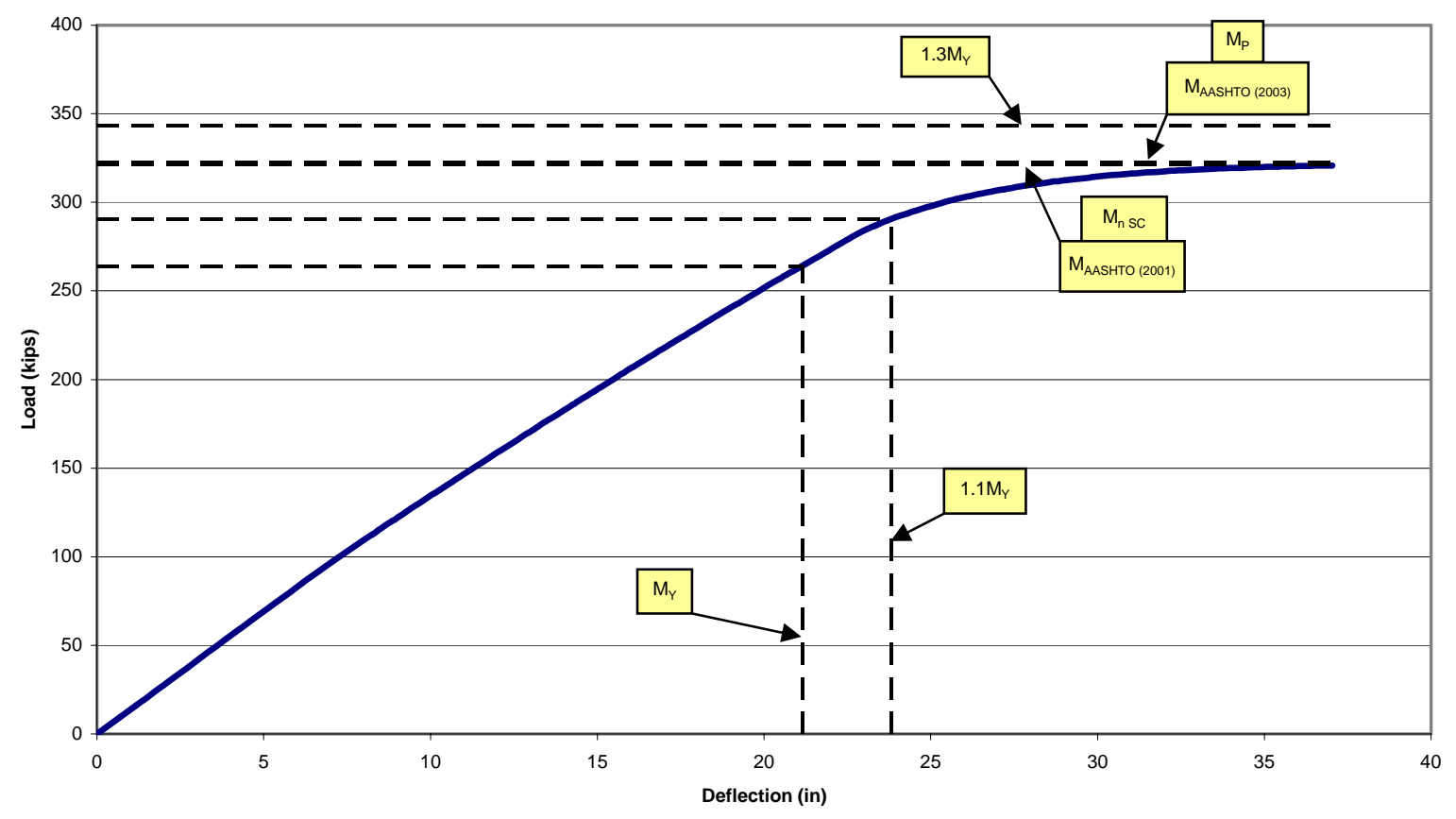

Figure 5.25 Midspan load-deflection plot - EFH50-70L

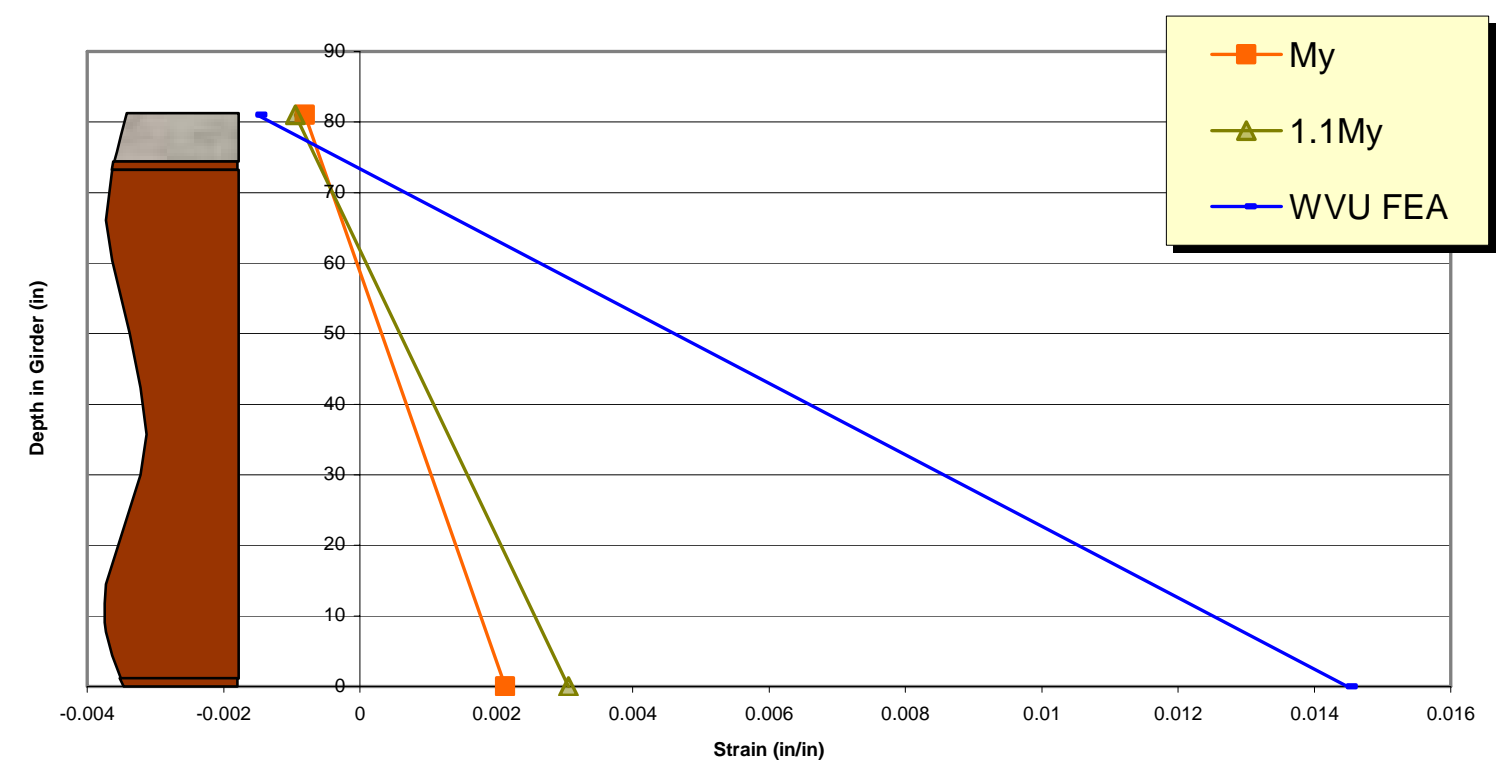

Figure 5.26 Midspan normal strain - EFH50-70L 


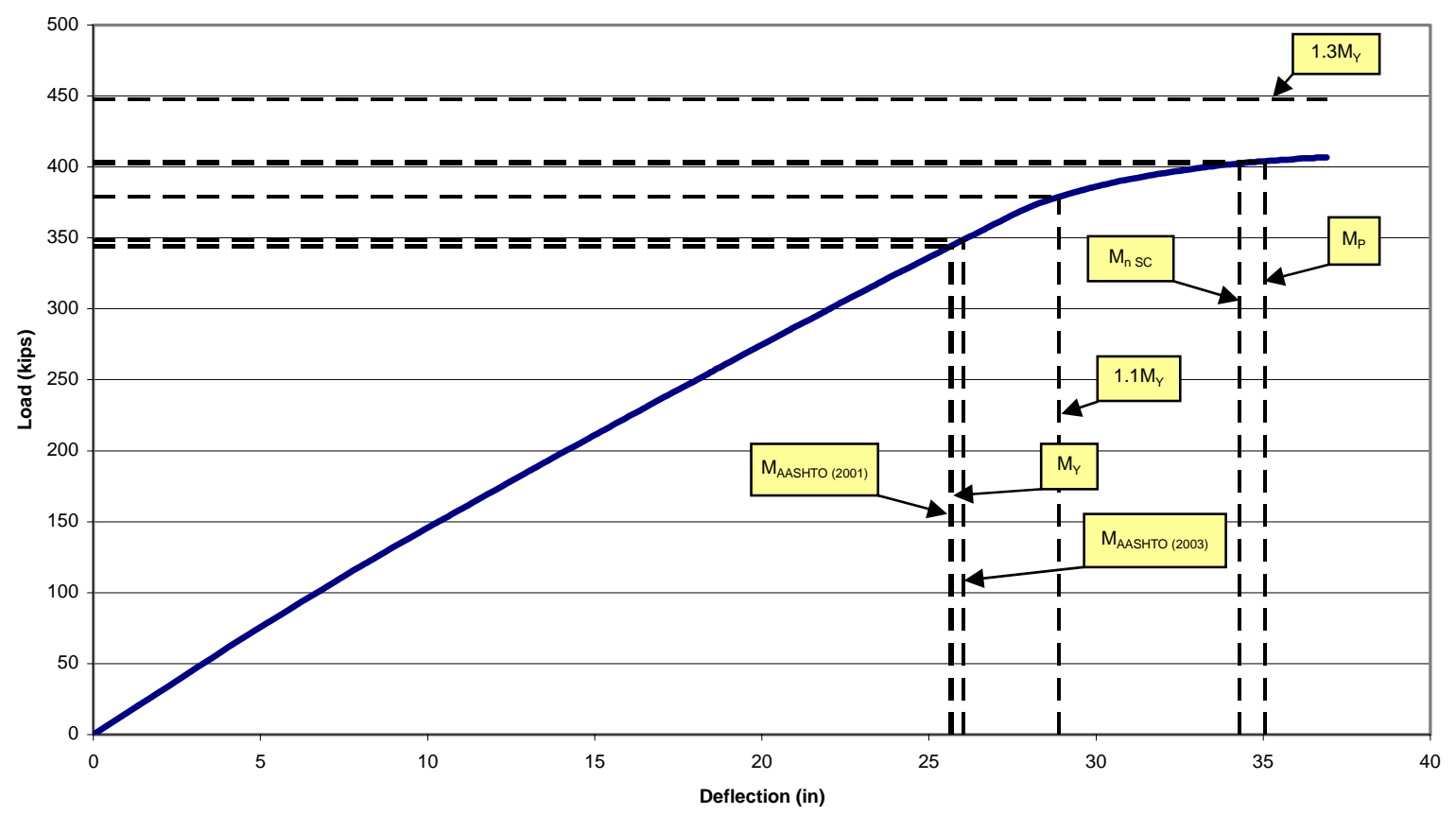

Figure 5.27 Midspan load-deflection plot - EFH50-70I

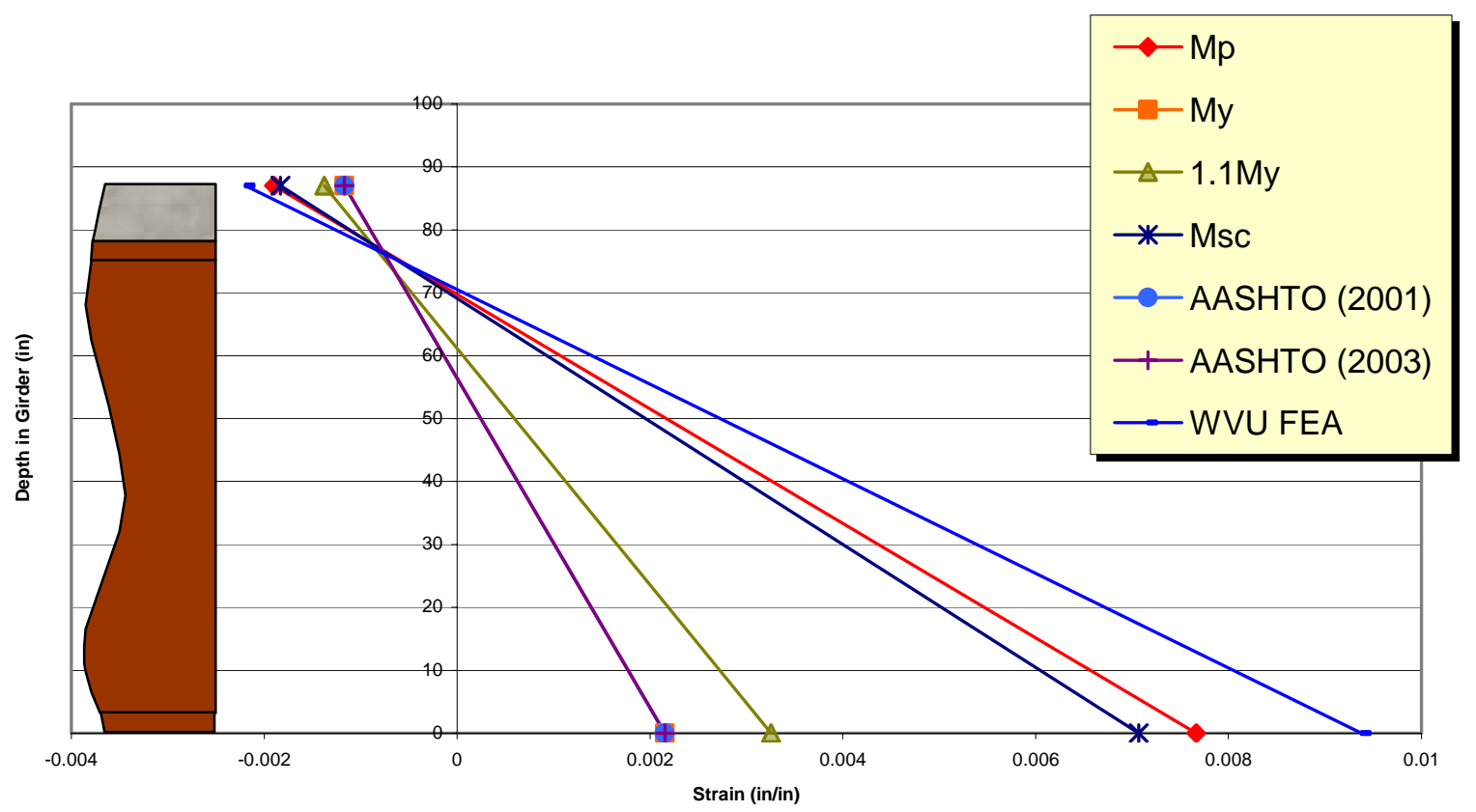

Figure 5.28 Midspan normal strain - EFH50-70I 


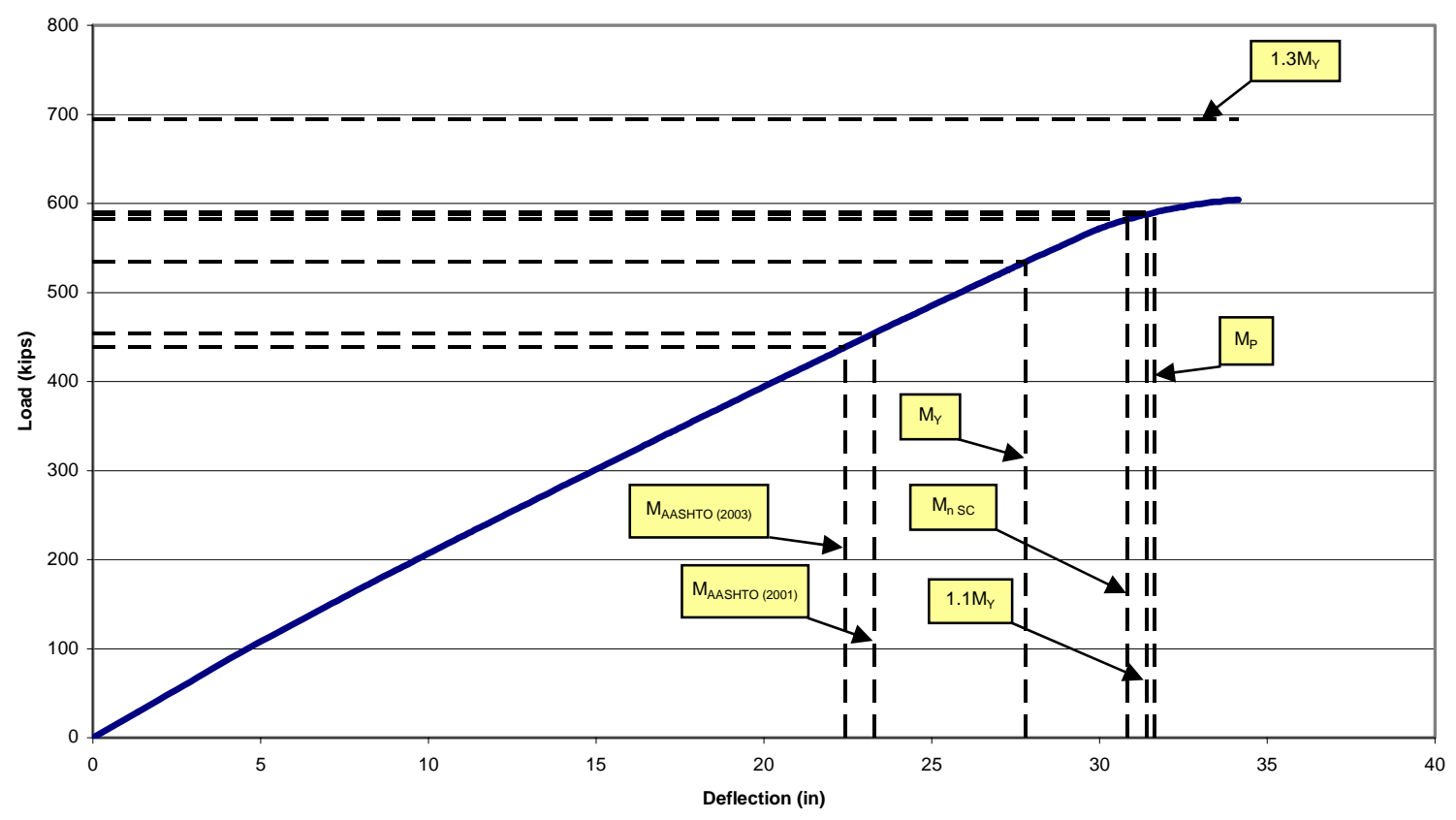

Figure 5.29 Midspan load-deflection plot - EFH50-70H

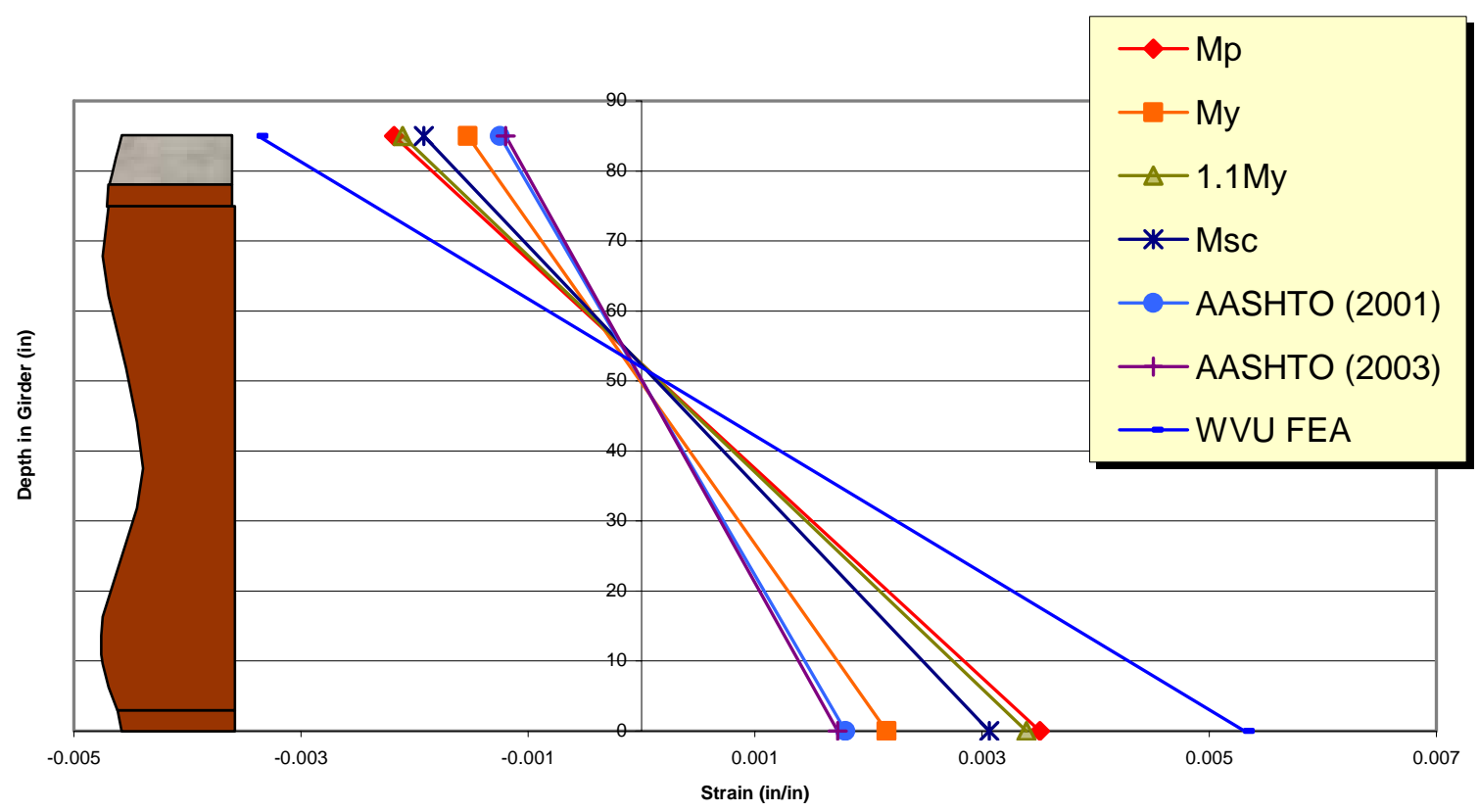

Figure 5.30 Midspan normal strain - EFH50-70H 


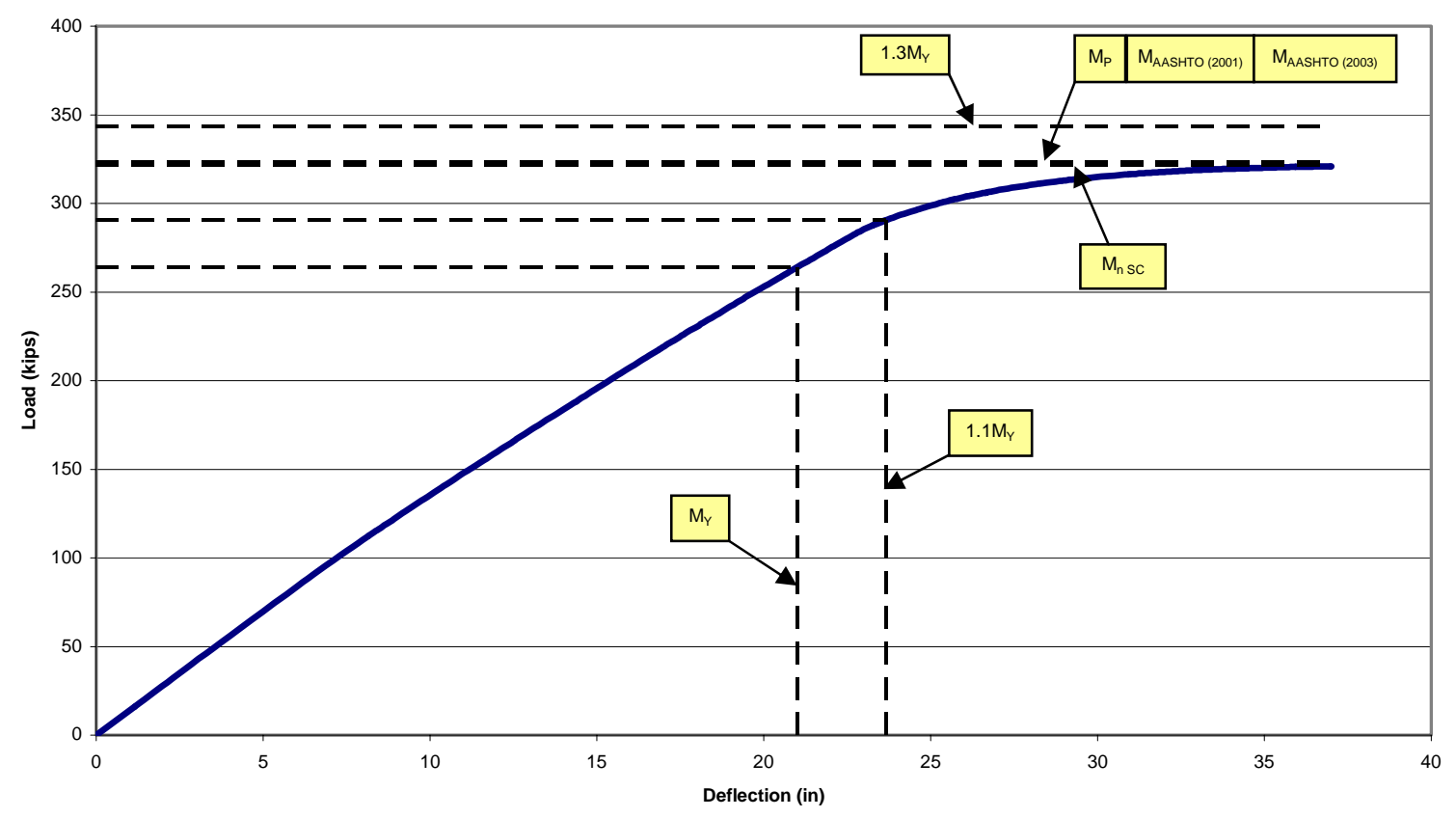

Figure 5.31 Midspan load-deflection plot - EFH70-70L

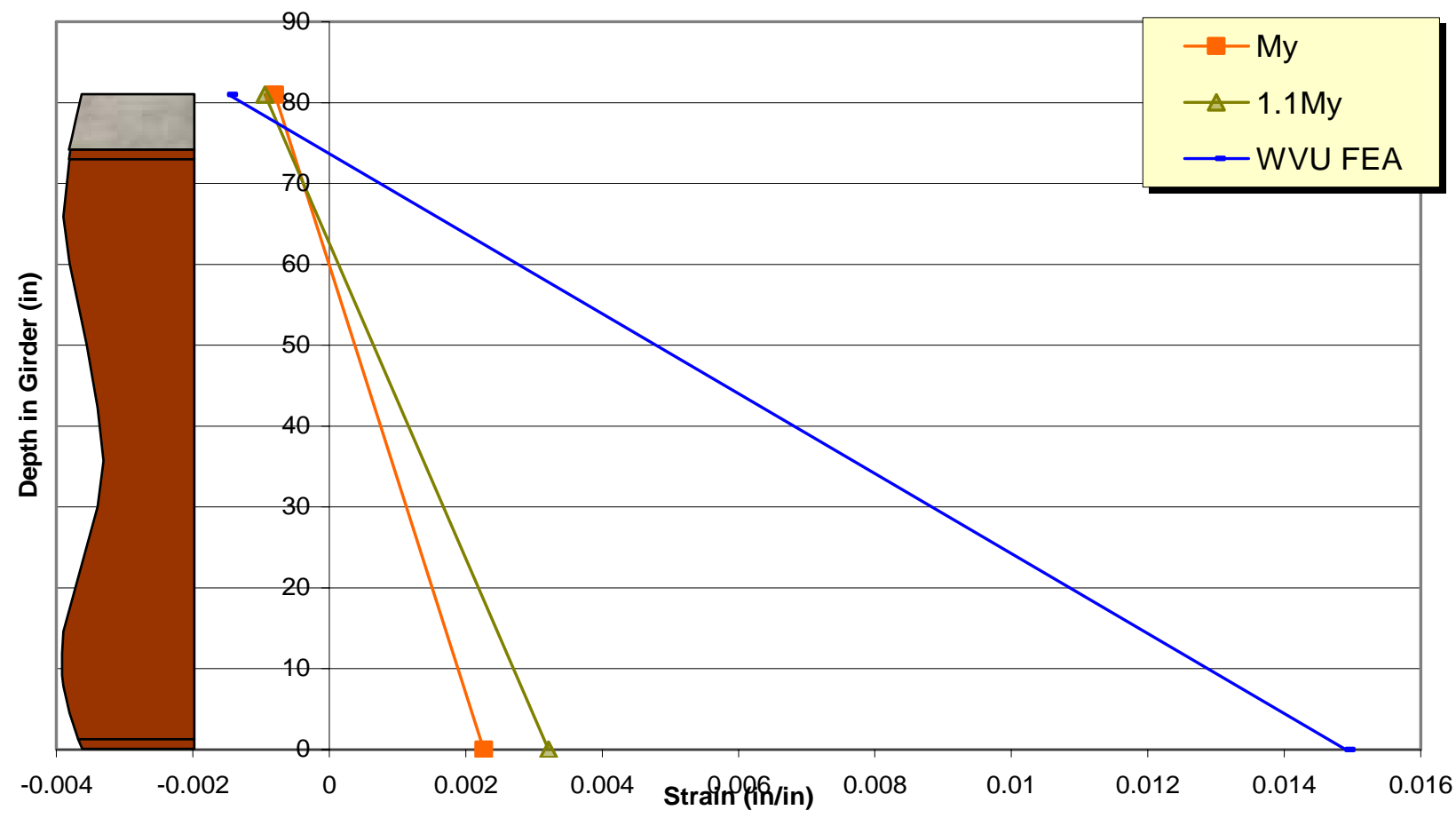

Figure 5.32 Midspan normal strain - EFH70-70L 


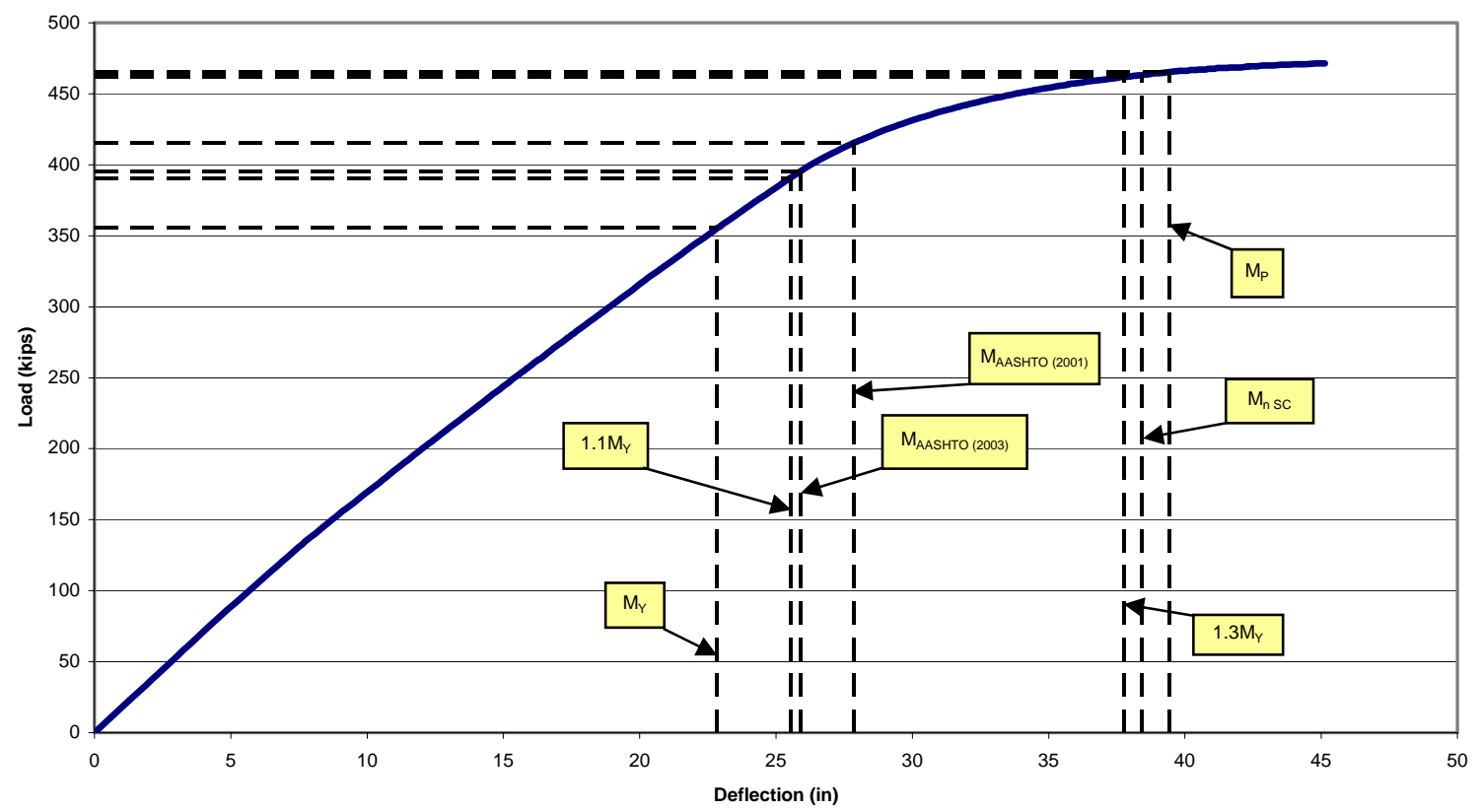

Figure 5.33 Midspan load-deflection plot - EFH70-70I

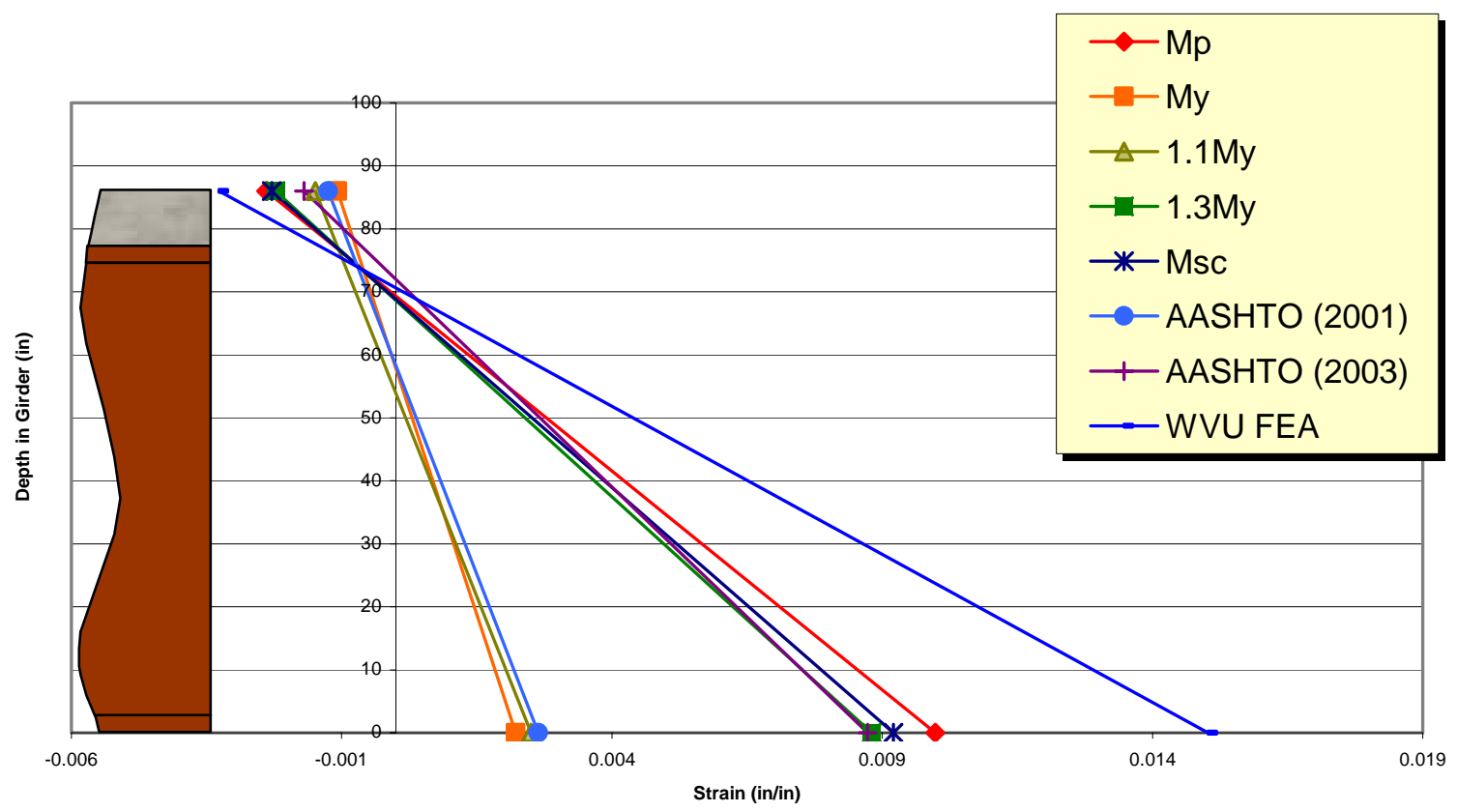

Figure 5.34 Midspan normal strain - EFH70-70I 


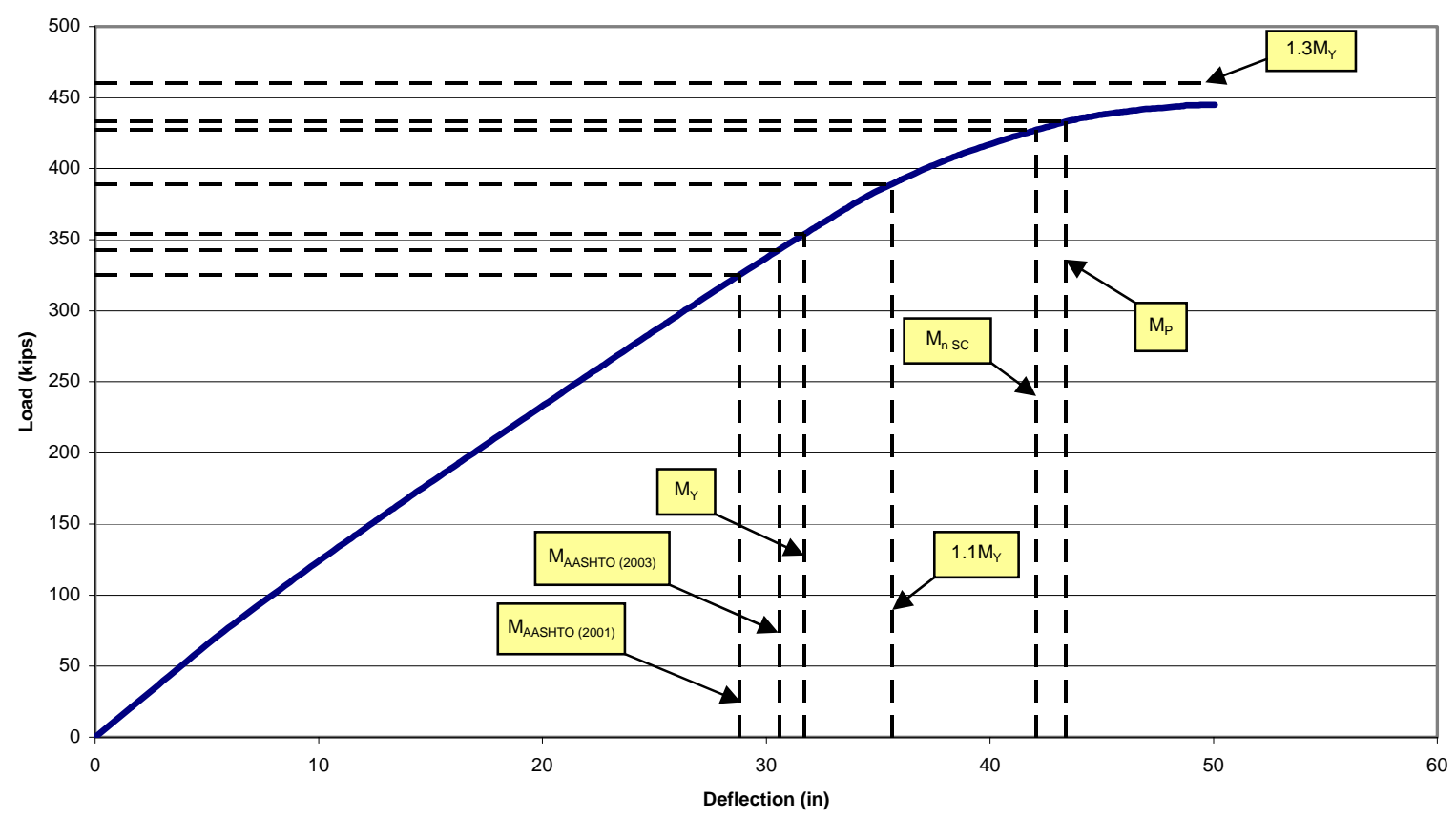

Figure 5.35 Midspan load-deflection plot - EFH70-70H

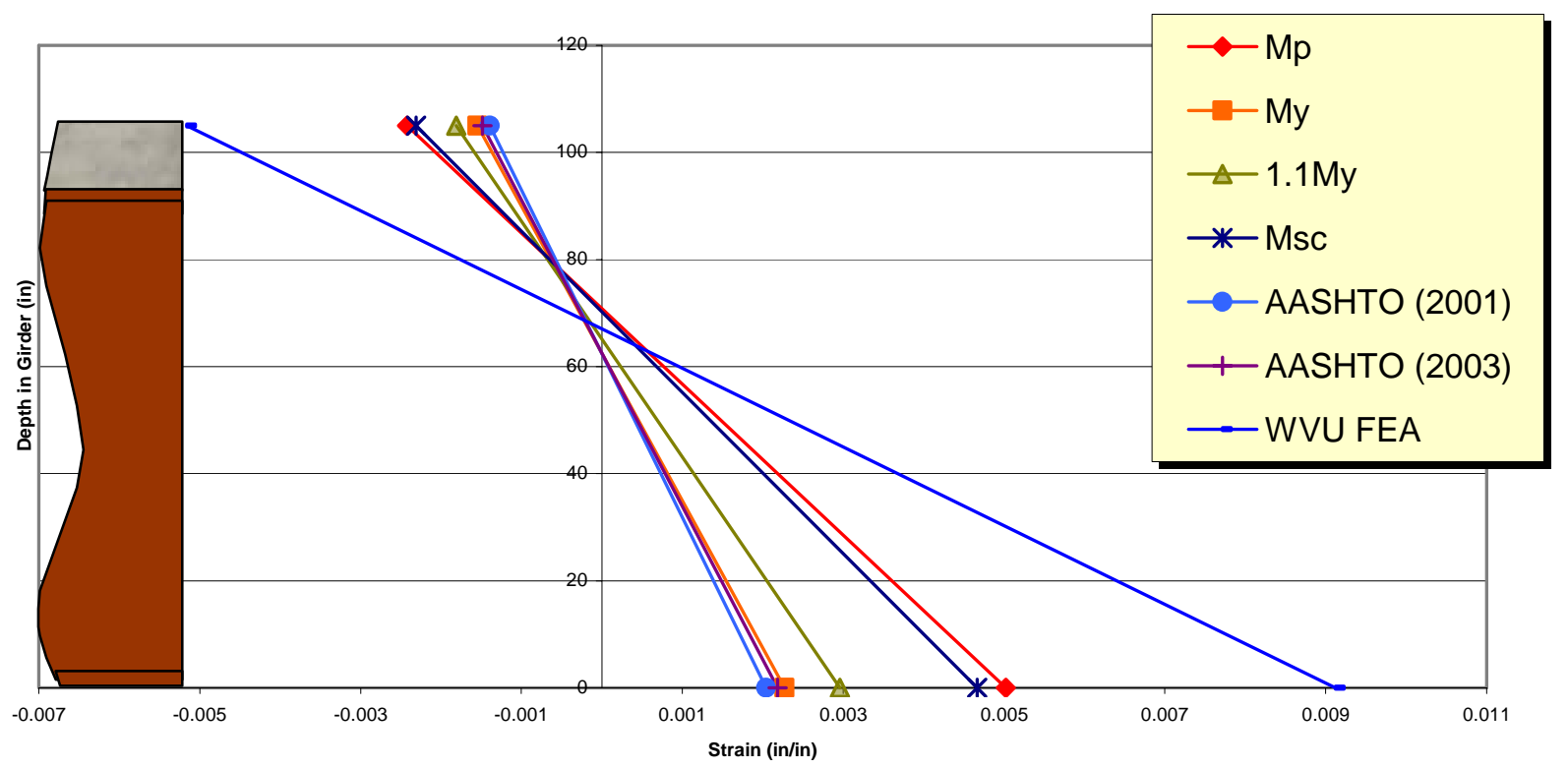

Figure 5.36 Midspan normal strain - EFH70-70H 


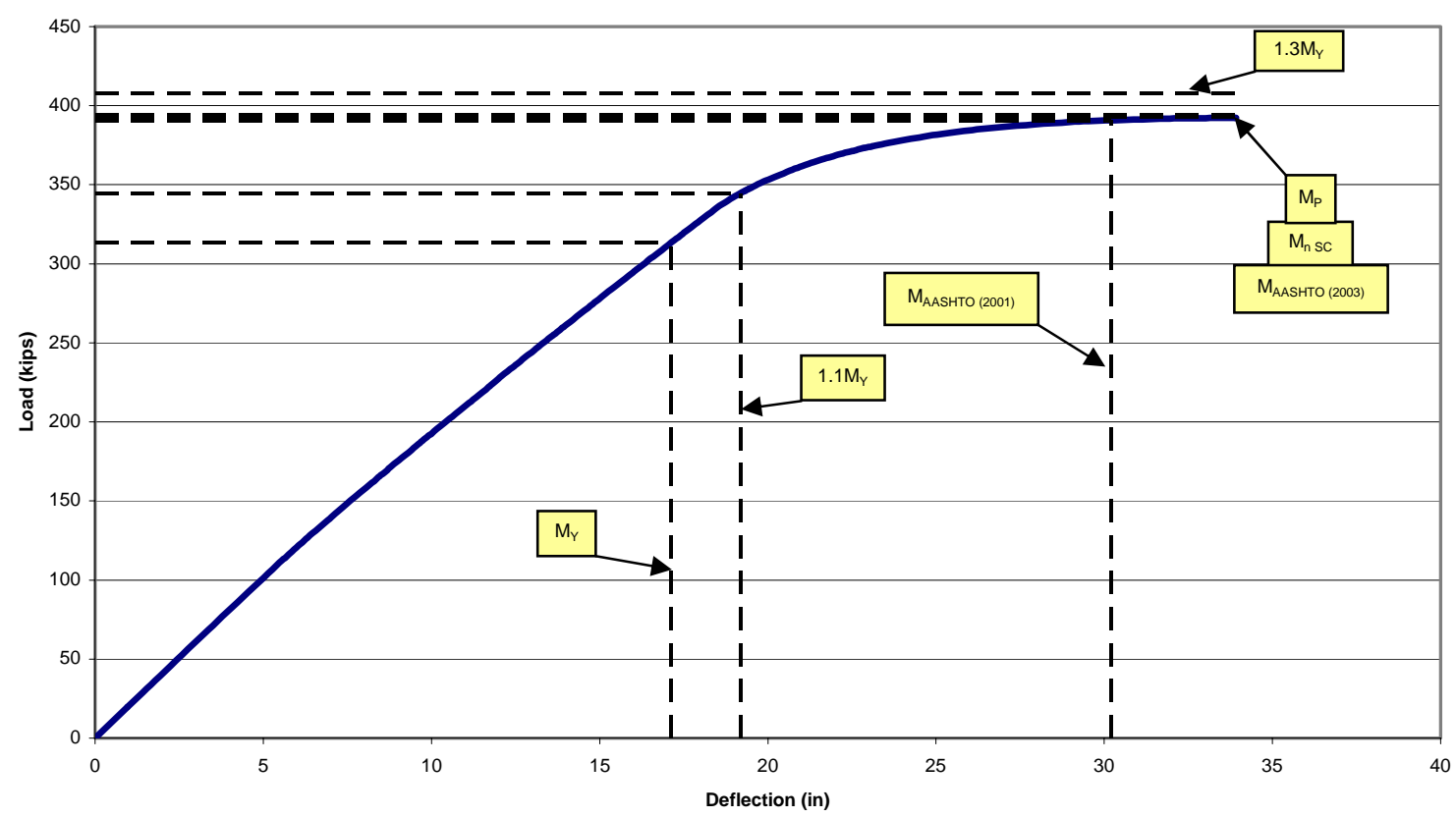

Figure 5.37 Midspan load-deflection Plot - UFA50L

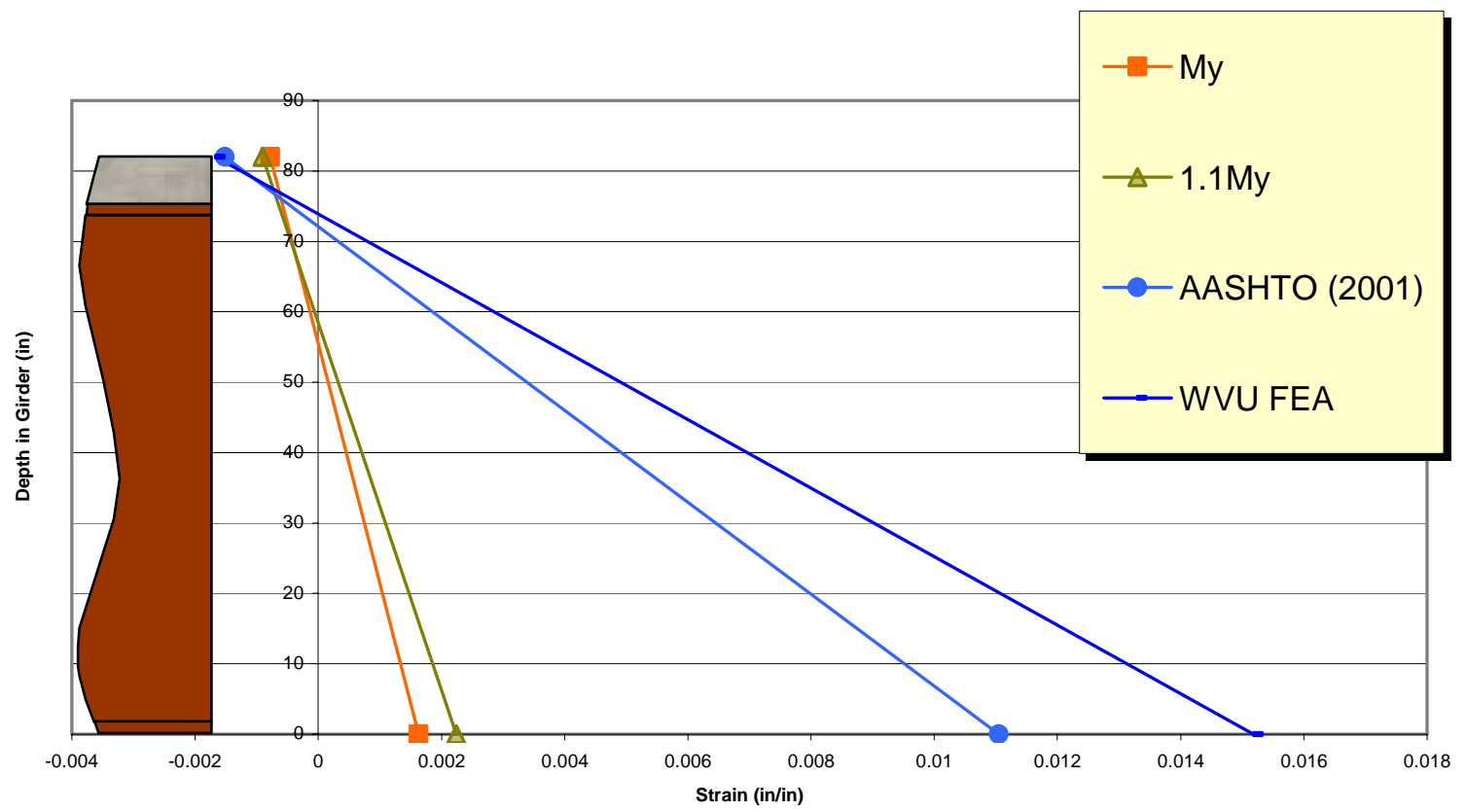

Figure 5.38 Midspan normal strain - UFA50L 


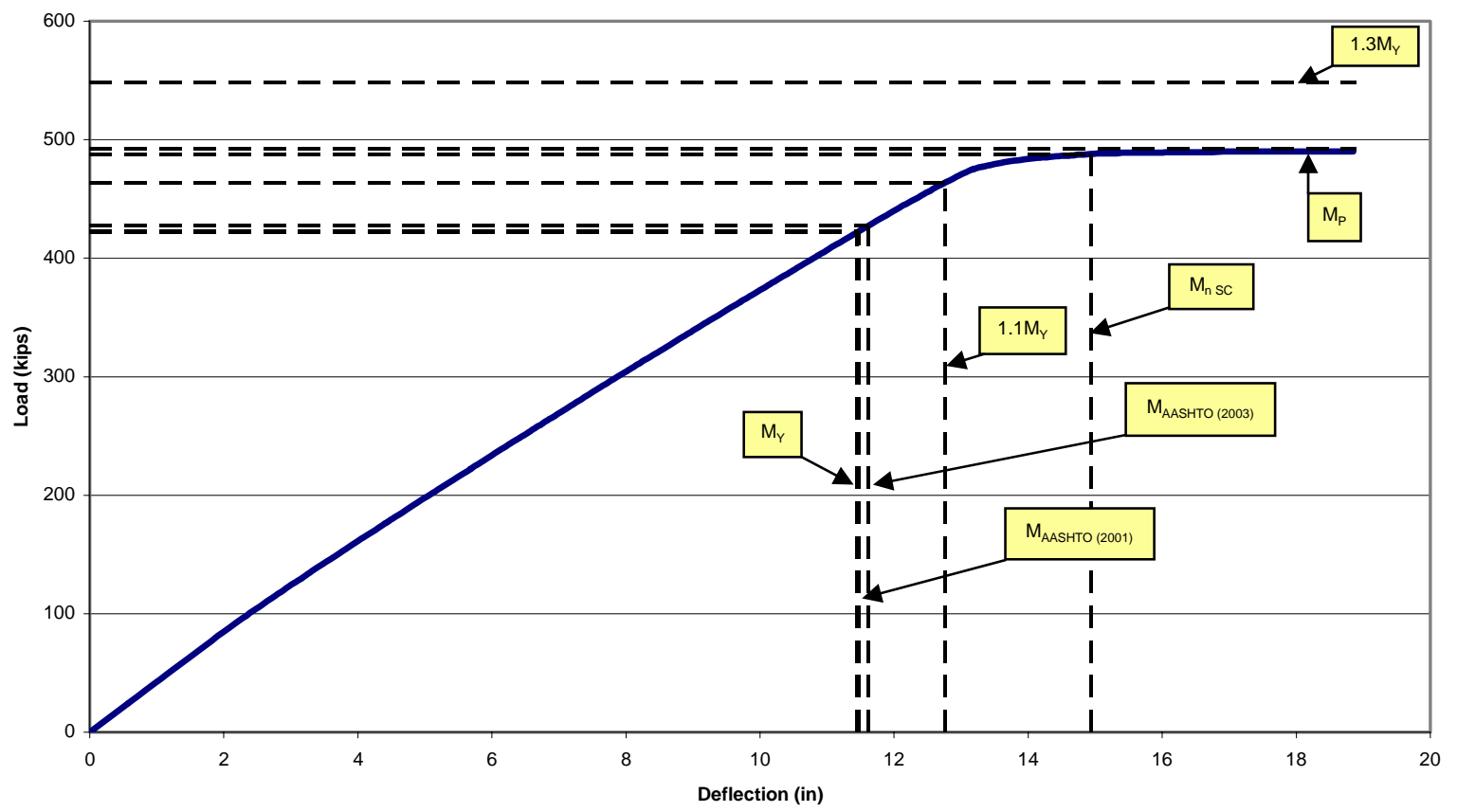

Figure 5.39 Midspan load-deflection plot - UFA50I

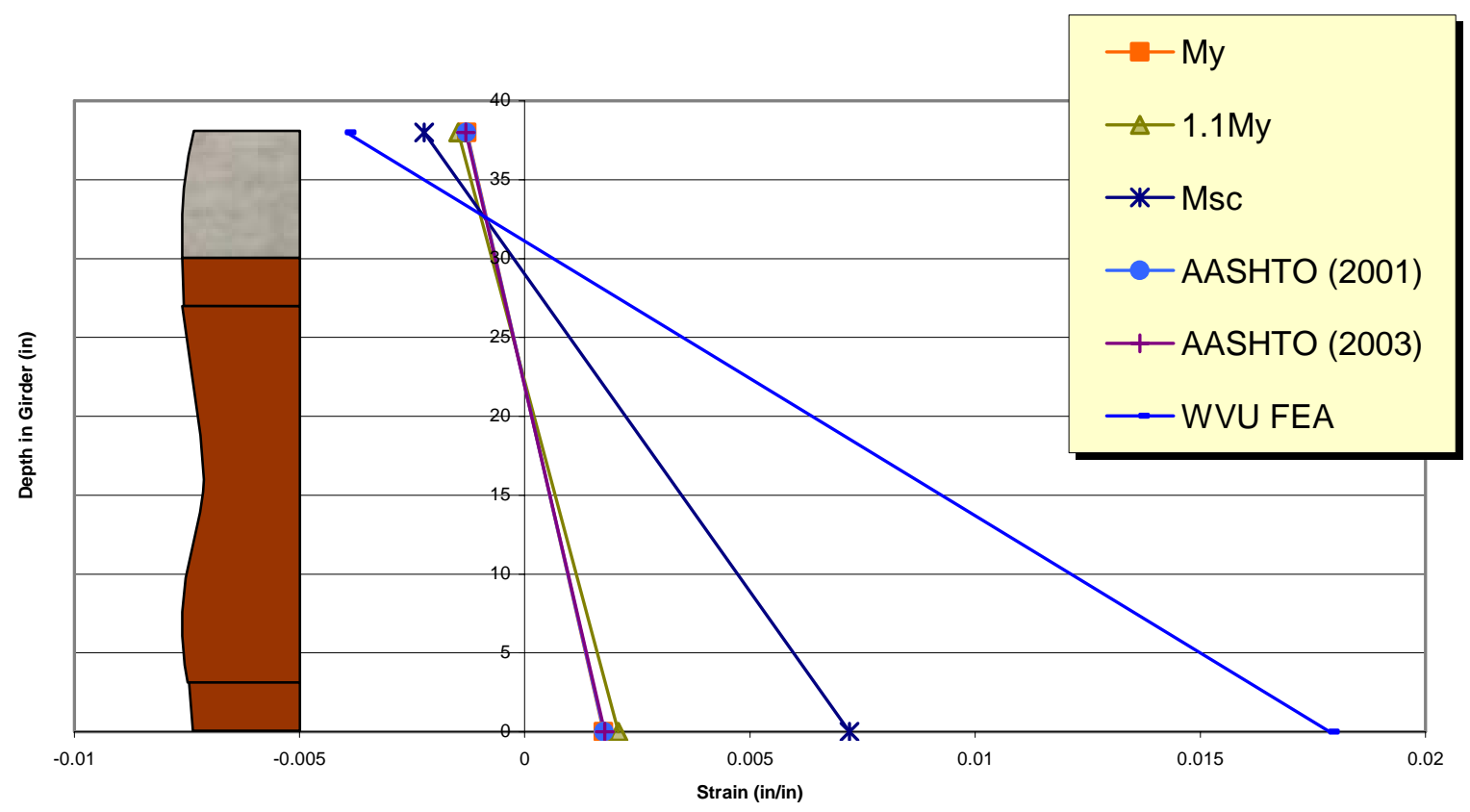

Figure 5.40 Midspan normal strain - UFA50I 


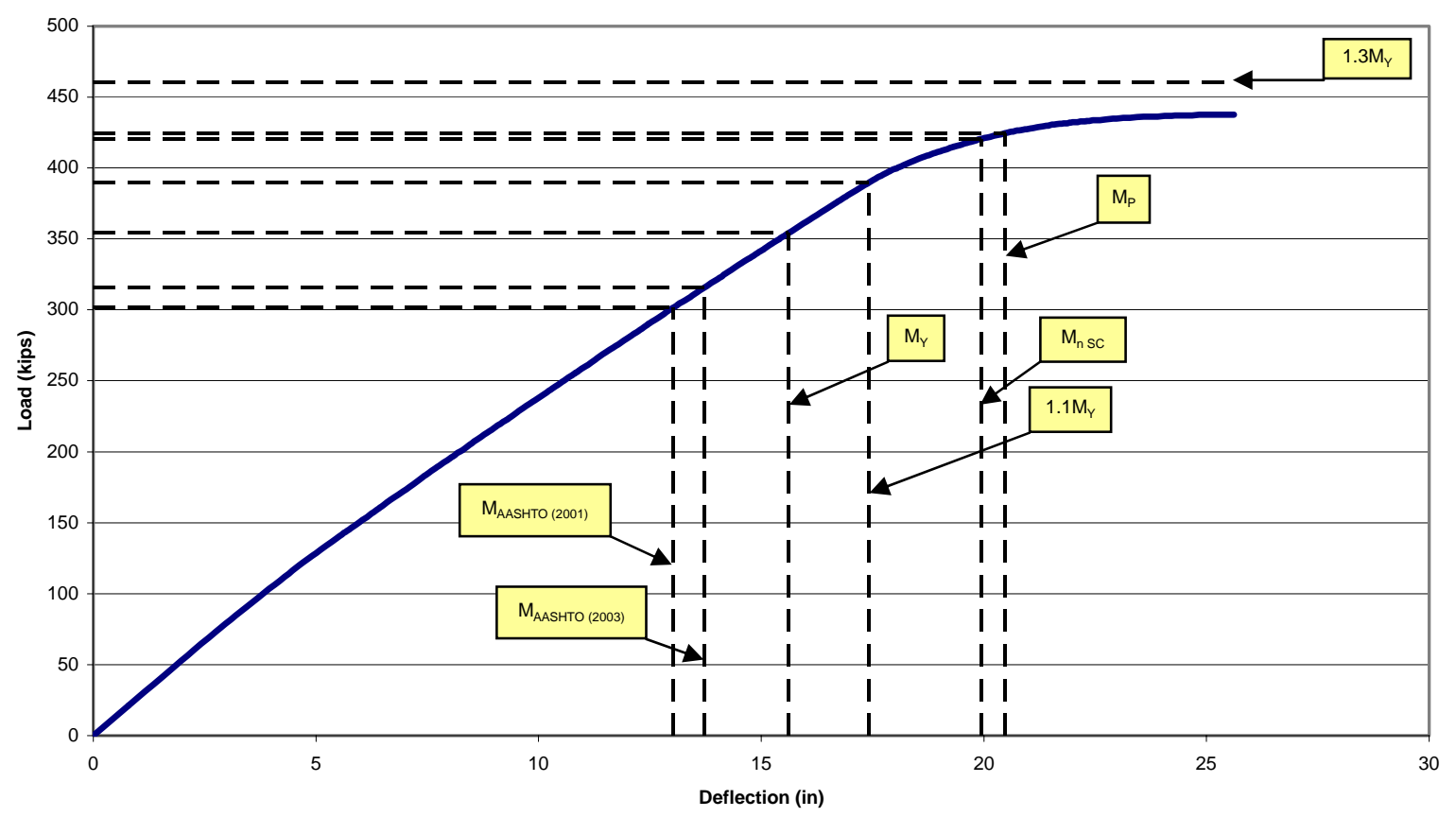

Figure 5.41 Midspan load-deflection plot - UFA50H

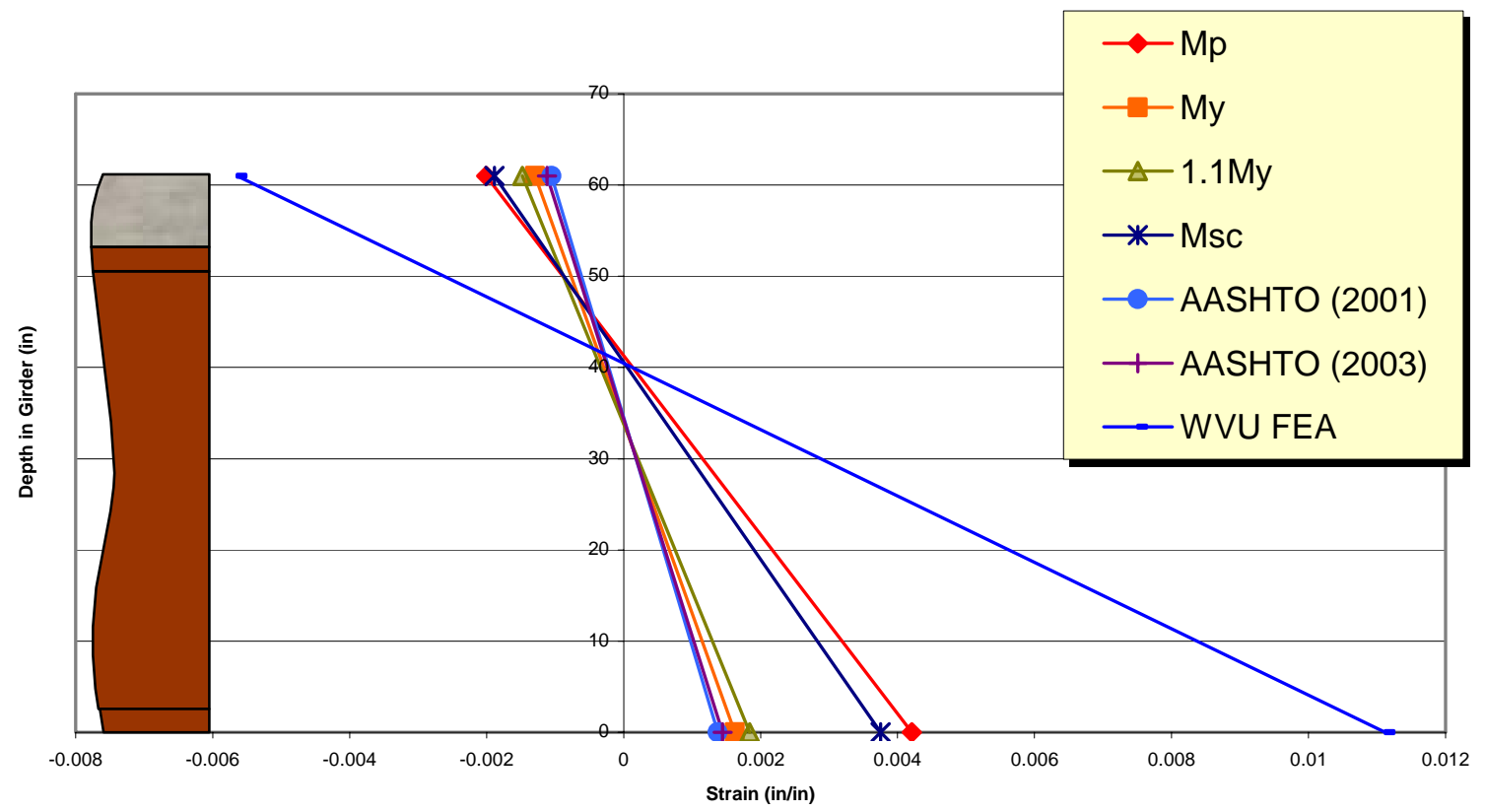

Figure 5.42 Midspan normal strain - UFA50H 


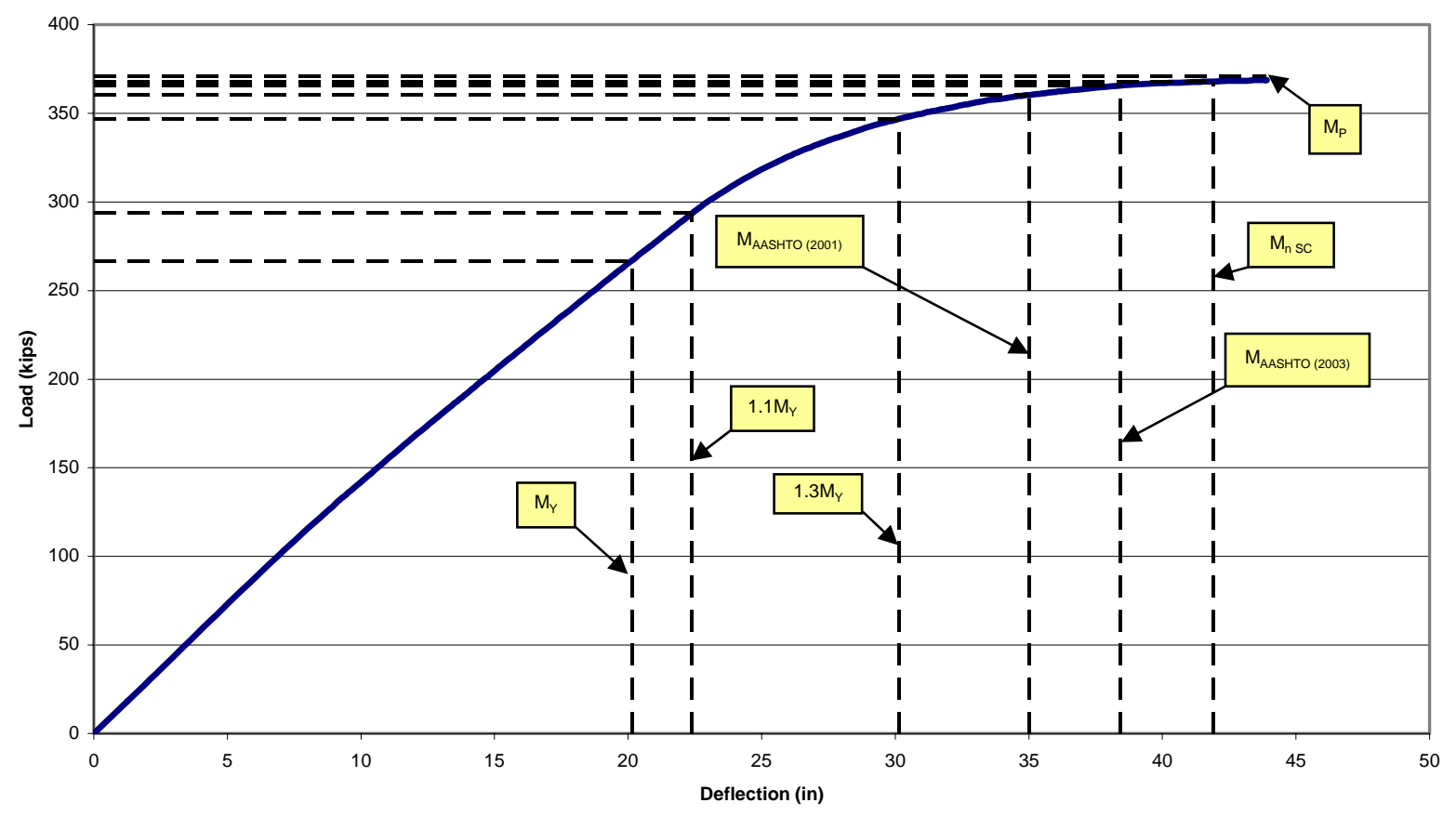

Figure 5.43 Midspan load-deflection plot - UFA70L

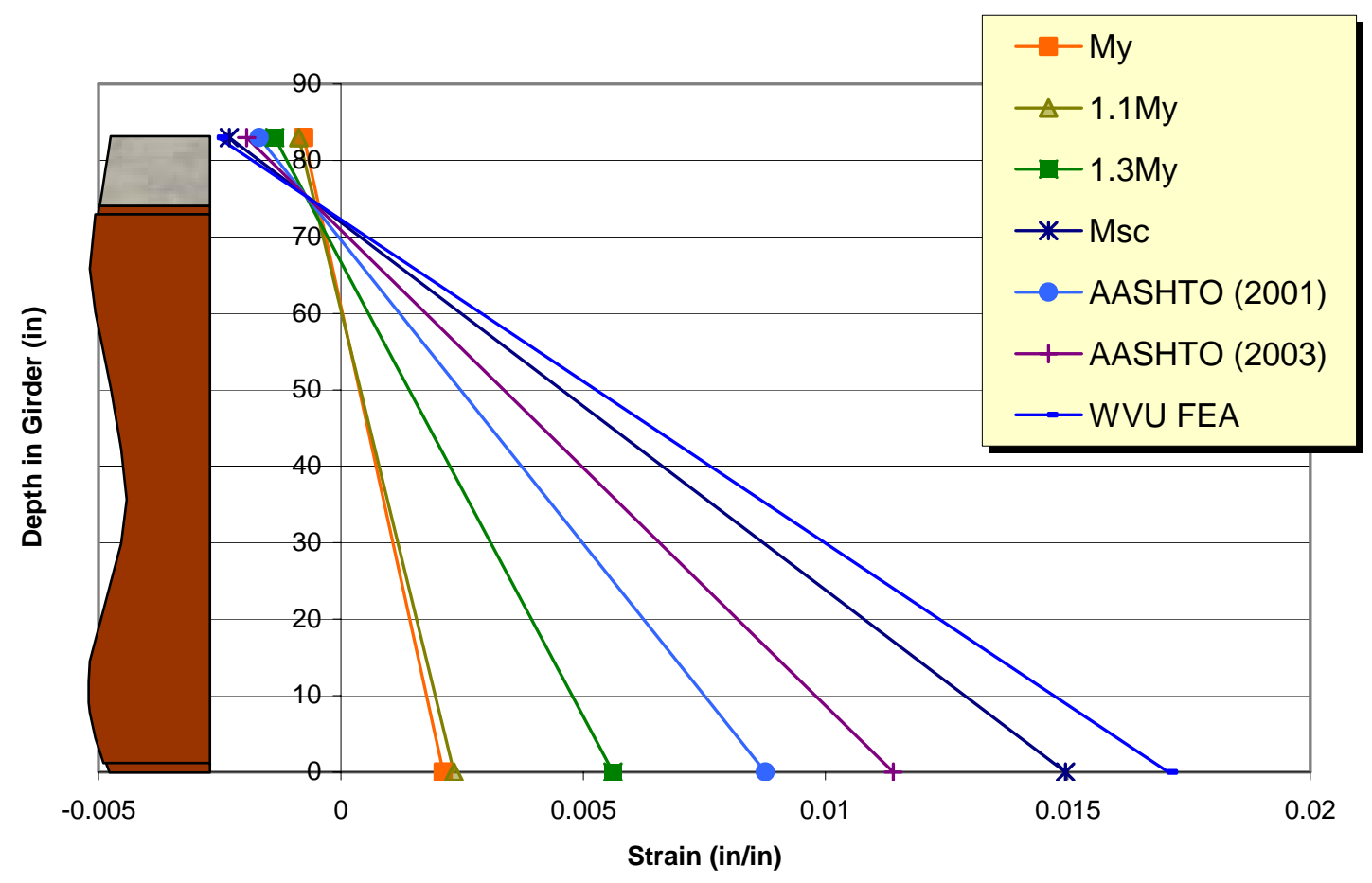

Figure 5.44 Midspan normal strain - UFA70L 


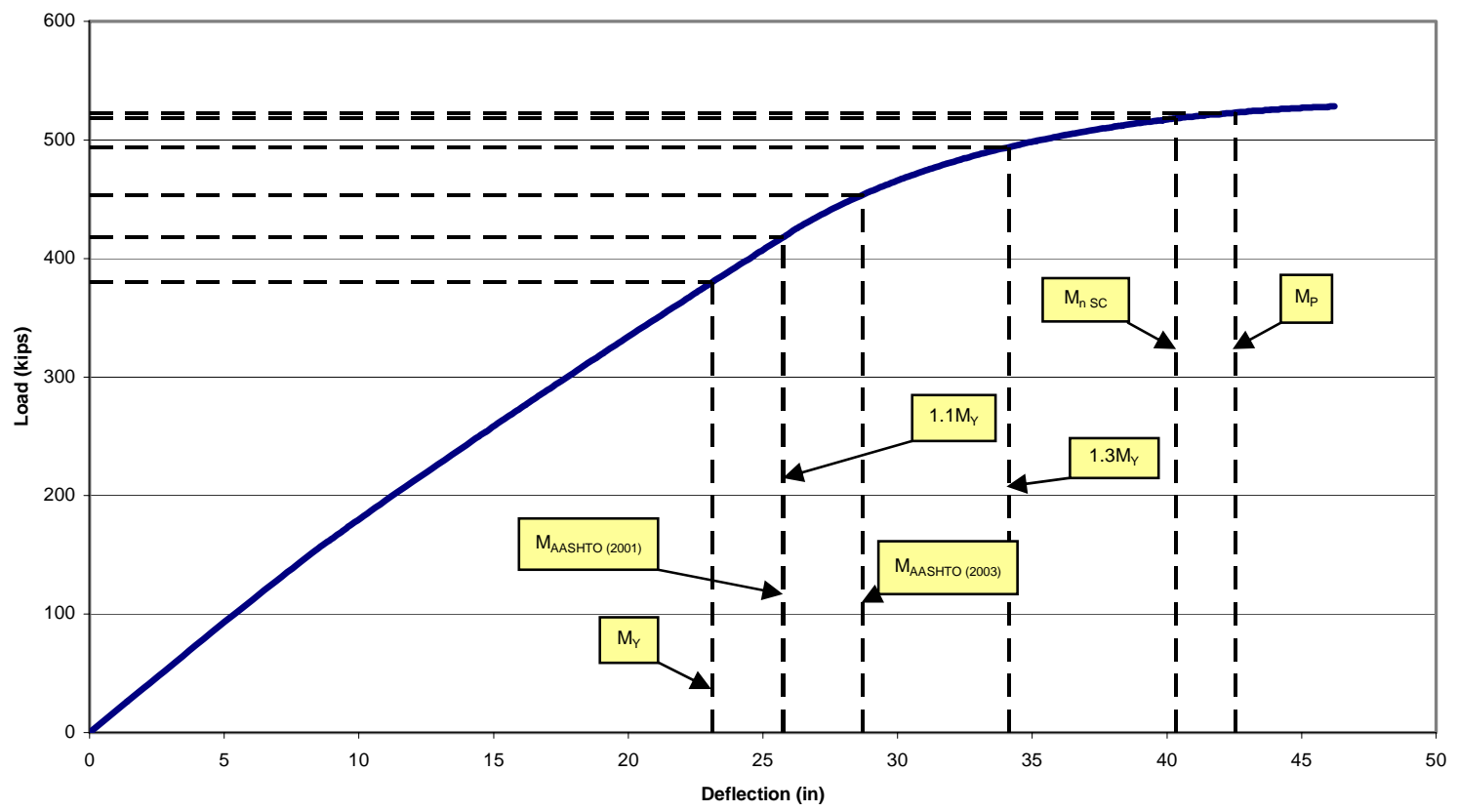

Figure 5.45 Midspan load-deflection plot - UFA70I

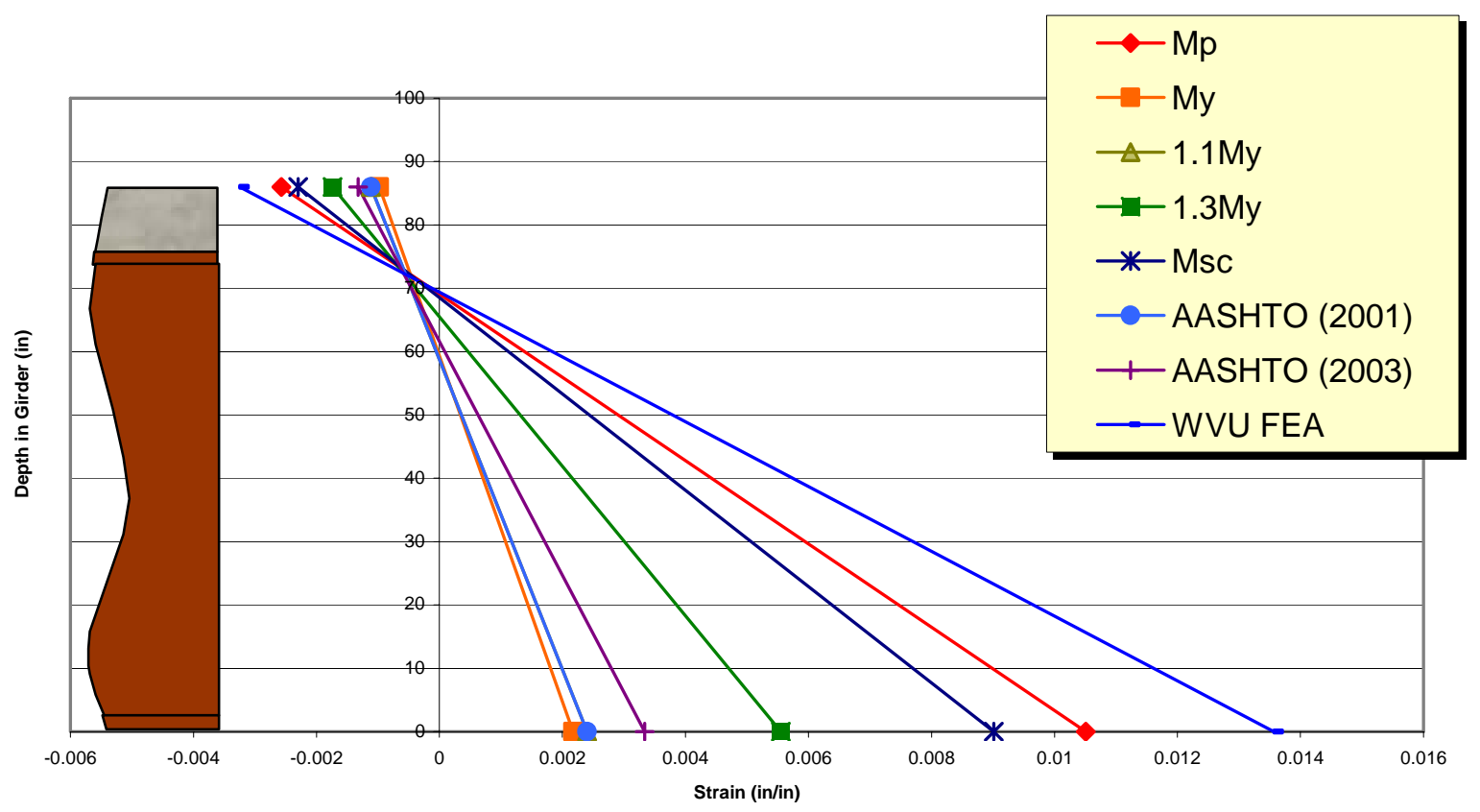

Figure 5.46 Midspan normal strain - UFA70I 


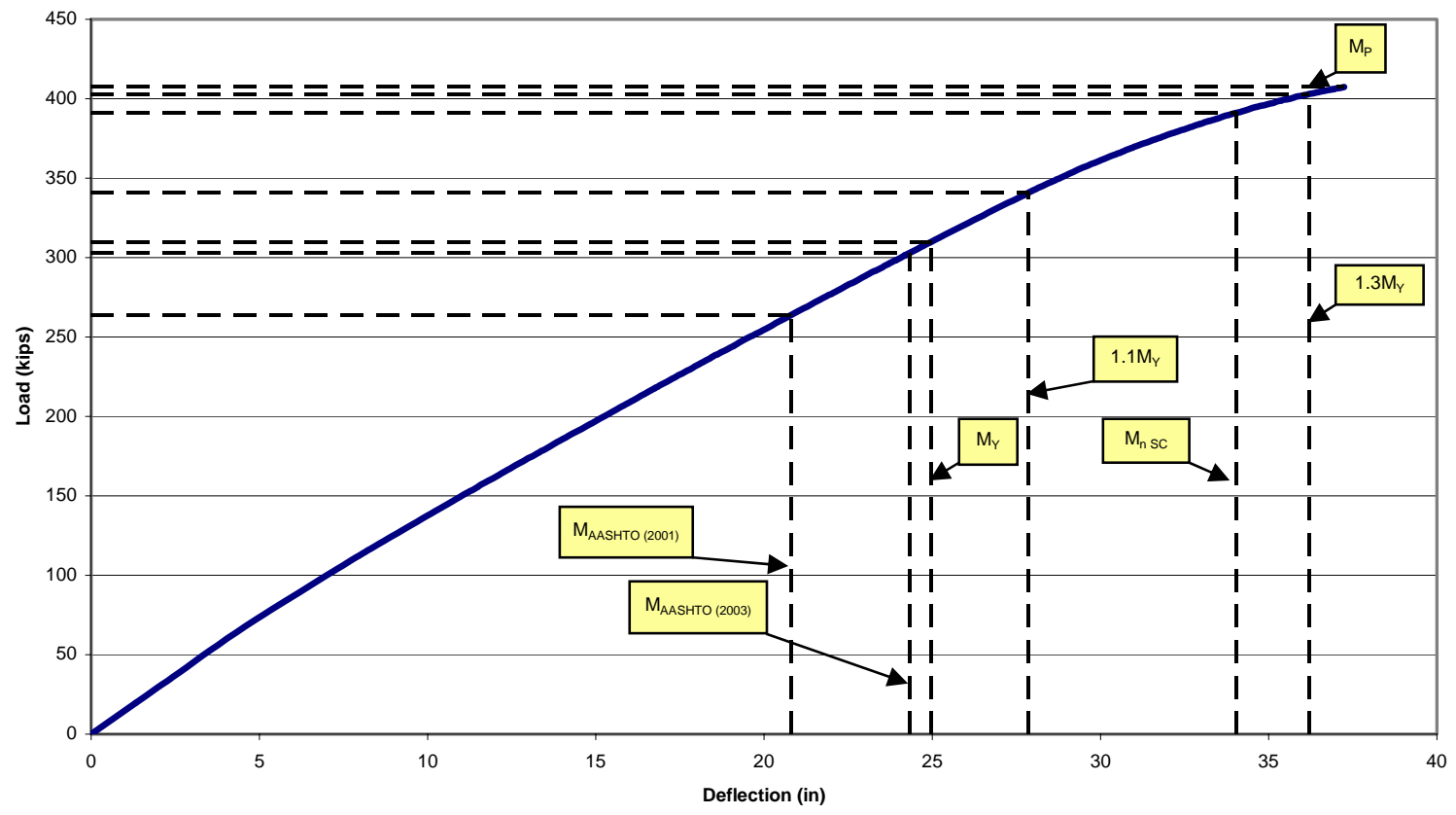

Figure 5.47 Midspan load-deflection plot - UFA70H

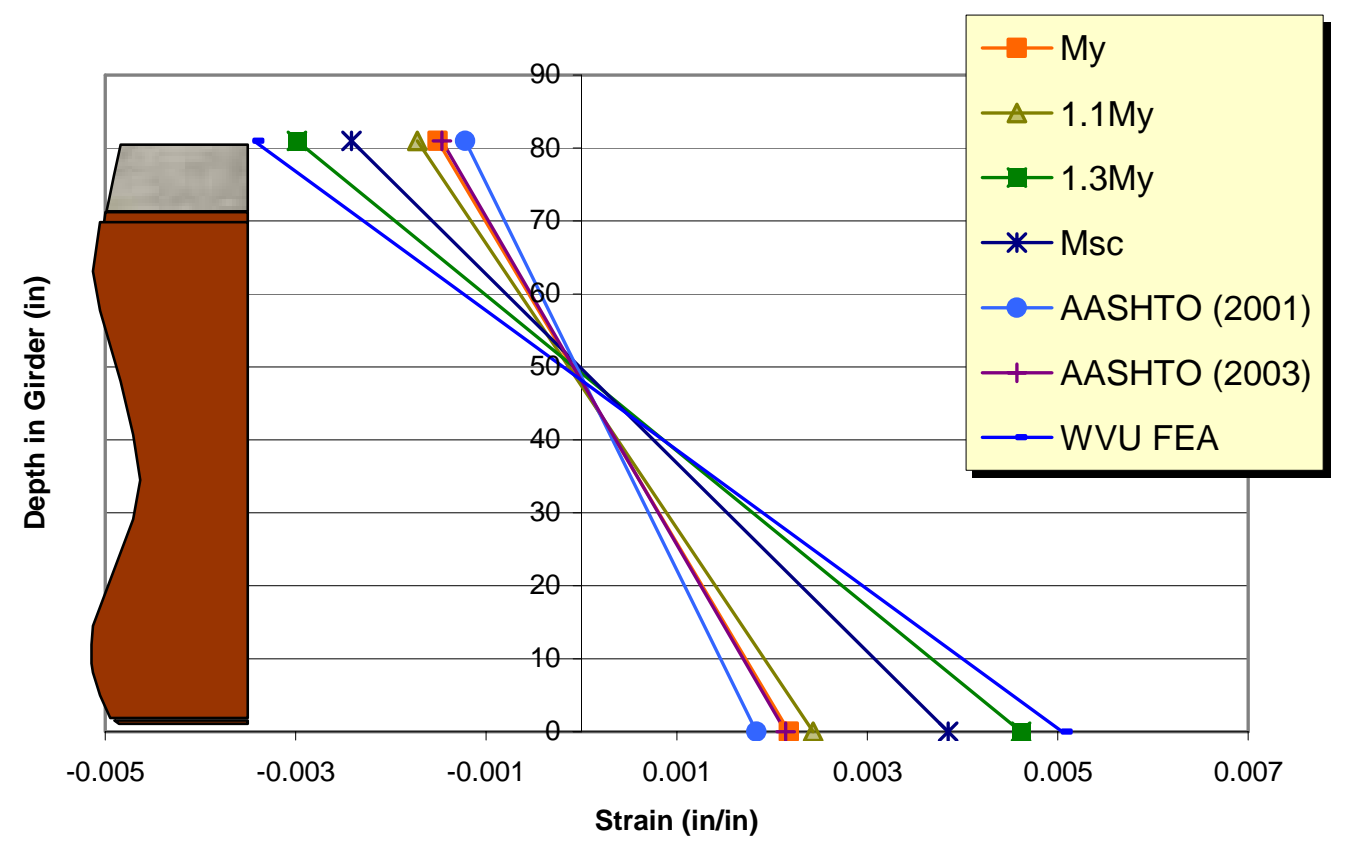

Figure 5.48 Midspan normal strain - UFA70H 


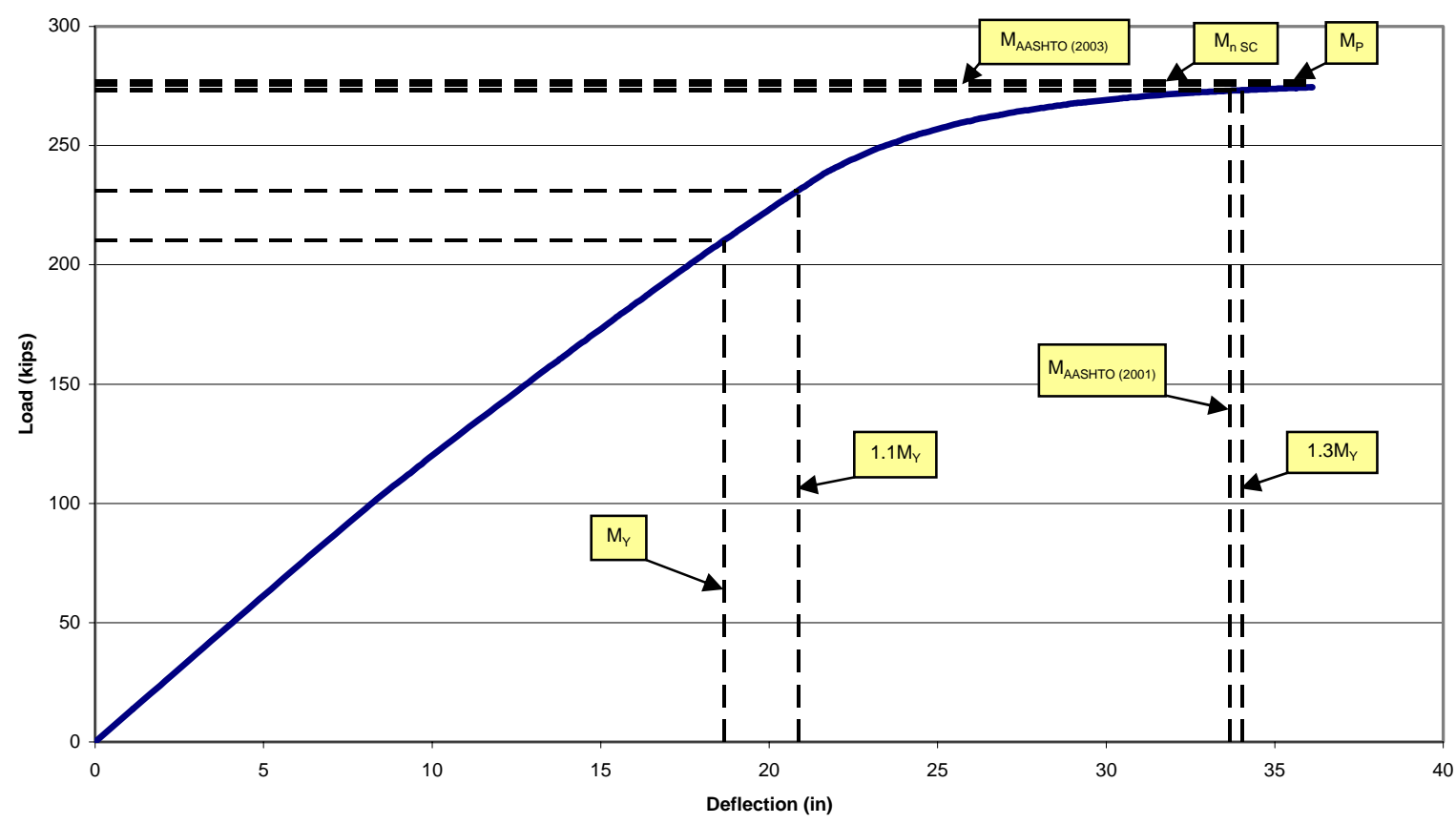

Figure 5.49 Midspan load-deflection plot - UFH50-70L

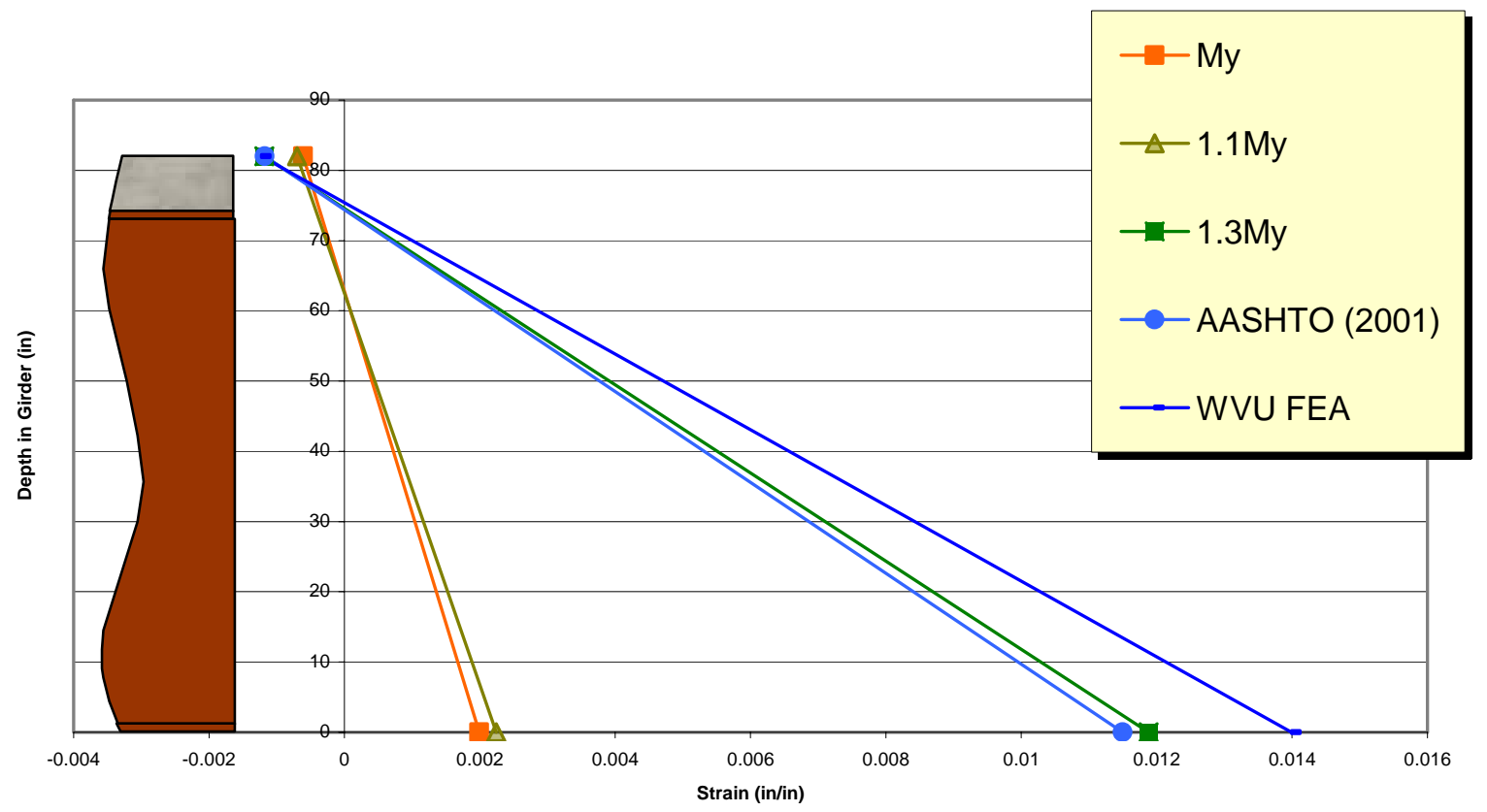

Figure 5.50 Midspan normal strain - UFH50-70L 


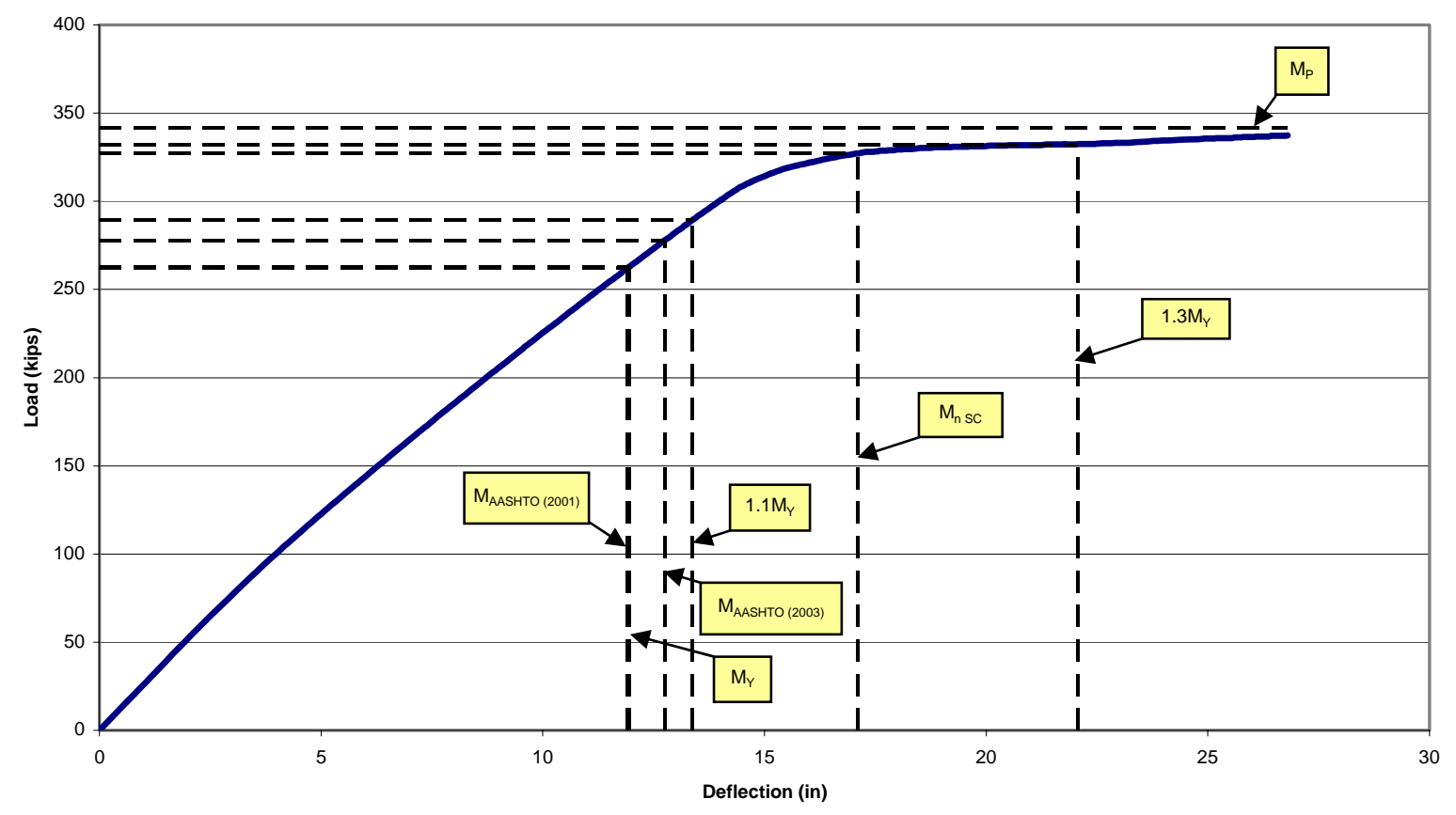

Figure 5.51 Midspan load-deflection plot - UFH50-70I

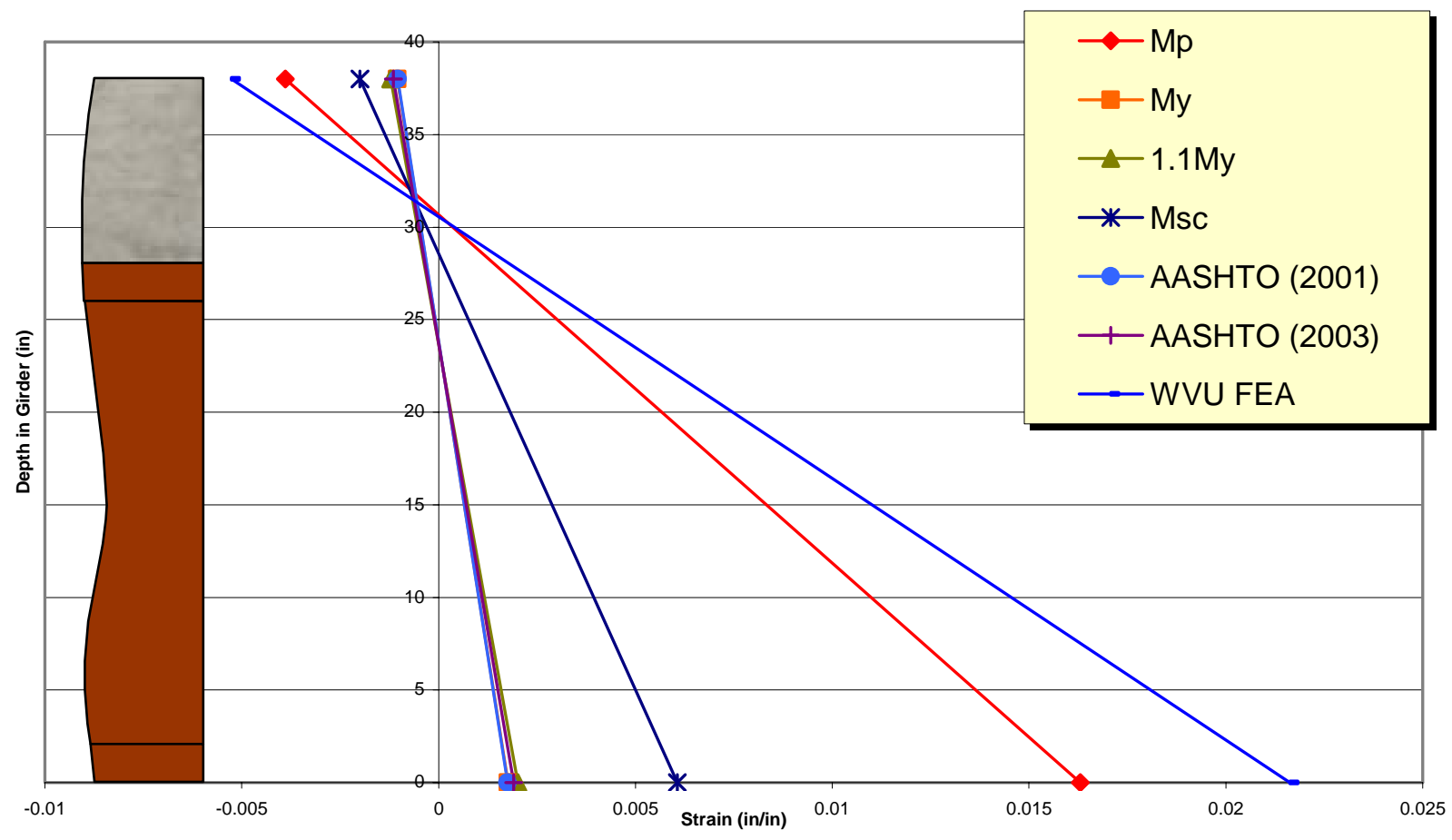

Figure 5.52 Midspan normal strain - UFH50-70I 


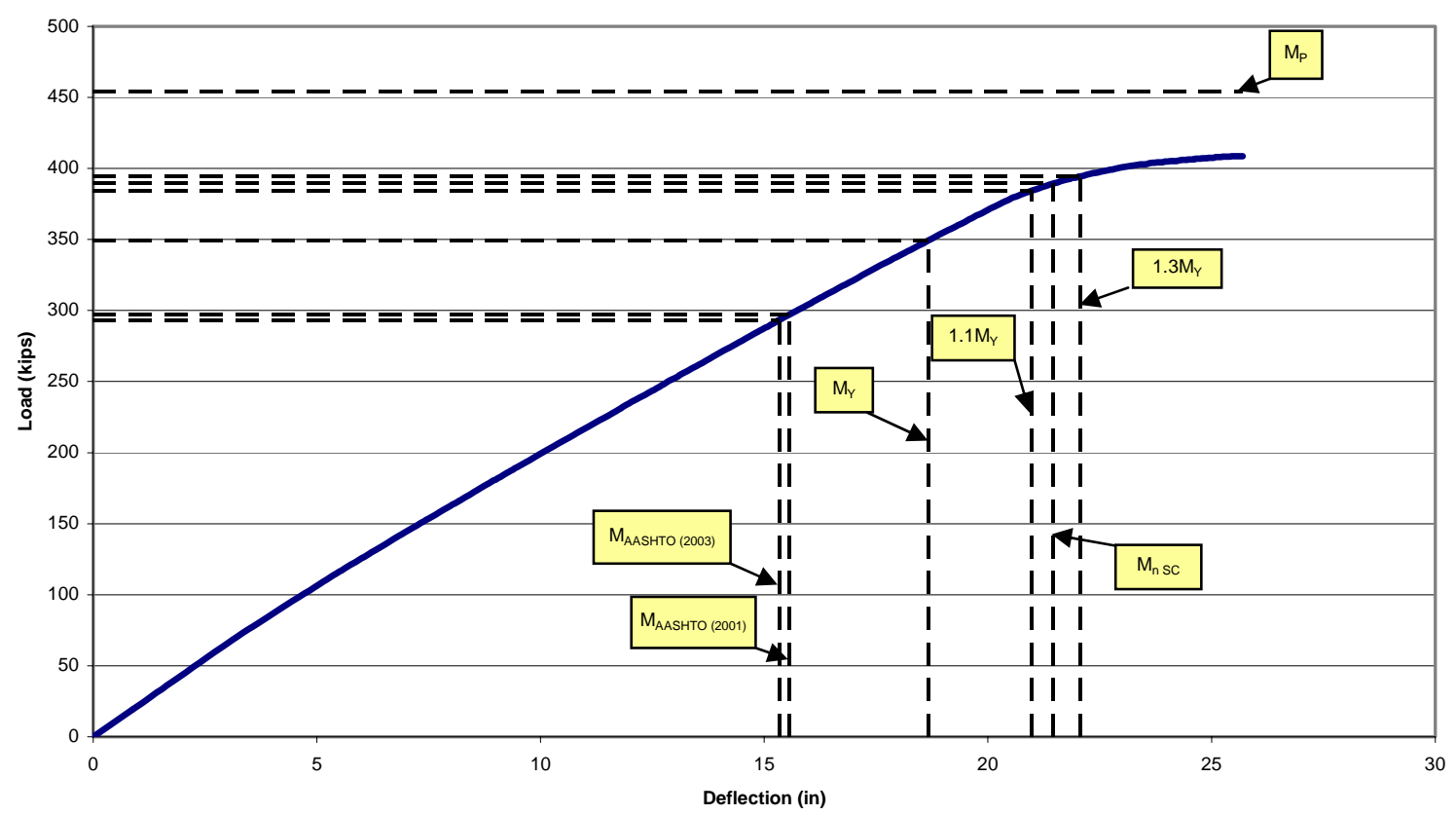

Figure 5.53 Midspan load-deflection plot - UFH50-70H

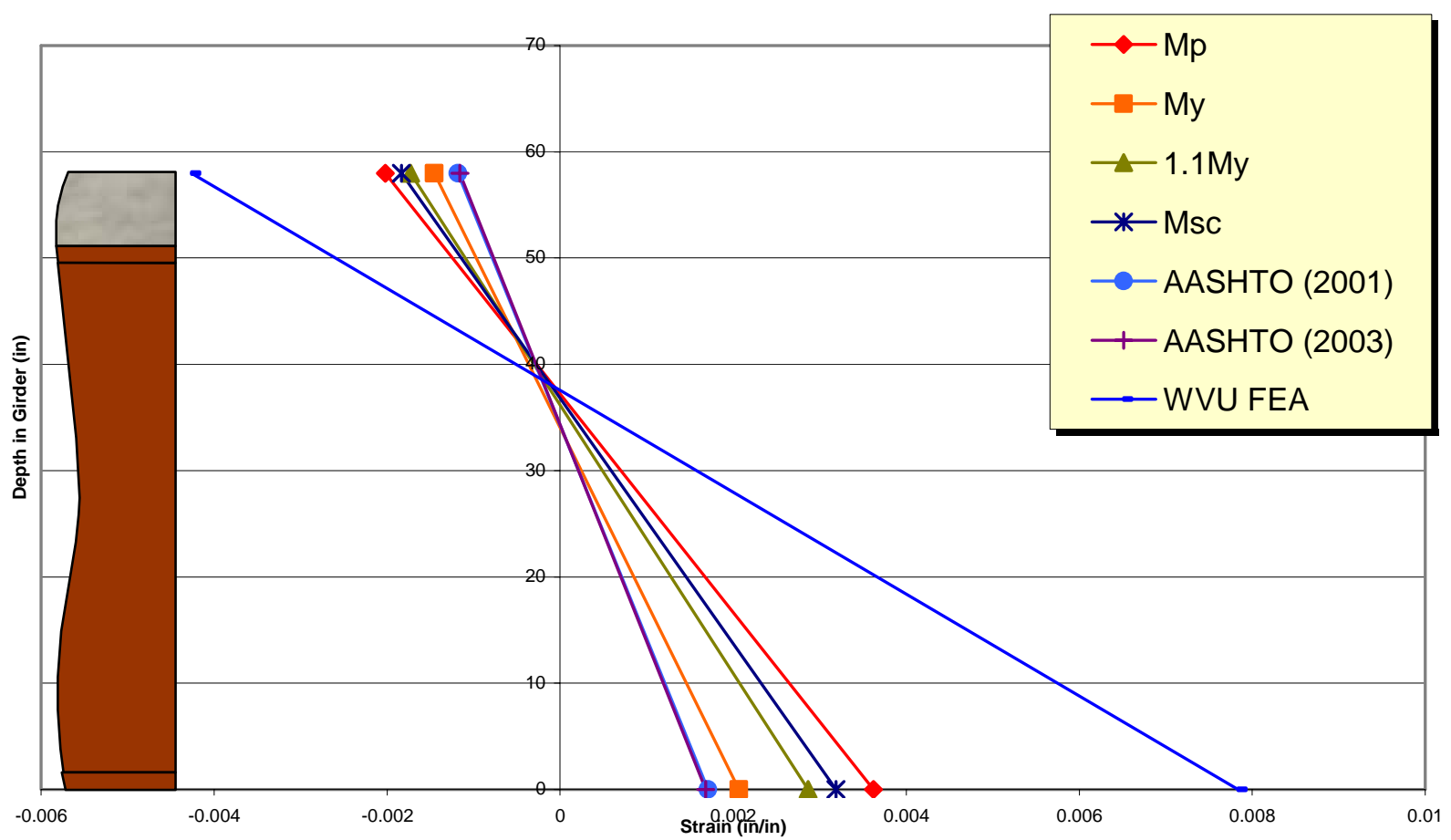

Figure 5.54 midspan normal strain - UFH50-70H 


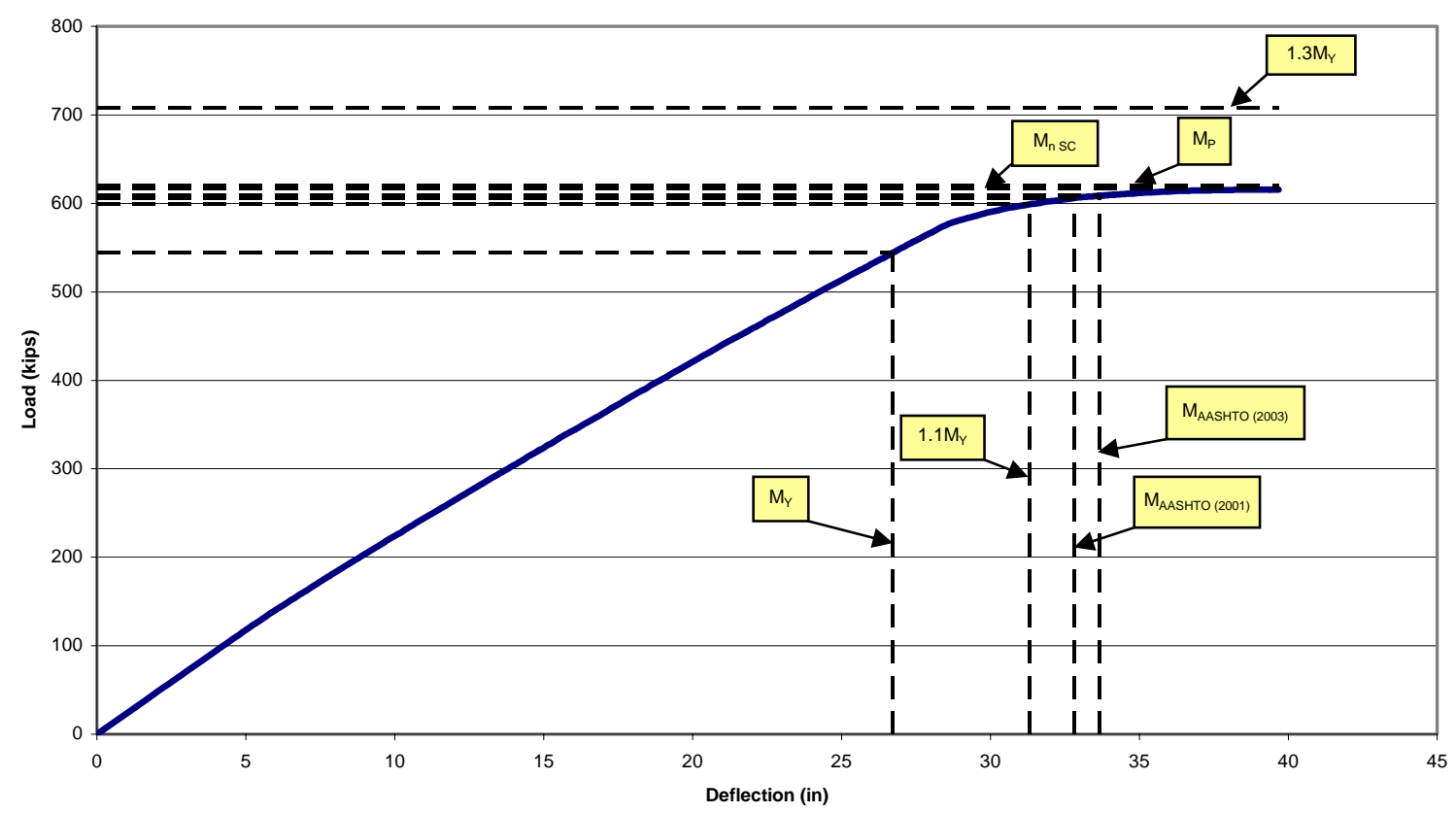

Figure 5.55 Midspan load-deflection plot - UFH70-70L

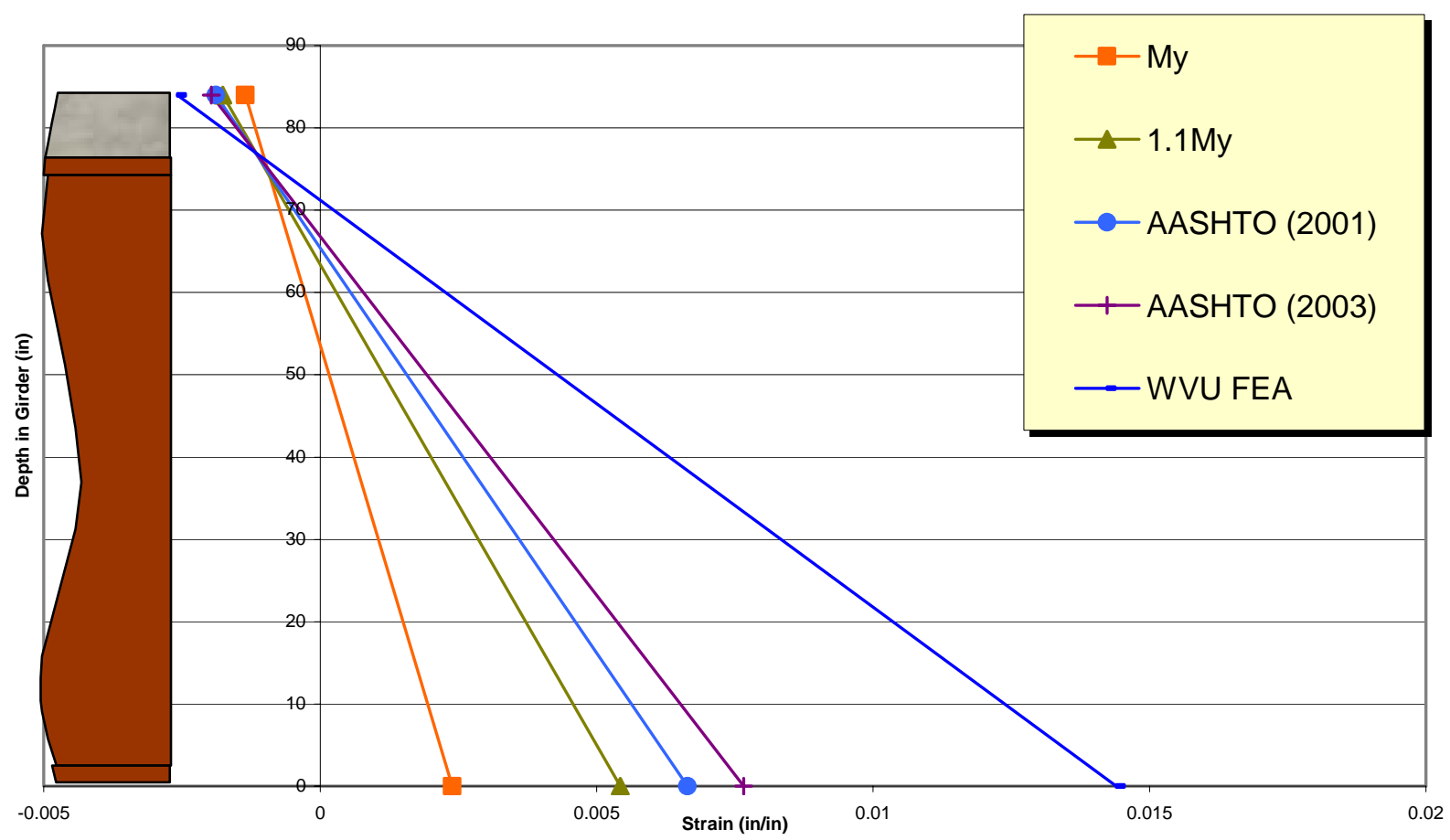

Figure 5.56 Midspan normal strain - UFH70-70L 


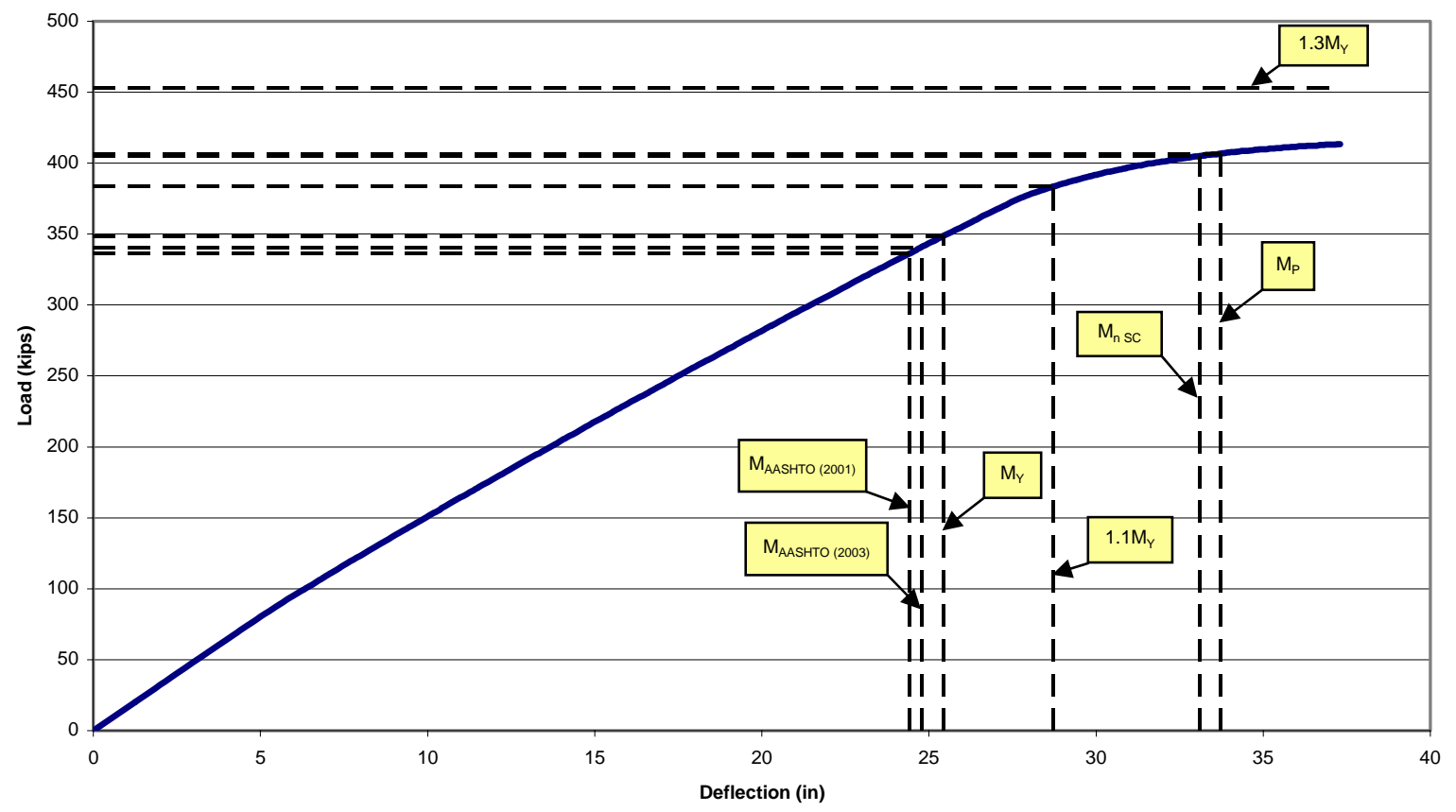

Figure 5.57 Midspan load-deflection plot - UFH70-70I

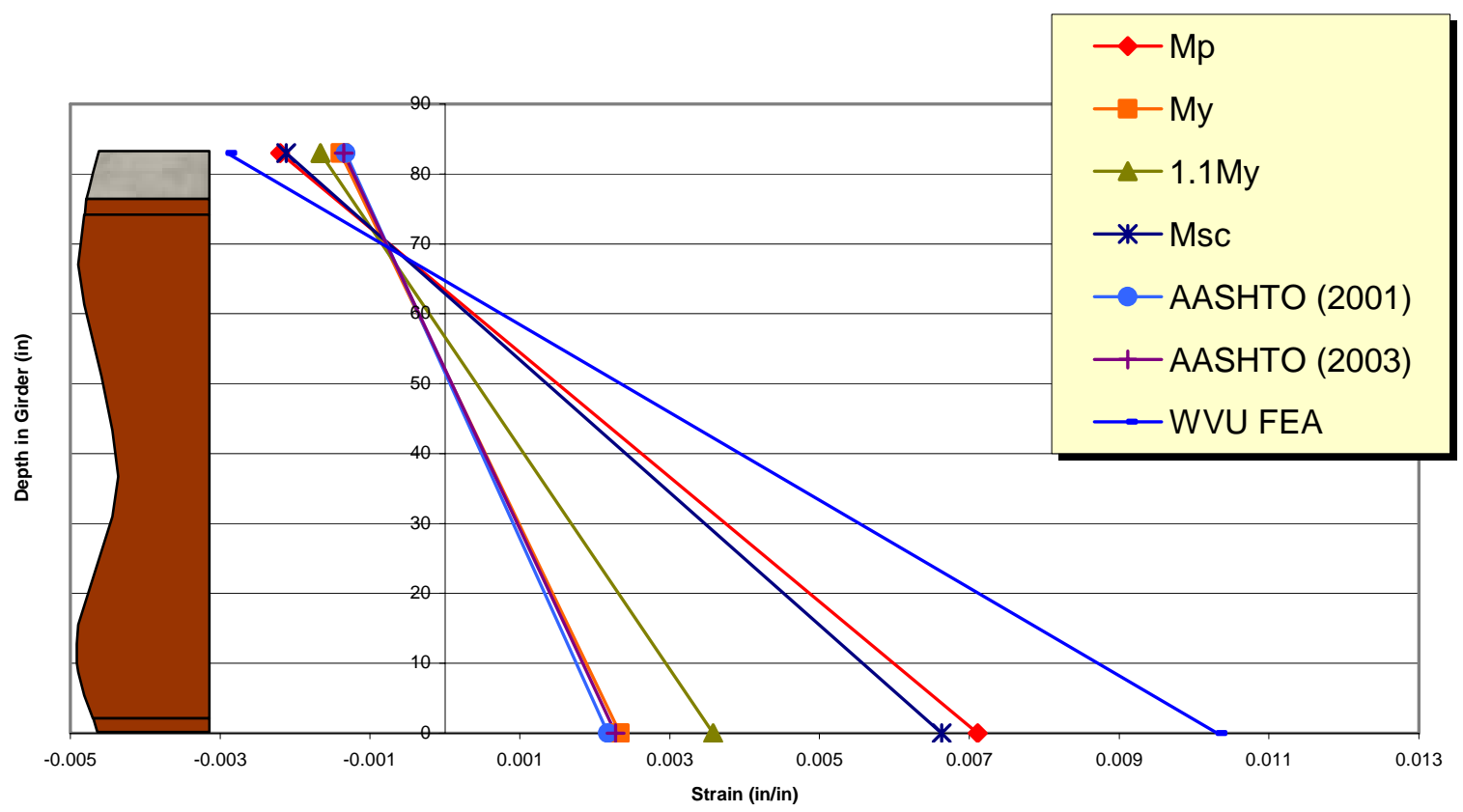

Figure 5.58 Midspan normal strain - UFH70-70I 


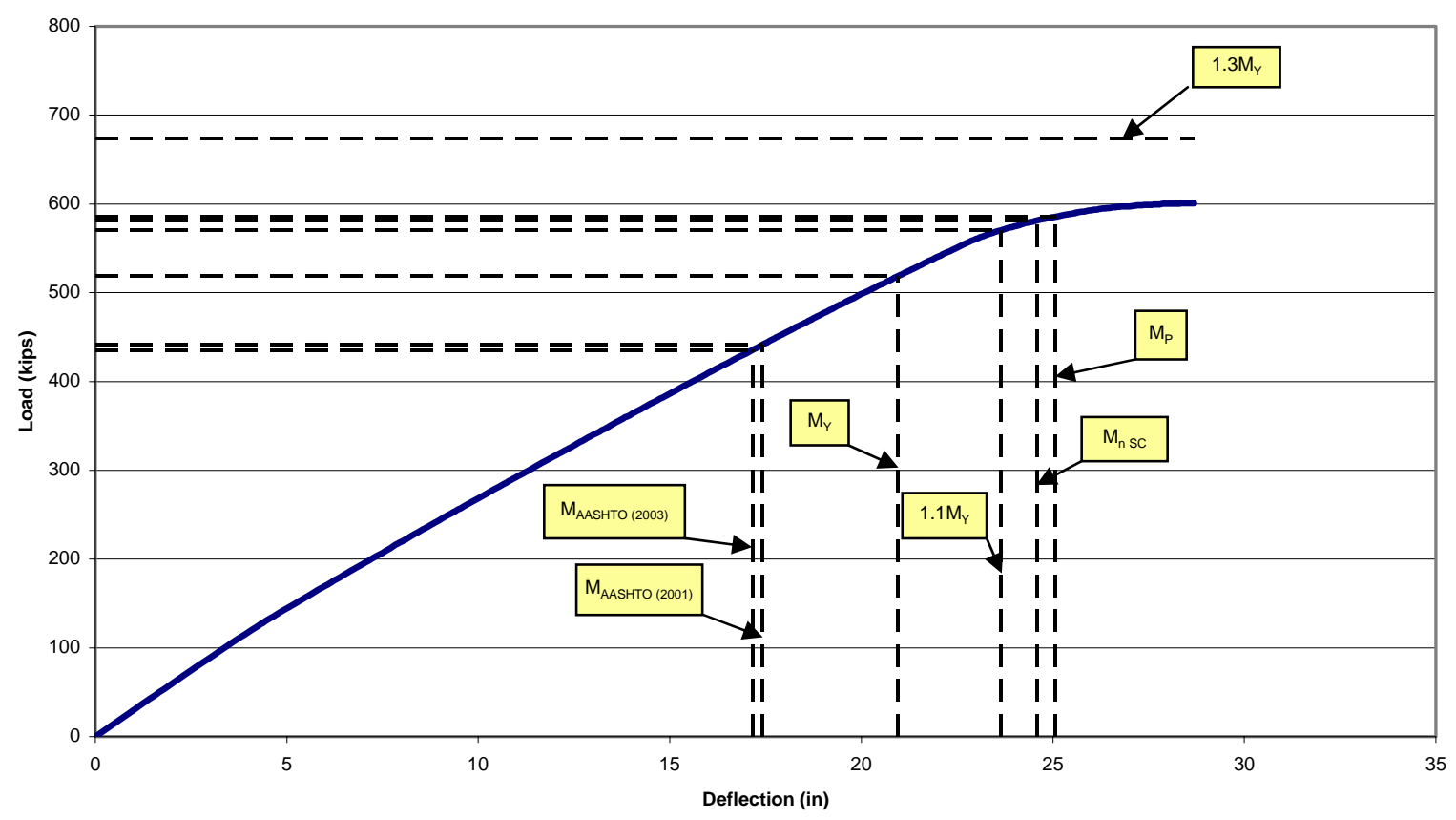

Figure 5.59 Midspan load-deflection plot - UFH70-70H

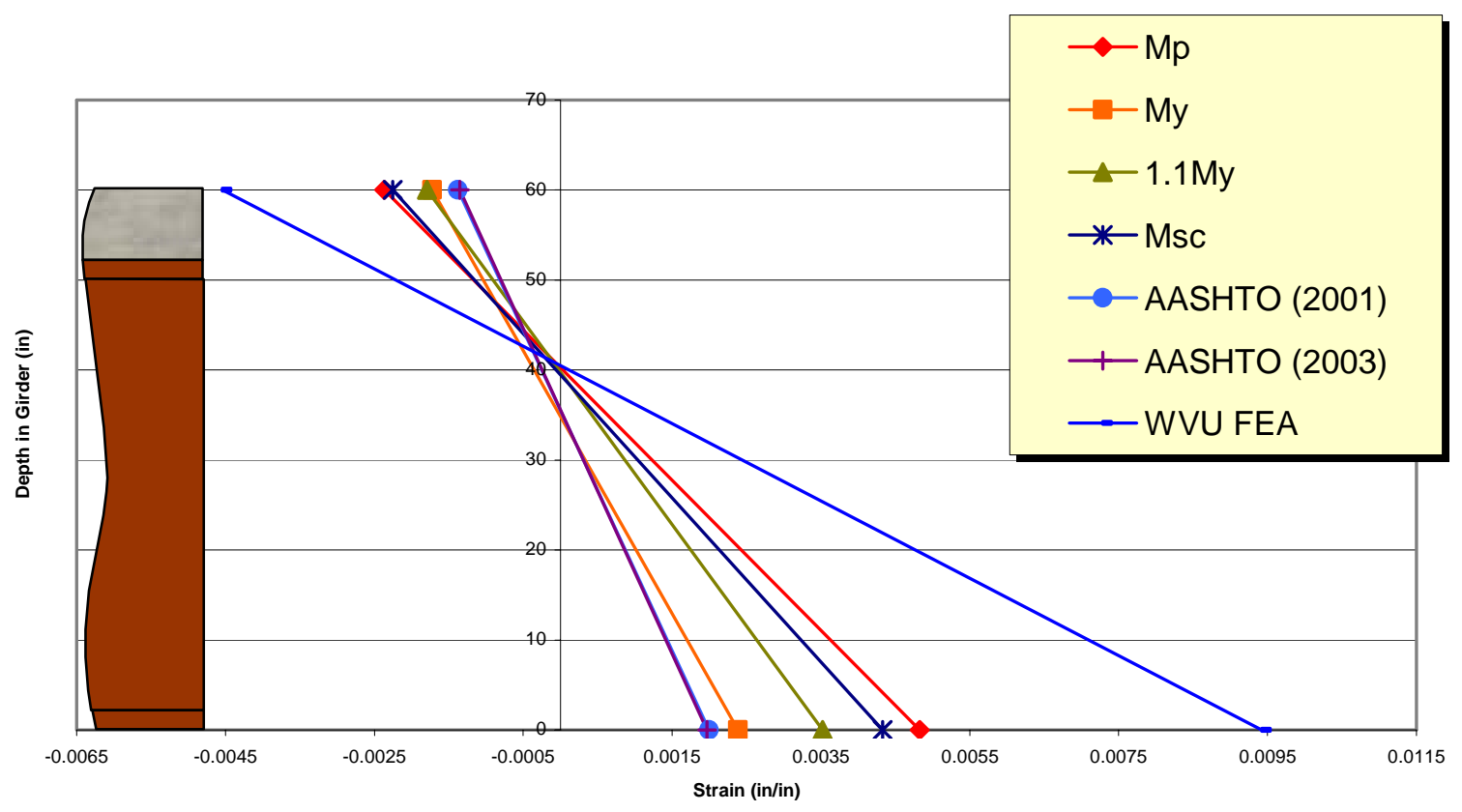

Figure 5.60 Midspan normal strain - UFH70-70H 


\section{Chapter 6}

\section{EVALUATION OF RESULTS}

\subsection{Introduction}

This chapter provides a comparison between the results of the strain compatibility analyses and the capacities predicted by both the AASHTO (2001) and the AASHTO (2003) Specifications. Results of the strain compatibility analyses are then used to develop a less conservative ultimate moment prediction equation for the range of girders assessed in this study.

\subsection{Comparison of Results}

As determined from the previous chapters, the strain compatibility approach provides results reasonably close to that obtained by the experimental tests and that of the finite element analyses. Therefore, the results from the extensive strain compatibility analyses will be used to evaluate the current limits on ductility. It was shown in Chapter 4 that different material configurations of 50 and 70 ksi steels do not affect the trends that govern the relationship between the ultimate capacity and the ductility ratio. As a result,

all of the strength configurations will be considered simultaneously in the development of more simple, less conservative prediction equations.

Histograms comparing the ultimate moments from the strain compatibility analyses with the predicted ultimate moments from AASHTO (2001), Eqn. 2.6, and 
AASHTO (2003), Eqn. 2.8, are given in Figs. 6.1 and 6.2, respectively. These histograms show that for the range of girders assessed in this study the AASHTO (2001) Specifications can be up to $50 \%$ conservative with the majority of the sections being between 15 and 20\% conservative. Also, Fig. 6.2 shows that the AASHTO (2003) Specifications can be up to $30 \%$ conservative with the majority of those sections being between 10 and 15\% conservative. Further illustrating the conservativeness of Eqns. 2.6 and 2.8 are Figs. 6.3 and 6.4, which contain the actual $M_{n} / M_{p}$ values for both, the AASHTO (2001) Specifications and AASHTO (2003) Specifications, respectively.

\subsection{Development of Prediction Equations}

Because of the conservativeness resulting from the use of the Eqns. 2.6 and 2.8, new, less conservative prediction equations will be developed based on the data from the strain compatibility analyses. Two different prediction equations will be developed, one will employ the ductility ratio $D_{p} / D^{\prime}$ and the other will use the ductility ratio $D_{p} / D_{t}$.

By curve fitting a straight line to the $95^{\text {th }}$ percentile of the strain compatibility results with respect to $D_{p} / D^{\prime}$, Eqn. 6.1 can be used to more accurately predict the ultimate moment capacity of a composite steel girder in positive bending.

$$
M_{n}=M_{p}\left(1.015-0.015 \frac{D_{p}}{D^{\prime}}\right)
$$


Using the same technique, a straight line fitted to the $95^{\text {th }}$ percentile of the strain compatibility results with respect to $D_{p} / D_{t}$ provides Eqn. 6.2 , which also can be used to more accurately predict the ultimate moment capacity of a composite steel girder in positive bending.

$$
M_{n}=M_{p}\left(1.018-0.18 \frac{D_{p}}{D_{t}}\right)
$$

Predicting the ultimate moment using Equations 6.1 and 6.2, yields much less conservative values than predicting the ultimate moment capacity using Eqns. 2.6 and 2.8. Figures 6.5 and 6.6 graphically compare the proposed equations to both the AASTHO (2001) and AASHTO (2003) Specifications, respectively.

The conservativeness of the proposed prediction equations is illustrated in Figs. 6.7 and 6.8. These figures represent histograms comparing the ultimate moments determined by the strain compatibility method of analysis and the proposed prediction equations (Eqns. 6.1 and 6.2). As shown in Fig. 6.7, Eqn. 6.1 can up to be 6\% conservative. However, predominantly, Eqn. 6.1 is between $0 \%$ and $2 \%$ conservative. Equation 6.2, as shown in Fig. 6.8 can also be up to 6\% conservative at its highest. But, for the largest part, Eqn. 6.2 is between 0\% and 3\% conservative. 


\subsection{Recommendations}

From the preceding development of prediction equations, it can be seen that Eqns. 6.1 and 6.2 both exhibit nearly the same degree of conservativeness. However, because Eqn. 6.1 requires the calculation of $D^{\prime}$, an extra step is introduced into the overall prediction equation. Therefore, on the basis of simplifying the prediction processes, it is recommended that Eqn. 6.2 be used. Using Eqn. 6.2 to predict the ultimate strength eliminates the calculation of $D^{\prime}$ and provides the same degree of conservativeness as Eqn. 6.1.

The following format is recommended for use in future editions of the AASHTO Specifications for the prediction of ultimate moment capacity of composite steel girders in positive bending within the range $0.1<D_{p} / D_{t} \leq 0.42$ :

$$
\begin{aligned}
& M_{n}=M_{p} \\
& \text { where, } \frac{D_{p}}{D_{t}} \leq 0.1 \\
& M_{n}=M_{p}\left(1.0176-0.176 \frac{D_{p}}{D_{t}}\right) \\
& \text { where, } 0.1<\frac{D_{p}}{D_{t}} \leq 0.42
\end{aligned}
$$




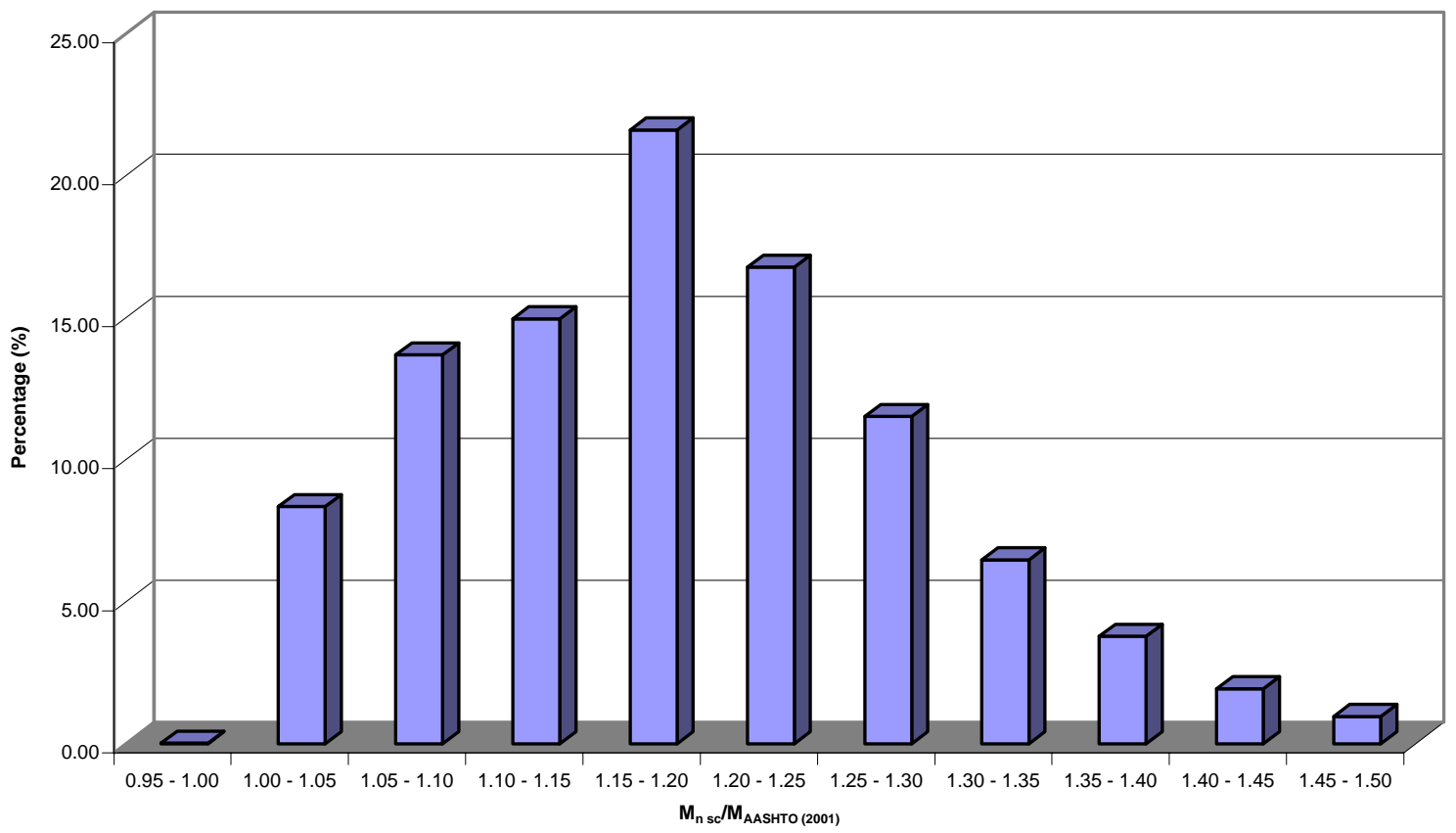

Figure 6.1 Histogram of comparing the ultimate strain compatibility moment to the ultimate moment predicted by AASHTO (2001) 


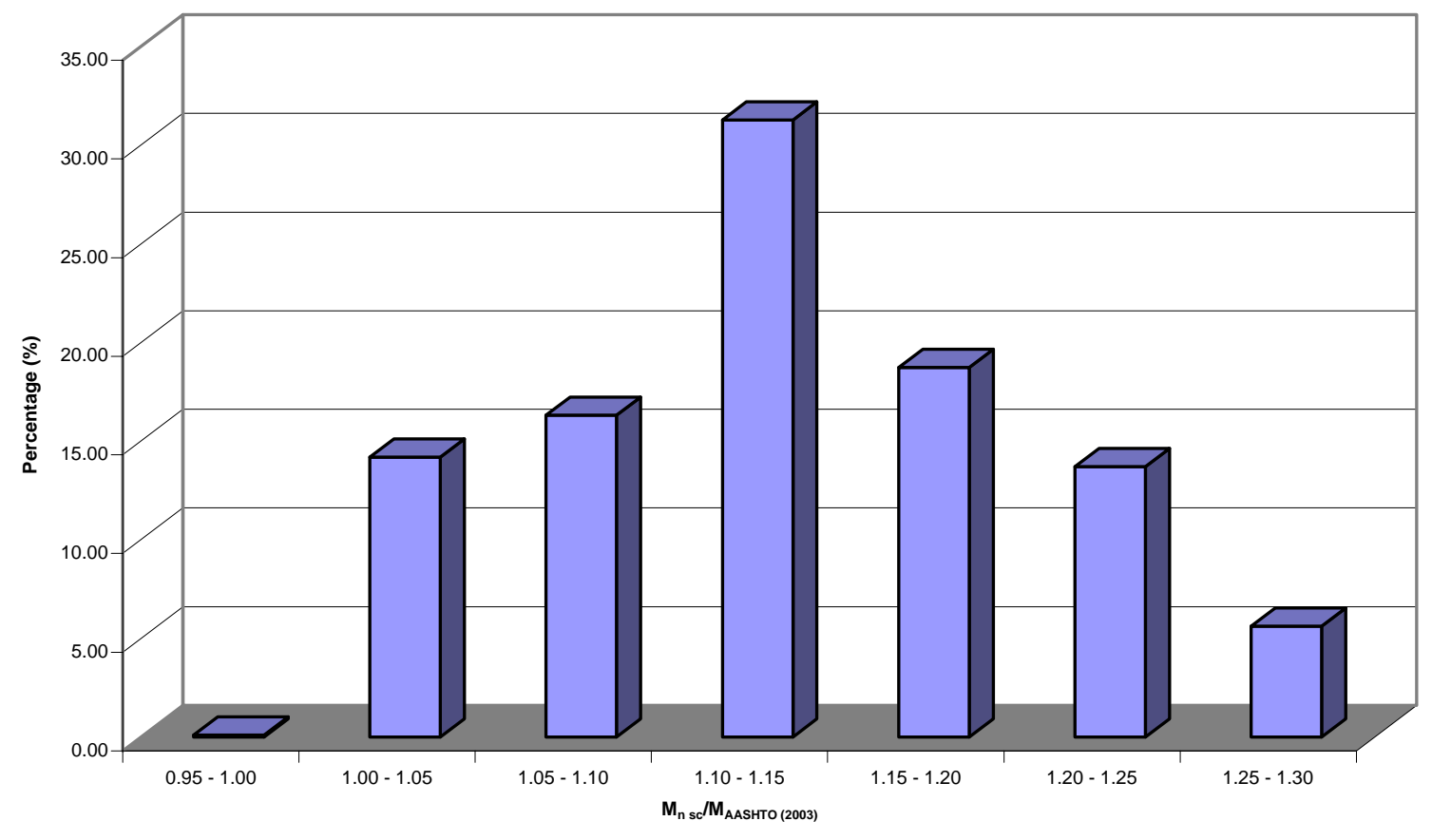

Figure 6.2 Histogram of comparing the ultimate strain compatibility moment to the ultimate moment predicted by AASHTO (2003) 


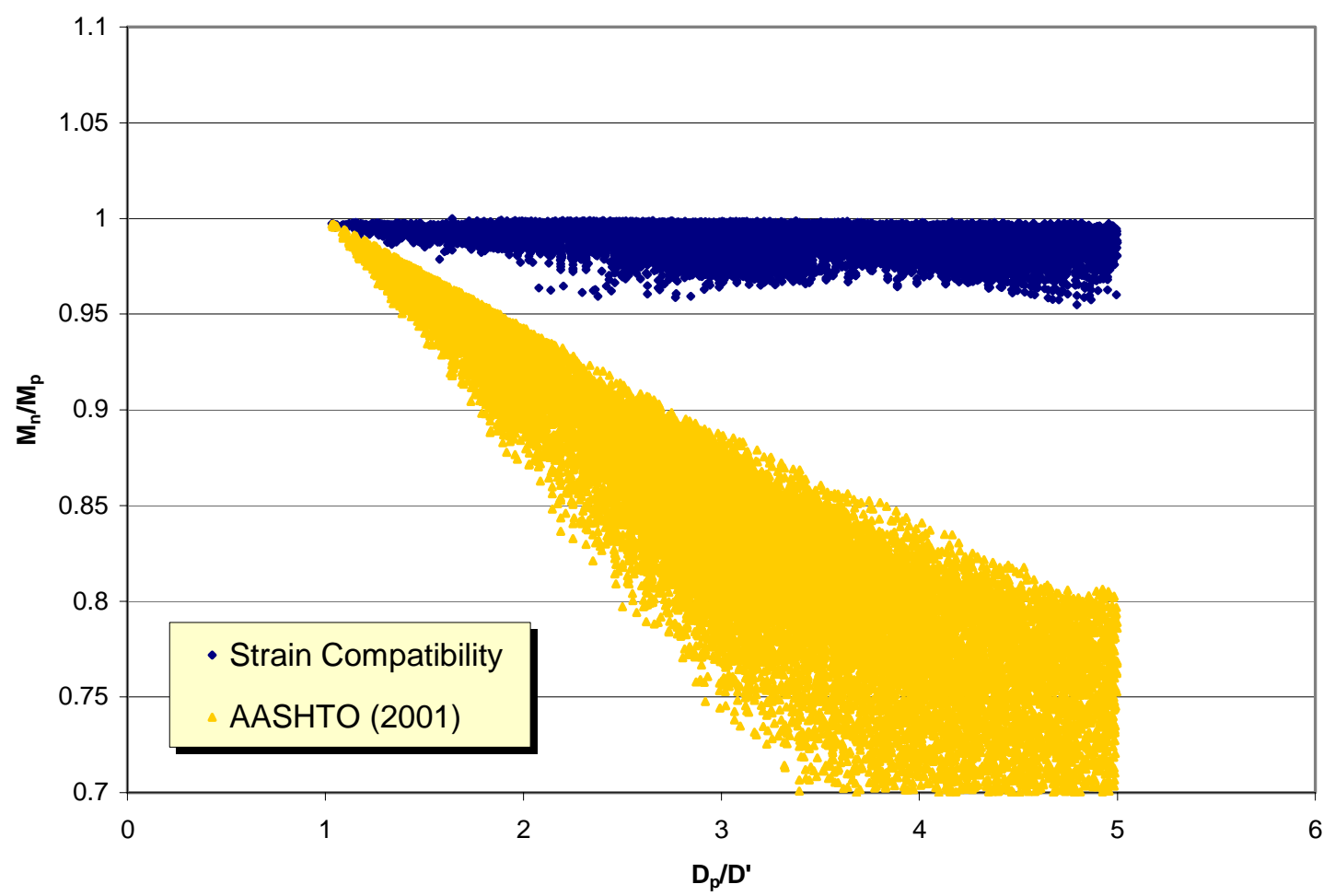

Figure 6.3 Comparisons of strain compatibility results to AASHTO (2001) 


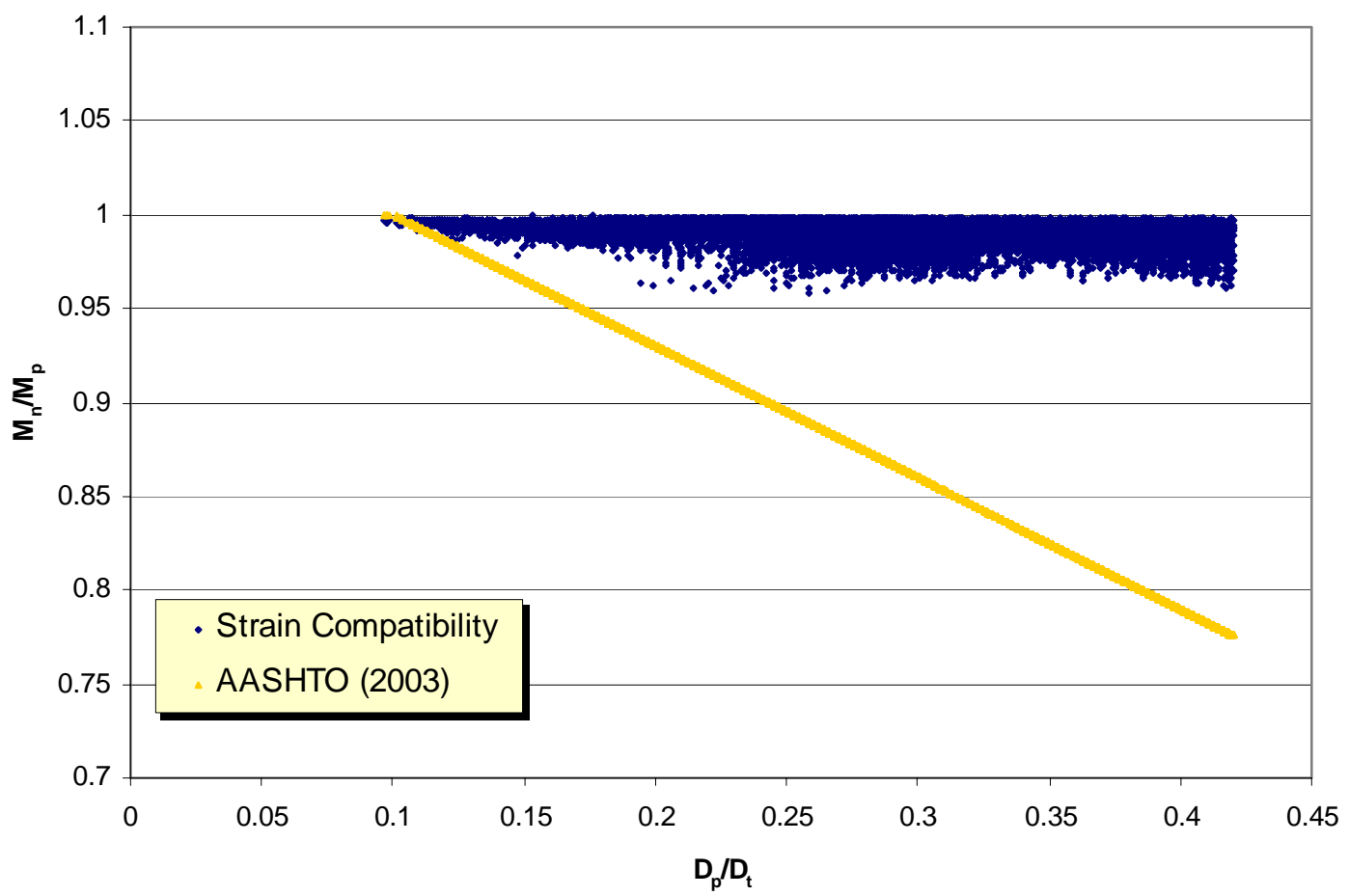

Figure 6.4 Comparison of strain compatibility results to AASHTO (2003) 


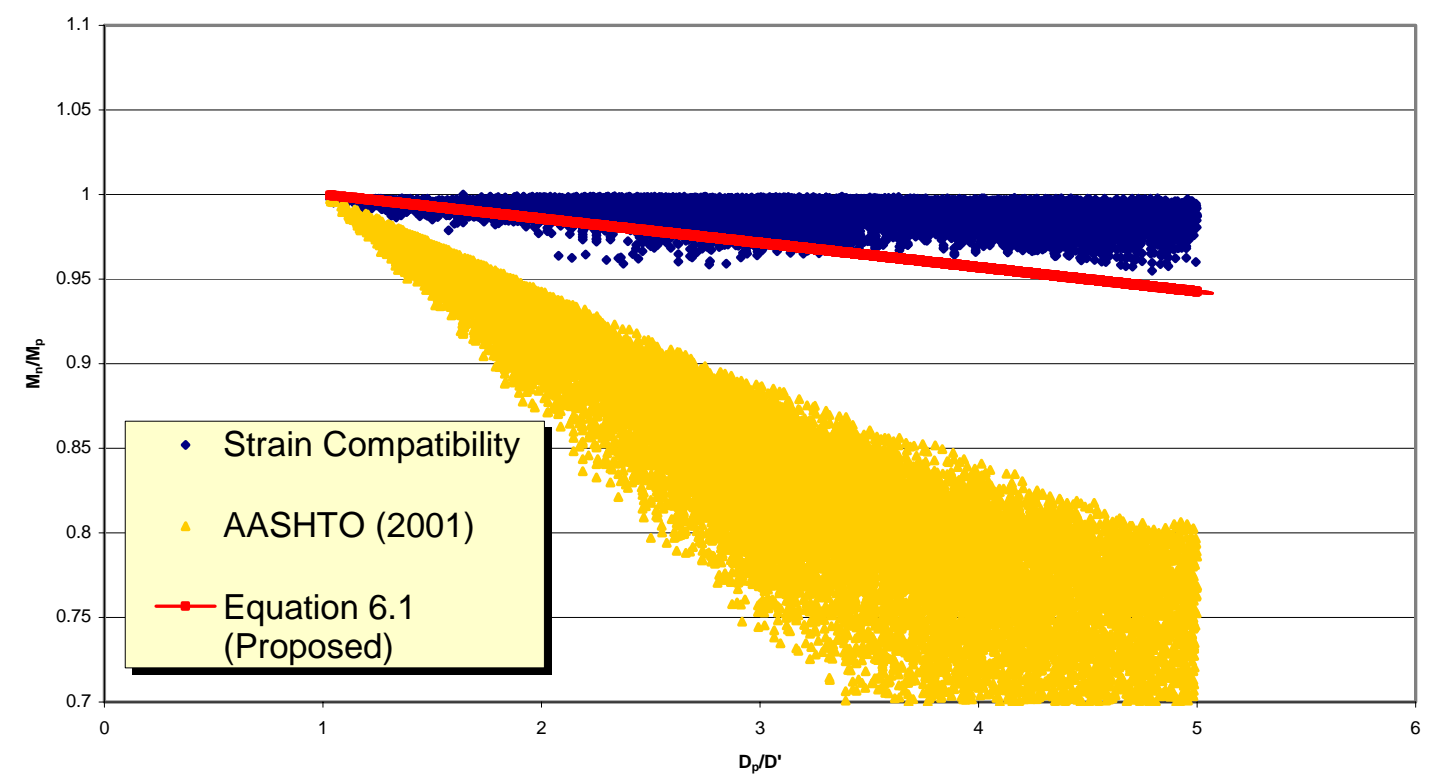

Figure 6.5 Comparison of proposed prediction equation (Eqn. 6.1) to strain compatibility results and AASHTO (2001) 


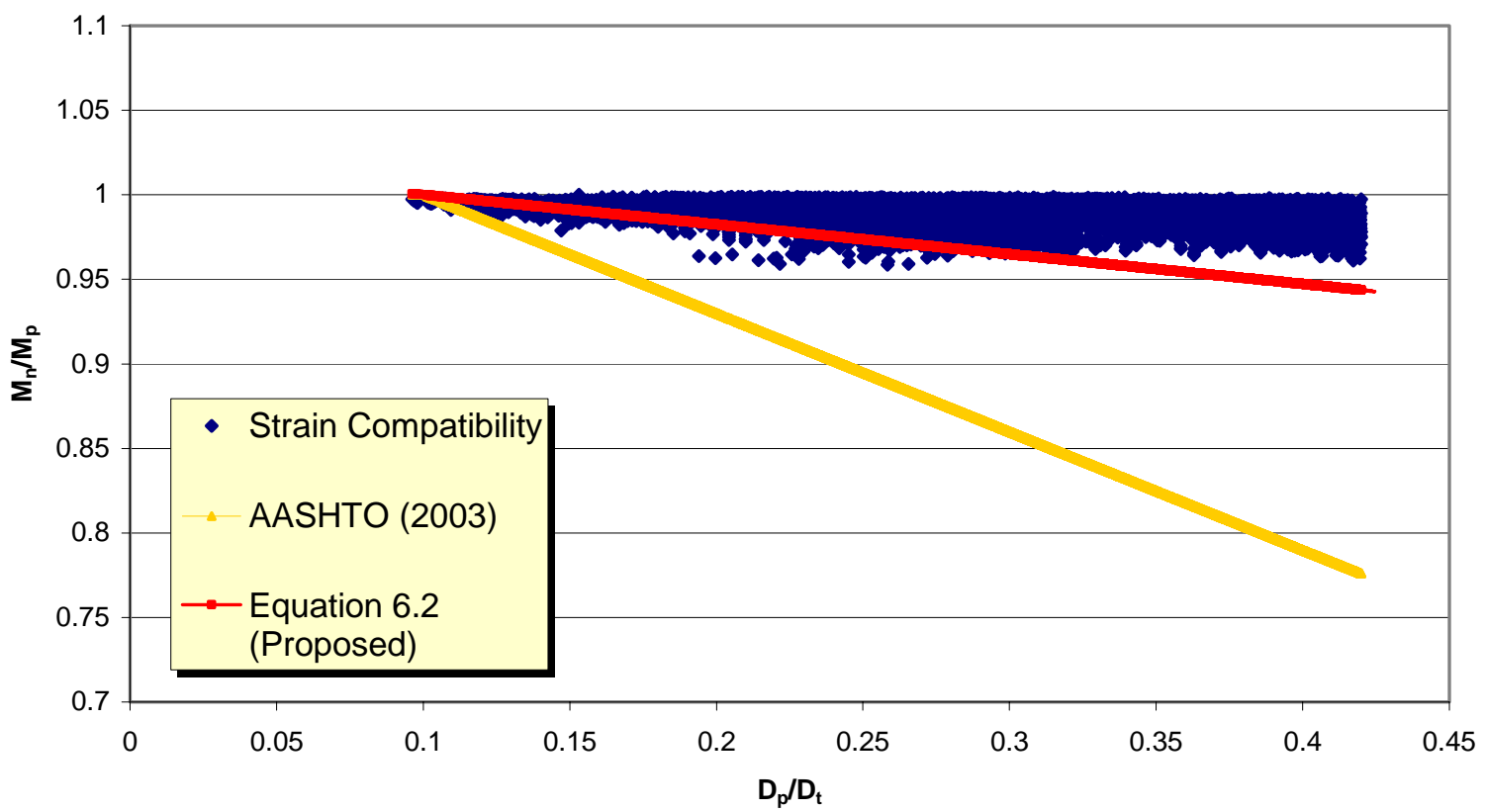

Figure 6.6 Comparison of proposed prediction equation (Eqn. 6.2) to strain compatibility results and AASHTO (2003) 


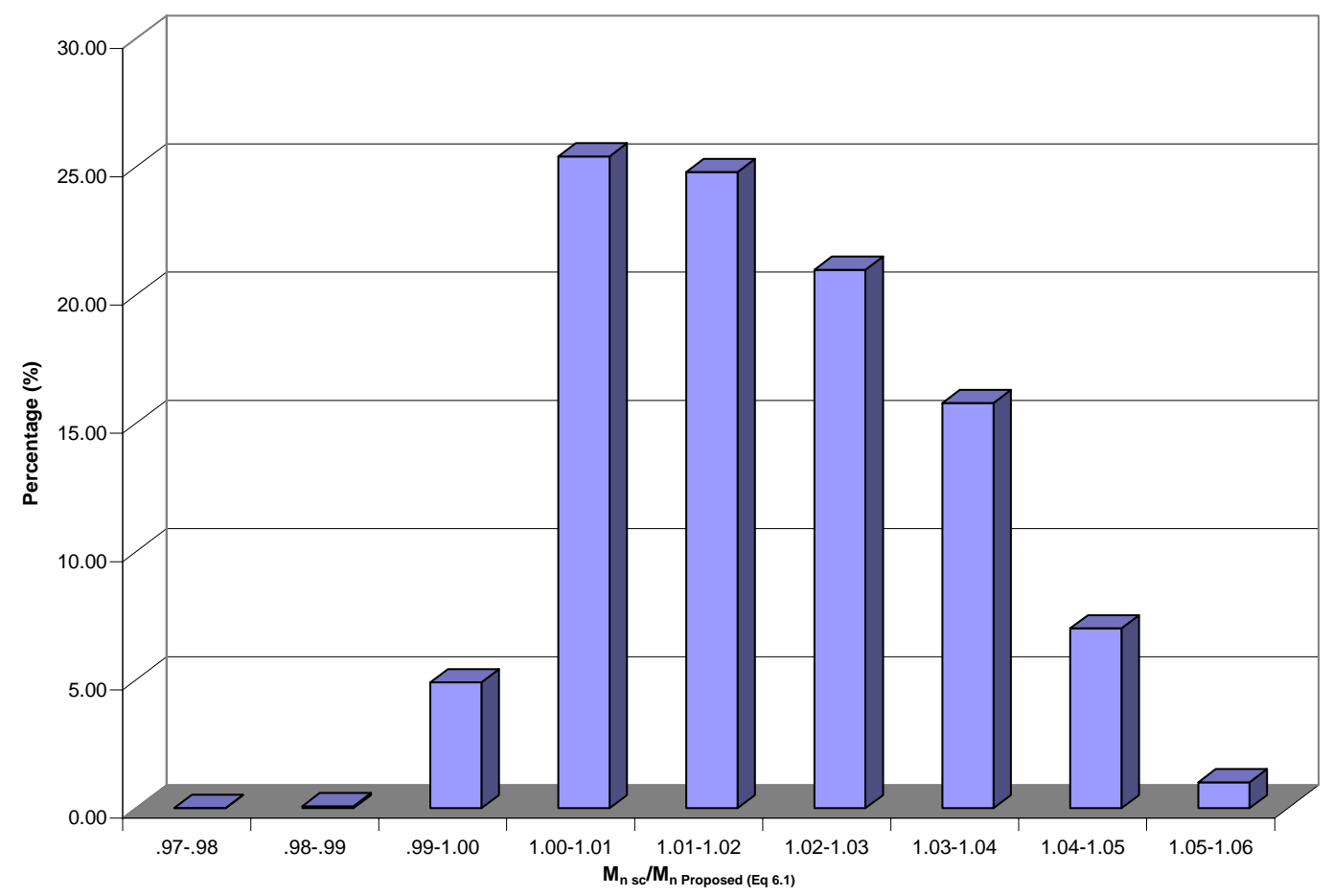

Figure 6.7 Histogram comparing the ultimate strain compatibility moment to the ultimate moment predicted by Eqn. 6.1 


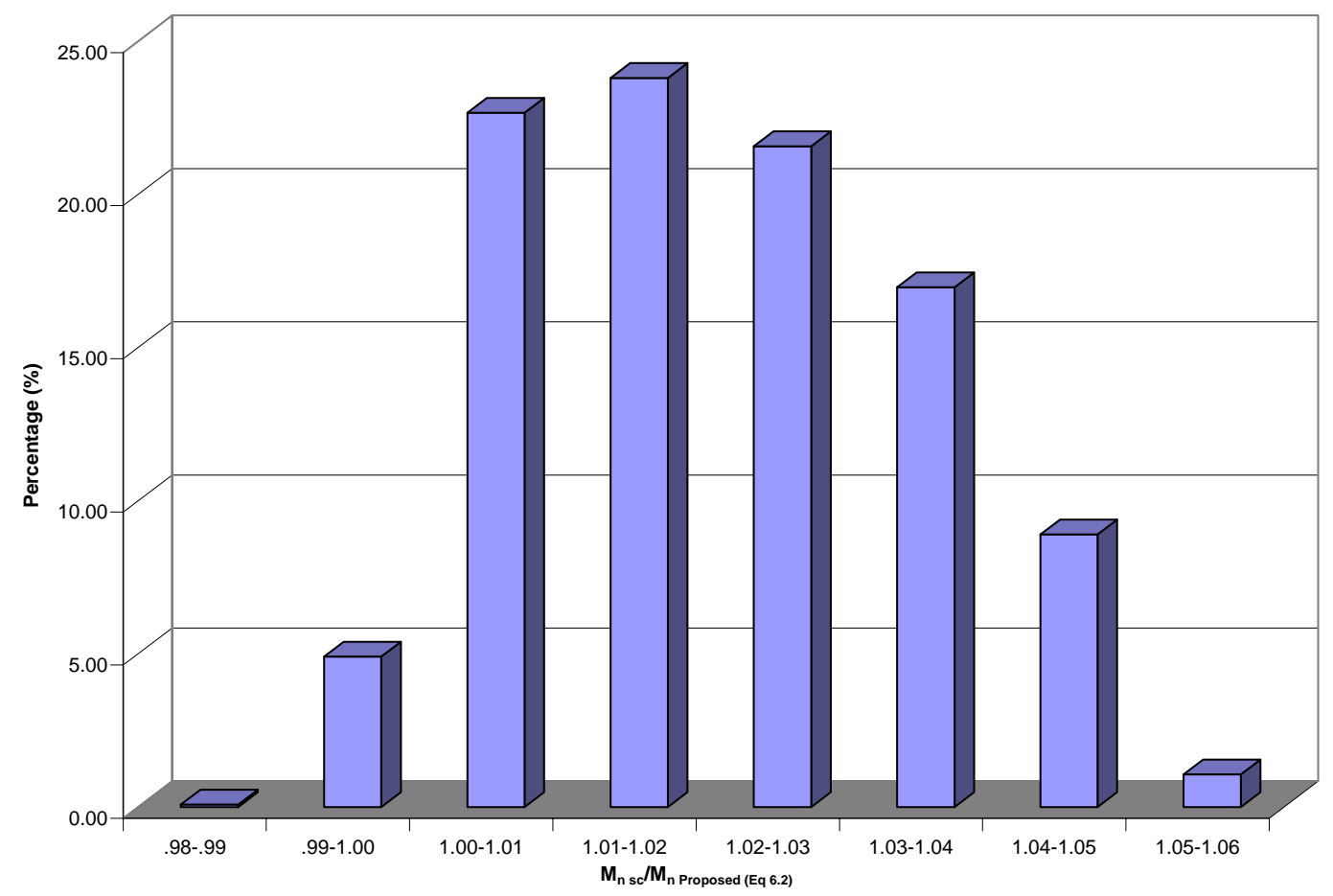

Figure 6.8 Histogram comparing the ultimate strain compatibility moment to the ultimate moment predicted by Eqn. 6.2 


\section{Chapter 7}

\section{CONCLUDING REMARKS AND RECOMMENDATIONS}

\subsection{Summary of Work}

This research investigated the ductility of composite steel girders in positive bending by performing three full-scale experimental tests, a comprehensive parametric study using a mechanistic strain compatibility approach and refined non-linear finite element analysis.

A literature review of domestic and foreign archival publications as well as research reports and university theses and dissertations was conducted and is summarized in Chapter 2.

Detailed in Chapter 3 are three full-scale experimental tests. The experimental testing program conducted in this study included ultimate load tests of composite girders, one of which was comprised of rolled steel section with the remaining two specimens comprised of plate girders. Appropriate instrumentation was provided to obtain the midspan load-deflection response for each girder.

Chapter 4 provided an extensive parametric study using a strain compatibility approach to analyze a wide range of typical composite highway girders. The chapter discussed the analysis methodology, including a description of the iterative procedure used to perform the analyses. The compatibility method was validated by comparing it to results of experimental testing conducted both in this study and by others. The variables 
used in the parametric study were described in this chapter and a comprehensive set of girder cross-sections was obtained using these variables. It was shown in this chapter that different material configurations containing Grade 50 and HPS 70W steels do not have a noticeable effect on the relationship between ultimate strength and the ductility ratio.

Chapter 5 discussed the non-linear finite element analyses employed in this study. This chapter discussed modeling techniques used in this research and provided an overview of a parametric study of hypothetical girders that were also analyzed using the strain compatibility method. The results of these analyses correlated well with both the full-scale experimental tests and the strain compatibility analyses.

An analysis of results and concluding recommendations were presented in Chapter 6 . The results of the parametric study were compared to the values predicted in the current AASHTO Specifications. It was found that, within the range of composite girders investigated, current specification predictions can be up to $50 \%$ conservative. New prediction equations were developed by fitting a line through the lower $95^{\text {th }}$ percentile of the parametric data. These equations were found to predict the peak capacity within 3 percent. 


\subsection{Conclusions}

The goal of this work was to gain a better understanding of the behavior of steelconcrete composite I-girders in positive bending. More specifically, the ultimate flexural resistance was studied with respect to the ductility of these types of sections. The ductility and the ultimate flexural capacity of these sections were extensively evaluated and new prediction equations were then developed. Key conclusions from this study may be summarized as follows:

1. The mechanistic strain compatibility method of analysis used in this work provides an accurate method for prediction of ultimate flexural capacity of a given composite steel girder cross-section.

2. The FEA model employed in this study is suitable to study the behavior of composite steel girders in positive bending

3. The ductility of a composite steel girder is not significantly affected by different material configurations within the combinations studied.

4. The ductility ratios $D_{p} / D^{\prime}$ and $D_{p} / D_{t}$ have the most significant effect on the behavior of composite steel girders in positive bending.

5. The recommended equations (Eqns. 6.3 and 6.4) are simple to use and provide much less conservative results than previous prediction equations. 


\subsection{Recommendations for Future Work}

The following recommendations for future work are given based on this study:

1. This research is based solely on girders comprised of $50 \mathrm{ksi}$ and $70 \mathrm{ksi}$ steels. Thus, experimental investigation of the behavior of girders containing HPS 100W steel should be performed to validate whether the results of this study can be applied to HPS 100W girders.

2. Because this research did not focus on the upper bound limit of $1.3 R_{h} M_{y}$ for girders adjacent to pier regions, extensive studies, including experimental tests, parametric studies and refined finite element analysis should be performed to better understand the effects of moment redistribution on the positive bending section.

3. Also, both experimental and FEA analysis should be performed on curved girders subject to positive bending. 


\section{Appendix A}

\section{Stress-Strain Configurations}

\section{Used for the Strain Compatibility Analyses}




\section{Girder Yield Configurations Used for the Strain Compatibility Analyses}

The strain compatibility analyses presented in Chapter 4 require the used of assumed girder yield configurations. In order more easily represent all possible girder yield configurations, strains in the top and bottom flanges were assumed to be perfectly uniform (i.e., no strain gradient). Assuming these uniform strains, seven (7) possible girder yield configurations were developed for the web and were used when performing the strain compatibility analyses. The girder yield configurations used are as follows and are illustrated in Figs. A.1-A.7:

- Girder Yield Configuration 1:

Top of web elastic in compression $\left(\frac{-F_{y w}}{E} \leq \varepsilon_{t w} \leq 0\right)$ and bottom of web elastic in tension $\left(0 \leq \varepsilon_{b w} \leq \frac{F_{y w}}{E}\right)$

- $\quad$ Girder Yield Configuration 2:

Top of web inelastic in compression $\left(\varepsilon_{t w} \leq \frac{-F_{y w}}{E}\right)$ and bottom of web elastic in tension $\left(0 \leq \varepsilon_{b w} \leq \frac{F_{y w}}{E}\right)$

- Girder Yield Configuration 3:

Top of web elastic in compression $\left(\frac{-F_{y w}}{E} \leq \varepsilon_{t w} \leq 0\right)$ and bottom of web inelastic in tension $\left(\frac{F_{y w}}{E} \leq \varepsilon_{b w}\right)$ 
- Girder Yield Configuration 4:

Top of web inelastic in compression $\left(\varepsilon_{t w} \leq \frac{-F_{y w}}{E}\right)$ and bottom of web inelastic in tension $\left(\frac{F_{y w}}{E} \leq \varepsilon_{b w}\right)$

- Girder Yield Configuration 5:

Top of web elastic in tension $\left(0 \leq \varepsilon_{t w} \leq \frac{F_{y w}}{E}\right)$ and bottom of web elastic in tension

$$
\left(0 \leq \varepsilon_{b w} \leq \frac{F_{y w}}{E}\right)
$$

- Girder Yield Configuration 6:

Top of web elastic in tension $\left(0 \leq \varepsilon_{t w} \leq \frac{F_{y w}}{E}\right)$ and bottom of web inelastic in tension $\left(\frac{F_{y w}}{E} \leq \varepsilon_{b w}\right)$

- $\quad$ Girder Yield Configuration 7:

Top of web inelastic in tension $\left(\frac{F_{y w}}{E} \leq \varepsilon_{t w}\right)$ and bottom of web inelastic in tension $\left(\frac{F_{y w}}{E} \leq \varepsilon_{b w}\right)$ 


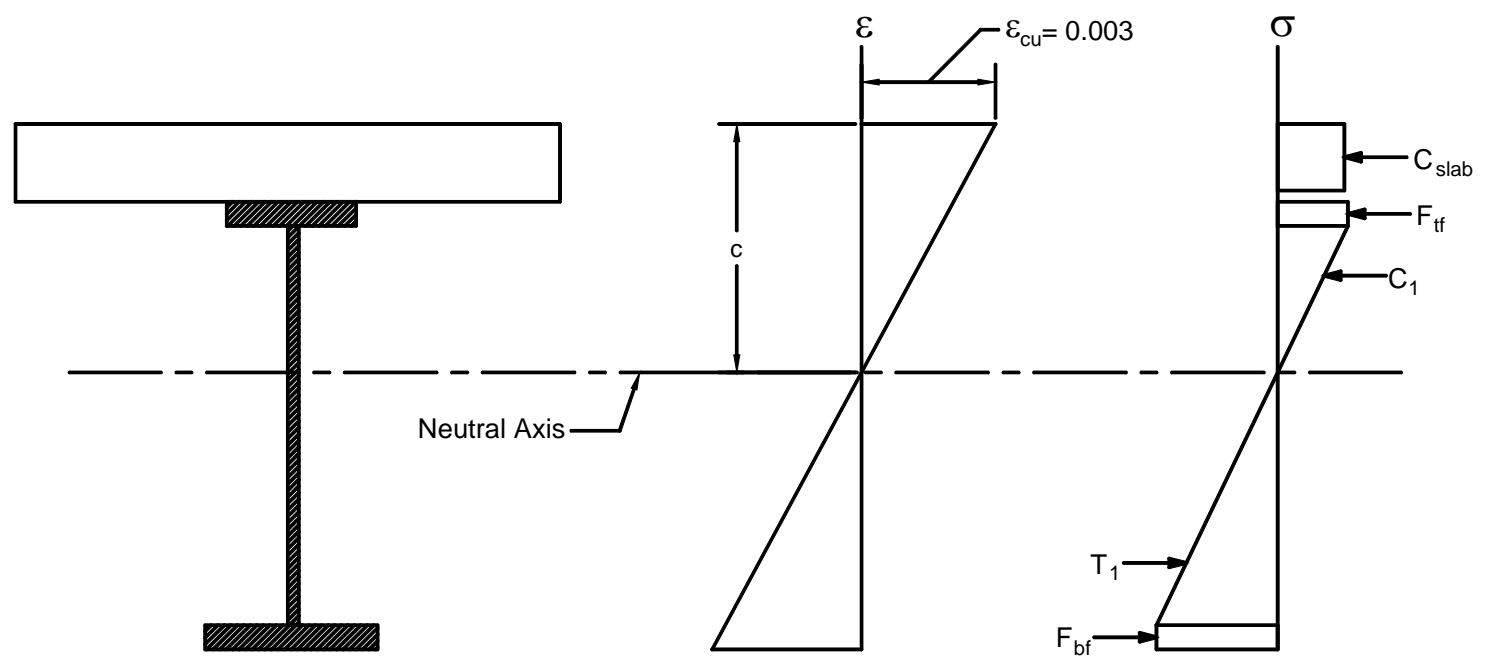

Figure A.1 Girder Yield Configuration 1

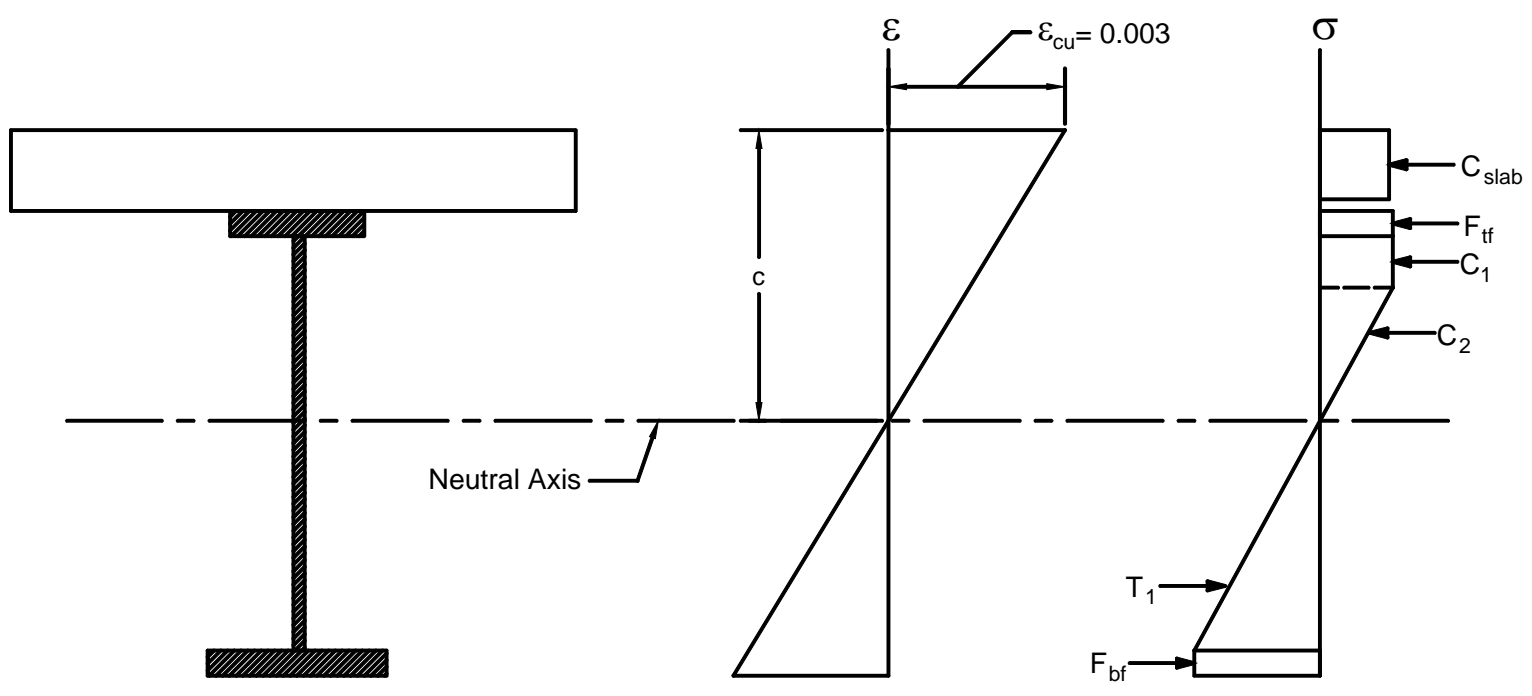

Figure A.2 Girder Yield Configuration 2 


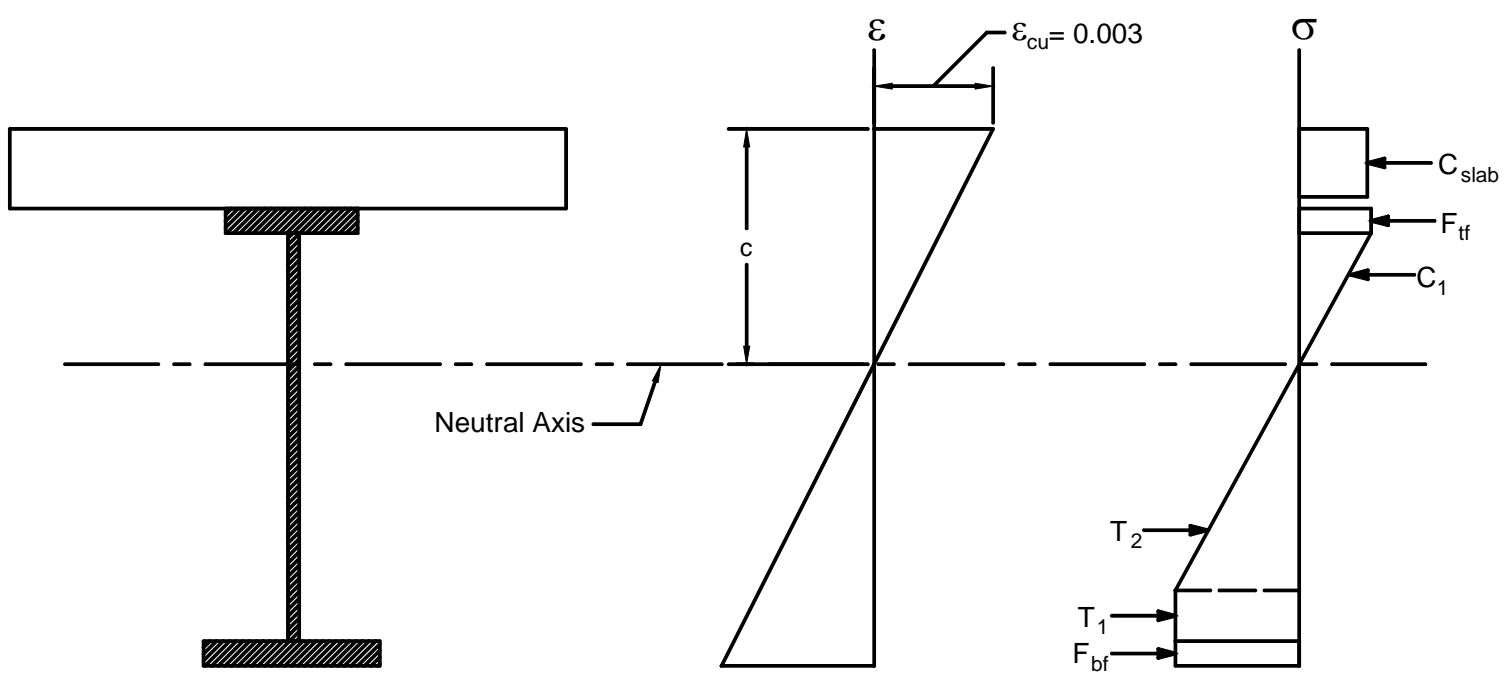

Figure A.3 Girder Yield Configuration 3

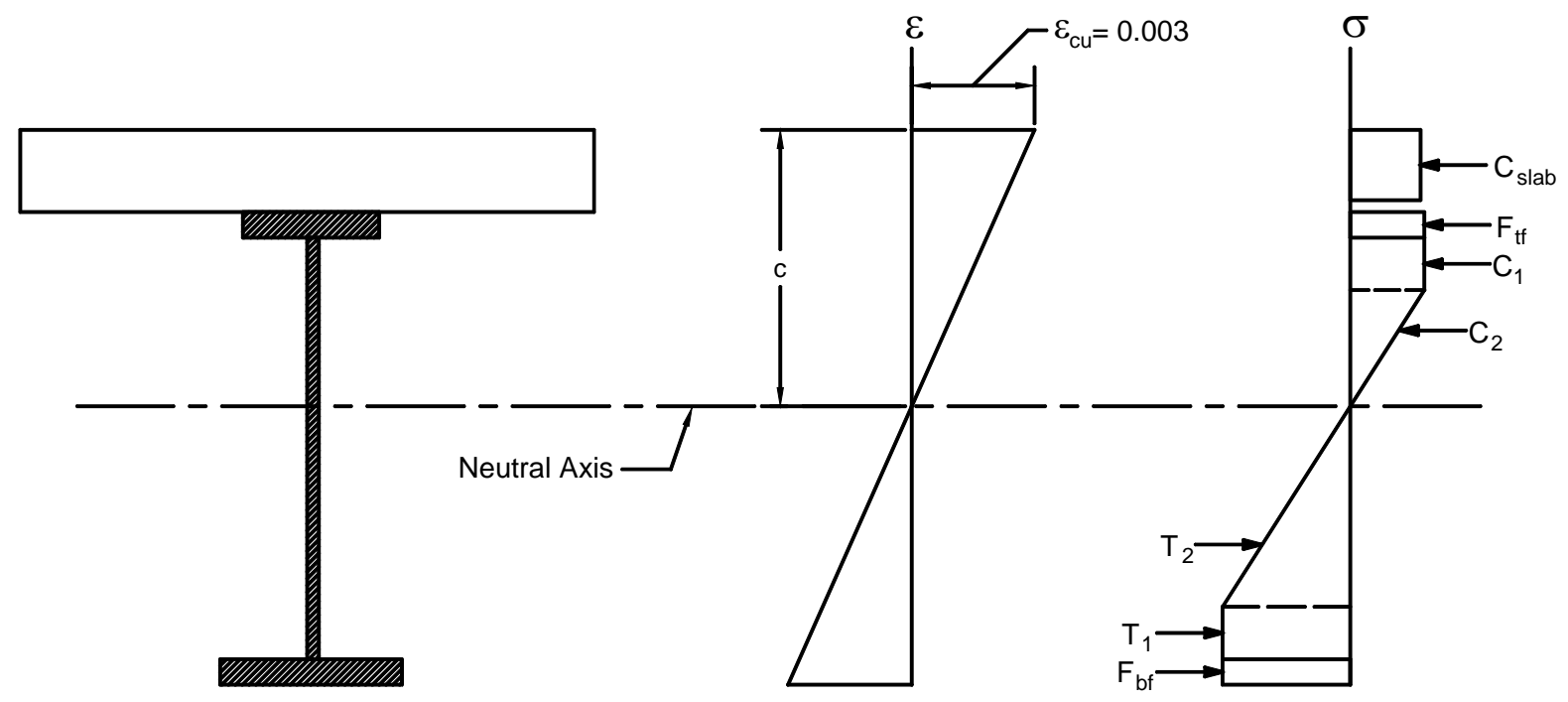

Figure A.4 Girder Yield Configuration 4 


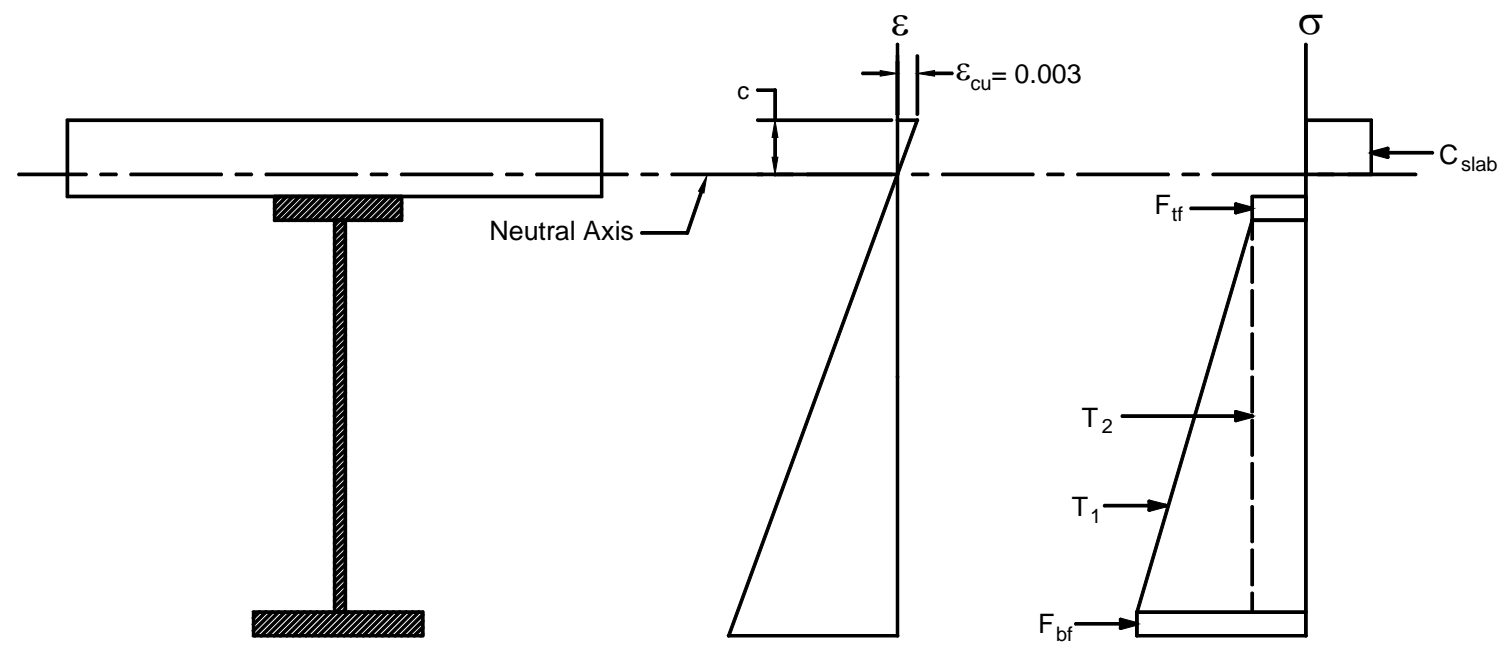

Figure A.5 Girder Yield Configuration 5

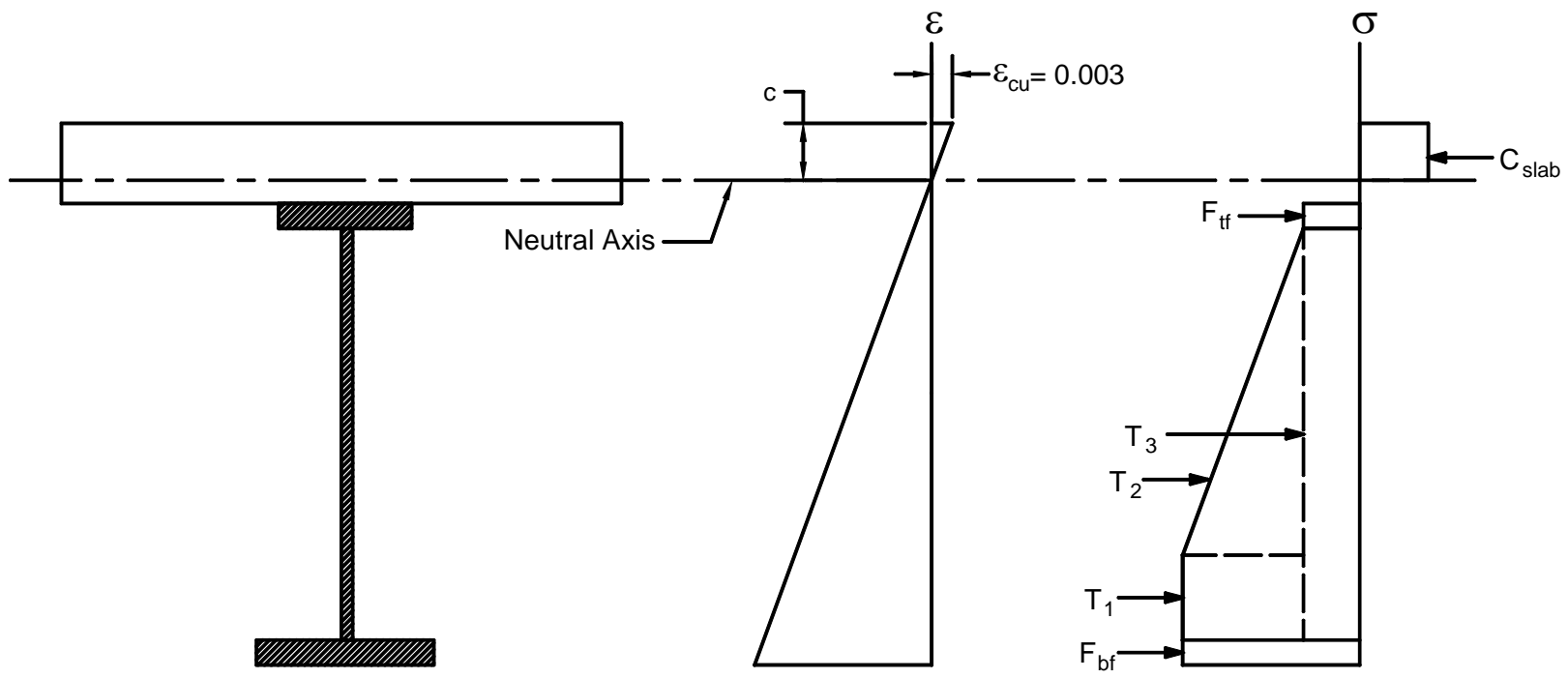

Figure A.6 Girder Yield Configuration 6 


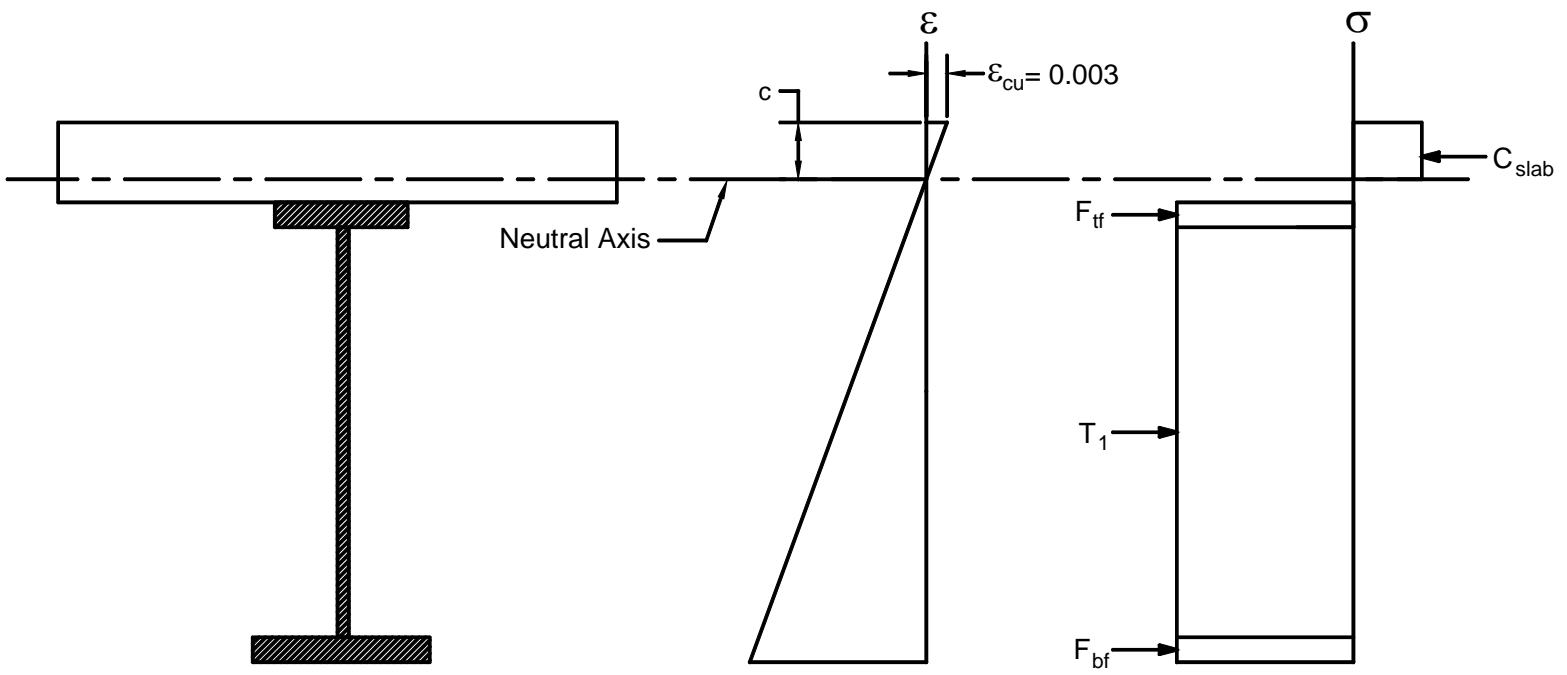

Figure A.7 Girder Yield Configuration 7 


\section{Appendix B}

\section{Example - Strain Compatibility Method of Analysis}




\section{Example - Strain Compatibility Method of Analysis}

Using the mechanistic strain compatibility approach described in Chapter 4, determine the ultimate moment capacity of the hypothetical girder cross-section shown below:

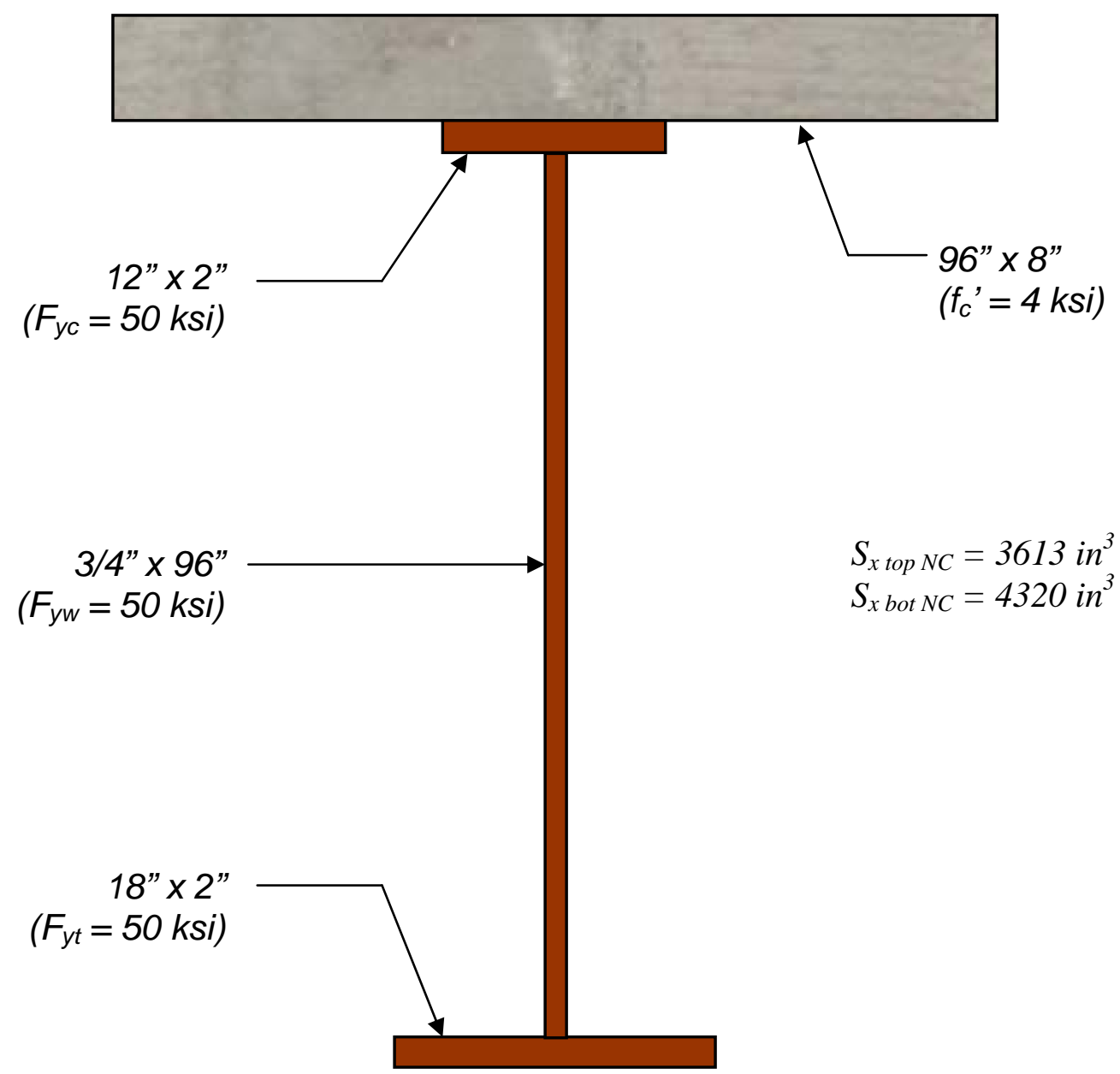

- Compute $M_{y}$ for the non-composite steel section,

$$
M_{y N C}=\min \left\{\begin{array}{ll}
S_{x t o p N C} & F_{y c}=(3613)(50) \\
S_{x b o t N C} & F_{y t}=(4320)(50)
\end{array}\right\}=180,661 \text { in-kips }
$$


- Assuming the ratio $M_{D L 1} / M_{y N C}=0.50$, compute the dead load moment acting on the non-composite steel section,

$$
M_{D L 1}=0.50 M_{y N C}=(0.5)(180,661)=90,331 \text { in }-k i p s
$$

- Assume a concrete crushing strain, $\varepsilon_{c}=0.003$, and a linear strain distribution.

- Choose $c=26.77$ in. and solve for the strains $\varepsilon_{f c}, \varepsilon_{t w}, \varepsilon_{b w}$, and $\varepsilon_{f t}$ (include strains induced by the dead load moment acting on the non-composite steel girder):

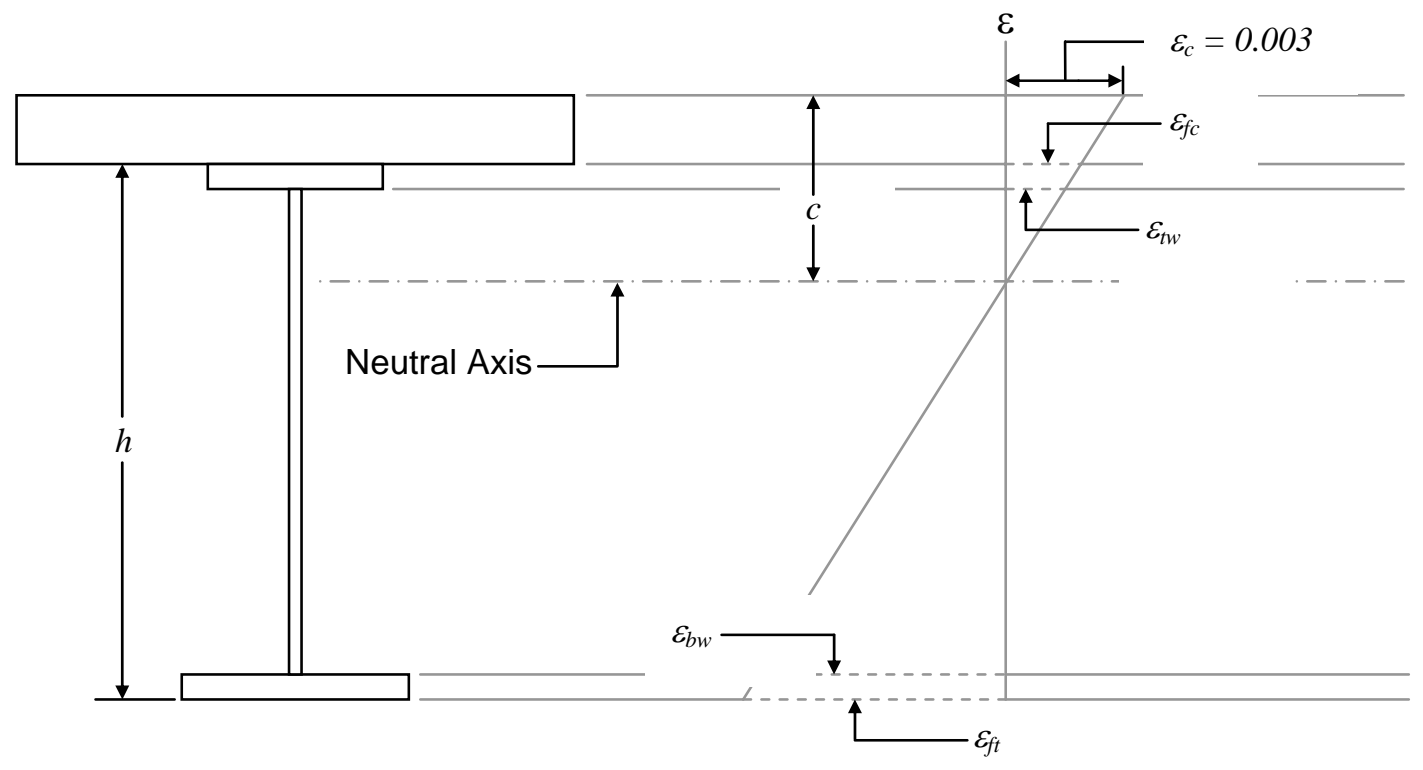

Using the principle of similar triangles and including the strains induced by the dead load, the strains can be solved for as follows:

$$
\begin{aligned}
& \varepsilon_{f c}=\varepsilon_{c}\left(\frac{c-t_{s}}{c}\right)-\frac{M_{D L 1} y_{t o p ~ N C}}{E I_{N C}} \\
& =-0.003\left(\frac{26.77-8}{26.77}\right)-\frac{(90331)(54.45)}{(29000)(196757)}=-0.00297 \\
& \varepsilon_{t w}=\varepsilon_{c}\left(\frac{c-t_{s}-t_{f c}}{c}\right)-\frac{M_{D L 1} y_{t w ~ N C}}{E I_{N C}} \\
& =-0.003\left(\frac{26.77-8-2}{26.77}\right)-\frac{(90331)(52.45)}{(29000)(196757)}=-0.00271
\end{aligned}
$$




$$
\begin{aligned}
\varepsilon_{b w} & =\varepsilon_{c}\left(\frac{h+t_{s}-c-t_{f t}}{c}\right)-\frac{M_{D L 1} y_{b w N C}}{E I_{N C}} \\
& =-0.003\left(\frac{100+8-26.77-2}{26.77}\right)-\frac{(90331)(43.55)}{(29000)(196757)}=0.00957 \\
\varepsilon_{f t} & =\varepsilon_{c}\left(\frac{h+t_{s}-c}{c}\right)-\frac{M_{D L 1} y_{b o t N C}}{E I_{N C}} \\
& =-0.003\left(\frac{100+8-26.77}{26.77}\right)-\frac{(90331)(45.55)}{(29000)(196757)}=0.00983
\end{aligned}
$$

- Assuming average strains for both the top and bottom flanges, determine which girder yield configuration (see Appendix A, Figs. A.1-A.7) the calculated strains will produce in the web:

$$
\begin{aligned}
& \left.\begin{array}{l}
\varepsilon_{t w}=-0.00271 \\
\frac{-F_{y w}}{E}=-0.00172
\end{array}\right\} \quad \varepsilon_{t w}<\frac{-F_{y w}}{E} \\
& \left.\begin{array}{l}
\varepsilon_{b w}=0.00957 \\
\frac{F_{y w}}{E}=0.00172
\end{array}\right\} \quad \varepsilon_{t w}>\frac{F_{y w}}{E}
\end{aligned}
$$

Therefore, the applicable girder yield configuration is $\underline{\text { Case } 4}$ (see Fig. A.4). 
- Using the stress-strain diagram for Case 4, determine the component forces $C_{\text {slab, }}$ $F_{t f}, C_{1}, C_{2}, T_{1}, T_{2}$ and $F_{b f}$ :

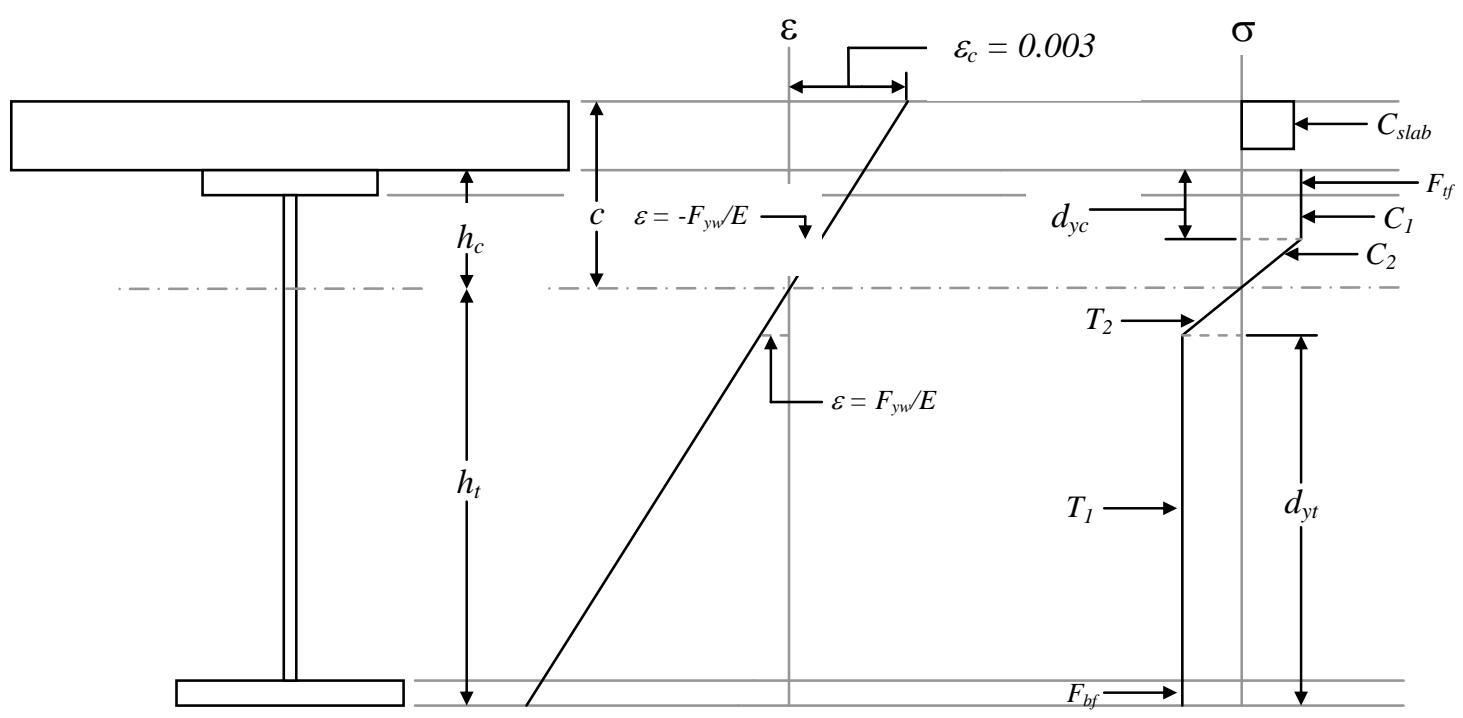

Again using the principle of similar triangles, the depth of the girder in compression is computed as,

$h_{c}=\frac{\left|\varepsilon_{f c}\right| h}{\left|\varepsilon_{f c}\right|+\varepsilon_{f t}}=\frac{0.00297(100)}{(0.00297+0.00983)}=23.184 "$

The depth of the girder in tension is then,

$h_{t}=h-h_{c}=100-23.184=76.816^{\prime \prime}$

Employing the principle of similar triangles again, the depth of the girder yielded in compression $\left(d_{y c}\right)$ and the depth of the girder yielded in tension $\left(d_{y t}\right)$ can be found as,

$$
\begin{aligned}
& d_{y c}=h_{c}\left[1-\frac{-F_{y w} / E}{\varepsilon_{f c}}\right]=23.184\left[1-\frac{-0.00172}{-0.00297}\right]=9.705^{\prime \prime} \\
& d_{y t}=h_{t}\left[1-\frac{F_{y w} / E}{\varepsilon_{f t}}\right]=74.816\left[1-\frac{0.00172}{0.00983}\right]=63.337^{\prime \prime}
\end{aligned}
$$


By taking the depth of the concrete stress block to be the minimum of $c$ and $t_{s}$, the concrete component force can be calculated as,

$$
C_{\text {slab }}=\min \left\{\begin{array}{l}
t_{s} \\
c
\end{array}\right\} 0.85 f_{c}{ }^{\prime} b_{\text {slab }}=(8)(0.85)(-4)(96)=-2611.20
$$

Because the average strains in both the top and bottom flanges are greater than the yield strains at those locations, the component forces from the flanges can be calculated as,

$$
\begin{aligned}
& F_{t f}=F_{y c} t_{f c} b_{f c}=(-50)(2)(12)=-1200 \text { kips } \\
& F_{b f}=F_{y t} t_{f t} b_{f t}=(50)(2)(18)=1800 \text { kips }
\end{aligned}
$$

Using the stress profile, the remaining component forces can be calculated as,

$$
\begin{aligned}
& C_{1}=-F_{y w}\left(d_{y c}-t_{f c}\right) t_{w}=(-50)(9.705-2)(0.75)=-288.92 \text { kips } \\
& C_{2}=\frac{-F_{y w}}{2}\left(h_{c}-d_{y t}\right) t_{w}=\frac{-50}{2}(23.184-9.705)(0.75)=-252.74 \text { kips } \\
& T_{1}=F_{y w}\left(d_{y t}-t_{f t}\right) t_{w}=(50)(63.337-2)(0.75)=2300.12 \text { kips } \\
& T_{2}=\frac{F_{y w}}{2}\left(h_{t}-d_{y t}\right) t_{w}=\frac{50}{2}(76.816-63.337)(0.75)=252.74 \text { kips }
\end{aligned}
$$

- Compute the force summation,

$$
\begin{aligned}
P & =C_{\text {slab }}+F_{t f}+C_{1}+C_{2}+T_{1}+T_{2}+F_{b f} \\
& =(-2611.20)+(-1200)+(-288.92)+(-252.74)+2300.12+252.74+1800 \\
& =0.00 \text { kips }
\end{aligned}
$$

$\therefore$ The assumed value $\underline{c}=\mathbf{2 6 . 7 7} \mathrm{in}$. provides force equilibrium and is the correct value of $\mathrm{c}$ for this case.

- For each component force, calculate the moment induced about the middle of the top flange:

$$
\begin{aligned}
& M_{C_{\text {slab }}}=C_{\text {slab }}\left[\frac{t_{s}}{2}+\frac{t_{f c}}{2}\right]=2611.20\left[\frac{8}{2}+\frac{2}{2}\right]=13,056 \text { in }- \text { kips } \\
& M_{C_{1}}=C_{1}\left[\frac{d_{y c}-t_{f c}}{2}+\frac{t_{f c}}{2}\right]=-288.92\left[\frac{9.705-2}{2}+\frac{2}{2}\right]=-1,401 \text { in }- \text { kips }
\end{aligned}
$$




$$
\begin{aligned}
M_{C_{2}} & =C_{2}\left[\frac{h_{c}-d_{y c}}{3}+d_{y c}-\frac{t_{f c}}{2}\right] \\
& =-252.74\left[\frac{23.184-9.705}{3}+7.705-\frac{2}{2}\right]=-3,336 \text { in }- \text { kips } \\
M_{T_{1}} & =T_{1}\left[\frac{d_{y t}-t_{f t}}{2}+h-d_{y t}-\frac{t_{f c}}{2}\right] \\
& =2300.12\left[\frac{63.337-2}{2}+100-63.337-\frac{2}{2}\right]=152,570 \text { in }-k i p s \\
M_{T_{2}} & =T_{2}\left[\frac{2\left(h_{t}-d_{y t}\right)}{3}+h-h_{t}-\frac{t_{f c}}{2}\right] \\
& =252.74\left[\frac{2(76.816-63.337)}{3}+100-76.816-\frac{2}{2}\right]=7,878 \text { in }-k i p s \\
M_{F_{b f}} & =F_{b f}\left[h-\frac{t_{f t}}{2}-\frac{t_{f c}}{2}\right]=1800\left[100-\frac{2}{2}-\frac{2}{2}\right]=176,400 \text { in }-k i p s
\end{aligned}
$$

- Summation of the respective moments will give the ultimate flexural capacity:

$$
\begin{gathered}
M_{n}=M_{C_{\text {slab }}}+M_{C_{1}}+M_{C_{2}}+M_{T_{1}}+M_{T_{2}}+M_{F_{b f}} \\
=13,056+(-1,401)+(-3,336)+152,570+7,878+176,400 \\
M_{n}=345,167 \text { in - kips }
\end{gathered}
$$




\section{References}

AASHTO (1989). LFD Standard Specifications, Fourteenth Edition, American Association of State Highway and Transportation Officials, Washington, D.C., 1996

AASHTO (2001). LRFD Bridge Design Specifications, $2^{\text {nd }}$ ed., American Association of State Highway and Transportation Officials, Washington, D.C. (with 2001 interims).

AASHTO (2003). LRFD Bridge Design Specifications, $3^{\text {rd }}$ ed., American Association of State Highway and Transportation Officials, Washington, D.C.

ABAQUS/Standard User’s Manual, Version 6.3 (2002). Hibbitt, Karlsson \& Sorensen, Inc.

American Society for Testing and Materials (ASTM) (2002). ASTM A 370-97a. Standard Test Methods and Definitions for Mechanical Testing of Steel Products.

Ansourian, P. (1982, March). Plastic Rotation of Composite Beams. Journal of the Structural Division, Proceedings of the American Society of Civil Engineers 108:ST3, 643-659.

Ansourian, P. \& Roderick, J.W. (1978, October). Analysis of Composite Beams. Journal of the Structural Division, Proceedings of the American Society of Civil Engineers 104:ST10, 1631-1645.

Aubé, S., Tremblay, R., \& Massicotte, B. (1997, May). Large Scale Testing Composite Bridge Girders with Slender Non-Compact Webs. Proceedings Canadian Society for Civil Engineers Part 7, 291-300.

Barker, M. G. and Schrage, S. D. (2000, June). High Performance Steel: Design and Cost Comparisons. Model Steel Construction, 16, 35-41.

Barnard, P.R. (1965, April). A Series of Tests on Simply Supported Composite Beams. Journal of the American Concrete Institute 62, 443-456.

Barnard, P.R. \& Johnson, R.P. (1965, October). Plastic Behaviour of Continuous Composite Beams. Proceedings of the Institution of Civil Engineers 32, 180-197.

Barnard, P.R. \& Johnson, R.P. (1965, October). Ultimate Strength of Composite Beams. Proceedings of the Institution of Civil Engineers 32, 161-179.

Barth, K. E. and White, D. W. (2000 a). Inelastic Design of Steel I-Girder Bridges. Journal of Bridge Engineering, 2000, 179-190. 
Barth, K. E., White, D. W. and Bobb, D. W. (2000 b). Negative Bending Resistance of HPS 70W Girders. Journal of construction Steel Research, Elsevier, 53 (1), 1-31.

Barth, K.E., and Wu, H., (2004, in review). Efficient Non-Linear Finite Element Modeling of Composite Steel Bridge Girders, Journal of Finite Elements in Analysis and Design.

Chapman, J.C. \& Balakrishnan, S. (1964, November). Experiments on Composite Beams. The Structural Engineer 42:11, 369-383.

Clingenpeel, B. F. (2001). The Economical Use of High Performance Steel in Slab-onSteel Stringer Bridge Design. MS Thesis, Department of Civil and Environmental Engineering, West Virginia University, Morgantown, West Virginia.

de G. Allen, D.N. \& Severn, R.T. (1961, May). Composite Action between Beams and Slabs Under Transverse Load. The Structural Engineer 39, 149-154.

Hamada, S. \& Longworth, J. (1976, July). Ultimate Strengths of Continuous Composite Beams. Journal of the Structural Division, Proceedings of the American Society of Civil Engineers 102:ST7, 1463-1479.

Hawkins, N.M. \& Roderick, J.W. (1976). The Behaviour of Composite Beams. Civil Engineering Transactions 18:2, 102-108.

Horton, R., Power, E., Van Ooyen, K., and Azizinamini, A. (2000). High Performance Steel Cost Comparison Study. Steel Bridge Design and Construction for the New Millennium with Emphasis on High Performance Steel Conference Proceeding, 120-137.

Mans, P.H. (2001, December). Full-Scale Testing of Composite Plate Girders Constructed Using 70-ksi High Performance Steel. MS Thesis, University of Nebraska-Lincoln.

Mans, P., Yakel, A.J., \& Azizinamini, A. (2001, November/December). Full-Scale Testing of Composite Plate Girders Constructed Using 485-MPa HighPerformance Steel. Journal of Bridge Engineering 6:6, 598-604.

Reddy, V.M. \& Hendry A.W. (1969, May). Ultimate Load Behaviour of Composite Steel-Concrete Bridge Deck Structures. The Indian Concrete Journal, 163-168

Rotter, J.M. \& Ansourian (1979, June). Cross-Section Behaviour and Ductility in Composite Beams. Proceedings of the Institute of Civil Engineers Part 2, 67, 453-474. 
Schilling, C.G. (1968, August). Bending Behavior of Composite Hybrid Beams. Journal of the Structural Division, Proceedings of the American Society of Civil Engineers 94:ST8, 1945-1964.

TxDOT (2000). Prefered Practices for Steel Bridge Design Fabrication and Erection. Texas Steel Quality Council, Texas Department of Transportation.

Vasseghi, A. (1989, May). Strength and Behavior of Composite Plate Girders under Shear and Bending Moment. Doctoral Dissertation, The University of TexasAustin.

Wittry, D.M. (1993, December). An Analytical Study of the Ductility of Steel-Concrete Composite Sections. MS Thesis, The University of Texas-Austin.

WVDOH (1999). Standard Bridge Plans. Standard Details Book, Vol. 3. West Virginia Department of Transportation, Division of Highways. 